University of Arkansas, Fayetteville

ScholarWorks@UARK

Graduate Theses and Dissertations

8-2012

\title{
The Development of a High Performance Concrete to Store Thermal Energy for Concentrating Solar Power Plants
}

\author{
Emerson Esmond John \\ University of Arkansas, Fayetteville
}

Follow this and additional works at: https://scholarworks.uark.edu/etd

Part of the Civil Engineering Commons, Environmental Engineering Commons, and the Oil, Gas, and Energy Commons

\section{Citation}

John, E. E. (2012). The Development of a High Performance Concrete to Store Thermal Energy for Concentrating Solar Power Plants. Graduate Theses and Dissertations Retrieved from https://scholarworks.uark.edu/etd/450

This Dissertation is brought to you for free and open access by ScholarWorks@UARK. It has been accepted for inclusion in Graduate Theses and Dissertations by an authorized administrator of ScholarWorks@UARK. For more information, please contact scholar@uark.edu. 

THE DEVELOPMENT OF A HIGH PERFORMANCE CONCRETE TO STORE THERMAL ENERGY FOR CONCENTRATING SOLAR POWER PLANTS 
A Dissertation submitted in partial fulfillment

of the requirements for the degree of

Doctor of Philosophy in Engineering

\title{
By
}

\author{
Emerson John \\ University of Camagüey \\ Bachelor of Science in Civil Engineering, 2004 \\ University of Arkansas \\ Master of Science in Civil Engineering, 2009
}

August 2012

University of Arkansas 


\section{ABSTRACT}

In recent years, due to rising energy costs as well as an increased awareness of the environmental effects of greenhouse gas emissions produced through traditional forms of energy production, there is great interest in developing alternative sources of energy. One of the most viable alternative energy sources is solar energy. In particular, concentrating solar power (CSP) technologies have been identified as an option for meeting utility needs in the U.S. Southwest. These systems are required to produce electricity not only during periods of high solar radiation but also during times of reduced radiation due to cloud cover, and even extend production to periods during the night. In order to achieve this goal, CSP plants must incorporate a thermal energy storage (TES) system from which energy can be sourced when needed. Besides the integration of a TES sub-system, another area where CSP technologies can be improved is in the development and use of heat transfer fluids (HTF) that can remain stable at temperatures up to and in excess of $1112^{\circ} \mathrm{F}\left(600^{\circ} \mathrm{C}\right)$.

This research explores the use of concrete as a TES storage medium for CSP technologies, specifically, parabolic trough power plants. Concrete is relatively inexpensive and the costs/ $\mathrm{kWh}_{\text {thermal }}$ of energy based on the concretes used in this research could be less than $\$ 1$. Researchers using concrete as a TES storage medium have achieved maximum operating temperatures of $752^{\circ} \mathrm{F}\left(400^{\circ} \mathrm{C}\right)$ with a 6-hour storage capacity. The operating temperature limit of $752^{\circ} \mathrm{F}\left(400^{\circ} \mathrm{C}\right)$ is dictated by the limitations of the concrete when exposed to elevated temperatures and by the stability of the heat transfer fluid at these temperatures. By exposing various concrete types to different heating regimens and subsequently measuring their thermomechanical properties, this research has identified concrete that can withstand temperatures up to $1112^{\circ} \mathrm{F}\left(600^{\circ} \mathrm{C}\right)$ for deployment as a TES medium. The benefits derived from using concretes that are resistant to higher temperatures are an increase in the operating efficiency of the CSP 
plant, an increase in the number of storage hours and a significant reduction in both the storage cost and the unit cost of solar generated electricity. 
This dissertation is approved for recommendation to the Graduate Council.

Dissertation Director:

Dr. W. Micah Hale

Dissertation Committee:

Dr. Ernest Heymsfield

Dr. Panneer Selvam

Dr. Rick Couvillion 


\section{DISSERTATION DUPLICATION RELEASE}

I hereby authorize the University of Arkansas Libraries to duplicate this dissertation when needed for research and/or scholarship.

Agreed

Emerson John

Refused

Emerson John 


\section{ACKNOWLEDGEMENTS}

Profound thanks to my advisor and doctoral dissertation supervisor Dr. Hale. I say thanks not only for your guidance throughout my program but especially for affording me the opportunity to pursue the most advanced research degree to be bestowed to an individual. Special thanks to the other members of my committee, Dr. Selvam, Dr. Heymsfield and Dr. Couvillion for your insightful remarks and input. Your feedback aided in the preparation of a better document.

Thanks to the laboratory technicians, Mark Kuss and David Peachee for their technical assistance and advice in conducting my experiments. I must also say a special thank you to fellow graduate students and friends Joel Skinner, Bradley Brown and Matt Strasser, who would have spent countless laboratory hours assisting in the collection of experimental data. 


\section{DEDICATION}

This dissertation is dedicated to my family, particular those members who because of a lack of financial resources never had the opportunity to realize their full academic potential. 


\section{TABLE OF CONTENTS}

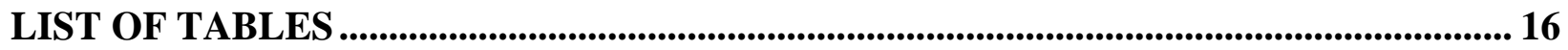

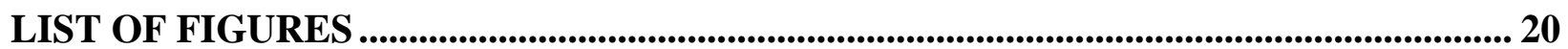

CHAPTER 1 INTRODUCTION .............................................................................................. 1

1.1 Concrete as a Thermal Energy Storage Medium …………........................................... 1

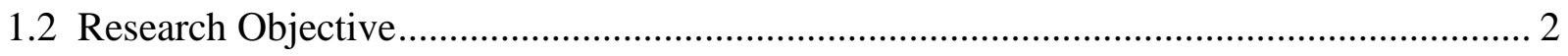

CHAPTER 2 LITERATURE REVIEW .................................................................................. 3

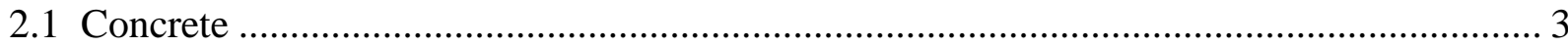

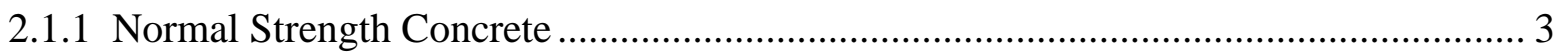

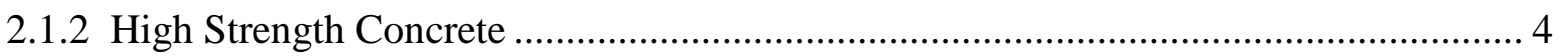

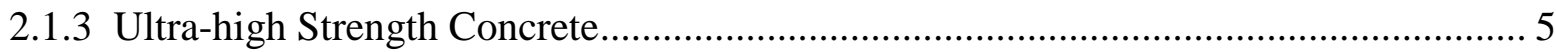

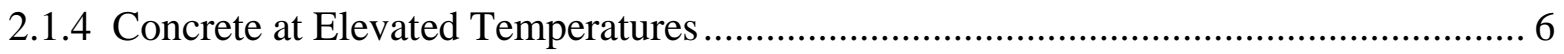

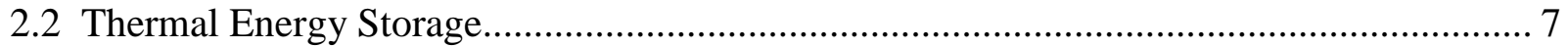

2.2.1 Background and Storage Concepts ................................................................... 7

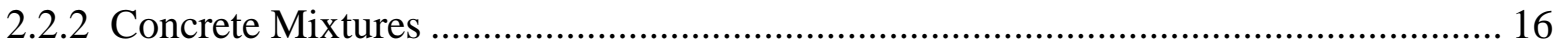

2.2.3 Concrete Design Criteria and Concerns ............................................................. 17

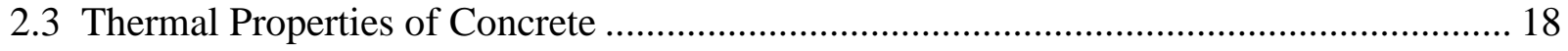

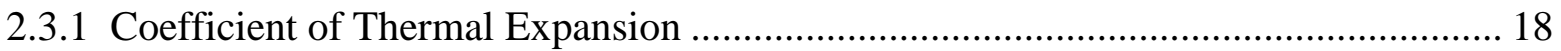

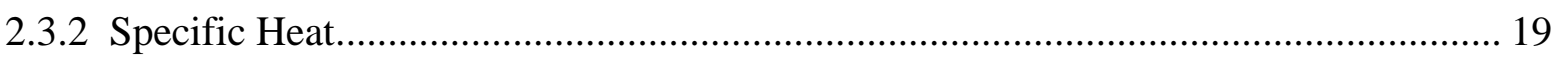

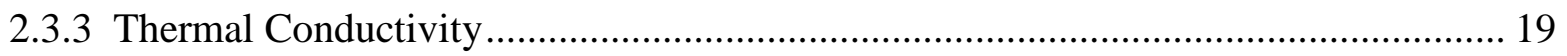

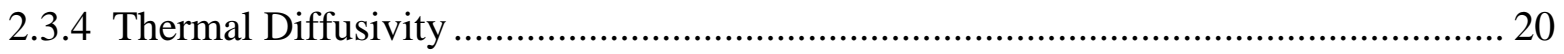


2.4 Effects of Elevated Temperature on Concrete

2.4.1 Cement Paste ............................................................................................... 21

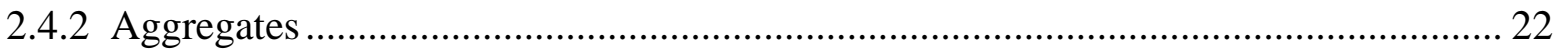

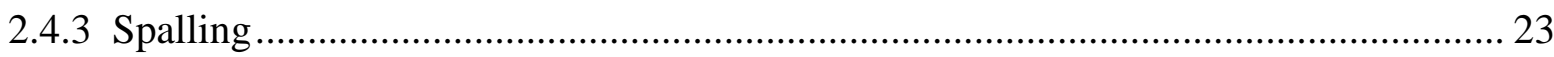

2.4.4 Factors Contributing to Spalling ...................................................................... 26

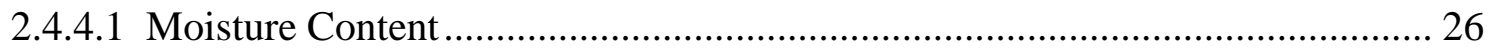

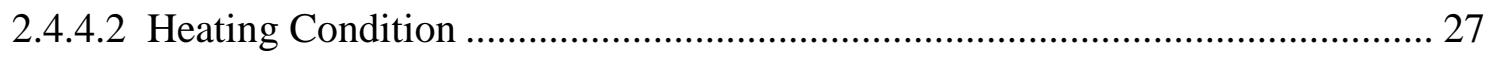

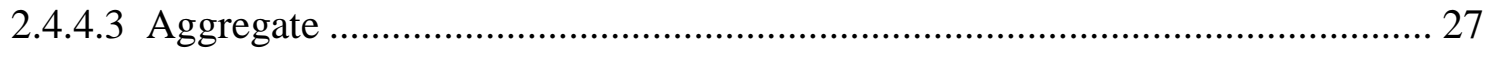

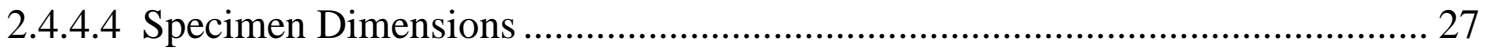

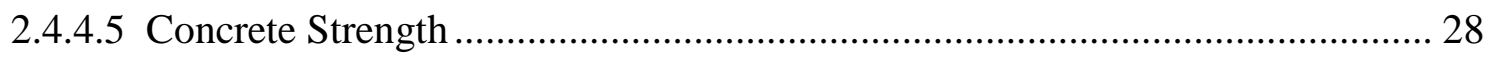

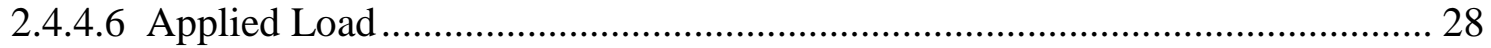

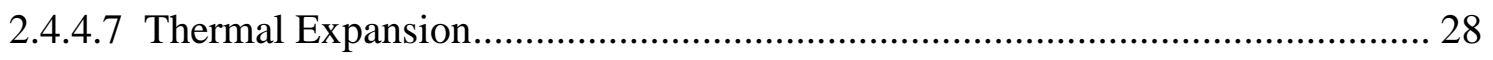

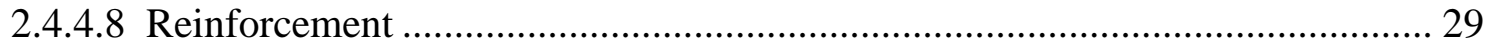

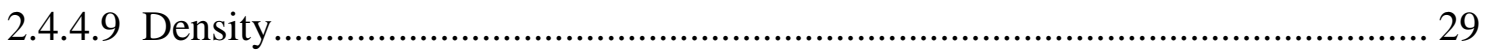

2.4.4.10 Spalling Mitigation Measure ................................................................. 29

2.5 Performance of Concrete at Elevated Temperatures................................................ 31

2.5.1 Behavior of Normal-strength Concrete (NSC) at High Temperatures ...................... 31

2.5.2 Behavior of HSC at Elevated Temperatures..................................................... 36

2.5.3 Behavior of Ultra-high Performance Concrete (UHPC) at Elevated Temperatures ... 44

2.6 Thermal Properties of Concrete at Elevated Temperatures .......................................... 45

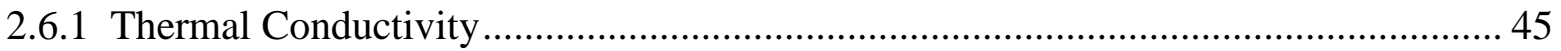




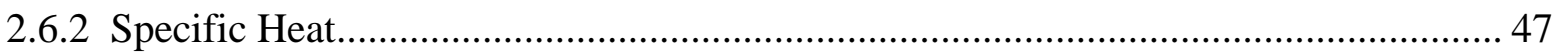

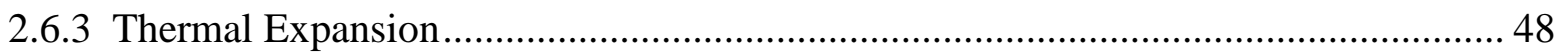

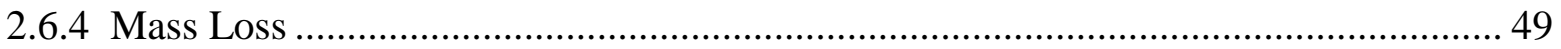

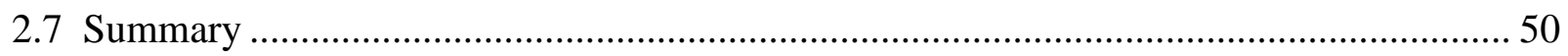

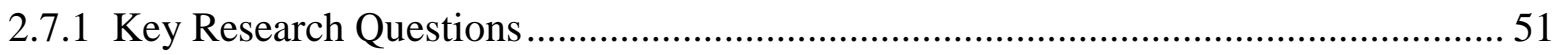

CHAPTER 3 METHODOLOGY AND EXPERIMENTAL PROCEDURES ......................... 53

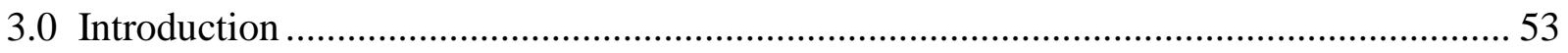

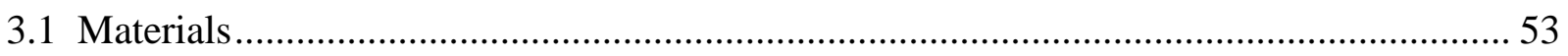

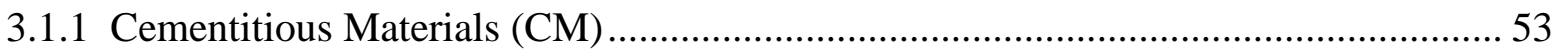

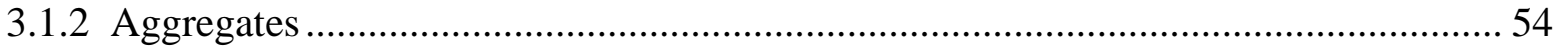

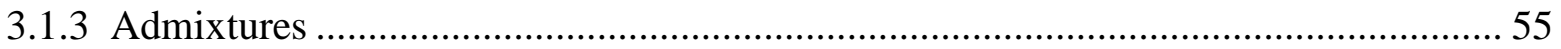

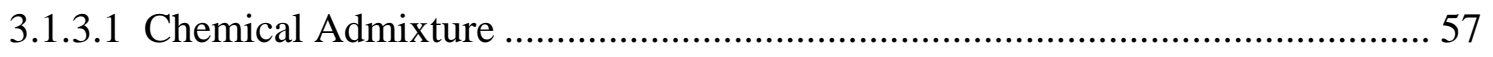

3.2 Phase I: Assessment of Heating Rates and PP Fiber Dosage on the Performance of Concrete at Elevated Temperatures................................................................................... 57

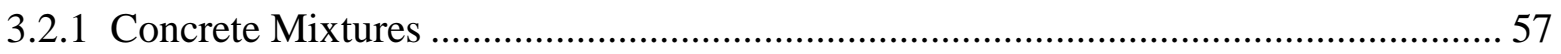

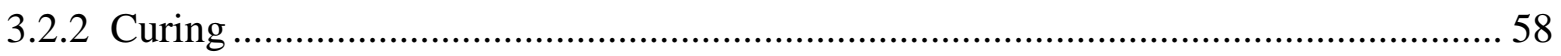

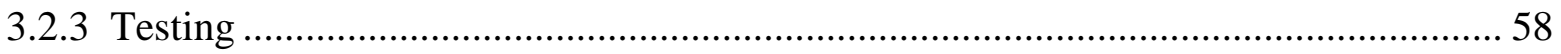

3.2.4 Effects of Polypropylene Fiber Dosage on Concrete Temperature Resistance........... 59

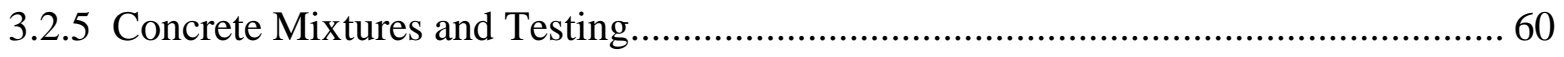

3.3 Phase II: Assessment of Concrete Developed for TES Option A …………………........... 62 


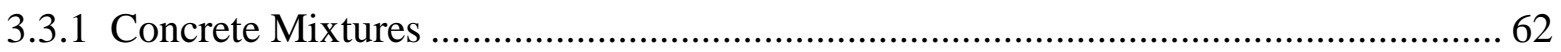

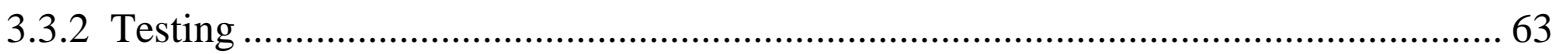

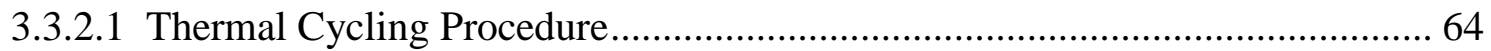

3.3.2.2 Assessment of the Concrete Performance with Molten Salt as the HTF .......... 64

3.4 Phase III: Assessment of Concrete Developed for TES Option B ....................................... 66

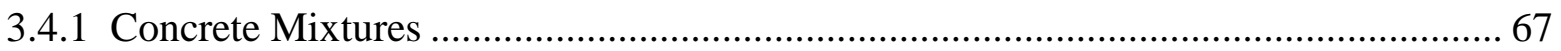

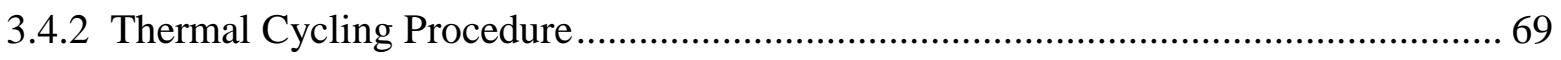

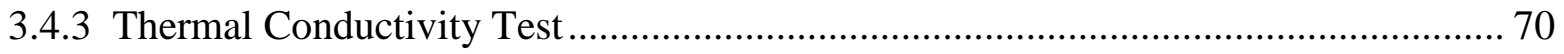

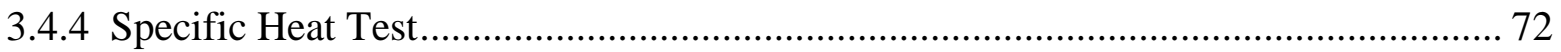

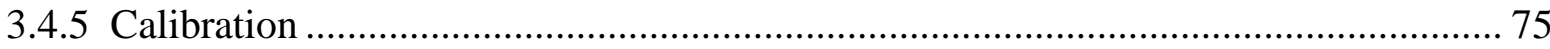

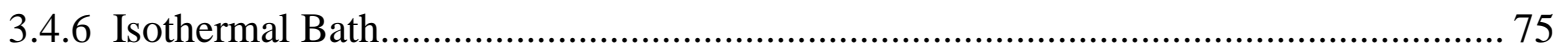

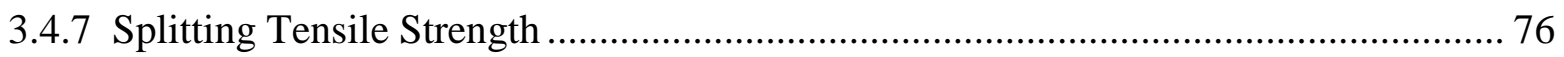

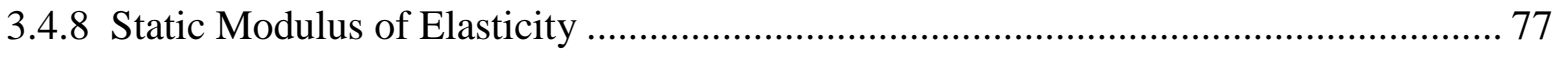

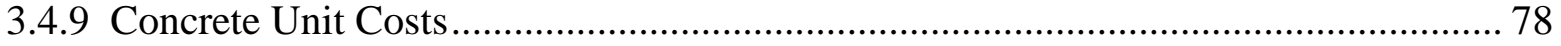

3.5 Characterization of Selected Concrete Mixtures............................................................ 79

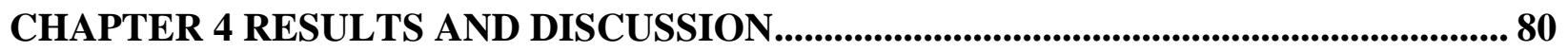

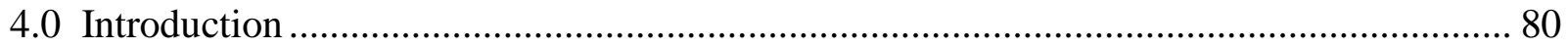

4.1 Phase I: Effects of Heating Rates and PP Fiber Dosage on the Performance of Concrete at

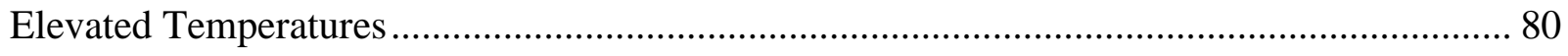

4.1.1 The Effects of Heating Rates and Elevated Temperatures on Concrete....................... 80

4.1.2 Effects of PP Fibers on the Residual Compressive Strength of Concrete .................... 86 
4.2 Phase II: Performance of Concrete Developed for TES Option A

4.2.1 Temperature Gradient within Test Specimens ................................................. 88

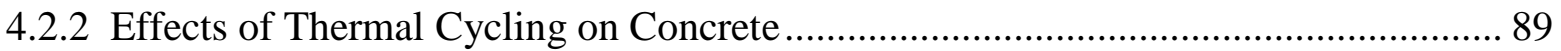

4.2.2.1 Effects of Thermal Cycling on Residual Compressive Strength..................... 89

4.2.2.2 Effects of Thermal Cycling on the Unit Weight ...................................... 92

4.2.2.3 Thermal Conductivity $(K)$ before and after Thermal Cycling ........................ 92

4.2.2.4 Specific Heat (Cp) before and after Thermal Cycling.................................. 93

4.2.3 Cost Effectiveness of Concrete...................................................................... 94

4.2.4 Assessment of Concrete Performance with Molten Salt as the Heat Transfer Fluid

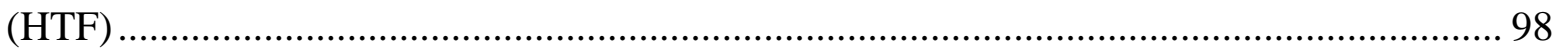

4.2.4.1 Finite Element Analysis .................................................................... 100

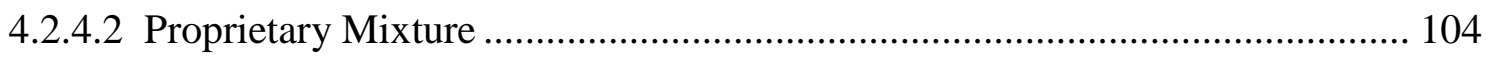

4.3 Phase III: Performance of Concrete Developed for TES Option B ............................ 105

4.3.1 Preliminary Testing Results of Concrete for Deployment in TES Option B ........... 105

4.3.2 Assessment of Concrete Specimens in Direct Contact with Molten Salt................ 116

4.4 Selection and Characterization of Concrete Mixtures for Final Testing....................... 123

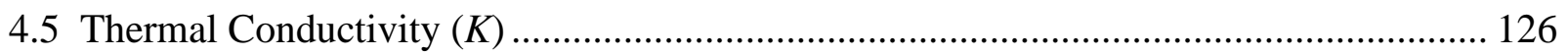

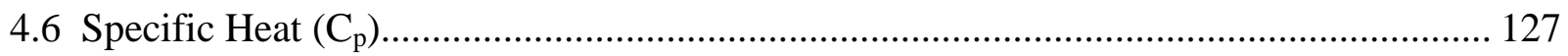

4.7 Significance of the Test Results as they Relate to Thermal Energy Storage Systems ..... 131

4.7.1 Thermal Energy Storage (TES) Option A …............................................... 132

4.7.2 Thermal Energy Storage Option B .............................................................. 135 


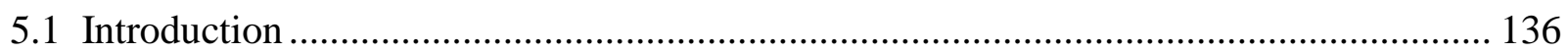

5.2 Phase I: Effects of Heating Rates and PP Fiber Dosage on the Performance of Concrete at

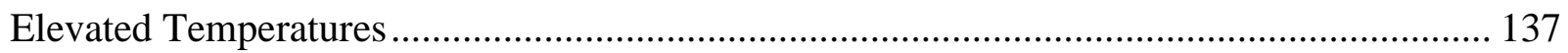

5.3 Phase II: Concrete Developed for TES Option A ………................................................ 138

5.4 Phase III: Concrete Developed for TES Option B ………………………………........ 140

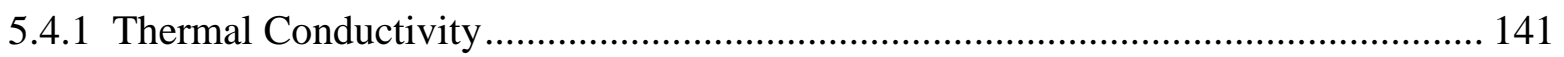

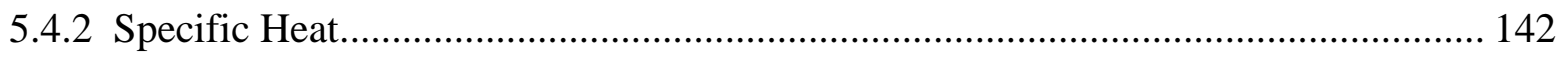

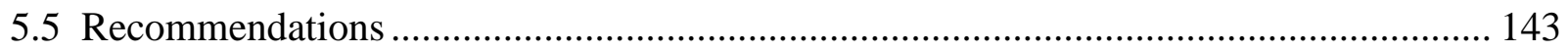

5.6 Contribution to Body of Knowledge........................................................................ 144

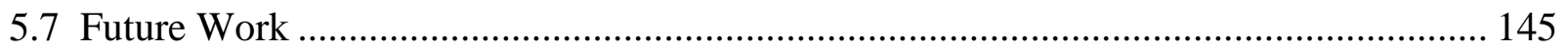

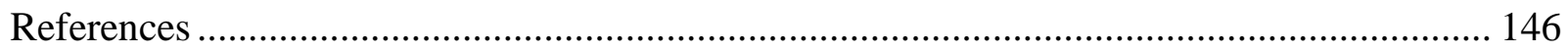

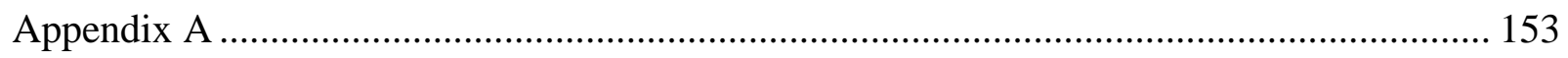

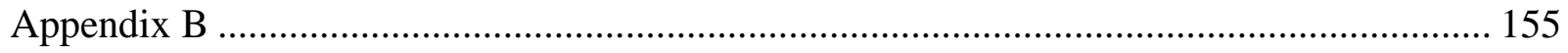

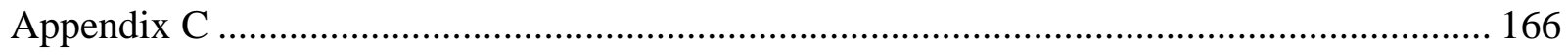

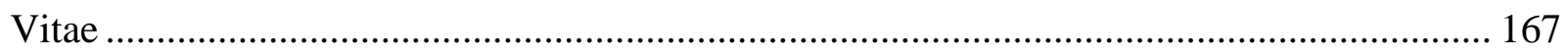




\section{LIST OF TABLES}

Table 2.1 Solid storage media for CSP/SEGS plants (Herrmann, 2002)...................................... 8

Table 2.2 Properties of tested thermal energy storage materials ................................................ 16

Table 2.3 Thermal conductivity values for commonly used aggregates .................................... 20

Table 2.4 Thermal diffusivity values for concrete with different coarse aggregates (Mehta and

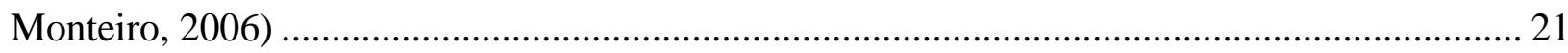

Table 2.5 Strength reduction factor for NSC according to French Standards (Phan and Carino,

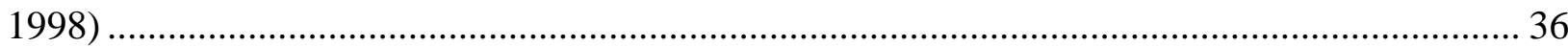

Table 2.6 Concrete mixtures tested by Phan (2007) ................................................................. 40

Table 3.1 Mixture proportions (Phase I: HSC and UHPC mixtures) …………………............. 59

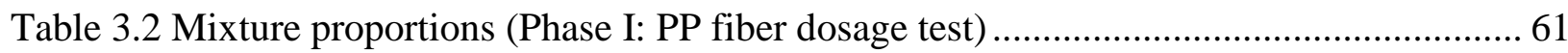

Table 3.3 Mixture proportions (Phase II: concrete for TES option A) ………………………........ 63

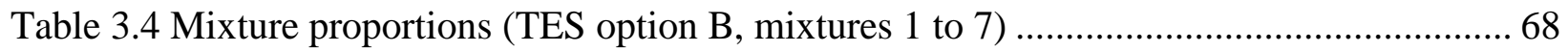

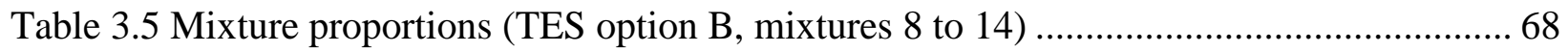

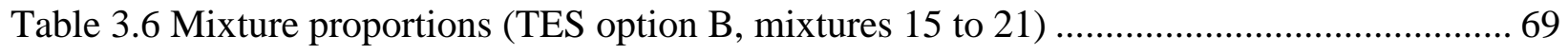

Table 3.7 Mixture proportions (TES option B, mixtures 22 to 26) ...............................................6 69

Table 3.8 Concrete materials specific heat values (Bentz et al., 2010) .......................................... 74

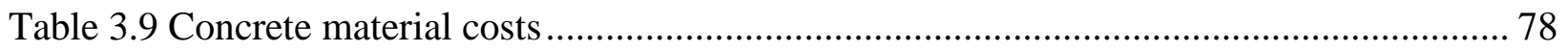


Table 4.1 Residual compressive strength results as a function of heating rates (John, 2010)..... 84

Table 4.2 Residual compressive strength of concrete with different dosages of PP fibers 87

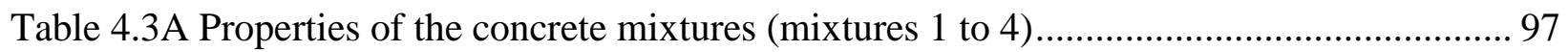

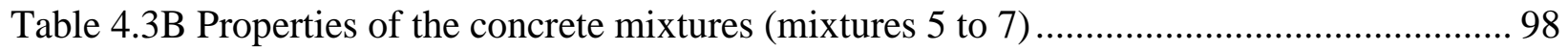

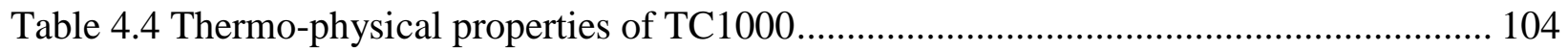

Table 4.5A Properties of thermocline concrete mixtures (Mixtures 1 to 4) ........................... 106

Table 4.5B Properties of thermocline concrete mixtures (Mixtures 5 to 8) ............................ 107

Table 4.5C Properties of thermocline concrete mixtures (Mixtures 9 to 12) ......................... 107

Table 4.5D Properties of thermocline concrete mixtures (Mixtures 13 to 16) ........................ 108

Table 4.5E Properties of thermocline concrete mixtures (Mixtures 17 to 20)........................ 108

Table 4.5F Properties of thermocline concrete mixtures (Mixtures 21 to 24)......................... 109

Table 4.5G Properties of thermocline concrete mixtures (Mixtures 25 and 26) ..................... 109

Table 4.6A Weights and dimensions before and after 500 hours in molten salt at $1085^{\circ} \mathrm{F}\left(585^{\circ} \mathrm{C}\right)$

Table 4.6B Weights and dimensions before and after thermal cycling in molten salt 120

Table 4.7A Compressive strength before and after 500 hours in molten salt at $1085^{\circ} \mathrm{F}\left(585^{\circ} \mathrm{C}\right)$

Table 4.7B Compressive strength before and after thermal cycling in molten salt..... 122 
Table 4.9 Thermo-mechanical properties of selected mixtures

Table 4.10 Predicted and measured $K$ values

Table 4.11 Specific heat $\left(C_{p}\right)$ values before and after thermal cycling

Table A3.1 Properties of ordinary portland cement, Type I.

Table A3.2 Categories of calcium aluminate cement

Table A3.3 Chemical composition and properties of Lumnite MG4

Table A3.4 Chemical composition and properties of Class C fly ash

Table A3.5 Chemical composition and properties of silica fume.

Tables B4.1 Actual measurements of the thermo-mechanical properties of Mixture 26 before exposure to thermal cycling.

Tables B4.2 Actual measurements of the thermo-mechanical properties of Mixture 26 after exposure to elevated temperature thermal cycling. 156

Tables B4.3 Actual measurements of the thermo-mechanical properties of Mixture TC 1000 before exposure to elevated temperature thermal cycling

Tables B4.4 Actual measurements of the thermo-mechanical properties of Mixture TC 1000 after exposure to elevated temperature thermal cycling...... 158

Tables B4.5 Actual measurements of the thermo-mechanical properties of Mixture 11 before exposure to elevated temperature thermal cycling. 159 
Tables B4.6 Actual measurements of the thermo-mechanical properties of Mixture 11 after

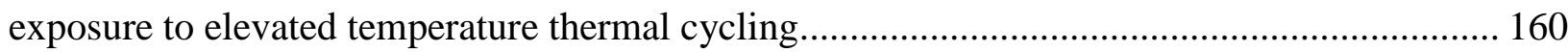

Tables B4.7 Actual measurements of the thermo-mechanical properties of Mixture 2 before exposure to elevated temperature thermal cycling ........................................................ 161

Tables B4.8 Actual measurements of the thermo-mechanical properties of Mixture 2 after

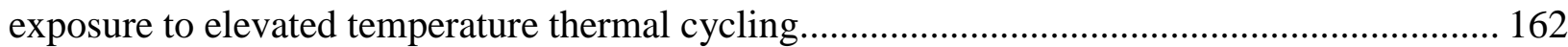

Tables B4.9 Actual measurements of the thermo-mechanical properties of Mixture 15 before exposure to elevated temperature thermal cycling 163

Tables B4.10 Actual measurements of the thermo-mechanical properties of Mixture 15 after exposure to elevated temperature thermal cycling. 165 


\section{LIST OF FIGURES}

Fig. 2.1. Concrete module with embedded heat exchanger (Tamme, 2003). ............................ 9

Fig. 2.2. Concrete test modules installed in laboratory (Herrmann and Kearney, 2002)........... 10

Fig. 2.3. Schematic of a concentrating solar power plant with integrated concrete thermal energy

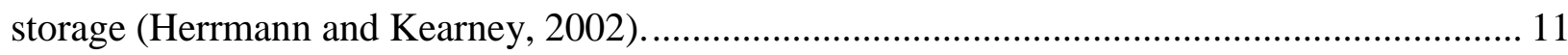

Fig. 2.4. Schematic of a thermocline TES system (Pacheco et al., 2003). .............................. 14

Fig. 2.5. Schematic of a concentrating solar power plant with integrated two-tank molten salt

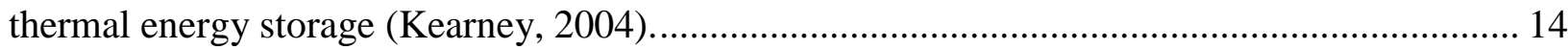

Fig. 2.6. Section of typical thermal tank indicating dimensions and filler materials (Kolb and

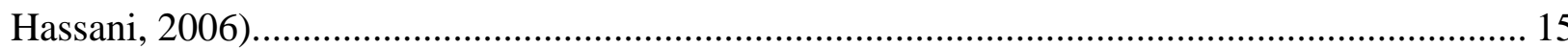

Fig. 2.7. Relative strength-temperature relationship for the stressed testing regimen $\left({ }^{\circ} \mathrm{C}\right.$ to ${ }^{\circ} \mathrm{F}=$

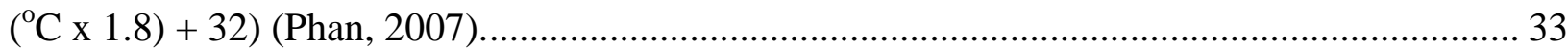

Fig. 2.8. Relative strength-temperature relationship for the unstressed testing regimen $\left({ }^{\circ} \mathrm{C}\right.$ to ${ }^{\circ} \mathrm{F}$

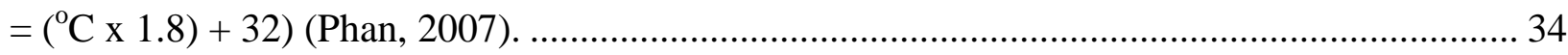

Fig. 2.9. Relative strength-temperature relationship for the unstressed residual testing regimen

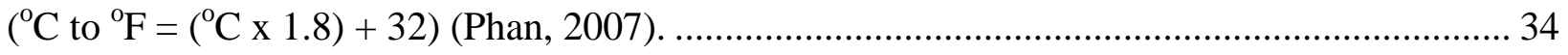

Fig. 2.10. Normalized elastic modulus of HSC as a function of temperature (Cheng et al., 2004).

Fig. 2.11. Normalized elastic modulus of HSC as a function of temperature (Phan et al., 2001). 
Fig. 2.12. Strength-temperature behavior of UHPC (Behloul et al., 2002).

Fig. 2.13. Thermal conductivity of plain high strength concrete (Kodur and Sultan, 2003)...... 46

Fig. 2.14. Thermal conductivity of steel fiber reinforced high strength concrete (Kodur and

Sultan, 2003).

Fig. 2.15. Specific heat capacity of high strength concrete (Kodur and Sultan, 2003). 48

Fig. 2.16. Thermal expansion of high strength concrete (Kodur and Sultan, 2003).

Fig. 2.17. Mass loss of high strength concrete (Kodur and Sultan, 2003)....... 50

Fig. 3.1. Cementitious materials used in the concrete mixtures. 54

Fig. 3.2. Photo of the different aggregates used in this research. 55

Fig. 3.3. Multifilament polypropylene fibers 56

Fig. 3.4. Bronze coated steel fibers. 56

Fig. 3.5. Heating profile. 61

Fig. 3.6. Instrumentation of concrete specimens. 64

Fig. 3.7. Prismatic concrete module used in the molten salt test (Skinner et al., 2011, John et al., 2011). 65

Fig. 3.8. Insulated molten salt heating apparatus (Skinner et al., 2011). 65

Fig. 3.9. Concrete thermal conductivity test set-up. 72

Fig. 3.10. Specific heat test set-up. 73 
Fig. 3.11. Splitting tensile strength test set-up.

Fig. 3.12. Modulus of elasticity test set-up. 78

Fig. 4.1. Explosive spalling of concrete specimens (John et al., 2010). 85

Fig. 4.2. Micro cracks on the surface of concrete specimens (John et al., 2010). 85

Fig. 4.3A. Localized shear failure of the cracked outer surfaces during compressive testing (John et al., 2010). 86

Fig. 4.3B. Cone failure of Mixture 6 in compression after heat testing (John et al., 2010). ...... 86

Fig. 4.4. Temperature at the core of the concrete specimens during heat-up. 89

Fig. 4.5. Effects of thermal cycling on compressive strength (John, 2011). 91

Fig. 4.6. Concrete specimens after 10 thermal cycles (John, 2011). 91

Fig. 4.7. Crack formations on the surface of the prismatic test blocks (Skinner et al., 2011, John et al., 2011). 100

Fig. 4.8. Axisymmetrical FE analysis of the stainless steel-concrete interface (Axes X and Y represent stresses in ksi, Skinner et al., 2011). 101

Fig. 4.9. Reduced level of cracking in concrete specimens with interface material (Skinner et al., 2011). 103

Fig. 4.10. Temperature profiles of HTF and concrete with aluminum foil (outer surface) during heat-up (Skinner et al., 2011). 103

Fig. 4.11A. Level of cracks of control specimens compared to CAC-FA mixtures. 113 
Fig. 4.11B. Level of cracks of control specimens compared to CAC-FA mixtures.

Fig. 4.12. Concrete samples in molten salt after thermal cycling.

Fig. 4.13. Concrete cubes before (left) and after (right) 500 hours in molten salt at $1085^{\circ} \mathrm{F}$

Fig. 4.14. Concrete cubes after compressive test before (left) and after (right) submersion in the molten salt for 500 hours at $1085^{\circ} \mathrm{F}\left(585^{\circ} \mathrm{C}\right)$ 118

Fig. 4.15. Measured and calculated values of specific heat.

Fig. C4.1. Specimens from mixtures 1 to 12 before and after thermal cycling in the presence of molten salt. 166

Fig. C4.2. Specimens from mixtures 15 to 26 after thermal cycling in the presence of molten salt. 166

Fig. C4.3. Disintegration of specimen (left) and specimens after residual compression test (right). 166 


\section{CHAPTER 1 INTRODUCTION}

\subsection{Concrete as a Thermal Energy Storage Medium}

Rising energy costs and the adverse effect on the environment caused by the burning of fossil fuels have triggered extensive research into alternative sources of energy. Harnessing the abundance of solar energy has been one of the most attractive energy alternatives. However, the development of an efficient and economical solar energy storage system is of major concern. The storage of energy obtained from the sun is as vital as developing systems to utilize the sun's energy directly (Ataer, 2008). According to the Department of Energy (DOE) (Olszewski, 1993), the energy cost per kilowatt hour from current technologies which utilize solar energy is high, estimated at approximately $\$ 0.15$ to $\$ 0.20 / \mathrm{kWh}_{\text {electric }}$ (approximately $\$ 30.00 / \mathrm{kWh}_{\text {thermal }}$ ). Based on traditional means of producing electricity (through burning fossil fuels), the unit cost of electricity is $\$ 0.05$ to $\$ 0.06 / \mathrm{kWh}$. Clearly, current solar energy technologies cannot compete with these traditional forms of electricity generation. In response, the DOE has established a goal of reducing the cost of solar generated electricity to $\$ 0.05$ to $\$ 0.07 / \mathrm{kWh}$ electric and achieving storage costs below $\$ 15.00 / \mathrm{kWh}_{\text {thermal }}$.

To accomplish these goals, the DOE has indicated that costs could be reduced by an improvement in the method of thermal energy storage (TES). Two areas where thermal energy storage is vital in the shift to alternative energy are in solar thermal power plants and industrial waste heat recovery (Ataer, 2008). In the case of solar thermal power plants, the TES option can collect energy in order to shift its delivery to a later time. This stored energy can then be utilized during cloudy conditions when insolation (solar radiation) is low, during the night, or when supplied energy is less than energy demand (Ataer, 2008). 
Today, where low temperature storage systems are needed, sensible heat storage using water is utilized (Laing et al., 2008). In the case of high temperature storage, exceeding $212^{\circ} \mathrm{F}$ $\left(100^{\circ} \mathrm{C}\right)$, non-pressurized water cannot be used as a storage medium (Laing et al., 2008). Therefore, the use of pressure vessels is necessary. Because of the high cost that will be incurred to design and build pressure vessels, this technology is not feasible. According to Laing et al. (2008) a viable option is the application of solid sensible heat storage media. Sensible heat storage refers to storing heat energy in a solid or liquid medium by raising the temperature of the medium.

A sensible heat storage system using concrete as the storage medium was successfully tested in Spain in 2003/2004 (Laing et al., 2008). To date, solid media storage using concrete can operate at temperatures ranging from 662 to $752^{\circ} \mathrm{F}\left(350\right.$ to $\left.400^{\circ} \mathrm{C}\right)$ at heating rates of $9^{\circ} \mathrm{F} / \mathrm{min}$ $\left(5^{\circ} \mathrm{C} / \mathrm{min}\right)$. The relatively low cost of concrete and its potential to store heat at very high temperatures make concrete a very appealing option (Laing et al., 2008). However, these systems do not meet the DOE goals. By developing a concrete mixture that can safely operate beyond these temperatures $\left(>752^{\circ} \mathrm{F}\right)$ and at increased heat transfer rates $\left(>9^{\circ} \mathrm{F} / \mathrm{min}\right)$, the operating efficiency of a concentrating solar energy system is improved thereby decreasing the cost of energy per $\mathrm{kWh}_{\text {thermal }}$ and meeting the goals of the DOE

\subsection{Research Objective}

The objective of this research is to develop a concrete mixture that can be used to meet the goals of DOE. This concrete should be able to withstand working temperatures of 932 to $1112^{\circ} \mathrm{F}$ (500 to $600^{\circ} \mathrm{C}$ ), which is 25 to $50 \%$ higher than current plants. At this operating temperature storage capacity will increase. These concrete mixtures will lessen our dependence on fossil fuels and increase the use of electricity generated by solar power. 


\section{CHAPTER 2 LITERATURE REVIEW}

\subsection{Concrete}

Concrete is a construction material comprised of cementitious materials (portland cement (PC) or PC in combination with other cementitious materials such as fly ash, slag cement and silica fume), coarse and fine aggregates, water and possibly some type of chemical admixture. After mixing, the mass solidifies and hardens due to a chemical process known as hydration. The main hydration product, which determines the strength of the concrete, is calcium silicate hydrate (CSH). The applications of concrete are numerous, particularly in civil engineering projects and, in fact, it is used more than any other man-made material (Lomborg, 2001).

Scalny and Roberts (1987) described concrete as a "composite material consisting of an intimate, but not necessarily homogeneous, mixture of crystalline and amorphous phases that differ in size, chemical composition, environmental stability and physical properties." However, the most critical physical trait of concrete is its porosity. Pores of different sizes and shapes present in the various phases of concrete influence its behavior more than the properties of the individual solids of which concrete consists (Scalny and Roberts, 1987).

Based on compressive strength, three distinct categories of concrete can be identified. These are normal strength, high strength and ultra-high strength concrete. Each category of concrete is discussed in greater details in the sections which follow.

\subsubsection{Normal Strength Concrete}

Normal strength concrete (NSC) has a 28-day compressive strength of less than $8 \mathrm{ksi}$ (55 $\mathrm{MPa}$ ). This is deduced from the lower bound compressive strength of $8 \mathrm{ksi}$ (55 MPa) that has been set by the American Concrete Institute (ACI) in 2002 for HSC (Mehta and Monteiro, 2006). Normal strength concrete is a combination of the materials mentioned in Section 2.1 with a range 
of total cementitious materials per cubic yard of approximately 550 to 750 lbs (326 to 445

$\left.\mathrm{kg} / \mathrm{m}^{3}\right)$. The water to cementitious materials ratio $(\mathrm{w} / \mathrm{cm})$ can range from 0.40 to as high as 0.74 dependent on the application. For most projects in which concrete is used, a 28-day compressive strength of less than $6 \mathrm{ksi}$ (42 MPa) is normally specified which makes NSC a so called "typical concrete."

\subsubsection{High Strength Concrete}

American Concrete Institute (ACI) Committee 363 on high strength concrete (HSC) in 2002 defined HSC as concrete with a specified design strength of $8 \mathrm{ksi}(55 \mathrm{MPa})$ or more. The use of HSC is common in the US and around the world, particularly in columns of high rise building structures. HSC is produced by incorporating supplementary cementitious materials (SCM) such as silica fume, slag cement and fly ash into the mixture design. These SCMs are added as a fraction of the total cementitious materials used in the mixture proportioning. They are mainly pozzolanic materials, some of which possess cementing properties, which react with the calcium hydroxide $(\mathrm{CH})$ that is produced from the reaction of portland cement with water to produce additional calcium silicate hydrates (CSH) (Malhotra, 1990). The main advantages derived from the use of pozzolans are; the reaction between the pozzolans and the $\mathrm{CH}$ is slow and as a result, the heat of hydration is also low, the reaction consumes $\mathrm{CH}$ instead of producing it thereby enhancing the concrete's durability and thirdly, the reaction product reduces the void spaces thus enhancing the concrete's strength and reduces permeability (Mehta and Monteiro, 2006).

Also, key to obtaining HSC is reducing the w/cm below 0.40 . The ability to reduce the w/cm below 0.40 is achieved by the use of a chemical admixture (superplastizer) as a constituent of the mixture. The superplastizer permits the reduction in the $\mathrm{w} / \mathrm{cm}$ without sacrificing the concrete's consistency and workability. The reduction in the w/cm results in a more uniform 
distribution of the cement particles and the formation of hydration products with higher surface areas (Malhotra, 1990). The reduction in the w/cm also decreases the porosity of the concrete which increases strength.

\subsubsection{Ultra-high Strength Concrete}

Ultra-high performance/strength concrete (UHPC) is a new class of concrete developed in recent decades. UHPC possesses strengths exceeding $20 \mathrm{ksi}$ (138 MPa) and is highly durable. According to Graybeal (2006), UHPC should possess the following properties: compressive strengths that are greater than $21.8 \mathrm{ksi}(150 \mathrm{MPa})$, internal fiber reinforcement to ensure nonbrittle behavior, and high binder (cementitious material) content with special aggregates (fine filler material). In order to obtain such high strengths, UHPC must have very low water content $(\mathrm{w} / \mathrm{cm}<0.20)$ and a dense matrix. Ordinarily, at w/cm less than 0.20 , concrete mixing becomes difficult. However, through a combination of optimized granular packing and the addition of high-range water reducing admixtures, UHPC with satisfactory rheological properties is attained (Graybeal, 2006).

Typically, UHPC is composed of portland cement, fine sand, silica fume, ground quartz, superplasticizer, steel fibers and water. As previously mentioned, the constituent material proportions are determined based on an optimization of the granular packing of the particulate materials. This method allows for a finely graded and highly homogeneous concrete matrix. The fine aggregate is generally 0.006 to $0.024 \mathrm{in}$. (150 to $600 \mu \mathrm{m})$, and represents the largest granular constituent. The next largest particle is cement with an average diameter of approximately 0.0006 in. $(15 \mu \mathrm{m})$. The crushed quartz has an average diameter of 0.0004 in. (10 $\mu \mathrm{m})$. The smallest particle, the silica fume, has a diameter small enough to fill the interstitial voids between the cement and the crushed quartz particles. Dimensionally, the largest 
constituent in the mix is the steel fibers. The fibers have a diameter of $0.008 \mathrm{in} .(0.20 \mathrm{~mm})$ and a length of 0.5 in. (12.7 mm) (Graybeal, 2006).

\subsubsection{Concrete at Elevated Temperatures}

The effects of high temperature on the mechanical properties of concrete have been investigated as early as the 1940s (Phan and Carino, 1998). Those early studies established that the mechanical properties of concrete are modified with high temperature exposure. However, those early studies were performed using the available concrete at the time, normal strength concrete (NSC) with 28 days compressive strengths less than $5 \mathrm{ksi}$ (35 MPa). In the 70's, high strength/performance concrete (HSC) became available and tests by Abrams (1971), Hertz (1984), Diederichs et al. (1988), Castillo and Durani (1990), Morita et al. (1992), Sullivan and Shansar (1992), Furumura et al. (1995), Hammer (1995), Felicetti et al. (1996), and Noumowe et al. (1996) were performed on HSC specimens at heating rates ranging from 1.8 to $45^{\circ} \mathrm{F} / \mathrm{min}$. (1 to $25^{\circ} \mathrm{C} / \mathrm{min}$. $)$ to temperatures as high as $1472^{\circ} \mathrm{F}\left(800^{\circ} \mathrm{C}\right)$.

These tests revealed that exposure to elevated temperature affect the mechanical properties and behavior of HSC and NSC differently. The differences are in two main areas: (1) strength loss in the temperature range, 212 to $752^{\circ} \mathrm{F}\left(100\right.$ to $\left.400^{\circ} \mathrm{C}\right)$; and (2) the occurrence of explosive spalling in $\mathrm{HSC}$ at temperatures between 572 and $932^{\circ} \mathrm{F}\left(300\right.$ to $\left.500^{\circ} \mathrm{C}\right)$. Both of these material behavioral differences have structural implications. The safety of buildings or other structures built with HSC can be questioned, based on the fact that HSC behaves differently when compared to NSC at elevated temperatures and that most design codes for concrete are based on tests results from NSC (Phan, 2007).

Today, concrete with compressive strength greater than $20 \mathrm{ksi}(138 \mathrm{MPa})$ is commercially available. The extraordinary strength implies that the concrete has a very dense microstructure 
and thus, low permeability. Elevated temperature tests have also shown that this category of concrete is particularly susceptible to explosive spalling along with changes in its mechanical properties similar to those that occur in NSC and HSC.

Fletcher et al. (2007) described spalling as the explosive ejection of portions of concrete from the surface of concrete elements caused by excessive internal stresses within the concrete at high temperature exposure. They hypothesized that explosive spalling is caused by thermal stresses and/or rapid build-up of vapor pressure within the concrete element. The occurrence of spalling within concrete, particularly high strength concrete, and its overall performance at elevated temperatures are influenced by many interacting factors. These factors include concrete type, the constituent materials, moisture content etc. Each will be elaborated upon later in this document.

\subsection{Thermal Energy Storage}

\subsubsection{Background and Storage Concepts}

According to a report by the National Renewable Energy Laboratory (NREL) released in 2000, a symposium workshop on thermal energy storage (TES) systems for solar electric generating systems (SEGS) was held in 1989 to discuss the various options for TES. The

following three concepts were discussed; Latent heat storage, which is the means of storing energy via the heat of transition from a solid to liquid state; Sensible heat storage, which is storing energy by increasing the temperature of a solid or liquid; and heat from chemical reactions. In the case of a solid sensible heat storage system, the materials listed in Table 2.1 were selected as possible options for this application. 
Table 2.1 Solid storage media for CSP/SEGS plants (Herrmann, 2002)

\begin{tabular}{|l|c|c|}
\hline Storage Medium & Heat capacity $\left(\mathbf{k W h} \mathbf{h}_{\mathbf{t}} / \mathbf{m}^{\mathbf{3}}\right)$ & Media $\mathbf{C o s t} \mathbf{( \$ \mathbf { k W h }} \mathbf{\mathbf { t }})$ \\
\hline Reinforced concrete & 100 & 1 \\
\hline $\mathrm{NaCl}$ (solid) & 100 & 2 \\
\hline Cast iron & 160 & 32 \\
\hline Cast steel & 180 & 150 \\
\hline Silica fire bricks & 60 & 18 \\
\hline Magnesia fire bricks & 120 & 30 \\
\hline
\end{tabular}

$1 \mathrm{kWh}=3412.14 \mathrm{Btu}, 1 \mathrm{~m}^{3}=1.308 \mathrm{yd}^{3}$

The report concluded that on the basis of experimental progress at the time and the cost estimates

shown in Table 2.1, that concrete as a thermal energy storage medium merits priority as a candidate for deployment.

The concept uses a concrete-heat exchanger (steel) medium, referred to herein as thermal energy storage (TES) Option A; this is shown in Figure 2.1. 


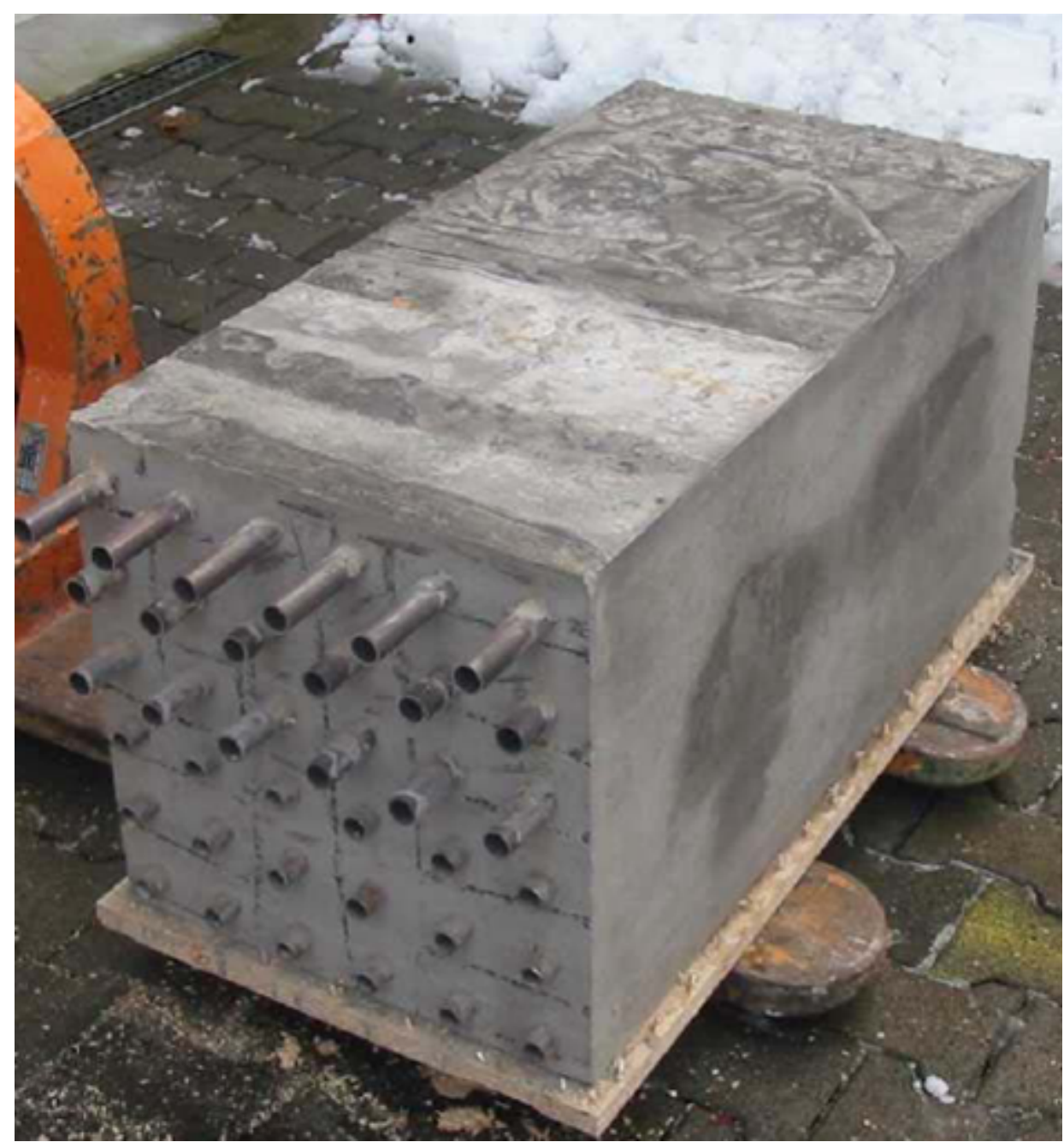

Fig. 2.1. Concrete module with embedded heat exchanger (Tamme, 2003).

Figure 2.1 shows a concrete block in which steel pipes are embedded. These steel pipes function as conduits (heat exchangers) for the circulation of a heat transfer fluid (HTF). The HTF is pumped through the pipes at high temperatures. Through the process of heat conduction, the concrete block is charged. The HTF flows through the piping system long enough to ensure the concrete block attains the same temperature as the HTF. The duration of this process is dependent on the thermal conductivity of the concrete. Energy stored in the block can then be extracted by circulating the same HTF at a temperature lower than that used during the charging process. 
Two of these concrete storage modules were tested at the Center for Solar Energy and Hydrogen Research in Stuttgart, Germany. Figure 2.2 shows the prototype concrete modules installed at the center's laboratory.

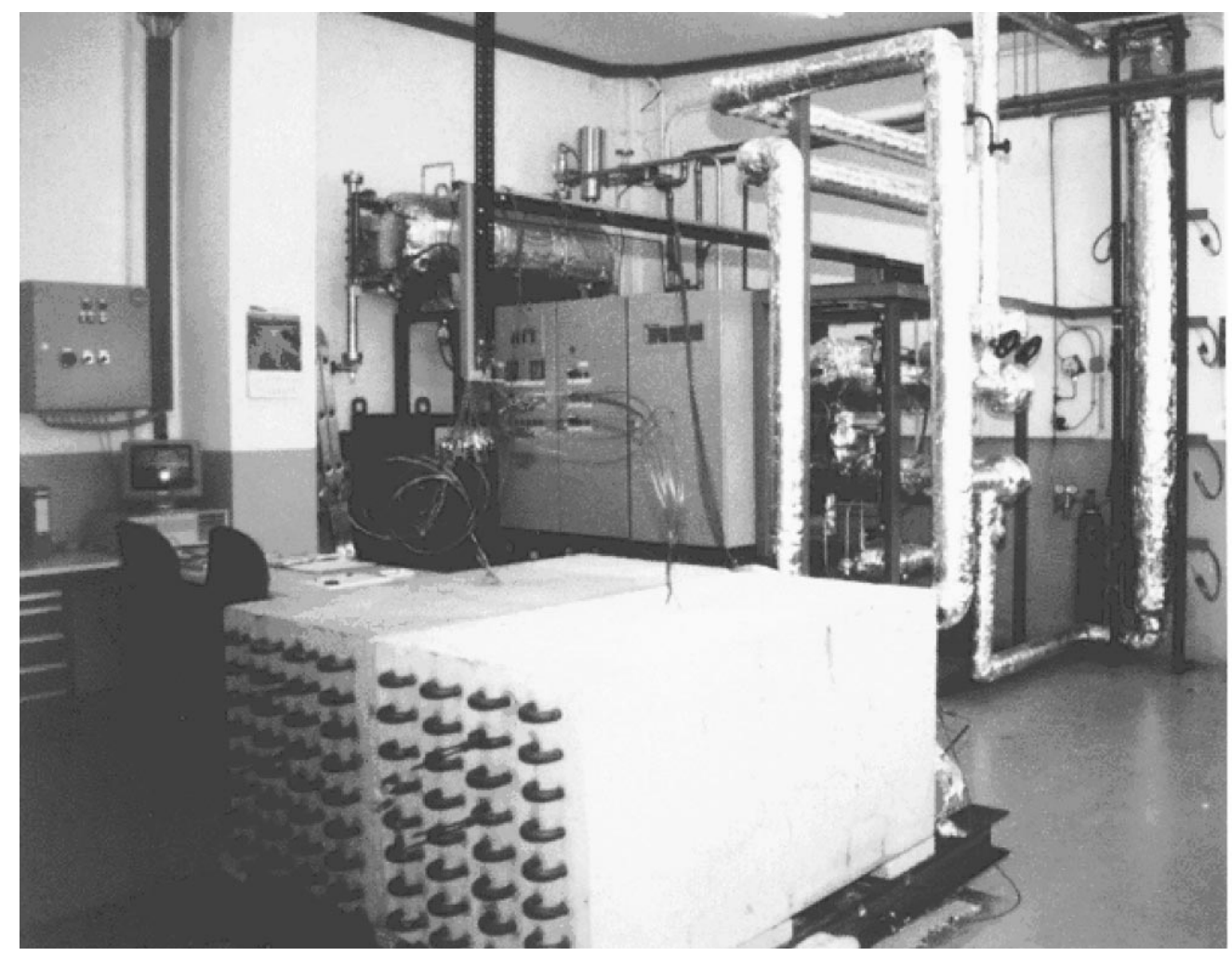

Fig. 2.2. Concrete test modules installed in laboratory (Herrmann and Kearney, 2002).

The results obtained from the laboratory experiment confirmed the predicted performance of the system and prompted the development of a large scale project in which a concrete thermal energy storage system was integrated into a concentrating solar power (CSP) plant. This project was sponsored by the German Government and was implemented in a parabolic trough test loop in Spain in 2003 (Laing, 2006). Figure 2.3 shows a schematic of the concrete thermal energy storage integrated into the parabolic trough solar energy power plant system. 


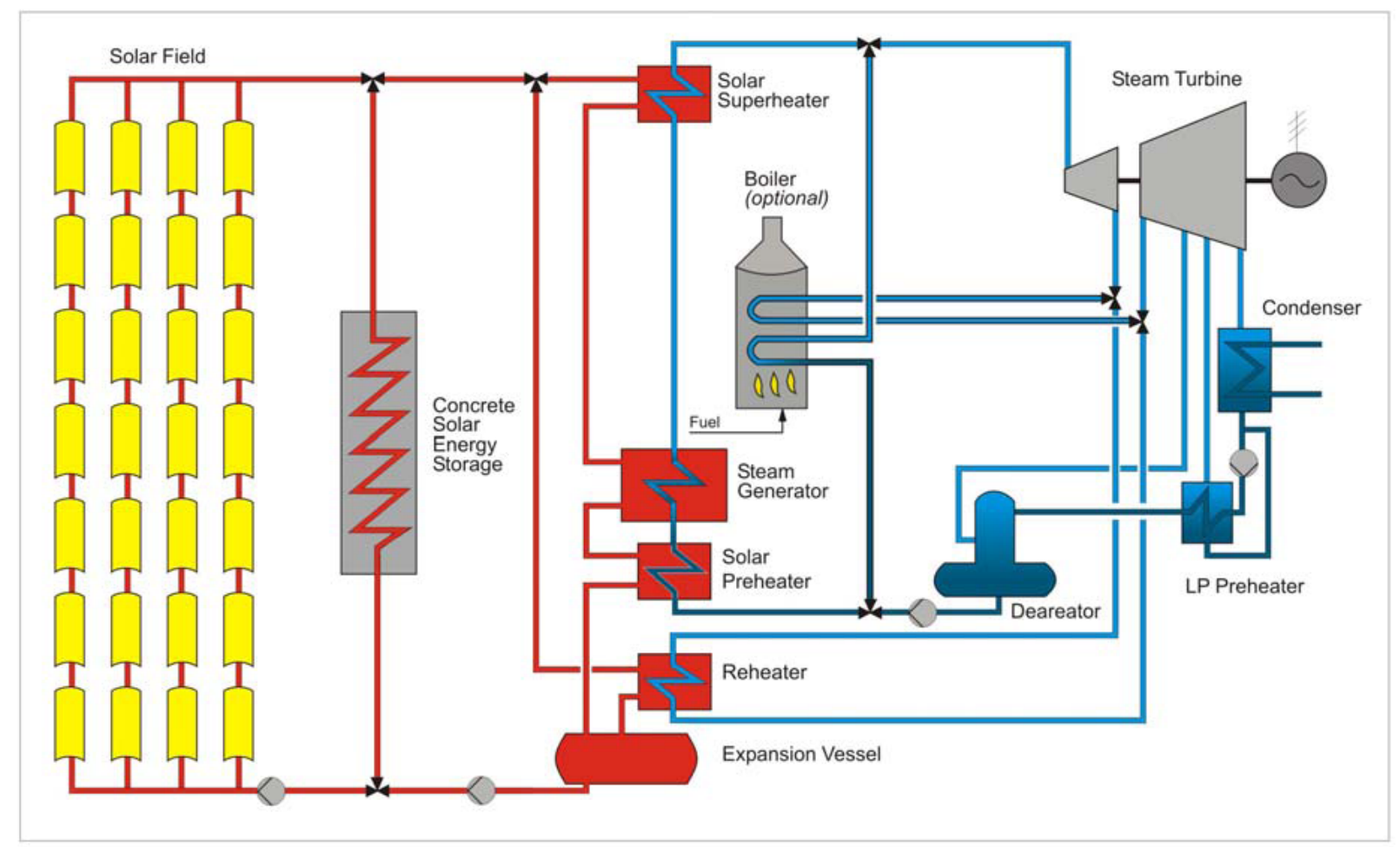

Fig. 2.3. Schematic of a concentrating solar power plant with integrated concrete thermal energy storage (Herrmann and Kearney, 2002).

In this set-up, the HTF flows through the solar field where it is charged to the maximum allowable operating temperature. It flows through the loop simultaneously charging the concrete and providing heat to generate steam which is used to feed a steam turbine that produces electricity. The energy stored in the concrete storage medium is then used as a buffer during times of adverse weather conditions, for "dispatchability", and to provide uniform electricity production.

The goal of a buffer is to provide continued energy during times of reduced solar input caused by passing clouds which can significantly affect operation of a CSP plant. Herrmann and Kearney explained that "if regular and substantial cloudiness occurs over a short period, turbine steam conditions and/or flow can degrade enough to force turbine trips if there is no supplementary thermal source to "ride through" the disturbance." Dispatchability refers to the 
shifting of the energy stored during periods of high insolation to a later period with higher electricity demand.

The present CSP plant system with solid media thermal storage in Spain operates at a maximum temperature of $752^{\circ} \mathrm{F}\left(400^{\circ} \mathrm{C}\right)$. This ceiling on operating temperature is governed by the type of HTF used and also by the ability of the concrete medium to withstand the temperatures. The present system uses synthetic oil (Therminol) as the HTF. Therminol becomes unstable at temperatures beyond $752^{\circ} \mathrm{F}\left(400^{\circ} \mathrm{C}\right)$, thereby limiting the operating temperature of the CSP plant (Laing et al., 2006). This research program aims to increase the operating temperature to above $932^{\circ} \mathrm{F}\left(500^{\circ} \mathrm{C}\right)$ by using molten salt (solar salt) as the HTF. Molten salt is a eutectic mixture of $40 \%$ by weight potassium nitrate $\left(\mathrm{KNO}_{3}\right)$ and $60 \%$ by weight sodium nitrate $\left(\mathrm{NaNO}_{3}\right)$ which remains stable at temperatures up to $1085^{\circ} \mathrm{F}\left(585^{\circ} \mathrm{C}\right)$. The concrete storage medium must also withstand temperatures of $932^{\circ} \mathrm{F}\left(500^{\circ} \mathrm{C}\right)$ and beyond without significant degradation of its mechanical and thermal properties. This increase in operating temperature will result in a reduction in energy prices per $\mathrm{kWh}_{\text {thermal }}$ and consequently the price per $\mathrm{kWh}_{\text {electric. }}$

An alternative to TES Option A is a thermocline system, referred to herein as TES Option B. TES Option B is a one-tank system in which both the hot and cold fluid occupy the same tank as shown in Figure 2.4, resulting in reduced storage tank volume (Pacheco et al., 2001, Kolb and Hassani, 2006, Yang and Garimella, 2010, Faas, 1983). That is, the use of two separate tanks in which the hot and cold fluids are stored separately, as shown in Figure 2.5, is not necessary. Molten salt is relatively expensive $(\$ 0.22 / \mathrm{lb}$ ) (Kearney, 2002) and in order to reduce the cost of the storage system, the option shown in Figure 2.6 was proposed by Pacheco et al., 2003. In Figure 2.6, heated molten salt enters the top of the tank which contains a packed bed of quartzite 
rock and silica sand as the TES medium. The TES medium is charged and the cooler salt moves to the bottom of the tank. This creates a temperature gradient referred to as a thermocline, inside the tank (Pacheco et al., 2001, Kolb and Hassani, 2006, Yang and Garimella, 2010, Faas, 1983). The thermocline storage system uses less than half the salt that is required by a two-tank system for a required storage capacity and maintaining the thermocline within the tank is vital to its efficient functioning.

Nevertheless, a major technical issue with this system is thermal ratcheting. Repeated thermal cycles result in the settlement of the quartzite and silica filler as they occupy the increased tank volume during the charging phase. During the discharging phase, the compacted filler material prevents the contraction of the tank walls, thus generating high lateral pressures on the lower tank wall (Yang and Garimella, 2010, Faas, 1983). This phenomenon, referred to as thermal ratcheting, can potentially lead to yielding of the tank walls. One way to address this problem is to use packed concrete bricks in place of the aggregate filler, an approach that has never been investigated. 


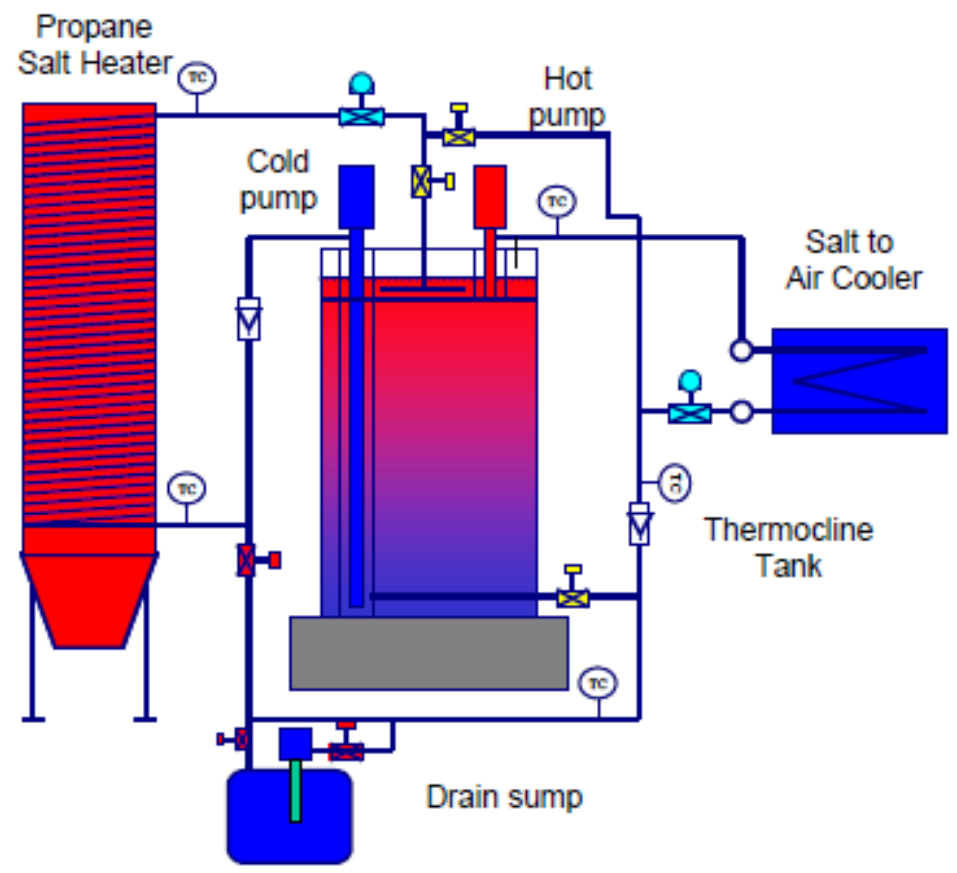

Fig. 2.4. Schematic of a thermocline TES system (Pacheco et al., 2003).

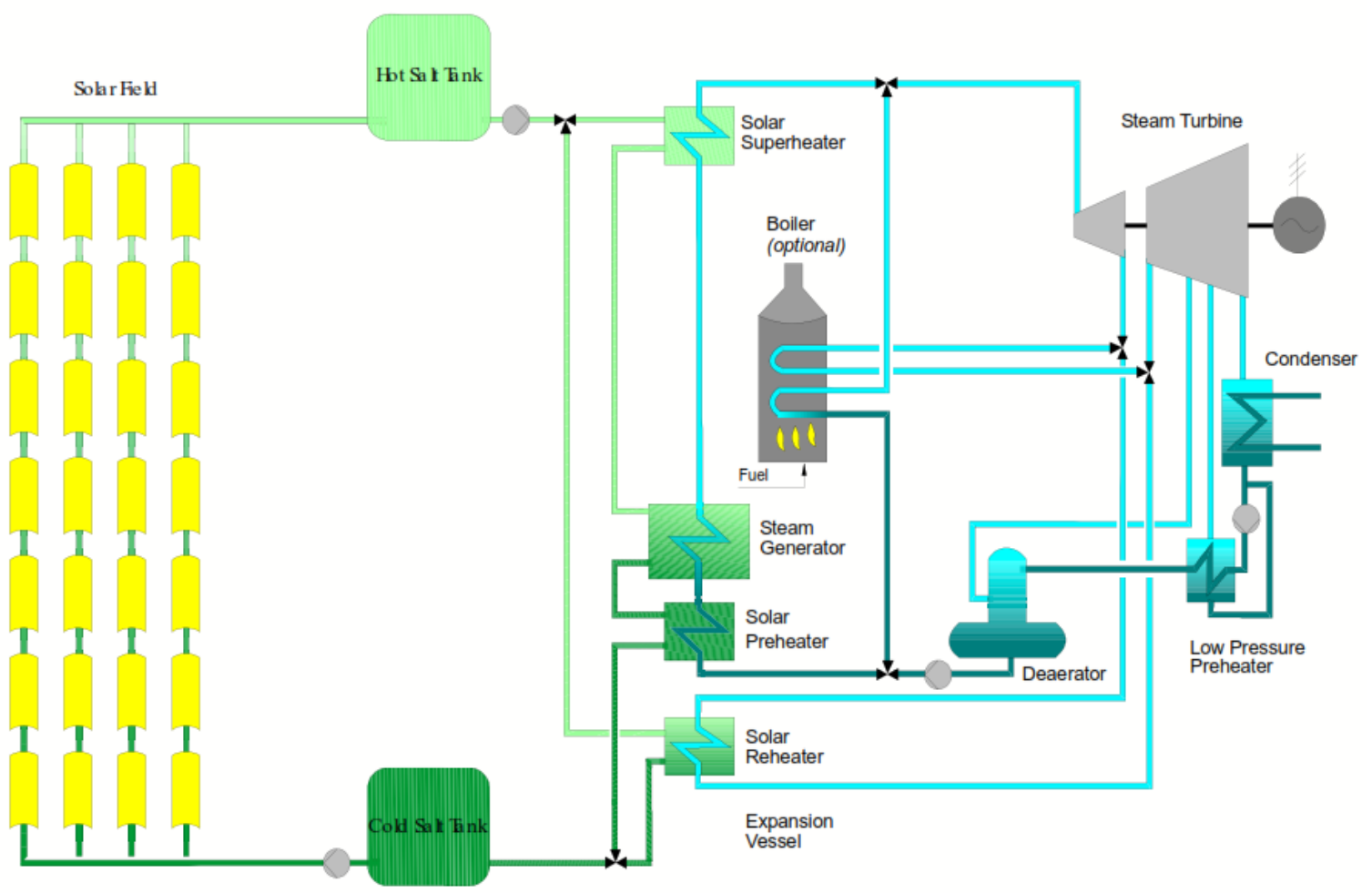

Fig. 2.5. Schematic of a concentrating solar power plant with integrated two-tank molten salt thermal energy storage (Kearney, 2004). 


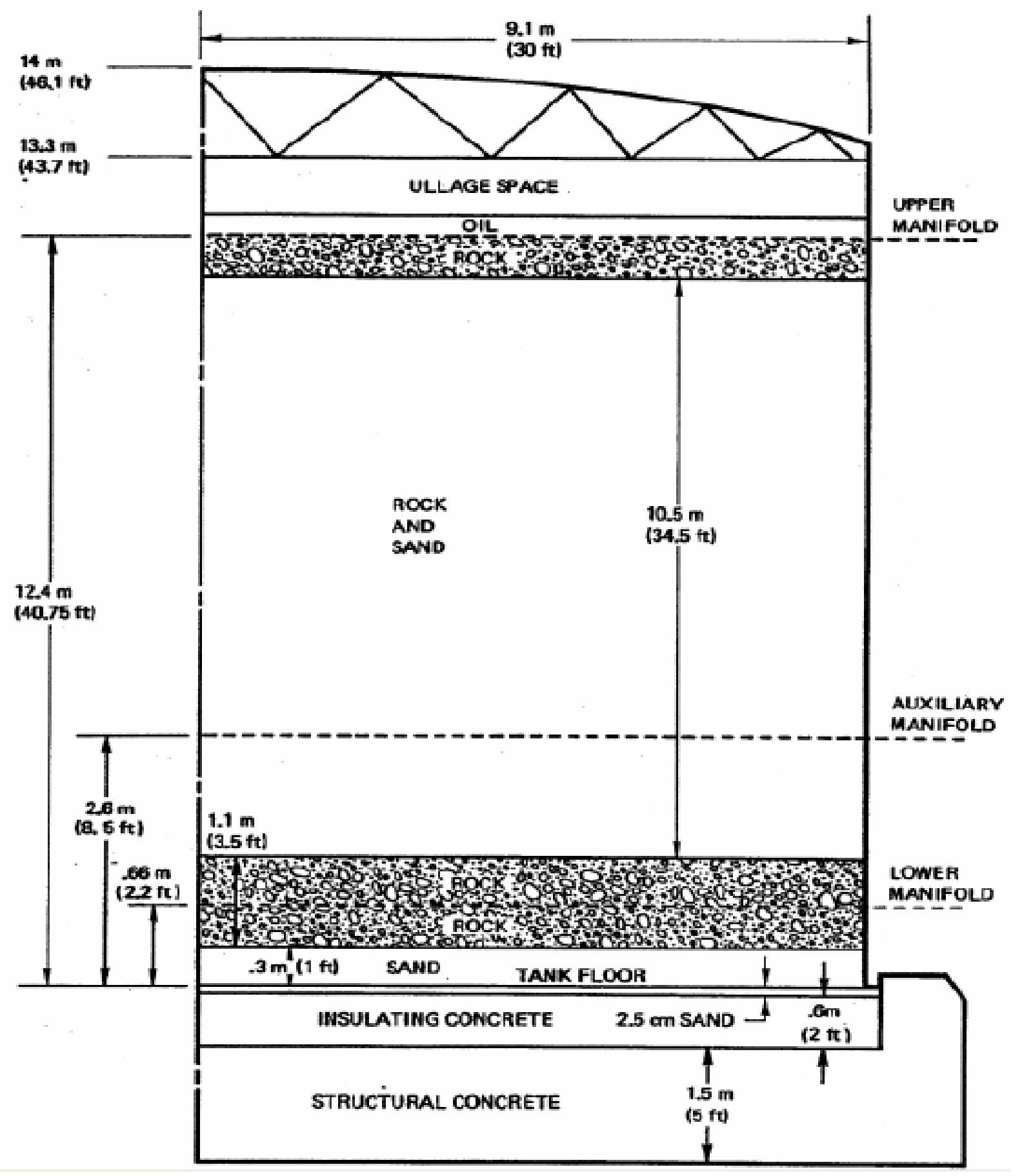

Fig. 2.6. Section of typical thermal tank indicating dimensions and filler materials (Kolb and Hassani, 2006). 


\subsubsection{Concrete Mixtures}

According to Tamme et al. (2003) two different storage materials were developed for deployment in the pilot project in Spain. A castable ceramic based on a binder composed of aluminates $\left(\mathrm{Al}_{2} \mathrm{O}_{3}\right)$, and iron oxides accumulated as waste material in strip steel production as the aggregates. Auxiliary materials were incorporated to improve the workability of the mixture. The other storage material was a high strength concrete in which slag cement was used as the binder, iron oxides as the main aggregate, some fly ash and auxiliary materials to improve workability. Table 2.2 summarizes the properties and costs of both mixtures.

Table 2.2 Properties of tested thermal energy storage materials

\begin{tabular}{|c|c|c|}
\hline \multirow{2}{*}{ Storage Material Properties } & \multicolumn{2}{|c|}{ Storage Material } \\
\hline & High Temperature Concrete & Castable Ceramic \\
\hline $\begin{array}{l}\text { Density }(\rho) \\
\left(l b / f t^{3}\right)\end{array}$ & 172 & 218 \\
\hline $\begin{array}{l}\text { Specific heat }\left(\mathrm{C}_{\mathrm{p}}\right) \text { at } 662^{\circ} \mathrm{F} \\
\left(\text { Btu/lbm }^{\circ} F\right)\end{array}$ & 0.219 & 0.207 \\
\hline $\begin{array}{l}\text { Thermal conductivity }(K) \text { at } \\
662^{\circ} \mathrm{F}\left(\text { Btu/ft. } h^{\circ} F\right)\end{array}$ & 0.578 & 0.78 \\
\hline $\begin{array}{l}\text { Coefficient of thermal } \\
\text { expansion at } 662^{\circ} \mathrm{F}\left(10^{-6} / K\right)\end{array}$ & 9.30 & 11.80 \\
\hline $\begin{array}{l}\text { Costs } \\
\left(\$ / y d^{3}\right)\end{array}$ & 130 & 256 \\
\hline
\end{tabular}

$1 \mathrm{Btu} / \mathrm{lbm}^{\circ} \mathrm{F}=4.1868 \mathrm{~J} / \mathrm{gK}, 1 \mathrm{Btu} / \mathrm{ft} . \mathrm{h} .{ }^{\circ} \mathrm{F}=1.73 \mathrm{~W} / \mathrm{mK}, 1 \mathrm{lb} / \mathrm{ft}^{3}=16.02 \mathrm{~kg} / \mathrm{m}^{3}, 1 \mathrm{yd}^{3}=0.7645$ $\mathrm{m}^{3}$

According to Tamme, though the castable ceramic had a higher heat capacity (20\%) and thermal conductivity $(35 \%)$ than the high temperature concrete, the concrete was chosen because of its lower cost, higher strengths and easier handling of the fresh mixture.

This research will focused on HSC of various binder (cementitious material) types and combinations, combined with different types of aggregates. Cementitious material will include portland cement, silica fume, fly ash and calcium aluminate cement. Aggregate types will 
include limestone, sandstone, granite and siliceous sand. High strength concrete was chosen for this research for two main reasons. Firstly, there is a significant improvement in the interfacial transition zone (ITZ) phase of HSC compared to NSC. The ITZ refers to the zone between the coarse aggregates and the cement paste of a concrete mixture. In this zone, there is a higher localized w/cm which makes the hardened concrete more porous within the ITZ (Mehta and Monteiro, 2006). Additionally, after curing micro cracks are present within the ITZ, these micro cracks can easily propagate when concrete is exposed to elevated temperatures (Mehta and Monteiro, 2006). Improvement in the ITZ will be beneficial to the long-term stability of the concrete storage medium. Secondly, there is a reduction in the void spaces of HSC compared to NSC. This reduction in voids will increase matrix density which will facilitate heat transfer.

\subsubsection{Concrete Design Criteria and Concerns}

Key issues for the development and proper functioning of concrete as a solid media storage material are its thermo-physical properties such as density, specific heat capacity, thermal conductivity, coefficient of thermal expansion (CTE), cyclic stability and cost. A high heat capacity, which is the product of the concrete's mass and its specific heat, will reduce the storage volume and insulation requirements. A high thermal conductivity decreases the charging discharging time of the storage medium and reduces the number of heat exchangers. It is also important that the concrete's CTE matches the CTE of the embedded metallic conduits or heat exchangers. By achieving this, the probability of a reduction in the heat transfer process because of a gap developing between the heat exchanger and the concrete is reduced. Additionally, both the concrete and the metallic heat exchanger should contract and expand in unison so as to avoid the development of major cracks in the storage medium. To ensure that the storage unit performs well throughout its design life, concrete must be resistant to numerous thermal cycles. 
Explosive spalling of the concrete during the initial heating is another major concern. The factors contributing to this phenomenon and ways to avoid it are discussed separately in Section 2.4.4.

\subsection{Thermal Properties of Concrete}

\subsubsection{Coefficient of Thermal Expansion}

The coefficient of thermal expansion (CTE) is the change in unit length per degree of temperature change. According to Mehta and Monteiro (2006), selecting an aggregate with a low coefficient of thermal expansion is critical for crack prevention in concrete, particularly mass concrete. They explained that the thermal shrinkage strain is dependent both on the magnitude of temperature change and the coefficient of linear thermal expansion of concrete. The thermal expansion of the concrete is in turn controlled by the coefficient of linear thermal expansion of the aggregate, which is the primary constituent of concrete. The CTE for portland cement pastes of varying w/c, mortars (with cement to sand ratio of 1:6) and concrete mixtures with different aggregate types are approximately $10,6.7$ and 3.3 to $6.7 \times 10^{-6} /{ }^{\circ} \mathrm{F}(18,12$ and 6 to $\left.12 \times 10^{-6} /{ }^{\circ} \mathrm{C}\right)$, respectively. Commonly used aggregates such as limestones and gabbros have a CTE of approximately $2.8 \times 10^{-6} /{ }^{\circ} \mathrm{F}\left(5 \times 10^{-6} /{ }^{\circ} \mathrm{C}\right)$ and 6.1 to $6.7 \times 10^{-6} /{ }^{\circ} \mathrm{F}\left(11\right.$ to $\left.12 \times 10^{-6} /{ }^{\circ} \mathrm{C}\right)$ for sandstones, natural gravels and quartzite (Mehta and Monteiro, 2006). In Section 2.2.3, the importance of controlling concrete's CTE when used as a TES medium was discussed.

However, the CTE of the HSC mixtures proposed for this research are not known and therefore the performance of the concrete-stainless steel system will only be known through experimentation. 


\subsubsection{Specific Heat}

Concrete specific heat is the quantity of heat needed to raise the temperature of a unit mass by one degree. The specific heat of normal weight concrete is not significantly affected by the type of aggregate, temperature and other parameters such as total cementitious material constituents. Typically, concrete specific heat ranges from 0.215 to $0.239 \mathrm{Btu} / \mathrm{lbm}^{\circ} \mathrm{F}(0.9$ to 1.0 $\mathrm{J} / \mathrm{gK}$ ) (Neville, 1996). Equation 1 highlights the importance of concrete's specific heat as it relates to thermal energy storage.

$$
Q_{s}=M C_{p} \Delta T=V \rho C_{p} \Delta T
$$

In Equation 1, $\mathrm{Q}_{s}$ represents the amount of energy stored, $\mathrm{M}$ represents the mass, $\mathrm{C}_{\mathrm{p}}$ is the specific heat, $\rho$ is density, $\mathrm{V}$ is volume, and $\Delta \mathrm{T}$ is change in temperature. One can see the direct relationship which exists between the amount of energy stored and the specific heat. However, because the specific heat of concrete does not vary significantly from one concrete type to another, an increase in the amount of energy stored can only be attained by an increase in mass and/or a change in temperatures $(\Delta \mathrm{T})$.

\subsubsection{Thermal Conductivity}

The heat flux transmitted through a unit area of concrete, or any other material, under a unit temperature gradient is termed thermal conductivity. The thermal conductivity of concrete is influenced by the mineralogical characteristics of the aggregate and by the moisture content, density and temperature of concrete (Neville, 1996). The importance of concrete's thermal conductivity as it relates to its effectiveness as a thermal energy storage medium was explained in Section 2.2.3. The variation in thermal conductivity with respect to temperature for different types of concrete is discussed in Section 2.7. Compared to other materials like iron, steel and copper, the thermal conductivity of concrete is low. This is one of the major concerns with using 
concrete as a TES medium. In an effort to improve concrete's thermal conductivity, different combinations of aggregates and steel fibers were used in the mixtures. Typical values of thermal conductivity for some commonly used aggregates are given in Table 2.3.

Table 2.3 Thermal conductivity values for commonly used aggregates

\begin{tabular}{|l|c|}
\hline Aggregates & Thermal Conductivity $\left(\right.$ Btu/ft.h. $\left.{ }^{\boldsymbol{o}} \boldsymbol{F}\right)$ \\
\hline Granite & 1.00 to 2.30 \\
\hline Limestone & 0.728 to 0.769 \\
\hline Marble & 1.20 to 1.70 \\
\hline Sandstone & 1.06 \\
\hline
\end{tabular}

$1 \mathrm{Btu} / \mathrm{ft} . \mathrm{h} .{ }^{\circ} \mathrm{F}=1.73 \mathrm{~W} / \mathrm{mK}$

\subsubsection{Thermal Diffusivity}

Thermal diffusivity is defined as the thermal conductivity divided by the heat capacity (product of mass and specific heat). Heat will move more readily through concrete with higher thermal diffusivity. For normal-weight concrete, the conductivity usually controls the thermal diffusivity because the density and specific heat do not vary much (Neville, 1996). In Section 2.2.3, the need for concrete as a TES medium to possess adequate thermal conductivity was discussed. Thermal conductivity and thermal diffusivity are directly related. Some typical values of thermal diffusivity for concrete with different coarse aggregates are given in Table 2.4. 
Table 2.4 Thermal diffusivity values for concrete with different coarse aggregates (Mehta and Monteiro, 2006)

\begin{tabular}{|l|c|c|}
\hline Coarse aggregates & $\mathbf{f t}^{2} / \mathbf{h}$ & $\mathbf{m}^{\mathbf{2}} / \mathbf{h}$ \\
\hline Quartzite & 0.058 & 0.0054 \\
\hline Dolomite & 0.051 & 0.0047 \\
\hline Limestone & 0.050 & 0.0046 \\
\hline Granite & 0.043 & 0.0040 \\
\hline Rhyolite & 0.035 & 0.0033 \\
\hline Basalt & 0.032 & 0.0030 \\
\hline
\end{tabular}

\subsection{Effects of Elevated Temperature on Concrete}

Many factors control the response of concrete to elevated temperatures. The composition (cement paste and aggregates) of concrete is one of these factors. The cement paste and the aggregate undergo different levels of transformation and decomposition at distinct temperature ranges dependent on cementitious material and aggregate type. Concrete permeability, the size of the element and heating rate also influence the behavior of concrete at high temperatures. These factors govern the development of internal pressures within the concrete from the gaseous decomposition products. Concrete behavior at high temperatures may be difficult, if not impossible, to predict. However, in an attempt to understand how concrete may behave when exposed to elevated temperatures, a place to start would be a thorough analysis of the effects of high temperatures on its constituent materials.

\subsubsection{Cement Paste}

According to Petzold and Rohrs (1970), when portland cement paste is subjected to heat after it has set, it loses its adsorbed and free water (capillary water) in certain ranges of temperature. Subsequently, after passing through an intermediate water free state, new phases are built; the mineralogical composition of these phases is determined by the temperature. For 
example, between 392 and $1472^{\circ} \mathrm{F}\left(200\right.$ and $\left.800^{\circ} \mathrm{C}\right)$, wollastonite is formed and there is also the presence of free calcium oxide $(\mathrm{CaO})$. Petzold and Rohrs have cited a number of researchers who have demonstrated that after portland cement paste has been subjected to elevated temperatures, there is an initial increase in strength around $572^{\circ} \mathrm{F}\left(300^{\circ} \mathrm{C}\right)$ which is then followed by a general strength loss.

Through differential thermo-analysis, it is observed that between temperatures of 212 to $392^{\circ} \mathrm{F}\left(100\right.$ to $\left.200^{\circ} \mathrm{C}\right)$, hydrated cement paste loses its capillary water and some of the adsorbed water. Between 932 and $1112^{\circ} \mathrm{F}\left(500\right.$ and $\left.600^{\circ} \mathrm{C}\right)$, interlayer water is lost and the dehydration of calcium hydroxide occurs (Petzold and Rohrs, 2006). Temperatures of $1652^{\circ} \mathrm{F}\left(900^{\circ} \mathrm{C}\right)$ are required for the complete dehydration and decomposition of calcium silicate hydrate $(\mathrm{C}-\mathrm{S}-\mathrm{H})$. These phenomena were also explained by Mehta and Monteiro (2006). Petzold and Rohrs showed that the reactions associated with the evaporation of water do not occur continuously but happens periodically at the different temperature ranges mentioned above. The periodic dispersion of water affects the structure and the bonding of the cement mass which leads to the development of numerous cracks and fissures.

\subsubsection{Aggregates}

Aggregate, both coarse and fine, constitute approximately 60 to $80 \%$ of the volume of concrete. Therefore, any aggregate damage at elevated temperatures impacts the overall behavior of the concrete. Cruz (1966) explained that aggregate porosity and mineralogy influence the behavior of concrete exposed to high temperatures. Cruz outlined that depending on the rate of heating and the size, permeability, and moisture state of the aggregate, the porous aggregates themselves may be susceptible to destructive expansion leading to aggregate "popouts". It must be noted though, that most aggregates used in the production of concrete are low 
porosity aggregates hence considerably reducing any problems related to internal moisture movement.

Cruz (1966) and Yan et al. (2007) explained that siliceous aggregates like granites and sandstone, which contain quartz, can be problematic in concrete at temperatures of about $1058^{\circ} \mathrm{F}$ $\left(570^{\circ} \mathrm{C}\right)$. At this temperature, there is a transformation of quartz from alpha to beta form which results in a sudden expansion of the order of $0.85 \%$. In the case of carbonate rocks, both authors indicated that a similar distress can begin above $1292^{\circ} \mathrm{F}\left(700^{\circ} \mathrm{C}\right)$ as a result of decarbonization reactions. In addition to the phase transformation and thermal decomposition that aggregates undergo because of their mineralogical composition, the mineralogy also determines the differential thermal expansions between the aggregate and the cement paste and ultimately, the strength of the interfacial transition zone (Cruz, 1966).

Yan et al. (2007) mentioned that calcareous aggregates perform well at high temperature exposures. The reasons given are that the calcareous aggregates typically have a low coefficient of thermal expansion, closer to that of cement paste, producing lower internal stresses on heating. There is however one drawback when calcareous aggregates are exposed to temperatures beyond $1292^{\circ} \mathrm{F}\left(700^{\circ} \mathrm{C}\right)$. The calcium and magnesium carbonate constituent of the aggregates breakdown. During cooling, the carbonates that transformed during heating, rehydrate. This re-hydration reaction causes post-cooling spalling in calcareous aggregate concretes (Arup, 2005).

\subsubsection{Spalling}

One of the most complex and poorly understood behavioral characteristics in the reaction of concrete to high temperatures is explosive spalling (Khoury, 2000, Tenchev and Purnell, 2005). Explosive spalling is often assumed to occur only at high temperatures; however, results from 
fire tests have painted a different picture. Phan (2007), Castillo and Durrani (1990), Both et al. (1999), and Carnisius et al. (2003) have all reported the occurrence of spalling in the early stages of a fire and at temperatures as low as $392^{\circ} \mathrm{F}\left(200^{\circ} \mathrm{C}\right)$. Severe spalling affects the strength of concrete members in two ways; (1) by reducing or even eliminating the layer of concrete cover on reinforced concrete members, thereby directly exposing the reinforcement and (2) reducing the cross sectional area of the concrete member thereby reducing the load bearing capacity. These structural effects are not of major concern for concrete as a thermal energy storage medium, however, the reasons for spalling are a concern.

The mechanism leading to spalling involves the build-up of pressure within the concrete developed from the phase change of water when concrete is exposed to high temperatures, and high thermal stresses resulting from rapid heating. High strength concrete, because of its dense microstructure, is not able to dissipate the pressure build-up. The pressure build-up coupled with the thermal stresses, exceed the tensile strength of the concrete and hence fractures develop and portions of material from the surface layers of concrete elements are expulsed (Fletcher et al., 2007).

Bazant $(1996,1997)$ explained that high pore pressures are only important in initiating the process of explosive spalling. Bazant explained that the pressure build-up within the concrete initiates the formation of fissures. However, as cracks open, avenues are created for the dissipation of pressure within the concrete. Energy to propagate the cracks is provided by the strain energy generated by the thermal stresses. High strength concrete is more brittle than conventional concrete, so it is more sensitive to brittle crack growth and, consequently, to explosive spalling when exposed to high temperatures (Bazant 1996, 1997). 
Most researchers agree that the major causes of spalling are concrete's low permeability and moisture migration which results in the build-up of pore pressure at elevated temperatures (Bilodeau et al., 2002, Kodur, 2005, Kodur and Phan, 2007). Due to the low permeability of HSC and UHPC, high pressures are generated within these concrete types at elevated temperatures resulting in an increased propensity to spall.

Experimental studies to investigate spalling in HSC have been conducted on small scale specimens by Phan (2007), Han et al. (2005), Hertz (2003), and Phan et al. (2001), and on structural components (columns, beams and slabs) by Park et al. (2007), Kodur and Sultan (2003), Kodur and McGrath (2003), Kodur et al. (2003), and Bilodeau et al. (2004). These studies have shown that HSC members are more susceptible to spalling when compared to NSC members. Investigations on the effects of high temperatures on concrete carried out by Phan (2007), revealed two other important findings. (1) Phan reported no incidences of spalling in any of the NSC specimens and (2) that spalling occurred in the HSC specimens at relatively low temperatures, less than $752^{\circ} \mathrm{F}\left(<400^{\circ} \mathrm{C}\right)$. Other researchers (Diederichs et al., 1995, Hammer 1995, Furumura et al., 1995) also reported the occurrence of explosive spalling of their HSC specimens. It is interesting to note that this spalling occurred even though the heating rates were low, 1.8 and $3.6^{\circ} \mathrm{F} / \mathrm{min}$. in the cases of Furumura and Hammer, respectively $\left(1^{\circ} \mathrm{C} / \mathrm{min}\right.$. for Furumura and $2^{\circ} \mathrm{C} / \mathrm{min}$. for Hammer).

Dwaikat and Kodur (2010) also investigated the spalling phenomenon in concrete. They used NSC and HSC beams in their studies. Results from their experiments showed that no spalling occurred in the NSC beams, whereas significant spalling occurred in the HSC beams. Again, this is mainly attributed to the low permeability of HSC. The reduced permeability prevents the water vapor, generated with increasing temperatures in concrete from escaping and 
this leads to excessive build-up of vapor pressure within concrete. Once the vapor pressure exceeds the tensile strength of the concrete (which is lower than the tensile strength at ambient temperatures), spalling will occur. In the case of the NSC beams, the high level of permeability provided a mechanism for the water vapor dissipation and thus alleviates significant vapor pressure build up.

UHPC does not perform any better at high temperature exposures. In fact, the very low porosity of UHPC leads to greater internal stresses. In these materials, the porosity is totally enclosed, which prevents water vapor from escaping. The term "totally enclosed pores" means the pores are not interconnected. This increases the pressure within the material which causes spalling (Behloul et al., 2002).

\subsubsection{Factors Contributing to Spalling}

From the many studies on the performance of HSC at elevated temperatures, some of the factors that contribute to spalling are; concrete's strength, moisture content, and density, heating rate (Hydrocarbon fueled fire curves as opposed to standard fire curves), specimens' dimension and shape, loading conditions, fiber reinforcement, aggregate type, reinforcement layout and configuration (Khoury and Anderberg, 2000, Arup, 2005, Kodur and Phan, 2007).

\subsubsection{Moisture Content}

Concrete's moisture content, expressed in terms of relative humidity $(\mathrm{RH})$, is one of the main factors causing spalling. Concrete with high RH levels, especially those exposed to external environment, will exhibit extensive spalling if exposed to elevated temperatures. According to Kodur and Phan (2007), the time required to attain an acceptable RH level (below $75 \%$ ) in HSC members is longer than that required for NSC members because of the low permeability of HSC. Ultra-high performance concrete, which has an even lower permeability 
value, will therefore retain moisture for longer periods. Fire resistance tests on full-scale HSC columns have shown that significant spalling occurred when the $\mathrm{RH}$ of the specimen, at the time of fire tests, was higher than $80 \%$ (Kodur, 2000).

\subsubsection{Heating Condition}

The extent of spalling in HSC and UHPC is more severe in fires characterized by fast heating rates or high fire intensities (Kodur, 2000). Building and hydrocarbon fueled fires pose a severe threat in this regard. Building fires reach temperatures of $1832^{\circ} \mathrm{F}\left(1000^{\circ} \mathrm{C}\right)$ and over 2192 $\left(1200^{\circ} \mathrm{C}\right)$, in the case of hydrocarbon fires, with heating rates as high as $198^{\circ} \mathrm{F} / \mathrm{min} .\left(110^{\circ} \mathrm{C} / \mathrm{min}\right.$.) within the first 5 minutes of a fire.

\subsubsection{Aggregate}

Aggregate type influences the fire resistance of concrete and the occurrence of spalling. The two commonly used aggregate types in concrete are carbonate and siliceous aggregates. Carbonate aggregate concrete has a higher fire and spalling resistance compared to siliceous aggregate concrete. Carbonate aggregates possess higher heat capacity which is beneficial in preventing spalling of the concrete (Kodur and Sultan, 1998, Kodur, 2005).

\subsubsection{Specimen Dimensions}

Specimen size also influences the extent of spalling in concrete. The risk of explosive spalling increases with an increase in specimen size. A larger specimen (or structural element) will not facilitate moisture transport. The distance to a boundary of the element is longer; this makes it more difficult for pressure build-up to dissipate (Kodur, 2000). Additionally, larger structures have the capacity to store more energy. Specimen size must be evaluated when assessing the performance of concrete exposed to high temperatures. A review of the literature 
showed that most high temperature tests are conducted on scaled specimens (Kodur, 2005, Kodur and Phan, 2007, Fletcher et al., 2007).

\subsubsection{Concrete Strength}

High strength and ultra-high strength concretes are characterized by their low permeability and hence high strengths. Information from the literature show that concrete with strengths higher than $8 \mathrm{ksi}(55 \mathrm{MPa})$ are more susceptible to spalling and may result in lower fire/heat resistance. HSC with compressive strength of $10 \mathrm{ksi}(70 \mathrm{MPa})$ and greater, have permeability values in the range $10^{-15}$ to $10^{-19} \mathrm{ft}^{2}\left(10^{-16}\right.$ to $\left.10^{-20} \mathrm{~m}^{2}\right)$, compared to concrete with strengths ranging from 3 to $10 \mathrm{ksi}\left(20\right.$ to $70 \mathrm{MPa}$ ) which have permeability values of $10^{-12}$ to $10^{-15} \mathrm{ft}^{2}\left(10^{-}\right.$

${ }^{13}$ to $10^{-16} \mathrm{~m}^{2}$ ) (Kodur and Dwaikat, 2008). Spalling of concrete can be prevented if its permeability is greater than $5 \times 10^{-14} \mathrm{ft}^{2}\left(5 \times 10^{-15} \mathrm{~m}^{2}\right.$ or 0.005 darcies) (Harmathy, 1965).

\subsubsection{Applied Load}

The probability of explosive spalling increases relative to the type of load and the intensity of that load. A loaded HSC structural member is susceptible to higher spalling than an unloaded member. This occurs because a loaded structural member is subjected to stresses due to both load and internal steam pressure at high temperature exposures. Further, the extent of spalling is higher if the load is of an eccentric (or bending) type since this will induce additional tensile stresses (Kodur, 1998).

\subsubsection{Thermal Expansion}

Concrete expansion is an indication of its likelihood to spall. Concrete that has its thermal expansion restrained is more susceptible to spalling. Consequently, concrete with low thermal expansion reduces the thermal stresses developed in a fire, thereby increasing its spalling resistance (Khoury and Anderberg, 2000, Arup, 2005). 


\subsubsection{Reinforcement}

The presence of reinforcement in concrete will generally improve the spalling resistance of a concrete member because it halts or delays the development of spalling at the line of the reinforcement (Kodur, 2000). This is particularly important for concrete members such as columns, beams, and double reinforced walls and slabs. Kodur (1998) showed that the configuration of the tie bars influence the fire resistance of reinforced concrete members. Ties with $135^{\circ}$ hooks improve the resistance.

\subsubsection{Density}

Concrete density depends on the aggregate used and the w/cm. High strength concrete using normal weight aggregates is made dense by lowering the w/cm and in many instances adding silica fume. The inclusion of silica fume in the mix results in even lower values of permeability. It therefore means that the risk of spalling will increase. Additionally, Bilodeau et al. (1998) reported occurrences of high spalling in HSC made from light weight aggregates. The spalling is mainly due to the presence of higher free moisture in the lightweight aggregate which creates higher vapor pressures at high temperature exposure (Kodur, 2000).

\subsubsection{Spalling Mitigation Measure}

Hannant (1998), Tatnall (2002), Segre et al. (1998), Bilodeau et al. (1998), Kodur and Lie, (1997) have revealed that the amount of explosive spalling and the extent of cracking, can be reduced considerably or even eliminated by the use of suitable amounts of polypropylene (PP) fibers. The mechanism by which the PP fibers mitigate spalling in concrete is based on the melting of the fibers at a temperature of approximately $338^{\circ} \mathrm{F}\left(170^{\circ} \mathrm{C}\right)$. This occurrence creates "channels" for the steam pressure in concrete to dissipate, and thus reduces the high stresses that are partly responsible for spalling of the concrete (Kodur, 2000, Fletcher, 2007). 
A good demonstration of the effect of PP fibers in the reduction of internal pore pressure in concrete was provided by Phan (2007). The pore pressures at spalling for a number of concrete specimens were measured. The pressures at spalling were measured at 293 to 305 psi (2.02 to 2.1 MPa). Polypropylene fibers were subsequently added to the same mixes and tested, results showed that the additions of PP fibers reduced maximum pore pressure and prevented explosive spalling in the specimens that were otherwise identical. The highest pore pressure measured for specimens with $2.5 \mathrm{lb} / \mathrm{yd}^{3}\left(1.5 \mathrm{~kg} / \mathrm{m}^{3}\right)$ of PP fibers was $206 \mathrm{psi}(1.42 \mathrm{MPa})$, a drop of about $45 \%$ when compared with the exploded specimen. For specimens with $5 \mathrm{lb} / \mathrm{yd}^{3}\left(3.0 \mathrm{~kg} / \mathrm{m}^{3}\right)$ of PP fibers, the pressure measured was 96 psi (0.66 MPa), a more than 300\% drop. However, Phan did not attribute the dissipation of pressure build-up entirely to the melting of the fibers. Phan explained that thermal gradient is also an influencing factor in the process of pore pressure buildup and/or dissipation. Higher thermal gradients, caused by high heating rates, can cause micro cracks to develop early in concrete specimens or elements thereby providing an additional avenue for vapor pressure dissipation.

Literature (Khoury and Anderberg, 2000, Allen, 2006, Fletcher et al., 2007, Phan, 2007) indicates that relatively small amounts of PP fibers ranging from $0.80 \mathrm{lb} / \mathrm{yd}^{3}\left(0.5 \mathrm{~kg} / \mathrm{m}^{3}\right)$ of concrete up to $8.50 \mathrm{lb} / \mathrm{yd}^{3}\left(5 \mathrm{~kg} / \mathrm{m}^{3}\right)$ may be adequate for spall mitigation/explosion prevention. The types of fibers used were monofilament, multifilament and fibrillated with a diameter of $0.00072 \mathrm{in.} \mathrm{(18} \mathrm{microns).} \mathrm{However,} \mathrm{a} \mathrm{dosage} \mathrm{rate} \mathrm{of} 3.40 \mathrm{lb} / \mathrm{yd}^{3}\left(2 \mathrm{~kg} / \mathrm{m}^{3}\right)$ of fibers is more prevalent throughout the literature (Kutzing, 1999, Kodur, 2005). 


\subsection{Performance of Concrete at Elevated Temperatures}

\subsubsection{Behavior of Normal-strength Concrete (NSC) at High Temperatures}

A review of the literature shows that in most of the testing programs for concrete at elevated temperatures, the following three testing conditions are employed;

1- An unstressed test in which specimens are heated under no initial stress and loaded to failure at the desired elevated temperature.

2- A stressed test where a fraction of the ultimate strength at room temperature is applied and sustained during heating and, when the target temperature is reached, the specimens are loaded to failure.

3- A residual unstressed test where the specimens are heated without load then allowed to cool and subsequently loaded to failure.

The literature reviews that follow will reference these three testing regimens.

Mehta and Monteiro (2006) examined the effect of short-duration, $1598^{\circ} \mathrm{F}\left(870^{\circ} \mathrm{C}\right)$, exposure on concrete specimens with an average compressive strength of $3.9 \mathrm{ksi}(27 \mathrm{MPa})$ prior to the temperature exposure. The variables that were studied included aggregate type (carbonate, siliceous or lightweight expanded shale) and testing conditions (mentioned previously). They reported that NSC when heated without load and tested hot (Regimen 1), the specimens made with the carbonate aggregate and the lightweight aggregate retained more than $75 \%$ of their initial strengths up to $1202^{\circ} \mathrm{F}\left(650^{\circ} \mathrm{C}\right)$. Concrete specimens containing the siliceous aggregate were only able to retain $75 \%$ of their original strength up to approximately $797^{\circ} \mathrm{F}\left(425^{\circ} \mathrm{C}\right)$ and lost $75 \%$ of their original strength at $1202^{\circ} \mathrm{F}\left(650^{\circ} \mathrm{C}\right)$. They attributed the superior performance of the concretes containing either the carbonate or the lightweight aggregate to a stronger 
interfacial transition zone (ITZ) and a smaller difference in the coefficients of thermal expansion (CTE) between the matrix mortar and the coarse aggregate.

Results also indicate that the compressive strength of specimens tested hot (Regimen 2) was up to $25 \%$ higher than those of unloaded companion specimens. Mehta and Monteiro (2006) also observed superior performance of carbonate and lightweight aggregate concretes for specimens subjected to this testing regimen. However, the effect of aggregate mineralogy on concrete strength was negligible when the specimens were tested after cooling (Regimen 3) to $70^{\circ} \mathrm{F}\left(21^{\circ} \mathrm{C}\right)$. They also reported that original strength did not play a major role in the percentage of compressive strength retained after the high-temperature exposure and that compared to the pattern of compressive strength loss, the elastic modulus of concrete made with the three types of aggregates dropped more rapidly as the temperature was increased. This is attributed to preexisting micro cracks in the ITZ and the rapid propagation of these cracks at high temperatures. Micro cracking has a more damaging effect on the flexural strength and the elastic modulus of concrete than on the compressive strength.

According to Castillo and Durrani (1990), NSC undergoes a sharp decrease in the residual unstressed strength (Regimen 3$)$ at temperatures above $842^{\circ} \mathrm{F}\left(450^{\circ} \mathrm{C}\right)$. This reduction in strength is due to a loss of bond between the aggregate and the cement paste. They also observed that if the concrete is stressed (Regimen 2) while being heated, the presence of compressive stresses retards the growth of cracks, resulting in less strength loss. Castillo and Durrani's test results also showed that with increased temperatures, NSC undergoes an approximate $10 \%$ loss in strength up to a temperature of $257^{\circ} \mathrm{F}\left(125^{\circ} \mathrm{C}\right)$. This loss in strength is followed by a gain of about $15 \%$ above the compressive strength at ambient temperatures up to $472^{\circ} \mathrm{F}\left(250^{\circ} \mathrm{C}\right)$. Thereafter, further increase in temperature results in strength loss which falls 
rapidly above $752^{\circ} \mathrm{F}\left(400^{\circ} \mathrm{C}\right)$. At temperatures around $1292^{\circ} \mathrm{F}\left(700^{\circ} \mathrm{C}\right)$, the NSC specimens only possess about 25 to $40 \%$ of their original strength. These results are illustrated graphically in Figures 2.7, 2.8 and 2.9.

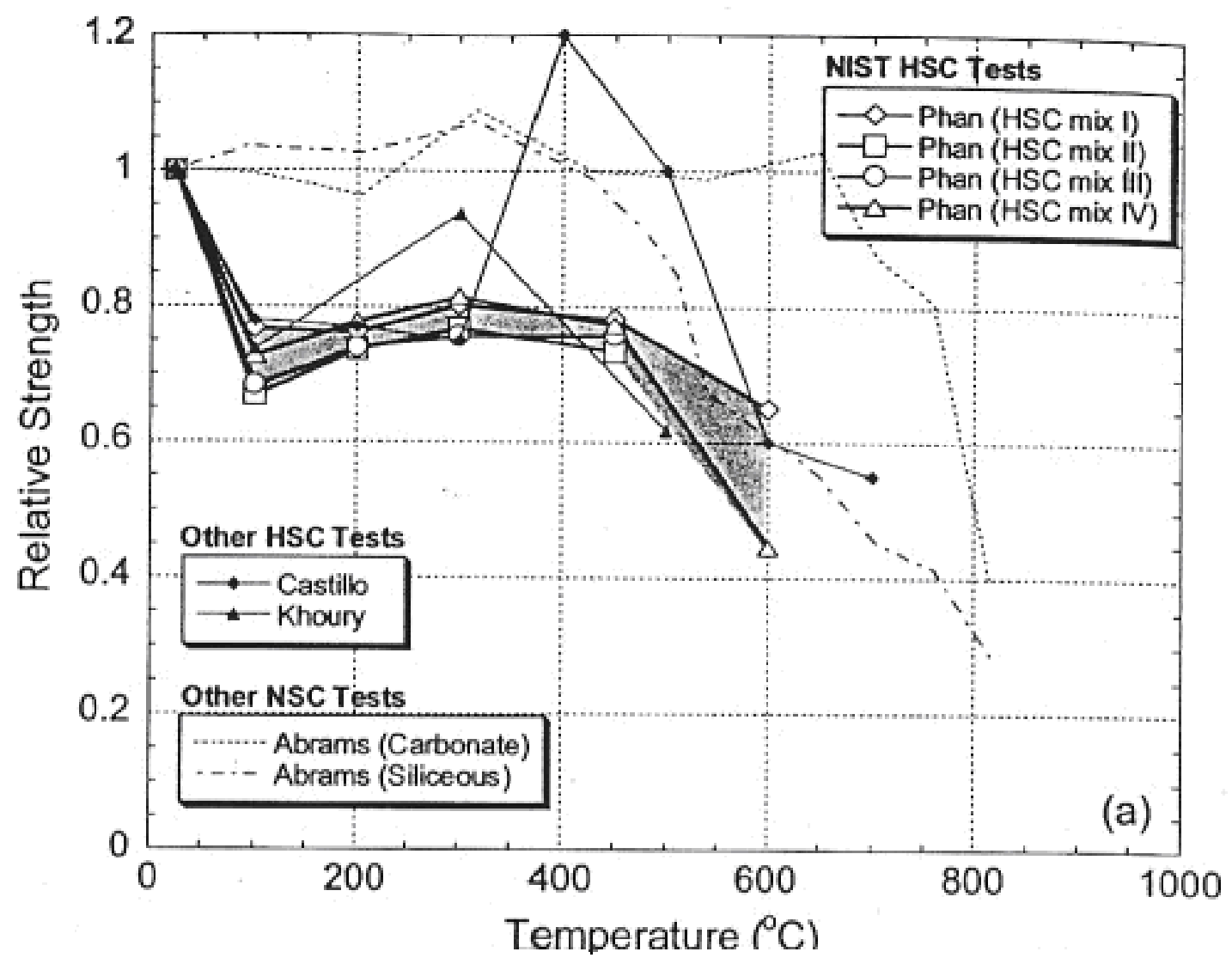

Fig. 2.7. Relative strength-temperature relationship for the stressed testing regimen $\left({ }^{\circ} \mathrm{C}\right.$ to $\left.{ }^{\circ} \mathrm{F}=\left({ }^{\circ} \mathrm{C} \times 1.8\right)+32\right)($ Phan, 2007). 


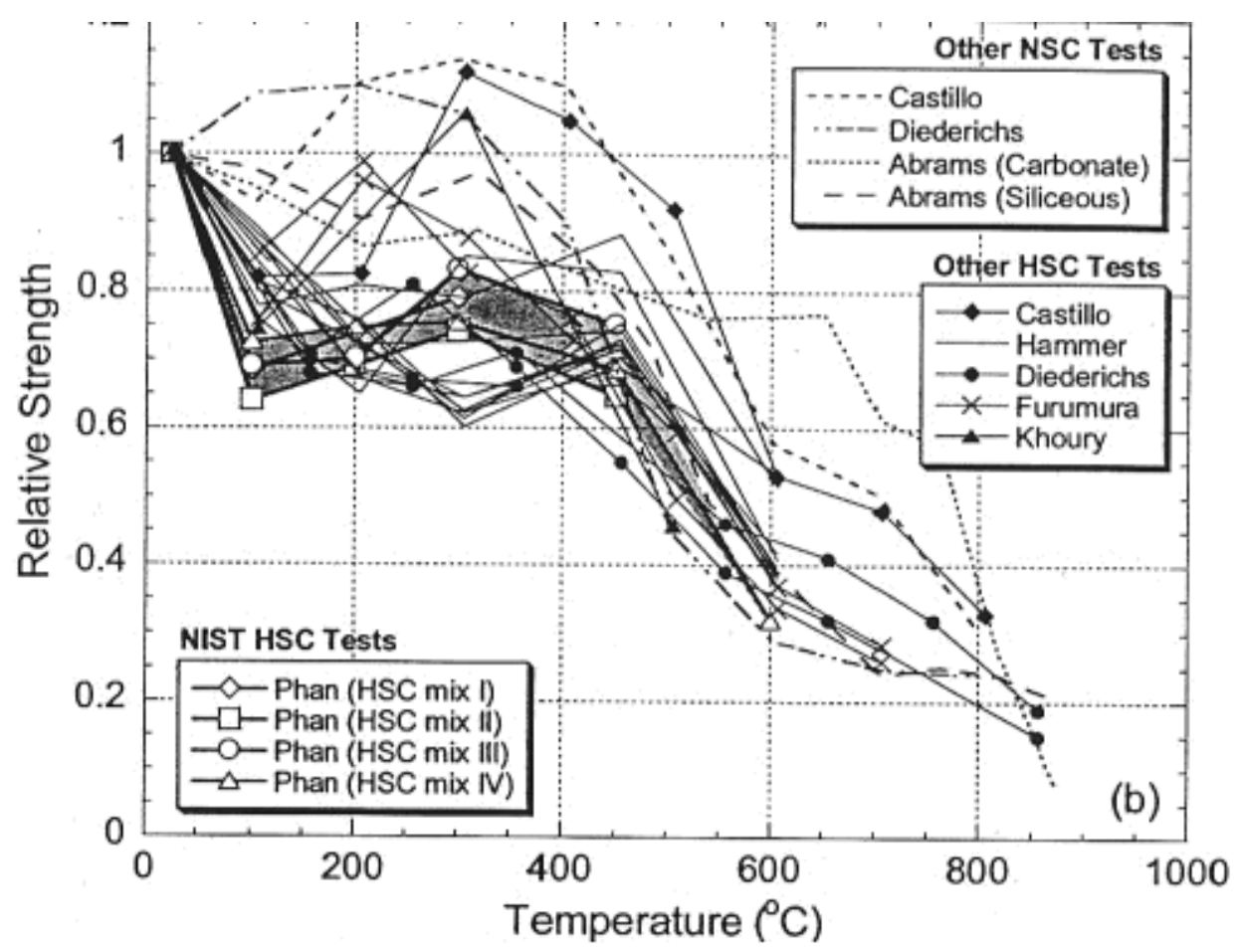

Fig. 2.8. Relative strength-temperature relationship for the unstressed testing regimen $\left({ }^{\circ} \mathrm{C}\right.$ to $\left.{ }^{\circ} \mathrm{F}=\left({ }^{\circ} \mathrm{C} \times 1.8\right)+32\right)($ Phan, 2007).

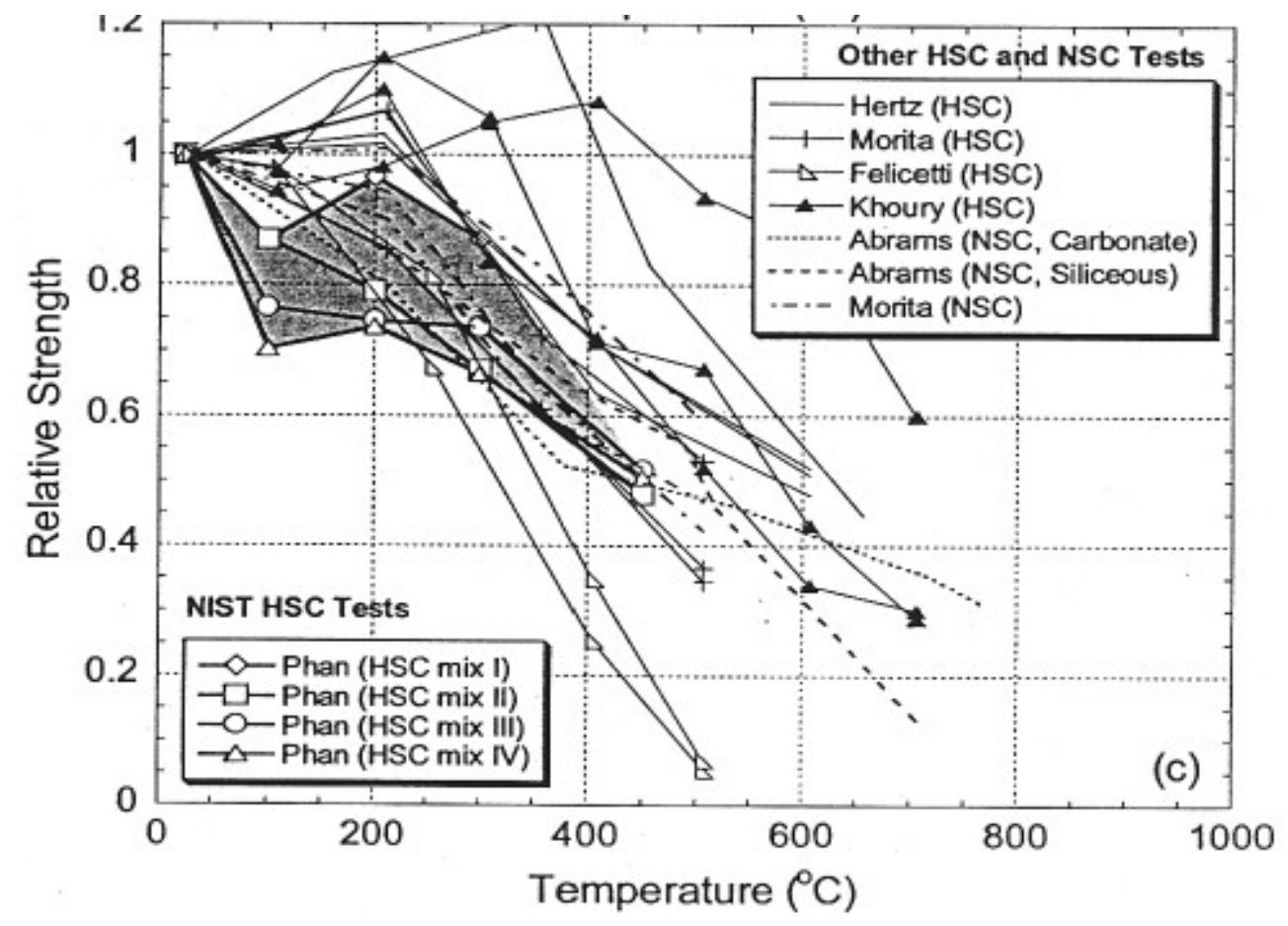

Fig. 2.9. Relative strength-temperature relationship for the unstressed residual testing regimen $\left({ }^{\circ} \mathrm{C}\right.$ to $\left.{ }^{\circ} \mathrm{F}=\left({ }^{\circ} \mathrm{C} \times 1.8\right)+32\right)($ Phan, 2007) . 
Results of compressive strength tests on NSC at elevated temperatures are summarized in Figures 2.7, 2.8 and 2.9. Figure 2.8, which summarizes tests results based on Regimen 1, highlights discrepancies between the results of Abrams (1971) and those of Castillo and Deiderichs. Test results by Abrams indicate that there was a slight strength gain (5 - 10\%) at temperatures up to $752^{\circ} \mathrm{F}\left(400^{\circ} \mathrm{C}\right)$, and strength loss was not observed until concrete reached temperatures above $752^{\circ} \mathrm{F}\left(400^{\circ} \mathrm{C}\right)$. This contradicts the findings of Castillo and Deiderichs whose results show that the compressive strength loss decreases with increasing temperatures. Additionally, Abrams' results in Figure 2.7 (Regimen 2) illustrated that NSC with calcareous aggregate showed no reduction in strength until $1202^{\circ} \mathrm{F}\left(650^{\circ} \mathrm{C}\right)$.

Based on the results of the various tests on NSC summarized in Figures 2.7 through to 2.9, the French authorities developed and published in the Comité Européen de Normalisation (CEN) $(1993,1994)$ a table of reduction factors that can be used to assess the effects of elevated temperatures on NSC comprised of siliceous, calcareous and light weight aggregates (LWA). The values for strength reduction as a function of temperature and aggregate type are presented in Table 2.5 based on CEN $(1993,1994)$. 
Table 2.5 Strength reduction factor for NSC according to French Standards (Phan and Carino, 1998)

\begin{tabular}{|c|c|c|c|}
\hline \multirow{2}{*}{$\begin{array}{c}\text { Concrete } \\
\text { Temperature }\left({ }^{\mathbf{o}} \mathbf{C}\right)\end{array}$} & \multicolumn{3}{|c|}{$k_{c, \theta}=f_{c, \theta} / f_{c, 20^{\circ} c}$} \\
\cline { 2 - 4 } & Siliceous & Calcareous & \multirow{2}{*}{ LWA } \\
\hline 20 & 1.00 & 1.00 & 1.00 \\
\hline 100 & 0.95 & 0.97 & 1.00 \\
\hline 200 & 0.90 & 0.94 & 1.00 \\
\hline 300 & 0.85 & 0.91 & 0.00 \\
\hline 400 & 0.75 & 0.85 & 0.76 \\
\hline 500 & 0.60 & 0.74 & 0.64 \\
\hline 600 & 0.45 & 0.60 & 0.52 \\
\hline 700 & 0.30 & 0.43 & 0.40 \\
\hline 800 & 0.15 & 0.27 & 0.28 \\
\hline 900 & 0.08 & 0.15 & 0.16 \\
\hline 1000 & 0.04 & 0.06 & 0.04 \\
\hline 1100 & 0.01 & 0.02 & 0.00 \\
\hline 1200 & 0.00 & 0.00 & \\
\hline
\end{tabular}

${ }^{\circ} \mathrm{C}$ to ${ }^{\circ} \mathrm{F}=\left({ }^{\circ} \mathrm{C} \times 1.8\right)+32$

\subsubsection{Behavior of HSC at Elevated Temperatures}

A number of researchers (Phan, 2001, Khoury, 2000, Diederichs, 1989) have shown through results from both laboratory and field tests that HSC behaves differently compared to normal strength concrete at similar temperature exposures. High strength concrete undergoes different levels of strength loss when exposed to elevated temperatures and is prone to spall in an explosive manner. Phan et al. (2001) carried out experiments which focused on the effects of elevated temperature exposure on HSC. The residual mechanical properties, namely compressive and tensile strengths were measured after heating 4 × 8 in. (100 x $200 \mathrm{~mm})$ cylindrical specimens to steady state thermal conditions at different temperature levels (maximum core temperature of $842^{\circ} \mathrm{F}$ at $9^{\circ} \mathrm{F} / \mathrm{min} .\left(450^{\circ} \mathrm{C}\right.$ at $5^{\circ} \mathrm{C} / \mathrm{min}$.)) and allowing them to cool to room temperatures. Four tests mixtures (two of which contained silica fume), which ranged in w/cm from 0.22 to 0.57 and compressive strengths from 7.4 to $13.5 \mathrm{ksi}$ (51 to $93 \mathrm{MPa}$ ) were used. 
Results from their experiments showed that HSC with higher initial strength, in which silica fume was incorporated, retained higher strengths than those of lower initial strengths (without silica fume). However, it was indicated that the specimens with lower w/cm and those containing silica fume were prone to explosive spalling. The residual tensile strength showed no significant differences for the various mixtures. Exposure to $842^{\circ} \mathrm{F}\left(450^{\circ} \mathrm{C}\right)$ caused all four concrete mixtures to lose more than $70 \%$ of their initial modulus of elasticity.

Castillo and Durrani (1990) also studied the effects of transient high temperature on HSC. Their main goal was to study the compressive strength and load-deformation behavior of HSC under both unloaded and preloaded conditions. The compressive strength and resulting stressstrain behavior of HSC was compared to that of NSC under the same testing conditions. The three testing regimens that were presented earlier were employed (Section 2.5.1). Specimens (2 $\mathrm{x} 4$ in.) used in the tests had compressive strengths of 10.5 and $12.5 \mathrm{ksi}$ (72 to $86 \mathrm{MPa}$ ) and heating rates ranged from 12.6 to $14.4^{\circ} \mathrm{F} / \mathrm{min}$. ( $\left(7\right.$ to $8^{\circ} \mathrm{C} / \mathrm{min}$.).

Castillo and Durrani's results indicate a common trend between both NSC and HSC for all three testing regimens. Initially, strengths decrease up to $212^{\circ} \mathrm{F}\left(100^{\circ} \mathrm{C}\right)$ by as much as $20 \%$. The reduced strength remains constant for a temperature range above $212^{\circ} \mathrm{F}\left(100^{\circ} \mathrm{C}\right)$ which is dependent on the initial compressive strength and the preload conditions. Further increase in the temperature resulted in strength recovery for all specimens up to $752^{\circ} \mathrm{F}\left(400^{\circ} \mathrm{C}\right)$. The strength recovery ranged from 10 to $20 \%$ above ambient temperature strength. In the temperature range of 752 to $1112^{\circ} \mathrm{F}$ ( 400 to $600^{\circ} \mathrm{C}$ ), the strength in all cases dropped sharply, reaching a low of $30 \%$ of the room temperature strengths at $1472^{\circ} \mathrm{F}\left(800^{\circ} \mathrm{C}\right)$. These results are illustrated graphically in Figures 2.7 through to 2.9. Under the preload condition (Regimen 2), there are no 
results for specimens of $12.5 \mathrm{ksi}$ ( $86 \mathrm{MPa}$ ), because they failed in an explosive manner (Castillo and Durrani, 1990).

The pattern of strength variation between the temperature range 68 to $842^{\circ} \mathrm{F}\left(20\right.$ to $\left.450^{\circ} \mathrm{C}\right)$ is dependent on the moisture content of the specimens. Adsorbed water in concrete softens the cement gel (CSH) or attenuates the surface forces between gel particles (Van der waals forces), thus reducing the strength (Mehta and Monteiro, 2006). Reduction in concrete compressive strength at lower temperatures of 212 to $572^{\circ} \mathrm{F}\left(100\right.$ to $300^{\circ} \mathrm{C}$ ) has been attributed to the triaxial state of stresses existing within the paste pores when they become saturated (Schnieder, 1976, Davis, 1967). The increase in strength associated with increasing temperature is attributed to the stiffening of the cement gel or the increase in surface forces between the gel particles due to the removal of adsorbed moisture. The temperature at which adsorbed water is removed and the strength begins to increase depends on the porosity of the concrete (Castillo and Durrani, 1990). The adsorbed moisture in specimens of NSC escapes soon after the temperature reaches $212^{\circ} \mathrm{F}$ $\left(100^{\circ} \mathrm{C}\right)$, resulting in an early increase in the compressive strength (Fig. 2.8). However, because HSC is less permeable, moisture movement within the specimens is restricted. The slow movement of moisture causes the HSC specimens to show a longer period of strength loss (Fig. 2.7 and 2.8). The unstressed specimens of 10.5 and $12.5 \mathrm{ksi}$ (72 and $86 \mathrm{MPa})$ used in Castillo and Durrani's tests maintained a $20 \%$ strength loss from 212 to $392^{\circ} \mathrm{F}$ and $572^{\circ} \mathrm{F}\left(100\right.$ to $200^{\circ} \mathrm{C}$ and $300^{\circ} \mathrm{C}$ ) respectively. With further increase in the temperature, specimens from both concretes recovered their strengths, even surpassing the strengths recorded at ambient temperatures by 10 to $20 \%$ up to $572^{\circ} \mathrm{F}\left(400^{\circ} \mathrm{C}\right)$. Beyond $572^{\circ} \mathrm{F}\left(400^{\circ} \mathrm{C}\right)$ all strength loss followed the same pattern of HSC (Fig. 2.7 and 2.8). 
Phan (2007) also studied the strength-temperature relationship of a number of HSC mixtures (Table 2.6). His results are shown in Figures 2.7, 2.8 and 2.9 along with results of other studies for comparison. In these figures, Phan's results represent the shaded regions.

In Figure 2.7, the relative strength-temperature relationship for HSC under the stressed test regimen (Regimen 1) is shown. Phan's test results show that HSC sustained an average strength loss of about $25 \%$ at $212^{\circ} \mathrm{F}\left(100^{\circ} \mathrm{C}\right)$. This strength loss is followed by a minor strength recovery when concrete reaches temperatures between 212 and $842^{\circ} \mathrm{F}\left(100\right.$ and $\left.450^{\circ} \mathrm{C}\right)$, where the maximum strength recovery occurs at $572^{\circ} \mathrm{F}\left(300^{\circ} \mathrm{C}\right)$. At temperatures between 842 and $1112^{\circ} \mathrm{F}$ (450 and $600^{\circ} \mathrm{C}$ ), the temperature rate of strength loss becomes more significant. Also, at temperatures above $842^{\circ} \mathrm{F}\left(450^{\circ} \mathrm{C}\right)$, Phan reported explosive spalling in all specimens from Mixtures II and III (Table 2.6). Analysis of the results indicates that Phan's findings are similar to the results of other researchers, with the exception of the significant strength gain reported by Castillo and Durrani (1990) and Khoury and Algar (1999). 
Table 2.6 Concrete mixtures tested by Phan (2007)

\begin{tabular}{|c|c|c|c|c|c|}
\hline & & $\begin{array}{l}\text { Mixture I } \\
(w / c m=0.22)\end{array}$ & $\begin{array}{l}\text { Mixture II } \\
(w / c m=0.33)\end{array}$ & $\begin{array}{l}\text { Mixture III } \\
(w / c m=0.33)\end{array}$ & $\begin{array}{l}\text { Mixture IV } \\
(w / c m=0.57)\end{array}$ \\
\hline \multirow{6}{*}{ 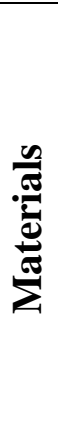 } & Cement $\left(\mathrm{lb} / \mathrm{yd}^{3}\right)$ & 1005 & 1005 & 1126 & 634 \\
\hline & Water $\left(\mathrm{lb} / \mathrm{yd}^{3}\right)$ & 224 & 336 & 327 & 359 \\
\hline & Coarse aggregates* $\left(\mathrm{lb} / \mathrm{yd}^{3}\right)$ & 1426 & 1426 & 1426 & 1440 \\
\hline & Fine aggregates* $\left(\mathrm{lb} / \mathrm{yd}^{3}\right)$ & 1238 & 1238 & 1238 & 1464 \\
\hline & Silica fume $\left(\mathrm{lb} / \mathrm{yd}^{3}\right)$ & 111 & 111 & 0.0 & 0.0 \\
\hline & $\operatorname{HRWRA}^{* * *}\left(\right.$ fl. oz/yd $\left.\mathrm{d}^{3}\right)$ & 103 & 91 & 40 & 0.0 \\
\hline \multirow{10}{*}{ 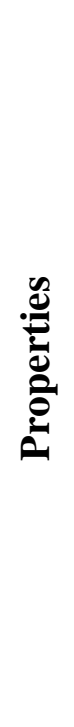 } & Fresh concrete & & & & \\
\hline & Slump (inches) & 9.5 & 9.0 & 1.4 & 3.0 \\
\hline & Air content (\%) & 3.2 & 2.8 & 2.0 & 2.5 \\
\hline & Hardened concrete & & & & \\
\hline & Initial moisture content (\%) & 5.0 & 6.1 & 6.3 & 7.3 \\
\hline & Compressive strength (ksi) & & & & \\
\hline & 28-day & 11.0 & 9.5 & 7.7 & 5.9 \\
\hline & 400-day & 14.0 & 11.8 & 10.5 & 6.8 \\
\hline & Dynamic Modulus (ksi) & & & & \\
\hline & 400-day & 6846 & 6338 & 6396 & 5323 \\
\hline
\end{tabular}

* Saturated surface-dry condition *** High-Range Water Reducing Admixture $1 \mathrm{lb} / \mathrm{yd}^{3}=0.593 \mathrm{~kg} / \mathrm{m}^{3}, 1 \mathrm{ksi}=6.9 \mathrm{MPa}, 1 \mathrm{~mL} / \mathrm{m}^{3}=0.258 \mathrm{fl} . \mathrm{oz} / \mathrm{yd}^{3}$

Figure 2.8 shows results for the unstressed test regimen (Regimen 2). In general, the results follow a similar trend to those obtained from the stressed test. It could also be seen that the majority of the studies reported higher strength loss for HSC compared to NSC within the temperature range of 212 to $842^{\circ} \mathrm{F}\left(100\right.$ to $\left.450^{\circ} \mathrm{C}\right)$. At temperatures exceeding $842^{\circ} \mathrm{F}\left(450^{\circ} \mathrm{C}\right)$, both HSC and NSC sustained similar rates of strength loss. Phan (2007) also reported high incidences of explosive spalling for the specimens under the unstressed test regimen.

In Figure 2.9, the results for the unstressed residual strength are shown. Phan's results have more scatter for strength loss between the four mixtures under this method than in the stressed or 
unstressed test methods. It can also be seen that the second phase of strength reduction begins around $392^{\circ} \mathrm{F}\left(200^{\circ} \mathrm{C}\right)$ for this testing regimen in comparison to $752^{\circ} \mathrm{F}\left(400^{\circ} \mathrm{C}\right)$ for the others.

Chan et al. (1996) also studied the behavior of HSC subjected to elevated temperatures. In their studies, they used three high strength concretes, with 28-day compressive strengths of 11, 11.5, $13.6 \mathrm{ksi}(76,79$ and $94 \mathrm{MPa})$. Specimens from the three concretes were heated to a series of maximum temperatures, $752,1112,1472,1832$ and $2192^{\circ} \mathrm{F}\left(400,600,800,1000\right.$ and $\left.1200^{\circ} \mathrm{C}\right)$, and maintained for 1 hour before their compressive and tensile splitting strengths were determined.

Their results showed that HSC maintained their initial compressive strength up to $752^{\circ} \mathrm{F}$ $\left(400^{\circ} \mathrm{C}\right)$, which is then followed by a decrease in strength to as low as $10 \%$ of the original strengths at temperatures over $1472^{\circ} \mathrm{F}\left(1000^{\circ} \mathrm{C}\right)$. This result contradicts the findings of Phan, Felicetti and Morita (Fig. 2.9) but is consistent with those of Hertz and Khoury in the temperature range 68 to $752^{\circ} \mathrm{F}\left(20\right.$ to $\left.400^{\circ} \mathrm{C}\right)$. This shows that there are some conflicting results as it relates to the pattern of HSC strength loss for this particular testing regimen (Regimen 3) up to $752^{\circ} \mathrm{F}\left(400^{\circ} \mathrm{C}\right)$. Beyond $752^{\circ} \mathrm{F}\left(400^{\circ} \mathrm{C}\right)$, the behavior of HSC was consistent with that reported by others.

Cheng et al. (2004) investigated the stress-strain properties of HSC at elevated temperatures. Stress-strain curve tests were conducted at various temperatures, 68, 212, 392, 752, 1112 and $1472^{\circ} \mathrm{F},\left(20,100,200,400,600\right.$, and $\left.800^{\circ} \mathrm{C}\right)$ for four types of HSC. The variables considered in the experimental study included concrete strength, aggregate type, and the addition of steel fibers. Results from the stress-strain tests show that plain HSC (HSC without steel fibers) exhibits brittle properties below $1112^{\circ} \mathrm{F}\left(600^{\circ} \mathrm{C}\right)$, and ductility above $1112^{\circ} \mathrm{F}\left(600^{\circ} \mathrm{C}\right)$. HSC with steel fibers exhibits ductility for temperatures over $752^{\circ} \mathrm{F}\left(400^{\circ} \mathrm{C}\right)$. The strain at peak loading 
increases with temperature from 0.003 at room temperature to 0.02 at $1472^{\circ} \mathrm{F}\left(800^{\circ} \mathrm{C}\right)$. The increase in strains for carbonate aggregate HSC is larger than that for siliceous aggregate HSC.

The elastic modulus, obtained by Cheng et al. (2004) from the four types of HSC is shown in Figure 2.10 as a function of temperature. The elastic modulus of all four types of HSC decreases monotonically at similar rates up to approximately $752^{\circ} \mathrm{F}\left(400^{\circ} \mathrm{C}\right)$. The rate of decrease in the elastic modulus of the steel fiber reinforced HSC is higher than that of plain HSC in the $752-1112^{\circ} \mathrm{F}\left(400-600^{\circ} \mathrm{C}\right)$ range. However, the steel fiber reinforced HSC possesses a higher modulus of elasticity (MOE) for the entire temperatures range. Another observation is that the aggregate type does not influence the variation of MOE of HSC with temperature. The MOE of the HSC tested by Phan et al. (2001), are shown in Figure 2.11 for comparison. They paint a similar picture to those results obtained by Cheng et al. (2004).

High strength concrete is generally brittle; it fails immediately after crack propagation is initiated (Cheng et al., 2004). However, beyond $1112^{\circ} \mathrm{F}\left(600^{\circ} \mathrm{C}\right)$, HSC exhibits less brittle failure. This phenomenon is attributed to an increase in the amount of voids due to the removal of pore water. The increase in voids prevents the rapid propagation of cracks, resulting in less brittle failure (Cheng et al., 2004). 


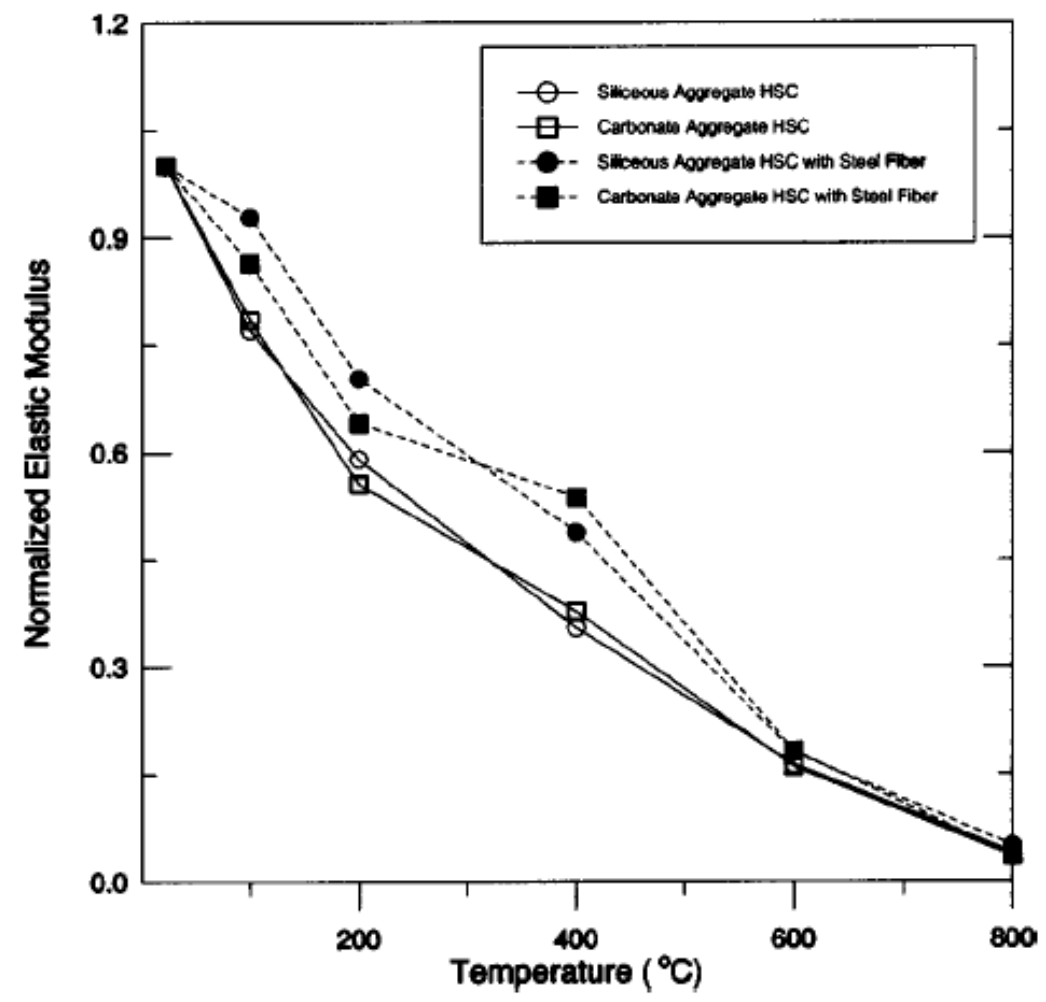

Fig. 2.10. Normalized elastic modulus of HSC as a function of temperature (Cheng et al., 2004).

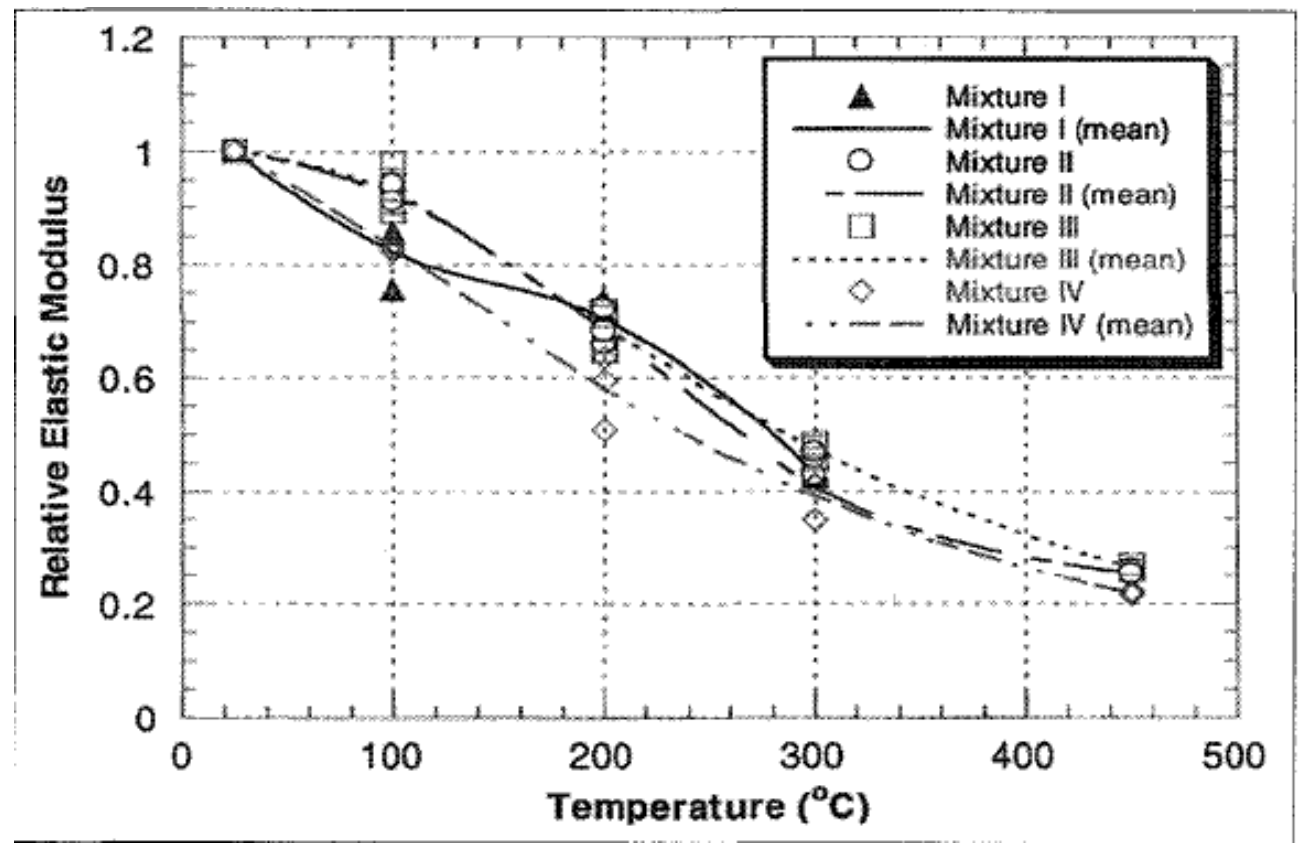

Fig. 2.11. Normalized elastic modulus of HSC as a function of temperature (Phan et al., 2001). 


\subsubsection{Behavior of Ultra-high Performance Concrete (UHPC) at Elevated Temperatures}

Behloul et al. (2002) investigated the performance of UHPC (marketed as Ductal) at elevated temperatures using heat cured and normally cured UHPC specimens. Heat cured means that the specimens were submerged in water of $194^{\circ} \mathrm{F}\left(90^{\circ} \mathrm{C}\right)$ for $48 \mathrm{hrs}$. The temperature test involved heating the specimens to the required test temperature, 1292 to $1472^{\circ} \mathrm{F}\left(700\right.$ to $\left.800^{\circ} \mathrm{C}\right)$, at a rate of $3.6^{\circ} \mathrm{F} / \mathrm{min} .\left(2^{\circ} \mathrm{C} / \mathrm{min}\right.$.) and maintaining the maximum temperature for one hour. Compressive strength and other mechanical and thermal tests of the specimens were performed hot and after cooling in some cases. The stressed test regimen (Regimen 1) was adopted for these studies. Preload was $20 \%$ of the nominal compression strength of the specimens at $68^{\circ} \mathrm{F}$ $\left(20^{\circ} \mathrm{C}\right)$. Compressive strength results from the tests are shown below in Figure 2.12. In Figure 2.12, SFC refers to testing conducted at the French ceramic laboratory, HITECO refers to a separate European project in which only cured Ductal was used and DTU is a French Standard.

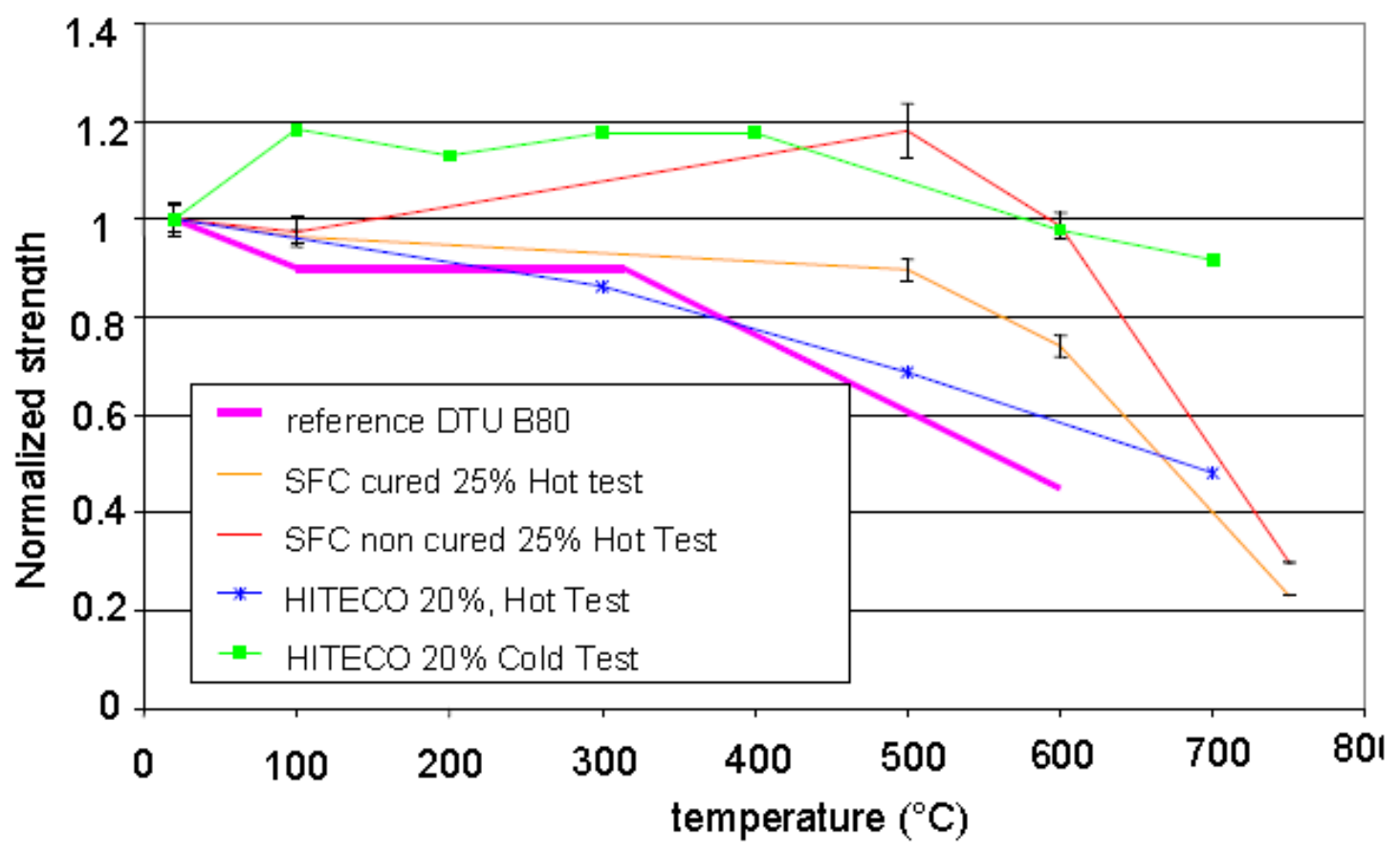

Fig. 2.12. Strength-temperature behavior of UHPC (Behloul et al., 2002). 
Results show that the specimens that were allowed to cool before the compressive strength tests was carried-out performed better than those measured hot. In the case of the uncured UHPC specimens, improved mechanical performances were obtained at temperatures above $212^{\circ} \mathrm{F}\left(100^{\circ} \mathrm{C}\right)$. The improved mechanical performance is caused by additional hydration of the microstructure's residual clinker (Behloul et al., 2002). The general trend of strength loss is quite similar to those seen in NSC and HSC. However, at temperatures up to $1292^{\circ} \mathrm{F}\left(700^{\circ} \mathrm{C}\right)$, UHPC is able to retain $50 \%$ of its original compressive strength compared to less than $30 \%$ retained by both NSC and HSC.

The loss of tensile strength and drop in the modulus of elasticity are also similar to those of NSC and HSC. However, UHPC is able to retain about $50 \%$ of its nominal tensile strength and modulus of elasticity up to $1292^{\circ} \mathrm{F}\left(700^{\circ} \mathrm{C}\right)$ exposure (Behloul et al., 2002).

\subsection{Thermal Properties of Concrete at Elevated Temperatures}

Kudor and Sultan (2003) studied the effects of temperature on the thermal properties of HSC. The properties studied were thermal conductivity, specific heat, thermal expansion, and mass loss. The goal of their research was to fully understand how the thermal properties vary with temperature in order to develop computer models that can be used to determine the behavior of HSC members.

\subsubsection{Thermal Conductivity}

Results from their research indicate that the thermal conductivity for both siliceous and carbonate aggregate concrete decreases with an increase in temperature (Fig. 2.13). However, the thermal conductivity of the siliceous aggregate concrete (without steel fibers) was higher in the temperature range studied, 392 to $1472^{\circ} \mathrm{F}\left(200-800^{\circ} \mathrm{C}\right)$. Kodur and Sultan explained that 
the reduction in the thermal conductivity of the siliceous aggregate HSC was less due to siliceous aggregates possessing a higher crystallinity than carbonate aggregates. The incorporation of steel fibers to the HSC mixtures increased the thermal conductivity of the siliceous aggregate HSC. Results also show that the thermal conductivity of both concrete types, after the incorporation of steel fibers, remained constant from 752 to $1832^{\circ} \mathrm{F}$ as shown in Figure 2.14 (400 to $1000^{\circ} \mathrm{C}$ ).

Behloul et al. (2002) studied the effects of temperature on the thermal properties of UHPC. They reported thermal conductivity values ranging from 1.45 to $1.00 \mathrm{Btu} / \mathrm{ft} . \mathrm{h} .^{\circ} \mathrm{F}(2.5$ to 1.75 $\mathrm{W} / \mathrm{mK}$ ) for temperatures from 68 to $1112^{\circ} \mathrm{F}\left(20\right.$ to $\left.600^{\circ} \mathrm{C}\right)$. These values are similar to those shown in Figure 2.14 for HSC.

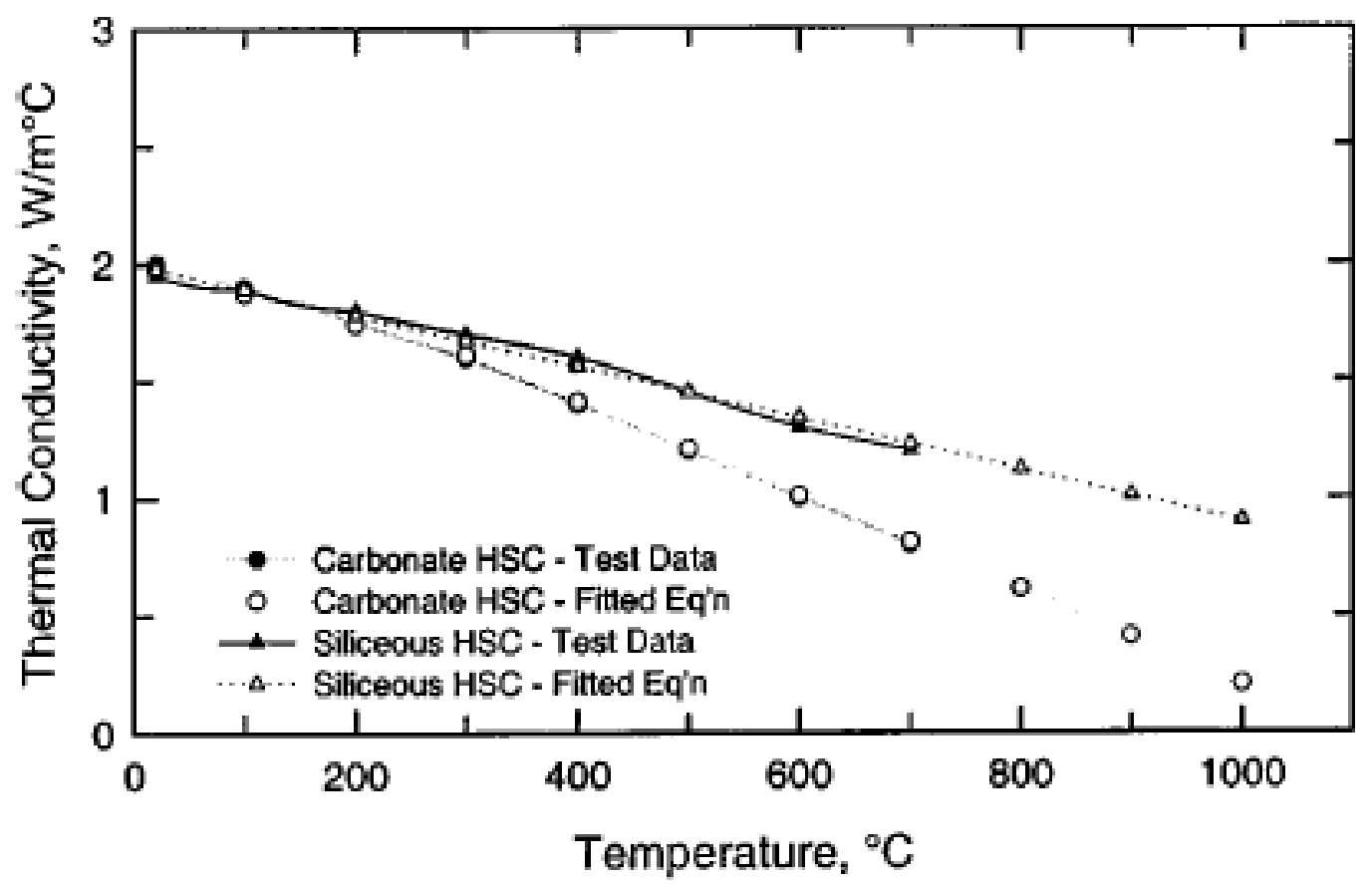

Fig. 2.13. Thermal conductivity of plain high strength concrete (Kodur and Sultan, 2003). 


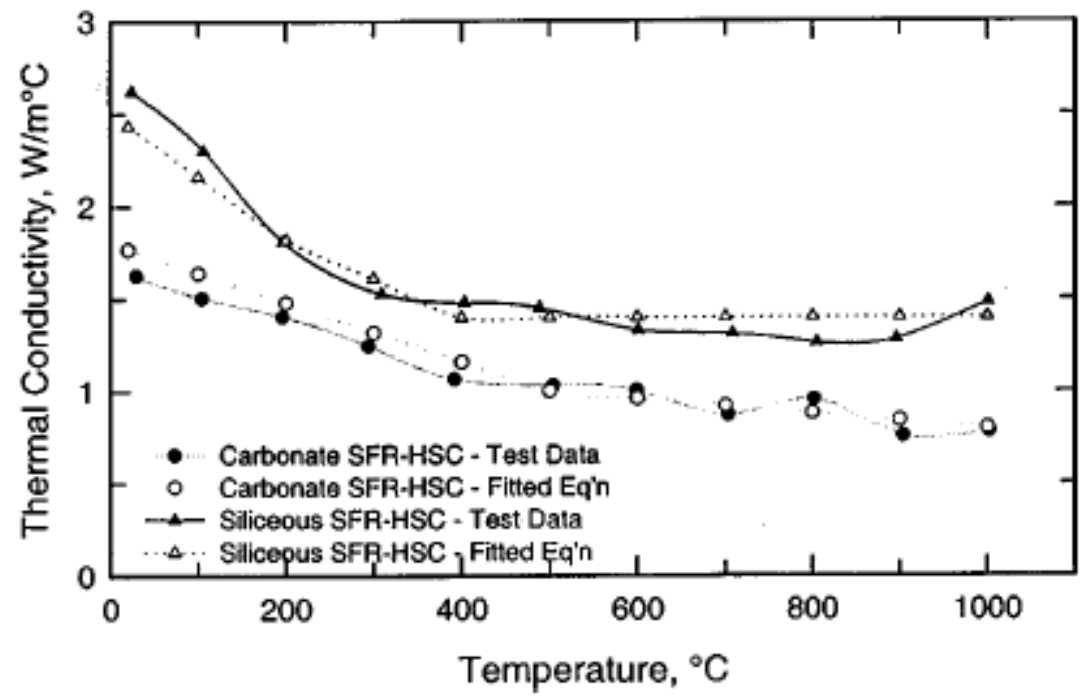

Fig. 2.14. Thermal conductivity of steel fiber reinforced high strength concrete (Kodur and Sultan, 2003).

\subsubsection{Specific Heat}

The specific heat for both carbonate and siliceous aggregate concrete remains constant and almost identical for temperatures up to $1112^{\circ} \mathrm{F}\left(600^{\circ} \mathrm{C}\right)$ as shown in Figure 2.15 . For higher temperatures, HSC made of carbonate aggregates has a higher specific heat and requires tremendous amount of heat to raise the temperature of the carbonate aggregate concrete. The huge change in the thermal capacity between 1112 and $1472^{\circ} \mathrm{F}\left(600\right.$ and $\left.800^{\circ} \mathrm{C}\right)$ shown in Figure 2.15 is caused by the dissociation of the dolomite in the carbonate concrete (Kodur and Sultan, 2003).

In the case of UHPC, Behloul et al. (2002) reported that the specific heat values ranged from 0.215 to $0.143 \mathrm{Btu} / \mathrm{bm}^{\circ} \mathrm{F}\left(0.90\right.$ to $0.60 \mathrm{~J} / \mathrm{gK}$ ) within the temperature range 0 to $1112^{\circ} \mathrm{F}$ ( 0 to $600^{\circ} \mathrm{C}$ ). These values can be converted to thermal capacity by multiplying by the concrete's density, assumed to be $156 \mathrm{lb} / \mathrm{ft}^{3}\left(2500 \mathrm{~kg} / \mathrm{m}^{3}\right)$. The resulting thermal capacity for a unit volume of concrete is 2.25 to $1.5\left(\mathrm{~J} / \mathrm{m}^{30} \mathrm{C}\right) \times 10^{-6}$. These values are similar to those of HSC shown in Figure 2.15 for the same temperature range. 


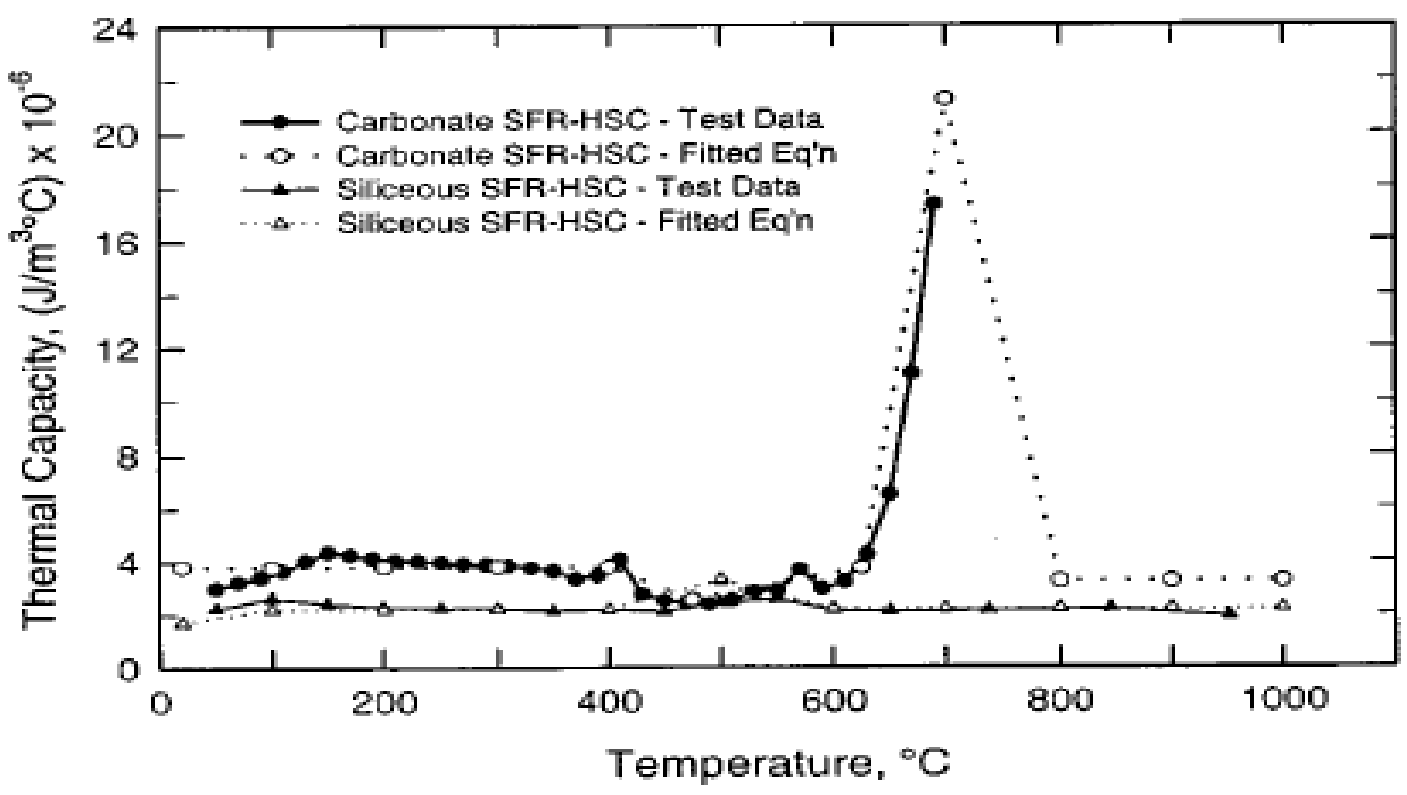

Fig. 2.15. Specific heat capacity of high strength concrete (Kodur and Sultan, 2003).

\subsubsection{Thermal Expansion}

The thermal expansion of both the carbonate and siliceous aggregate HSC increases with temperature (Fig. 2.16). High strength concrete made of siliceous aggregates undergoes higher expansions up to approximately $1562^{\circ} \mathrm{F}\left(850^{\circ} \mathrm{C}\right)$. It was explained in Section 2.4 .2 that siliceous aggregates undergo a quartz transformation at approximately $1058^{\circ} \mathrm{F}\left(570^{\circ} \mathrm{C}\right)$, hence the reason for the increased rate of change in expansion beginning at approximately $932^{\circ} \mathrm{F}\left(500^{\circ} \mathrm{C}\right)$ as shown in Figure 2.16.

Behloul et al. (2002) used dilatometric tests to determine the coefficient of thermal expansion (CTE) of UHPC. Results indicate that the CTE of UHPC is $0.355 \times 10^{-6} /{ }^{\circ} \mathrm{F}\left(12 \times 10^{-}\right.$ $\left.{ }^{6} /{ }^{\circ} \mathrm{C}\right)$. The CTE of NSC and HSC has values from 0.178 to $0.355 \times 10^{-6} /{ }^{\circ} \mathrm{F}\left(6\right.$ to $\left.12 \times 10^{-6} /{ }^{\circ} \mathrm{C}\right)$ dependent on the type of aggregates. 


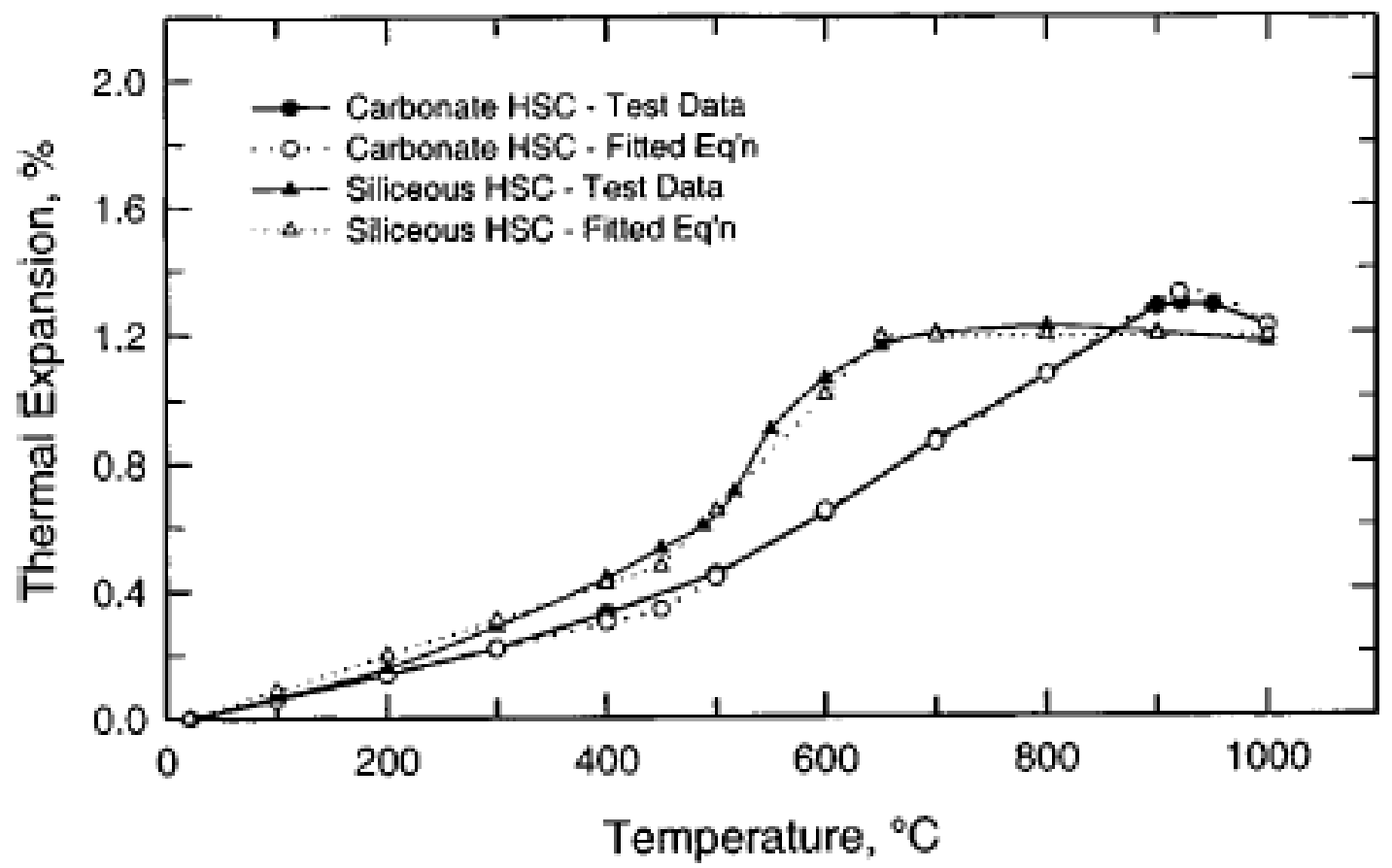

Fig. 2.16. Thermal expansion of high strength concrete (Kodur and Sultan, 2003).

\subsubsection{Mass Loss}

The mass loss for $\mathrm{HSC}$ of both aggregate types is insignificant up to $1112^{\circ} \mathrm{F}\left(600^{\circ} \mathrm{C}\right)$; however, beyond this temperature HSC made of calcareous aggregates undergoes a dramatic increase in mass loss from insignificant to a $30 \%$ reduction from 1112 to $1292^{\circ} \mathrm{F}\left(600\right.$ to $\left.700^{\circ} \mathrm{C}\right)$ as shown in Figure 2.17. Thereafter, the mass loss remains constant up to $1832^{\circ} \mathrm{F}\left(1000^{\circ} \mathrm{C}\right)$. On the other hand, HSC made with siliceous aggregates suffers very little mass loss up to $1832^{\circ} \mathrm{F}$ $\left(1000^{\circ} \mathrm{C}\right)$. The substantial mass loss and decrease in density for carbonate aggregate concrete is caused by the dissociation of the dolomite in the concrete (Kodur and Sultan, 2003). 


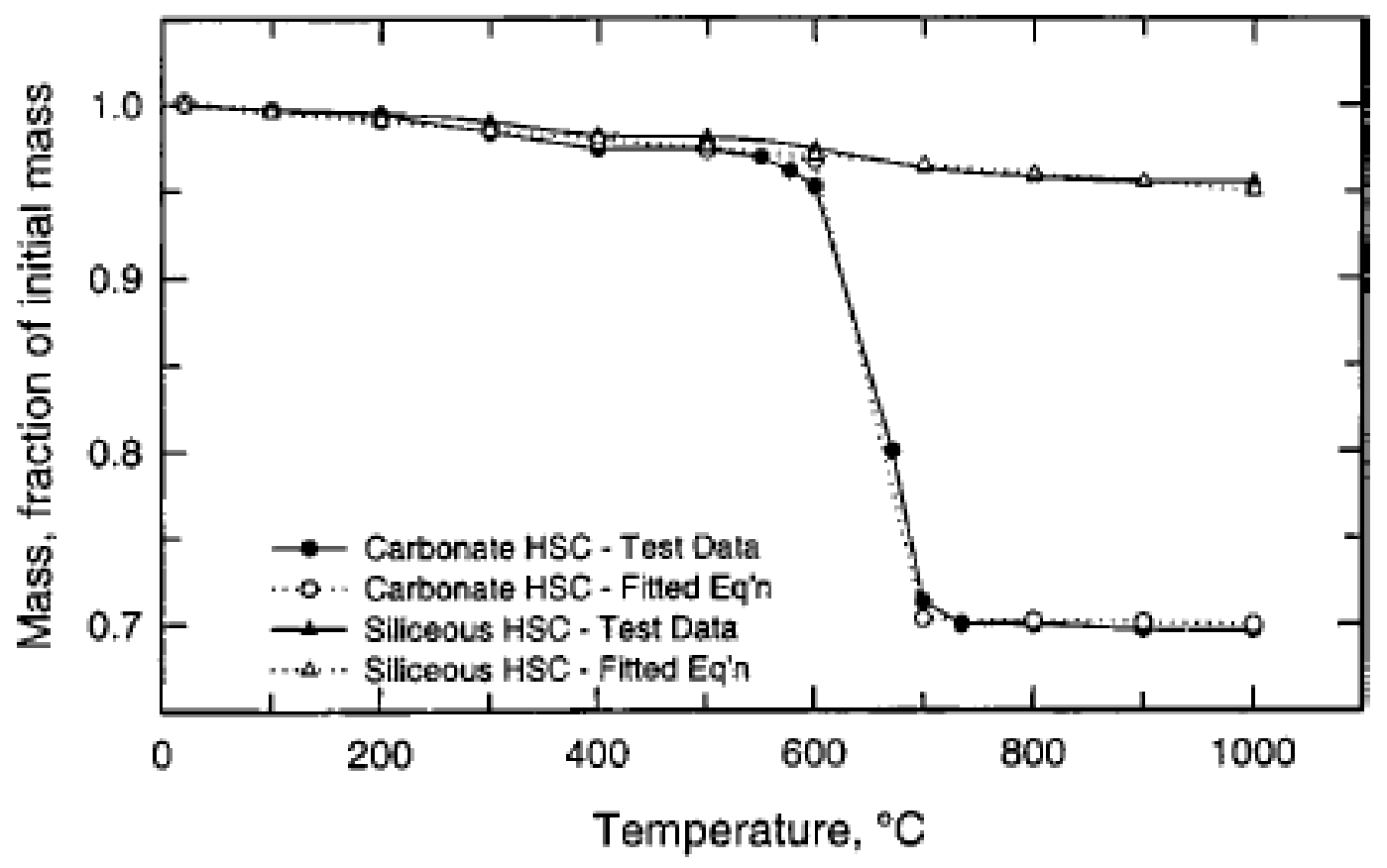

Fig. 2.17. Mass loss of high strength concrete (Kodur and Sultan, 2003).

\subsection{Summary}

The performance of concrete as a solid medium TES for solar electric generating plants has been proven both at the laboratory scale and as an integral part of an actual plant. However, to further decrease the cost per kWh of energy, both thermal and electric, and to improve the operating efficiency of the plant, higher operating temperatures are sought. The literature review showed that the amount of energy stored is dependent on the thermal capacity and the temperature change of the storage medium. It also shows that the thermal capacity of different concrete types does not vary significantly, irrespective of the concrete strength and the constituent materials. Therefore, to significantly increase the amount of energy stored in concrete for use in CSP plants, the most important parameter is the change in operating temperature $(\Delta \mathrm{T})$. Present CSP plants with concrete TES operate at a maximum temperature of $752^{\circ} \mathrm{F}\left(400^{\circ} \mathrm{C}\right)$ with a $\Delta \mathrm{T}$ of $104^{\circ} \mathrm{F}\left(40^{\circ} \mathrm{C}\right)$. 
The aim of this project is to increase the operating temperature to at least $932^{\circ} \mathrm{F}\left(500^{\circ} \mathrm{C}\right)$ which would increase $\Delta \mathrm{T}$ to $302^{\circ} \mathrm{F}\left(150^{\circ} \mathrm{C}\right)$ without an increase in the storage mass. The literature review shows that concrete of different types exhibits significant reduction in their mechanical properties at this temperature. However, of the three types of concrete reviewed, UHPC shows the most promise as it relates to the design criteria mentioned in Section 2.2.3. This concrete type retains more than $65 \%$ of its original compressive strength at $932^{\circ} \mathrm{F}\left(500^{\circ} \mathrm{C}\right)$ and a thermal capacity of $1.75\left(\mathrm{~J} / \mathrm{m}^{30} \mathrm{C}\right) \times 10^{-6}$ (equivalent to the concrete's density $(\rho)$ by $\mathrm{C}_{\mathrm{p}}$ ). This is compared to $40 \%$ strength retention and similar values of thermal capacity for HSC. The question that still remains is, whether this concrete can withstand the numerous thermal cycles that it will be subjected to throughout its design life and its performance when in direct contact with a heat transfer fluid (molten salt in this case).

Based on this knowledge, mixture proportions for the experimental phase consist of high quantities of cementitious materials (CM), various types and sizes of aggregates, steel fibers, polypropylene fibers and auxiliary materials to improve workability. The high quantity of CM will aid in strength development. Siliceous aggregates will generally be used, this will improve thermal conductivity. The steel fibers will also contribute to the increase in thermal conductivity and in addition, increase the tensile strength of the concrete. This increase in tensile strength, in combination with the use of polypropylene fibers, will aid in resistance to explosive spalling and increase durability.

\subsubsection{Key Research Questions}

The review of the literature has identified several holes which this research program will address. These items are listed below. 
- Can concrete resist temperatures of $1112^{\circ} \mathrm{F}\left(600^{\circ} \mathrm{C}\right)$ and maintain the properties that are key to the functioning of a CSP?

- Can concrete resist $1112^{\circ} \mathrm{F}\left(600^{\circ} \mathrm{C}\right)$ when in direct contact with molten salt?

- What is the optimal amount of polypropylene fibers required for prevention of concrete spalling at elevated temperatures?

- Can the concrete's heating rate be increased to facilitate reduced charging times?

- What steps can be taken to reduce concrete price whilst maintaining high performance?

- What are the thermal properties of the concretes that are developed and how are they affected after elevated temperature exposure? 


\section{CHAPTER 3 METHODOLOGY AND EXPERIMENTAL PROCEDURES}

\subsection{Introduction}

This chapter documents the development of concrete mixture proportions to resist temperatures from 932 to $1112^{\circ} \mathrm{F}\left(500\right.$ to $\left.600^{\circ} \mathrm{C}\right)$. The work was divided into three phases. In

Phase I, the effects of heating rate and polypropylene fiber dosage rate was determined. Phase I results form the basis for phase II. Phase II concrete mixtures were intended for deployment in TES Option A, the concrete storage system with the embedded metallic heat exchangers that was described in Chapter 2. Phase III deals with different approaches to reduce the unit cost of the concrete mixtures and the determination of the mechanical and thermal properties of those mixtures that withstood temperatures of $932^{\circ} \mathrm{F}\left(500^{\circ} \mathrm{C}\right)$ or higher. Additionally, 26 different concrete mixtures were developed and tested in Phase III for deployment in TES Option B, the thermocline storage system that was described in Chapter 2.

\subsection{Materials}

\subsubsection{Cementitious Materials (CM)}

The hydraulic binders that were used in the concrete mixtures in this research are referred to as the cementitious materials. These binders include ordinary portland cement (OPC), calcium aluminate cement (CAC), fly ash (FA), and silica fume (SF) (Fig. 3.1). Wherever OPC is mentioned in this work, reference is to Type I OPC. The ASTM standard (C 150) for Type I OPC is given in Appendix A (Table A3.1). Lumnite MG4, was the CAC used in this research. The categorization of CAC is based on its chemical composition. In Appendix A (Table A3.2), the different categories of CAC are given. The composition of Lumnite MG4, the class of CAC used in this work, is given in Appendix A (Table A3.3). Fly ash and silica fume are mineral 
admixtures that are added to the concrete mixtures as partial replacement of OPC and CAC. Fly ash is a by-product of the coal industry and SF is a by-product of the silicon and ferrosilicon alloys industries. Wherever FA is used in this research, reference is to Class $\mathrm{C}$ fly ash. The chemical compositions of Class C FA and SF are provided in Appendix A, Tables A3.4 and A3.5, respectively.

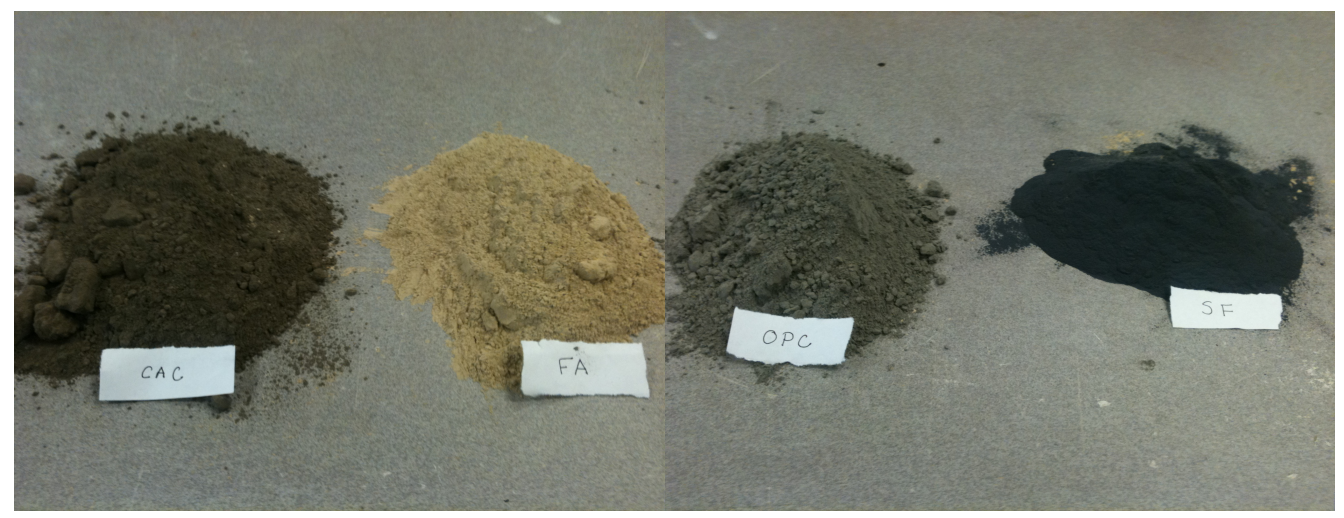

Fig. 3.1. Cementitious materials used in the concrete mixtures.

\subsubsection{Aggregates}

Different types and sizes of aggregates (Fig. 3.2) were used in the testing program.

Arkansas River sand with a fineness modulus of 2.5 and a specific gravity of 2.63 , supplied by Arkhola Sand \& Gravel Company, was one of the fine aggregates used in this research. The other, syenite, was obtained from the Granite Mountain Quarries (GMQ) in Arkansas. The maximum size of this material was $3 / 16 "(4.75 \mathrm{~mm})$ with a specific gravity of 2.63 . Limestone with a nominal maximum aggregate size (NMAS) of $3 / 8$ " and sandstone with a NMAS of $1 / 2 "$ were the coarse aggregates. Both aggregates were obtained from quarries in Arkansas and have a specific gravity of approximately 2.68 . 


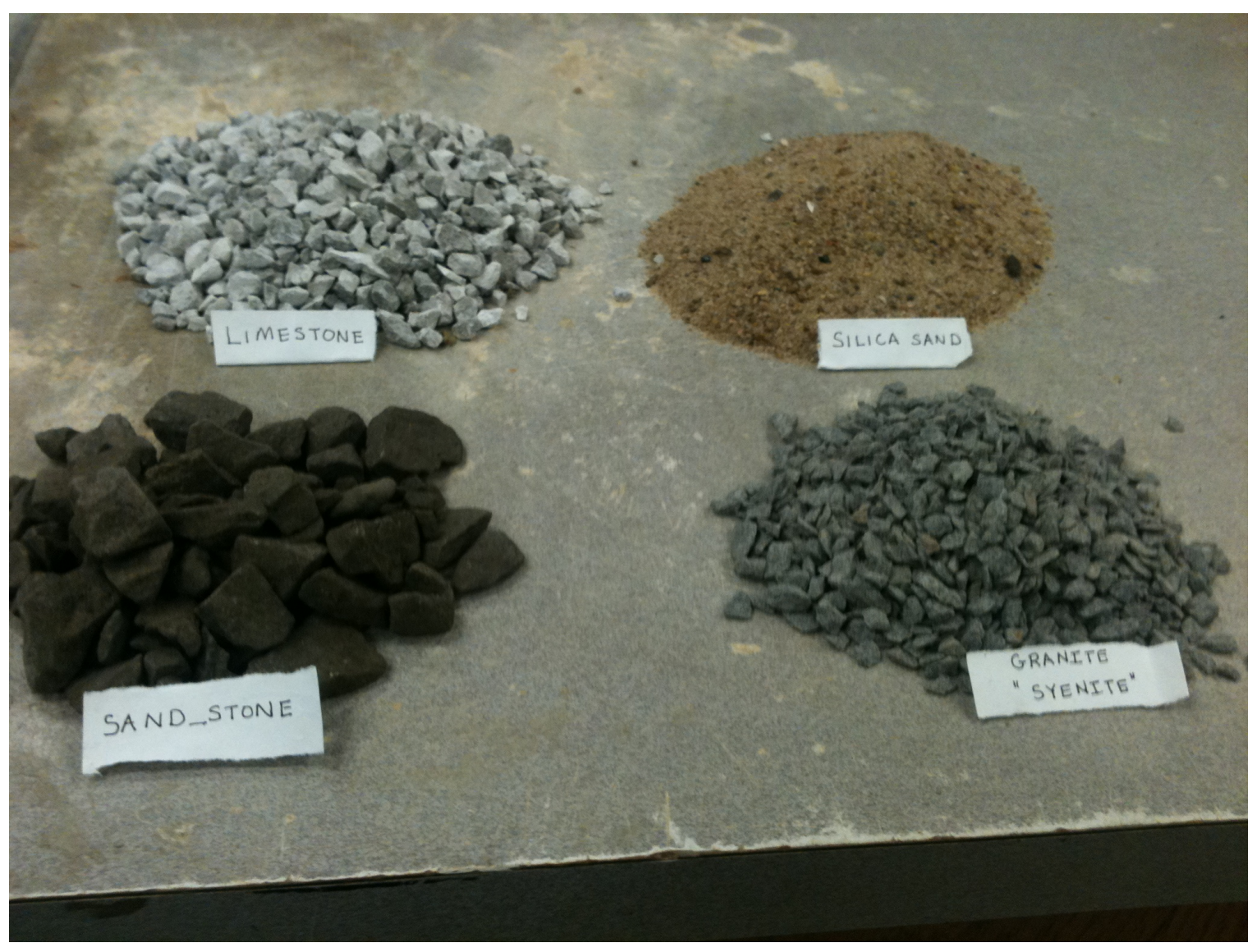

Fig. 3.2. Photo of the different aggregates used in this research.

\subsubsection{Admixtures}

Supplementary materials, referred to herein as admixtures, were added to improve a specific property of the fresh and/or hardened concrete. Multifilament polypropylene (PP) fibers (Fig. $3.3)$ with a diameter of 0.00072 in. $(18 \mu \mathrm{m})$, a specific gravity of 0.91 , length of $1 / 2 "$, and melting point of $324^{\circ} \mathrm{F}\left(162^{\circ} \mathrm{C}\right)$ were used as an explosive spalling prevention measure.

The steel fibers, shown in Figure 3.4, were straight wire fibers with a diameter of $1 / 125 "(0.20$ $\mathrm{mm})$ and a length of $1 / 2 "(12.7 \mathrm{~mm})$. These fibers possess tensile strengths of approximately 377 ksi (2600 MPa). The steel fibers increase thermal conductivity and increase the post cracking strength of the hardened concrete. 


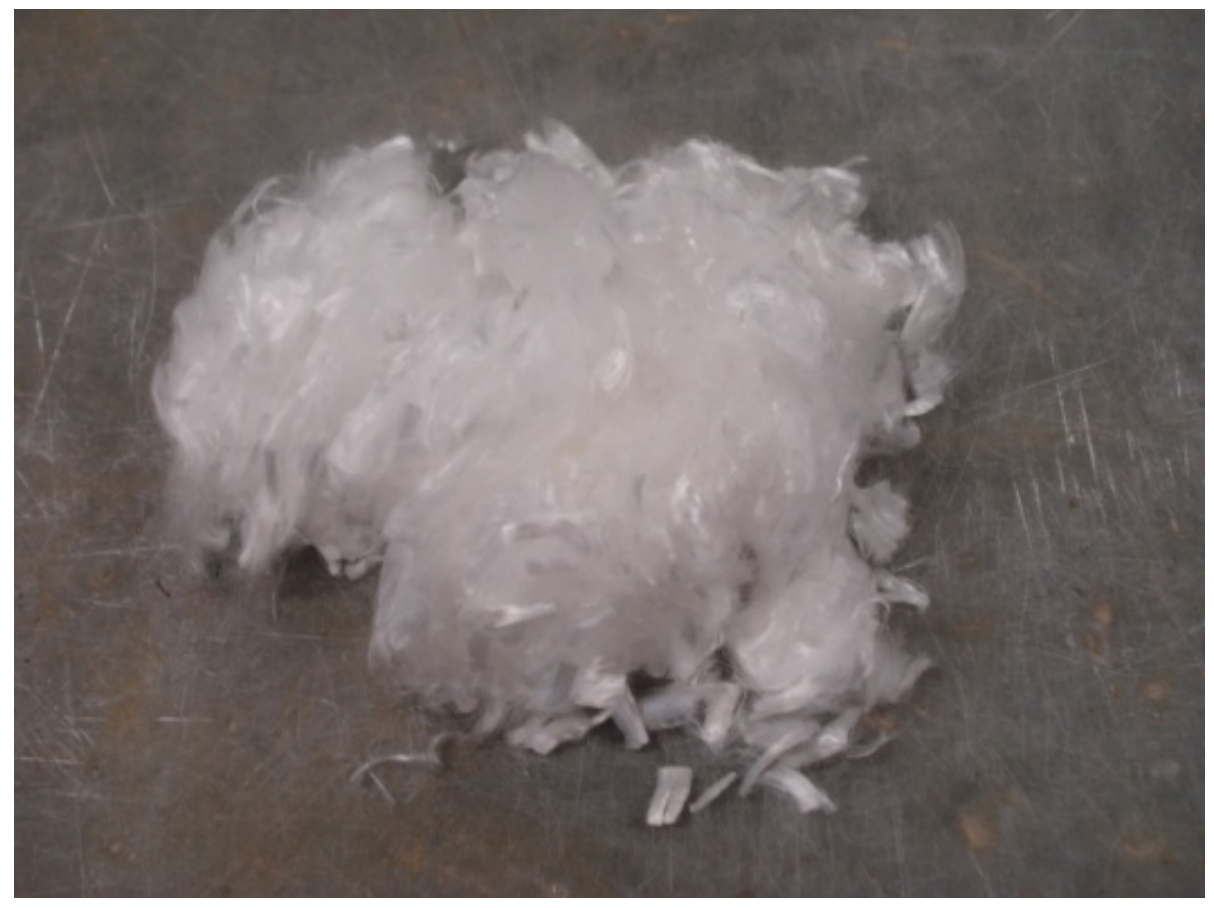

Fig. 3.3. Multifilament polypropylene fibers.

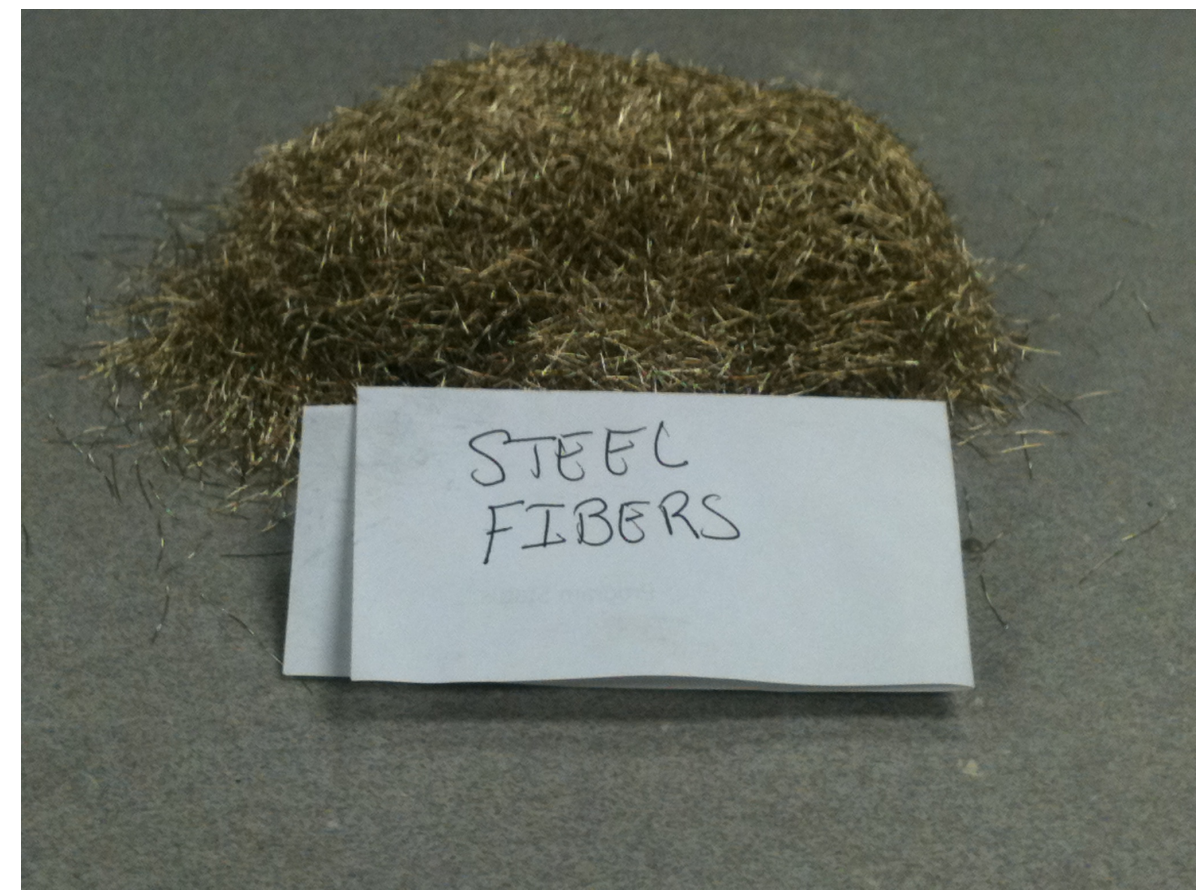

Fig. 3.4. Bronze coated steel fibers. 


\subsubsection{Chemical Admixture}

High range water reducers (HRWR) also referred to as superplasticizers were added to the concrete mixtures to improve concrete workability without increasing water content. Adva Cast 575, a product of W. R. Grace and Company, was the product used in this work.

\subsection{Phase I: Assessment of Heating Rates and PP Fiber Dosage on the Performance of Concrete at Elevated Temperatures}

\subsubsection{Concrete Mixtures}

Phase I assessed the behavior of high and ultra- high performance concrete when exposed to temperatures up to $1112^{\circ} \mathrm{F}\left(600^{\circ} \mathrm{C}\right)$. Seven different concrete mixtures, shown in Table 3.1, were examined. These mixtures vary in cementitious material type and content, aggregates type and content, fiber content, and water to cementitious material ratio $(\mathrm{w} / \mathrm{cm})$.

The first four mixtures shown in Table 3.1 contained no PP fibers; these were used as control mixtures to verify that high density concrete builds up excessive internal vapor pressure when exposed to elevated temperatures which leads to explosive spalling of the concrete. The remaining three mixtures contained $3.4 \mathrm{lb} / \mathrm{yd}^{3}\left(2 \mathrm{~kg} / \mathrm{m}^{3}\right)$ PP fibers. Ordinary portland cement described in Section 3.1.1 was used in all mixtures, solely or in combination with fly ash or silica fume (Mixtures 1, 3, 5, $6 \&$ 7). However, for Mixtures 2 and 4, the proprietary mixtures, the exact combination of cementitious materials is not known. These mixtures were the ultra-high performance concrete (UHPC) mixtures. Except for Mixtures 2 and 4, the fine and coarse aggregates used in the concrete mixtures were the river sand and the limestone described in Section 3.1.2. 


\subsubsection{Curing}

All specimens except those from Mixtures 2 and 4 were obtained and cured in accordance with ASTM C31. Specimens were immersed in water at $71 \pm 1.5^{\circ} \mathrm{F}\left(22 \pm 1^{\circ} \mathrm{C}\right)$ for 28 days after final set was reached (normally the day following casting). Specimens from Mixtures 2 and 4 were cured at $100 \%$ humidity at $194^{\circ} \mathrm{F}\left(90^{\circ} \mathrm{C}\right)$ for 2 days after achieving a compressive strength of approximately $12 \mathrm{ksi}(83 \mathrm{MPa})$.

\subsubsection{Testing}

Two cylindrical specimens, $4 \times 8$ in. $(100 \times 200 \mathrm{~mm})$, from each concrete mixture were subjected to temperatures of 932 to $1112^{\circ} \mathrm{F}\left(500\right.$ to $\left.600^{\circ} \mathrm{C}\right)$. Heating rates of 5.4, 9.0, $12.6^{\circ} \mathrm{F} / \mathrm{min} .\left(3,5,7^{\circ} \mathrm{C} / \mathrm{min}\right.$.) and in some instances, $16.2^{\circ} \mathrm{F} / \mathrm{min}$. $\left(9^{\circ} \mathrm{C} / \mathrm{min}\right.$.) were employed. Specimens were allowed to rest at the maximum temperature, 932 or $1112^{\circ} \mathrm{F}\left(500\right.$ or $\left.600^{\circ} \mathrm{C}\right)$ for two hours before the furnace temperature was gradually reduced to room levels. Specimens from mixtures 5, 6, and 7 were conditioned by raising the furnace temperature to $752^{\circ} \mathrm{F}\left(400^{\circ} \mathrm{C}\right)$

at the above mentioned heating rates. The temperature was maintained at $752^{\circ} \mathrm{F}\left(400^{\circ} \mathrm{C}\right)$ for two hours and subsequently increased at the same rates to the maximum temperature. 
Table 3.1 Mixture proportions (Phase I: HSC and UHPC mixtures)

\begin{tabular}{|c|c|c|c|c|c|c|c|}
\hline \multirow{2}{*}{$\begin{array}{l}\text { Materials } \\
\left(\mathbf{l b} / \mathbf{y d} \mathbf{d}^{3}\right)\end{array}$} & \multicolumn{7}{|c|}{ Mixtures } \\
\hline & 1 & 2 & 3 & 4 & 5 & 6 & 7 \\
\hline Cement & 900 & - & 1004 & - & 1004 & 1500 & 1125 \\
\hline Fly Ash & - & - & - & - & - & 500 & 375 \\
\hline Silica Fume & - & - & 112 & - & 112 & - & - \\
\hline Coarse Agg. & 1700 & - & 1420 & - & 1420 & - & - \\
\hline Fine Agg. & 1211 & - & 1350 & - & 1350 & 1435 & 1780 \\
\hline Water & 270 & 220 & 228 & 220 & 228 & 406 & 450 \\
\hline $\mathrm{w} / \mathrm{cm}$ & 0.30 & 0.15 & 0.22 & 0.15 & 0.22 & 0.20 & 0.30 \\
\hline HRWR & $4^{1}$ & 51 & $19^{1}$ & 51 & $23^{1}$ & $12^{1}$ & $8^{1}$ \\
\hline PP Fibers & - & - & - & - & 3.375 & 3.375 & 3.375 \\
\hline Steel Fibers & - & 264 & - & - & - & - & - \\
\hline $\mathrm{UHPC}^{2}$ & - & 3698 & - & 3698 & - & - & - \\
\hline
\end{tabular}

${ }^{1}$ Dosage rate of fluid ounces $/ 100 \mathrm{cwt}, \mathrm{cwt}=$ cement weight, $1 \mathrm{fl} \mathrm{oz} / 100 \mathrm{lb}=65.2 \mathrm{~mL} / 100 \mathrm{~kg}$

${ }^{2}$ Proprietary Premix, $1 \mathrm{lb} / \mathrm{yd}^{3}=0.593 \mathrm{~kg} / \mathrm{m}^{3}$

\subsubsection{Effects of Polypropylene Fiber Dosage on Concrete Temperature Resistance}

The effects of elevated temperatures on concrete were discussed in detail in Chapter 2. One of the main concerns with concrete exposed to elevated temperatures is explosive spalling. A review of the literature showed that the inclusion of PP fibers helps to prevent spalling. However, the amount and type of PP fibers necessary for spall mitigation/explosion prevention were not fully defined. The dosage rates used by previous researchers, discussed in Chapter 2, ranged from 1 to 8 pounds per cubic yard of concrete $\left(0.5\right.$ to $\left.5 \mathrm{~kg} / \mathrm{m}^{3}\right)$ using monofilament, multifilament and fibrillated fibers. Multifilament PP fibers in dosages of 3.4, 6.8 and 10.2 $\mathrm{lb} / \mathrm{yd}^{3}\left(2,4\right.$ and $\left.6 \mathrm{~kg} / \mathrm{m}^{3}\right)$ were used in this investigation. The objective of this particular 
investigation was to determine an adequate dosage of multifilament PP fibers needed to prevent concrete spalling/explosion.

\subsubsection{Concrete Mixtures and Testing}

Three concrete mixtures, shown in Table 3.2, were examined. Each mixture was mixed four times, once without PP fibers and again with 3.4, 6.8 and $10.2 \mathrm{lb} / \mathrm{yd}^{3}\left(2,4\right.$ and $\left.6 \mathrm{~kg} / \mathrm{m}^{3}\right)$ of PP fibers. Two cylindrical specimens, of dimensions 4 x 8 in. (100 x $200 \mathrm{~mm})$, from each of the concrete mixtures were subjected to the heating profile shown in Figure 3.5. In Figure 3.5, the ASTM 119 temperature curve represents the temperature rise associated with a building fire. The furnace temperature rise (the dotted line) was set as close as possible to simulate the ASTM 119 curve. The ASTM heating curve was chosen to subject the specimens to the most rigorous heating procedure based on a known standard. Specimens from Mixtures 1 and 2 were moist cured for 28 days, removed from the curing chamber and cured at $73^{\circ} \mathrm{F}\left(23^{\circ} \mathrm{C}\right)$ for a minimum of 28 days before testing. Mixture 3 specimens were steam cured at $108^{\circ} \mathrm{F}\left(60^{\circ} \mathrm{C}\right)$ for 3 days after attaining an initial compressive strength of $12 \mathrm{ksi}(83 \mathrm{MPa})$. Following exposure to the temperature profile shown in Figure 3.5, the residual compressive strength of the specimens was determined after ambient temperature state was attained. 
Table 3.2 Mixture proportions (Phase I: PP fiber dosage test)

\begin{tabular}{|l|c|c|c|}
\hline \multirow{2}{*}{ Materials lb/yd $^{\mathbf{3}}$} & \multicolumn{3}{|c|}{ Mixtures } \\
\cline { 2 - 4 } & $\mathbf{1}$ & $\mathbf{2}$ & $\mathbf{3}$ \\
\hline Cement & 810 & 738 & - \\
\hline Fly ash & 105 & 275 & - \\
\hline Silica fume & 37 & 88 & - \\
\hline Coarse aggregate & 1703 & 1602 & - \\
\hline Fine aggregate & 1130 & 1088 & 209 \\
\hline Water & 270 & 243 & 51 \\
\hline HRWR & $8^{1}$ & $21^{1}$ & $2,4 \& 6$ \\
\hline PP fibers $\left(\mathrm{kg} / \mathrm{m}^{3}\right)$ & $2,4 \& 6$ & $2,4 \& 6$ & 263 \\
\hline Steel fibers & - & - & 3698 \\
\hline Ductal & - & - & $\mathrm{kg}$ \\
\hline
\end{tabular}

${ }^{1}$ Dosage rate of fluid ounces $/ 100 \mathrm{cwt}, \mathrm{cwt}=$ cement weight, $1 \mathrm{fl} \mathrm{oz} / 100 \mathrm{lb}=65.2 \mathrm{~mL} / 100 \mathrm{~kg}$ $1 \mathrm{lb} / \mathrm{yd}^{3}=0.593 \mathrm{~kg} / \mathrm{m}^{3}$

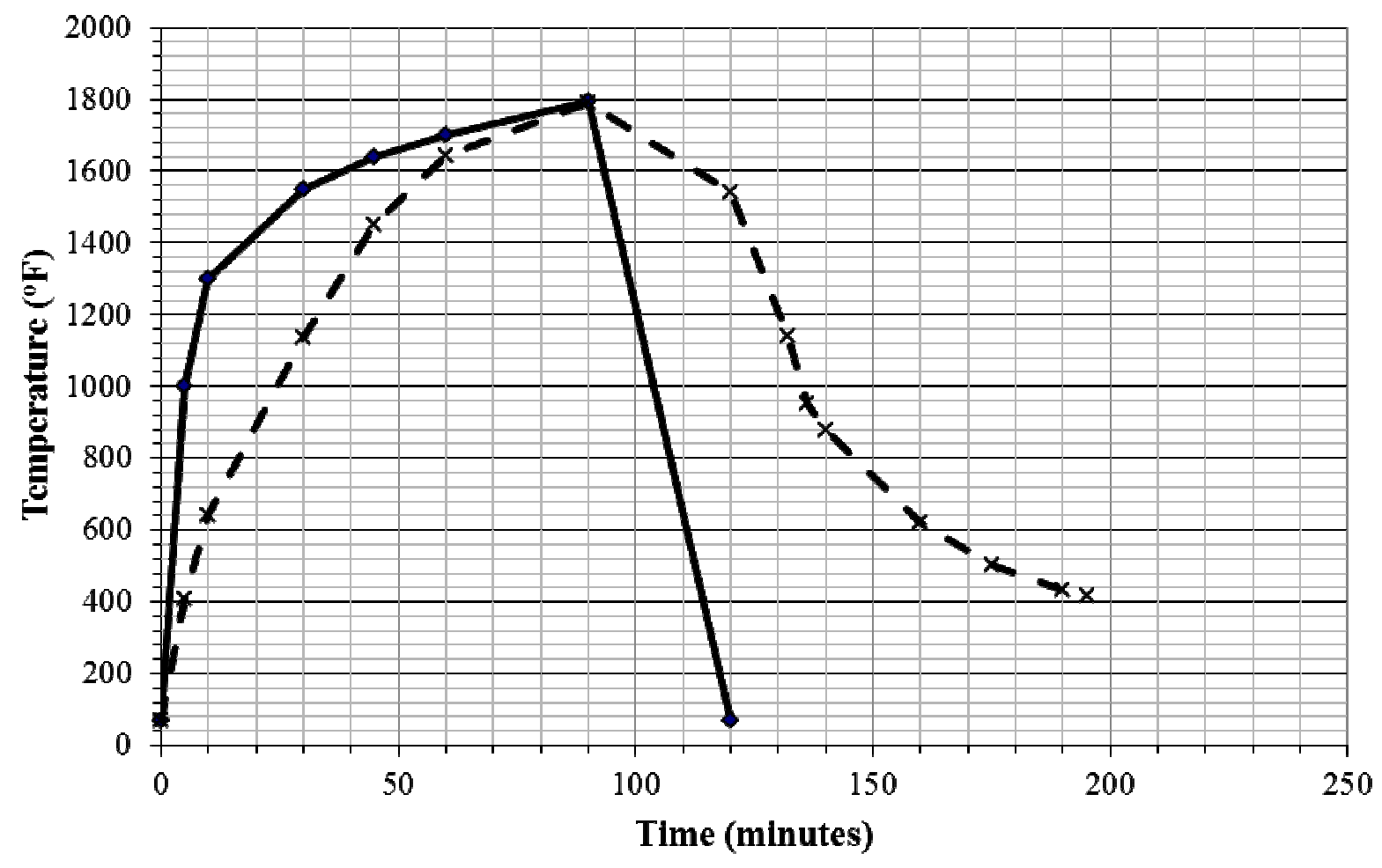

ASTM 119 temperature curve $\quad-\times \boldsymbol{-}$ Furnace temperature profile

Fig. 3.5. Heating profile. 


\subsection{Phase II: Assessment of Concrete Developed for TES Option A}

Phase II assessed the performance of seven concrete mixtures, shown in Table 3.3, in a prototype laboratory set-up. The set-up simulates the operation of a TES (Option A) system for concentrating solar power plants. The testing procedure for Phase II is described in details in Section 3.3.2.2. In TES Option A, the charging and discharging is achieved by circulating a heat transfer fluid (HTF) through heat exchangers embedded in the concrete modules. The concrete is required to sustain temperatures of at least $932^{\circ} \mathrm{F}\left(500^{\circ} \mathrm{C}\right)$. The other properties examined were compressive strength, thermal conductivity, and specific heat measured before and after testing.

\subsubsection{Concrete Mixtures}

The concrete mixtures tested in Phase II are shown in Table 3.3. All mixtures contained PP fibers for spall or explosion prevention and steel fibers to facilitate heat transfer and enhance the concrete's post cracking behavior. Ordinary concrete mixtures do not facilitate heat transfer because of their high porosity. Therefore the development of a denser high performance concrete with improved thermal conductivity was the motivation for the use of these mixtures. The mixture proportions and materials were chosen based on findings from Phase I. Phase I results showed that concrete containing the limestone aggregates (nominal maximum size of $3 / 8$ ") experienced high levels of cracking and a reduction in the mechanical properties after exposure to $1112^{\circ} \mathrm{F}\left(600^{\circ} \mathrm{C}\right)$. Polypropylene fiber dosage was determined from the work in Section 3.2.4. 
Table 3.3 Mixture proportions (Phase II: concrete for TES option A)

\begin{tabular}{|l|c|c|c|c|c|c|c|}
\hline $\begin{array}{l}\text { Material } \\
\left(\mathbf{l b / y d} \mathbf{d}^{\mathbf{3}}\right)\end{array}$ & \multicolumn{7}{|c|}{ Mixtures } \\
\cline { 2 - 8 } Cement & $\mathbf{1}$ & $\mathbf{2}$ & $\mathbf{3}$ & $\mathbf{4}$ & $\mathbf{5}$ & $\mathbf{6}$ & $\mathbf{7}$ \\
\hline Fly ash & - & 2000 & 1500 & 1500 & 1300 & 1300 & 1300 \\
\hline Silica fume & - & - & 500 & 500 & 500 & 500 & 500 \\
\hline Fine agg. & $1600^{2}$ & $1600^{3}$ & - & - & 200 & 200 & 200 \\
\hline Water & 305 & 305 & 305 & $1410^{3}$ & $1336^{3}$ & $1336^{2}$ & $1336^{4}$ \\
\hline HRWR & $11^{1}$ & $8^{1}$ & $8^{1}$ & $11^{1}$ & 305 & 305 & 305 \\
\hline Steel fiber & 100 & 100 & 100 & 100 & 100 & $17^{1}$ & $18^{1}$ \\
\hline PP fiber & 3.4 & 3.4 & 3.4 & 3.4 & 3.4 & 3.4 & 3.4 \\
\hline
\end{tabular}

* CA cement mixtures, $1 \mathrm{lb} / \mathrm{yd}^{3}=0.593 \mathrm{~kg} / \mathrm{m}^{3},{ }^{1}$ Dosage rate of fluid ounces $/ 100 \mathrm{cwt}, \mathrm{cwt}=$ cement weight, $1 \mathrm{fl} \mathrm{oz} / 100 \mathrm{lb}=65.2 \mathrm{~mL} / 100 \mathrm{~kg},{ }^{2}$ Arkansas river sand, ${ }^{3}$ Syenite (max. agg. size $2.35 \mathrm{~mm}),{ }^{4}$ Syenite (max. agg. size $4.50 \mathrm{~mm}$ ), 1 in. $=25.4 \mathrm{~mm}$

The concrete mixtures, shown in Table 3.3, are distinguished by the type of cementitious materials and the type and size of the fine aggregates. Mixture 1 contained calcium aluminate cement and river sand while Mixture 2 contained calcium aluminate cement and syenite with a maximum particle size of $3 / 32 "(2.35 \mathrm{~mm})$. Syenite was sieved in order the remove particles larger than $3 / 16 "(4.70 \mathrm{~mm})$. A combination of OPC and FA was used in Mixtures 3 and 4. Mixture 3 contained only syenite (NMSA $3 / 32 "(2.35 \mathrm{~mm})$ ) and Mixture 4 contained the river sand. Mixtures 5, 6 and 7 contained a combination of OPC, FA and SF. Syenite (NMSA $3 / 32$ "), river sand, and syenite with maximum particle size of 3/16" were used in Mixtures 5, 6 and 7, respectively.

\subsubsection{Testing}

Cylindrical specimens, 4 x 8 in. (100 x 200 mm), were instrumented with Type K Chromel Alumel thermocouples (Fig. 3.6) to monitor the temperature rise at the specimen core. Two specimens were heated at $16.2^{\circ} \mathrm{F} / \mathrm{min} .\left(9^{\circ} \mathrm{C} / \mathrm{min}\right.$.) up to $932^{\circ} \mathrm{F}\left(500^{\circ} \mathrm{C}\right)$. The rate of heating was based on results from Phase I. The furnace temperature was held constant at $932^{\circ} \mathrm{F}\left(500^{\circ} \mathrm{C}\right)$ for two hours before the programmed furnace temperature was returned to ambient levels. 


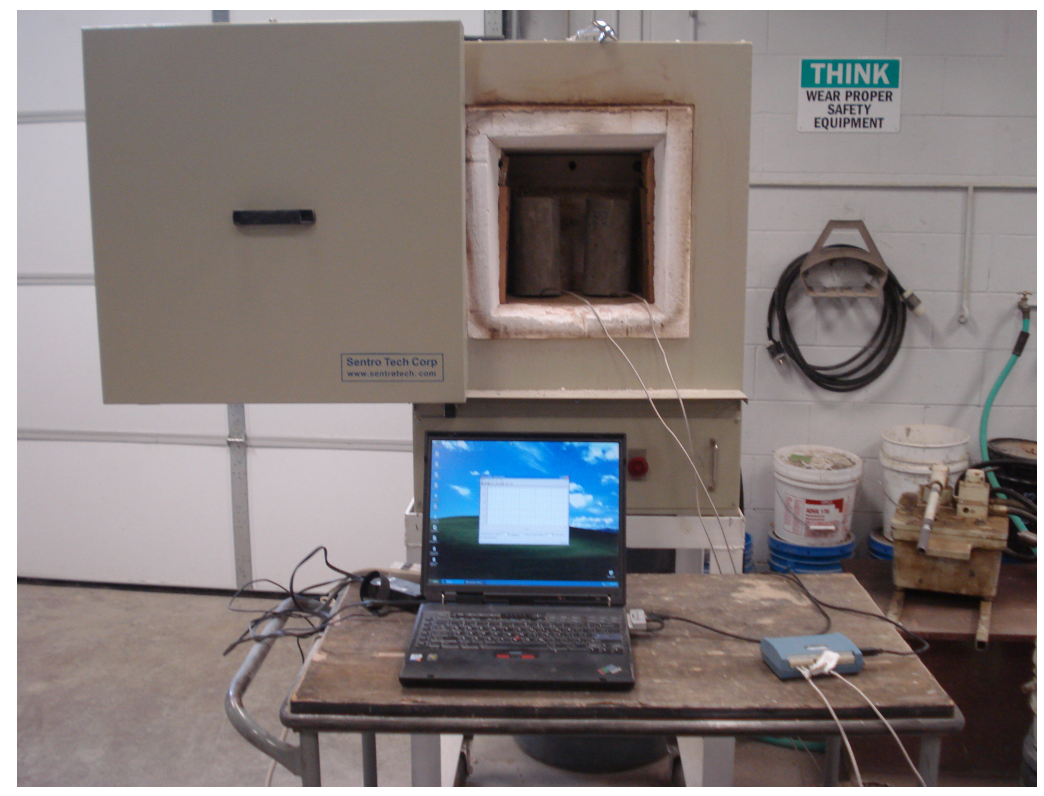

Fig. 3.6. Instrumentation of concrete specimens.

\subsubsection{Thermal Cycling Procedure}

Two 4 x 8 in. (100 x $200 \mathrm{~mm})$ cylindrical specimens from each mixture, shown in Table 3.3, were heated to $572^{\circ} \mathrm{F}\left(300^{\circ} \mathrm{C}\right)$ at a heating rate of $16.2^{\circ} \mathrm{F} / \mathrm{min} .\left(9^{\circ} \mathrm{C} / \mathrm{min}\right.$. $)$ in the furnace shown in Figure 3.6. The temperature remained at $572^{\circ} \mathrm{F}\left(300^{\circ} \mathrm{C}\right)$ for two hours and then increased to $932^{\circ} \mathrm{F}\left(500^{\circ} \mathrm{C}\right)$ at the same heating rate. The furnace temperature was held at this level for another two hours before returning to ambient levels. The time duration at which the temperature remained at $932^{\circ} \mathrm{F}\left(500^{\circ} \mathrm{C}\right)$ was based on the time required for the specimens to achieve steady state temperature. After each cycle, the specimens were removed and compressive strength was measured. This procedure was followed for 10 thermal cycles. Compressive strength (ASTM C39) was used to assess the concrete's performance.

\subsubsection{Assessment of the Concrete Performance with Molten Salt as the HTF}

Prismatic concrete blocks measuring $4 \times 4$ in. $(100 \times 100 \mathrm{~mm})$ in cross-section and $4 \mathrm{ft}(1.2$ m) in length, shown in Figure 3.7, were cast and subjected to an elevated temperature test. For 
the test, molten salt, a mixture of $60 \mathrm{wt} \% \mathrm{NaNO}_{3}$ and $40 \mathrm{wt} \% \mathrm{KNO}_{3}$, was the heat transfer fluid. The heat transfer fluid held in the tank was pumped through the heat exchanger which was embedded in the concrete block. The fluid was circulated until the concrete surface temperature reached $932^{\circ} \mathrm{F}\left(500^{\circ} \mathrm{C}\right)$. The apparatus used in this test is shown in Figure 3.8.

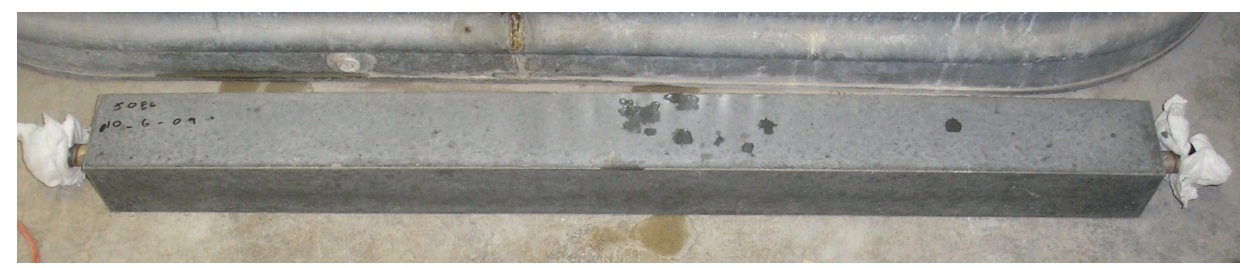

Fig. 3.7. Prismatic concrete module used in the molten salt test (Skinner et al., 2011, John et al., 2011).

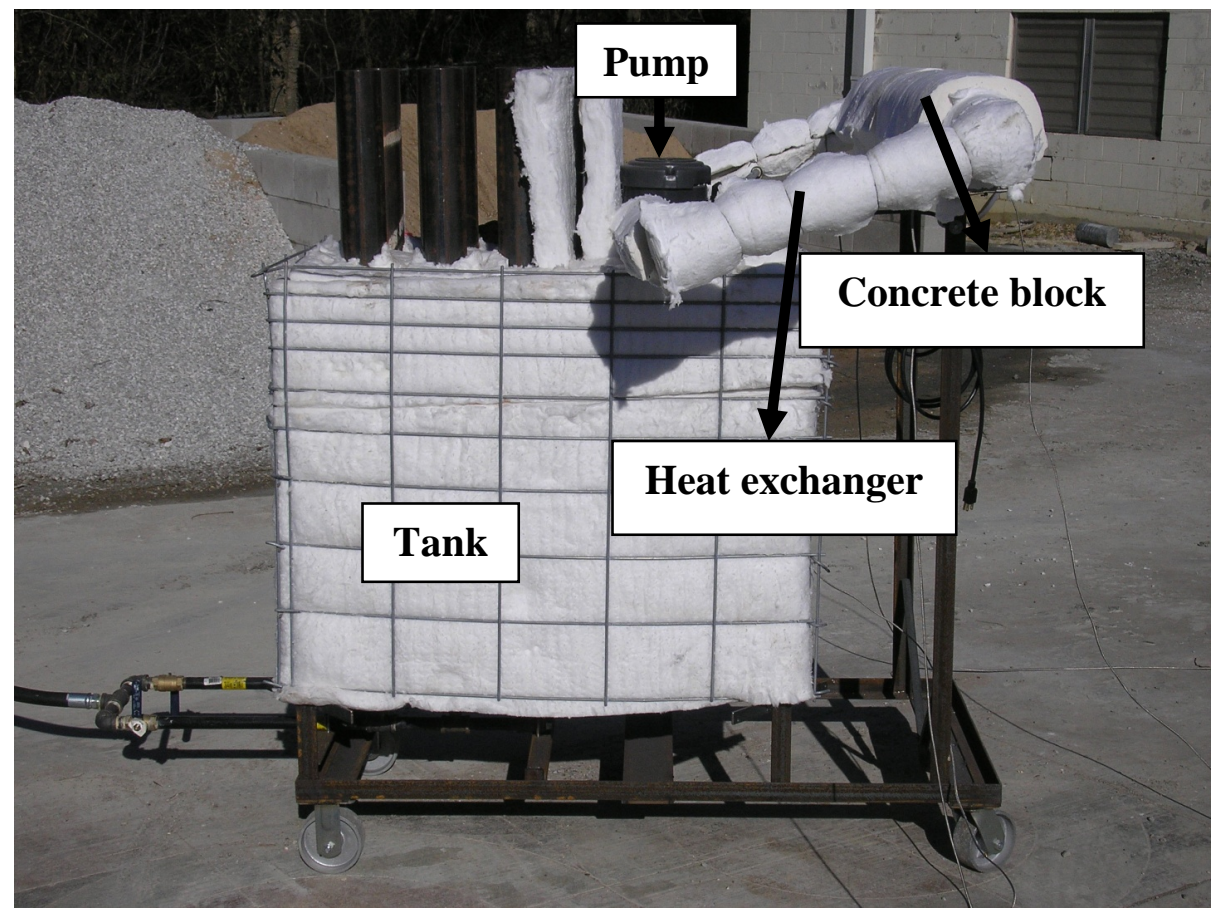

Fig. 3.8. Insulated molten salt heating apparatus (Skinner et al., 2011). 


\subsection{Phase III: Assessment of Concrete Developed for TES Option B}

Thermal energy storage system cost is one of the key variables in determining its viability. Cost comparisons between TES options, conducted by researchers in this area of work (Pacheco et al., 2001, Kolb and Hassani, 2006, Yang and Garimella, 2010, Faas, 1983), indicate that TES Option B is more economical. The high cost of TES Option A is derived primarily from the network of steel pipes used as heat exchangers. The heat exchangers accounts for 65 to $75 \%$ of the storage system cost (Tamme, 2006). As researchers push the frontier of the operating temperatures from $752^{\circ} \mathrm{F}\left(400^{\circ} \mathrm{C}\right)$ to temperatures in excess of $932^{\circ} \mathrm{F}\left(500^{\circ} \mathrm{C}\right)$, there is an equivalent need to employ a HTF that remains stable (no phase change) within this temperature range. One fluid that remains stable at these temperatures is molten salt. Molten salt can potentially withstand temperatures up to $1112^{\circ} \mathrm{F}\left(600^{\circ} \mathrm{C}\right)$ at normal pressure levels. However, the adverse reaction between molten salt and the steel pipe requires using stainless steel heat exchangers. Stainless steel is more expensive than ordinary carbon steel which increases the cost of the TES system.

The development of a suitable concrete as the main TES medium for Option B, which was discussed in Chapter 2, is explored in Phase III. Current thermocline systems use combinations of rock and sand or a heat transfer fluid as the main storage medium. These systems operate at a maximum temperature of $932^{\circ} \mathrm{F}\left(500^{\circ} \mathrm{C}\right)$. This research investigated the use of concrete bricks as the storage medium at operating temperatures of $1112^{\circ} \mathrm{F}\left(600^{\circ} \mathrm{C}\right)$.

The best performing mixtures from Phase II formed the basis for some of the mixtures used in this phase. Since the concrete's application changed from TES option A to option B, concrete strengths were reduced and measures were taken to reduce the unit cost of the concrete. These 
measures include, reducing the cementitious material content and including high volumes of fly ash.

\subsubsection{Concrete Mixtures}

Work in Phase II showed that mortar mixtures containing calcium aluminate cement (CAC) were resistant to temperatures up to $932^{\circ} \mathrm{F}\left(500^{\circ} \mathrm{C}\right)$. However, due to the high costs of CAC, FA was added to reduce cost. Twenty-six mixtures, shown in Tables 3.4, 3.5, 3.6 and 3.7 were batched and tested in a bath of molten salt at $1085^{\circ} \mathrm{F}\left(585^{\circ} \mathrm{C}\right)$ for 500 hours. The specimens were also subjected to 30 thermal cycles between $572^{\circ} \mathrm{F}\left(300^{\circ} \mathrm{C}\right)$ and $1085^{\circ} \mathrm{F}\left(585^{\circ} \mathrm{C}\right)$ when submerged in molten salt and between $572^{\circ} \mathrm{F}\left(300^{\circ} \mathrm{C}\right)$ and $1112^{\circ} \mathrm{F}\left(600^{\circ} \mathrm{C}\right)$ in the absence of molten salt.

The coarse aggregates used in these mixtures varied. Mixtures 5 - 14, 18, and 21 - 23 contained sandstone with nominal maximum size of 1/2” (12.7 mm). Mixtures 1 - 4, 15, and 16 contained no coarse aggregates. All mixtures employed washed river sand as the fine aggregates. Sandstone stone was chosen because of its availability and because it is the base material for the formation of quartzite. Pacheco et al. (2001) showed that quartzite rock and silica sand are highly resistant to elevated temperatures when in direct contact with molten salt. Since quartzite is not readily available in Arkansas, sandstone was used in these concrete mixtures. Limestone was used in Mixtures 17, 19, and 25, whereas, Mixtures 20 and 24 contained syenite of a single particle size of $3 / 16 "(4.7 \mathrm{~mm})$. The results of work published by Pacheco et al. (2001) indicated that limestone and granite, to which syenite has similar properties, softened when exposed to $932^{\circ} \mathrm{F}\left(500^{\circ} \mathrm{C}\right)$ in the presence of molten salt. Nonetheless, because the mineralogical compositions of these aggregates can exhibit variations depending on their origin, Arkansas limestone and syenite were used in 5 of the 26 mixtures that are shown in Tables 3.4 to 3.7 . 
A special mixture formulated by Lafarge North America was also used during Phase III.

The material is sold in a pre-mixed bag under the brand name TC1000. The mixture proportions (Mixture 26) are shown in Table 3.7.

All mixtures contained PP fibers for spall or explosion prevention. The fibers were added to the mixture, with a dosage of $3.4 \mathrm{lb} / \mathrm{yd}^{3}\left(2 \mathrm{~kg} / \mathrm{m}^{3}\right)$, during the final mixing stage to ensure that they were adequately distributed.

Table 3.4 Mixture proportions (TES option B, mixtures 1 to 7)

\begin{tabular}{|l|c|c|c|c|c|c|c|}
\hline \multirow{2}{*}{$\begin{array}{l}\text { Materials } \\
\left(\mathbf{l b} / \mathbf{y d}^{\mathbf{3}} \text { ) }\right.\end{array}$} & \multicolumn{9}{|c|}{ Mixtures } \\
\cline { 2 - 8 } & $\mathbf{1}$ & $\mathbf{2}$ & $\mathbf{3}$ & $\mathbf{4}$ & $\mathbf{5}$ & $\mathbf{6}$ & $\mathbf{7}$ \\
\hline Cement & 675 & 398 & 810 & 675 & 447 & 400 & 270 \\
\hline Fly ash & 675 & 927 & 540 & 540 & 447 & 400 & 630 \\
\hline Silica fume & - & - & - & 135 & - & - & - \\
\hline Fine aggregates & 1695 & 1855 & 1955 & 1906 & 1300 & 1250 & 1250 \\
\hline Coarse aggregates & - & - & - & - & 1300 & 1250 & 1332 \\
\hline Water & 486 & 398 & 405 & 405 & 324 & 400 & 305 \\
\hline PP fiber & 3.4 & 3.4 & 3.4 & 3.4 & 3.4 & 3.4 & 3.4 \\
\hline
\end{tabular}

$1 \mathrm{lb} / \mathrm{yd}^{3}=0.593 \mathrm{~kg} / \mathrm{m}^{3}$

Table 3.5 Mixture proportions (TES option B, mixtures 8 to 14)

\begin{tabular}{|l|c|c|c|c|c|c|c|}
\hline \multirow{2}{*}{$\begin{array}{l}\text { Materials } \\
\left.\text { (lb/yd } \mathbf{3}^{\mathbf{3}}\right)\end{array}$} & \multicolumn{9}{|c|}{ Mixtures } \\
\cline { 2 - 8 } & $\mathbf{8}$ & $\mathbf{9}$ & $\mathbf{1 0}$ & $\mathbf{1 1}$ & $\mathbf{1 2}$ & $\mathbf{1 3}$ & $\mathbf{1 4}$ \\
\hline Cement & 240 & 540 & 480 & 360 & 320 & 360 & 320 \\
\hline Fly ash & 560 & 360 & 320 & 540 & 480 & 450 & 400 \\
\hline S.fume & - & - & - & - & - & 90 & 80 \\
\hline Fine aggregates & 1275 & 1300 & 1265 & 1285 & 1234 & 1285 & 1234 \\
\hline Coarse aggregates & 1275 & 1334 & 1265 & 1285 & 1238 & 1285 & 1238 \\
\hline Water & 360 & 332 & 400 & 325 & 400 & 324 & 400 \\
\hline PP fiber & 3.4 & 3.4 & 3.4 & 3.4 & 3.4 & 3.4 & 3.4 \\
\hline
\end{tabular}

$1 \mathrm{lb} / \mathrm{yd}^{3}=0.593 \mathrm{~kg} / \mathrm{m}^{3}$ 
Table 3.6 Mixture proportions (TES option B, mixtures 15 to 21)

\begin{tabular}{|l|c|c|c|c|c|c|c|}
\hline \multirow{2}{*}{$\begin{array}{l}\text { Materials } \\
\mathbf{l l b / y d ~}^{\mathbf{3}} \text { ) }\end{array}$} & $\mathbf{1 5}$ & $\mathbf{1 6}$ & $\mathbf{1 7}$ & $\mathbf{1 8}$ & $\mathbf{1 9}$ & $\mathbf{2 0}$ & $\mathbf{2 1}$ \\
\hline Cement & 675 & 675 & 180 & 180 & 325 & 338 & 300 \\
\hline Fly ash & 675 & 540 & 420 & 420 & 293 & 303 & 270 \\
\hline S.fume & - & 135 & - & - & 32.5 & 34 & 30 \\
\hline Fine aggregates & 1978 & 1908 & 1068 & 1068 & 1160 & 1100 & 1080 \\
\hline Coarse aggregates & - & - & $1900^{1}$ & $1900^{2}$ & $1700^{1}$ & $1700^{3}$ & $1900^{2}$ \\
\hline Water & 378 & 405 & 288 & 288 & 325 & 338 & 300 \\
\hline PP fiber & 3.4 & 3.4 & 3.4 & 3.4 & 3.4 & 3.4 & 3.4 \\
\hline HRWR & 2 & 4 & - & - & - & - & - \\
\hline
\end{tabular}

$1 \mathrm{lb} / \mathrm{yd}^{3}=0.593 \mathrm{~kg} / \mathrm{m} 3,{ }^{1}$ Limestone (max. agg. size $\left.3 / 8 "\right),{ }^{2}$ Sandstone (max. agg. size $1 / 2 "$ ),

${ }^{3}$ Syenite (single size of $4.70 \mathrm{~mm}$ ), $1 \mathrm{in} .=25.4 \mathrm{~mm}$

Table 3.7 Mixture proportions (TES option B, mixtures 22 to 26)

\begin{tabular}{|l|c|c|c|c|c|}
\hline \multirow{2}{*}{$\begin{array}{l}\text { Materials } \\
\left(\mathbf{l b / y d} \mathbf{d}^{\mathbf{3}}\right)\end{array}$} & \multicolumn{5}{|c|}{ Mixtures } \\
\cline { 2 - 6 } Cement & $\mathbf{2 2}$ & $\mathbf{2 3}$ & $\mathbf{2 4}$ & $\mathbf{2 5}$ & $\mathbf{2 6}$ \\
\hline Fly ash & 650 & 325 & 325 & 325 & - \\
\hline S.fume & - & 325 & 325 & 325 & - \\
\hline Fine aggregates & - & - & - & - & - \\
\hline Coarse aggregates & 1473 & 1160 & 1160 & 1160 & - \\
\hline Water & $1500^{2}$ & $1700^{2}$ & $1700^{3}$ & $1700^{1}$ & - \\
\hline PP fiber & 325 & 325 & 325 & 325 & 236 \\
\hline Steel fiber & 3.4 & 3.4 & 3.4 & 3.4 & 3.4 \\
\hline HRWR & - & - & - & - & 263 \\
\hline Premix & - & - & - & - & 51 \\
\hline
\end{tabular}

$1 \mathrm{lb} / \mathrm{yd}^{3}=0.593 \mathrm{~kg} / \mathrm{m}^{3},{ }^{1}$ Limestone (max. agg. size $\left.3 / 8 "\right),{ }^{2}$ Sandstone (max. agg. size $\left.1 / 2 "\right)$,

${ }^{3}$ Syenite (single size of $4.70 \mathrm{~mm}$ ), 1 in. $=25.4 \mathrm{~mm}$

\subsubsection{Thermal Cycling Procedure}

Two 4 x 8 in. $(100 \times 200 \mathrm{~mm})$ cylindrical specimens from each mixture were heated at a rate of $16.2^{\circ} \mathrm{F} / \mathrm{min}$. $\left(9^{\circ} \mathrm{C} / \mathrm{min}\right.$.) to $1112^{\circ} \mathrm{F}\left(600^{\circ} \mathrm{C}\right)$. The temperature remained at $1112^{\circ} \mathrm{F}\left(600^{\circ} \mathrm{C}\right)$ for 6 hours, after which the oven temperature was reduced to $572^{\circ} \mathrm{F}\left(300^{\circ} \mathrm{C}\right)$ and remained there for another six hours before it was again raised at $16.2^{\circ} \mathrm{F} / \mathrm{min}$. $\left(9^{\circ} \mathrm{C} / \mathrm{min}\right.$.) to $1112^{\circ} \mathrm{F}\left(600^{\circ} \mathrm{C}\right)$. This procedure was followed for 30 cycles, following which, the specimens were removed and compressive strength was measured (ASTM C39). As in Phase II, compressive strength was 
used to assess the effects of thermal cycling.

Several of the mixtures (Mixtures 5, 7, 9-11, 15, 16 and 26) were conditioned by increasing the furnace temperature at $18^{\circ} \mathrm{F} /$ hour $\left(10^{\circ} \mathrm{C} /\right.$ hour $)$ up to $230^{\circ} \mathrm{F}\left(110^{\circ} \mathrm{C}\right)$ and at $72^{\circ} \mathrm{F} /$ hour $\left(40^{\circ} \mathrm{C} /\right.$ hour $)$ thereafter to $1112^{\circ} \mathrm{F}\left(600^{\circ} \mathrm{C}\right)$, prior to the thermal cycling procedure. Conditioning, recommended by Petzold and Rohrs (1970), was done to assess the effect of slow heating on the ability of concrete to withstand temperatures of $1112^{\circ} \mathrm{F}\left(600^{\circ} \mathrm{C}\right)$.

\subsubsection{Thermal Conductivity Test}

The thermal conductivity test was carried out in accordance with ASTM D $5334-05$. Thermal conductivity was determined using a needle probe of $1 / 4$ " in diameter and $51 / 2$ " in length. The method is based on the theory that the rise in the temperature of the heat source is dependent on the thermal conductivity of the medium into which it is inserted. The probe consists of a heating wire and a temperature measuring element. A known current is applied to the probe and the temperature rise is plotted against time. During the test, the probe was inserted into a predrilled hole in the specimens to a depth of no less than 4 inches. Thermal grease was used to fill air pocket at the probe to concrete interface. Equation 2 was used to obtain the thermal conductivity. The test set-up is shown in Figure 3.9.

$$
\begin{aligned}
& \lambda=\frac{Q}{4 \pi\left(T_{2}-T_{1}\right)} \ln \left(t_{2} / t_{1}\right) \\
& Q=\frac{E I}{L}=\frac{I^{2} R}{L}
\end{aligned}
$$

In Equations 2 and 3;

$\lambda$ is the thermal conductivity $(\mathrm{W} / \mathrm{mK})$,

$\mathrm{Q}$ is the heat input, 
$\mathrm{T}_{1}$ and $\mathrm{T}_{2}$ are the initial and final temperatures in ${ }^{\circ} \mathrm{C}$ respectively,

$t_{1}$ and $t_{2}$ are the initial and final time based on the length of application of the power source in seconds,

I is the current (A) flowing through the heating wire,

E is voltage $(\mathrm{V})$,

$\mathrm{R}$ is the total resistance $(\Omega)$ of the heating wire, and

$\mathrm{L}$ is the length (m) of the wire (the embedded length was used).

The probe, which was inserted into the predrilled hole, consisted of a heating wire with a

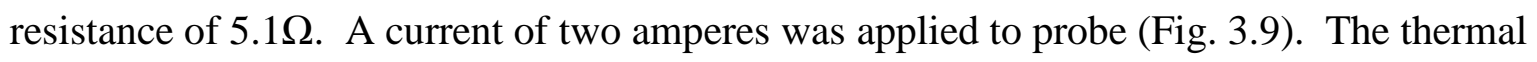
conductivity of the specimens was measured at ambient temperature before exposure to high temperatures and in some instances, after elevated temperature exposure. Thermal conductivity, after elevated temperature exposure, was also estimated based on the following equations proposed by Kodur and Sultan (2003).

$K=\lambda-0.0011 T$

Where $\lambda$ is the ambient temperature thermal conductivity and $\mathrm{T}$ is the temperature (in ${ }^{\circ} \mathrm{C}$ ) at which the thermal conductivity $(K)$ is required.

Equation 4 is applicable for concrete containing siliceous aggregates and at temperatures between 0 and $1832^{\circ} \mathrm{F}\left(0\right.$ and $\left.1000^{\circ} \mathrm{C}\right)$. For concrete containing carbonate aggregate, the following equations apply;

for $0 \leq \mathrm{T} \leq 300^{\circ} \mathrm{C}\left(0 \leq \mathrm{T} \leq 572^{\circ} \mathrm{F}\right)$

$K=\lambda-0.0013 T$

for $300<\mathrm{T} \leq 1000^{\circ} \mathrm{C}\left(572 \leq \mathrm{T} \leq 1832^{\circ} \mathrm{F}\right)$

$K=\lambda-0.0020 T$ 


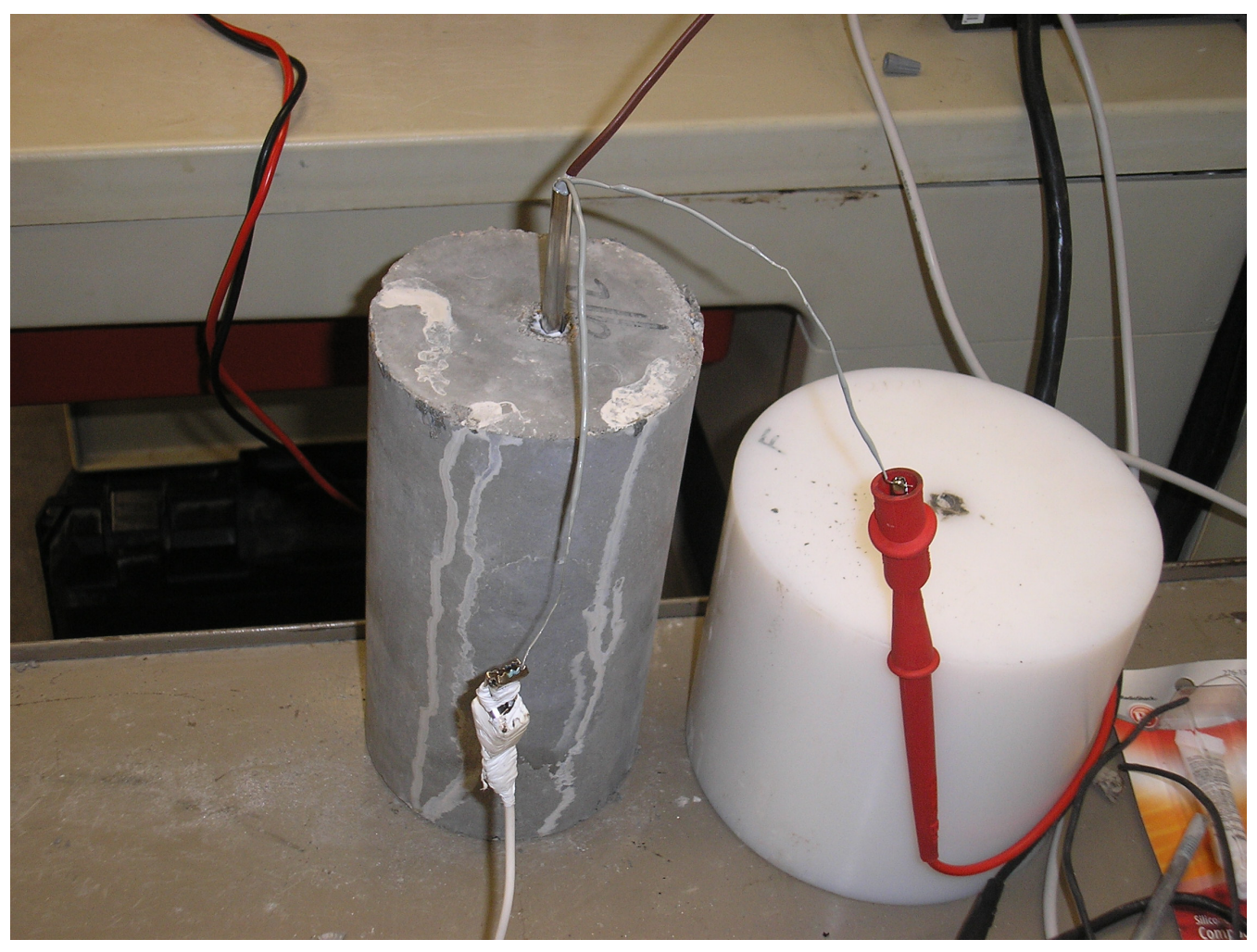

Fig. 3.9. Concrete thermal conductivity test set-up.

\subsubsection{Specific Heat Test}

Specific heat was based on the following equations and procedures:

$$
\begin{aligned}
& q_{\text {concrete }}=q_{\text {water }} \\
& q_{\text {concrete }}=M_{\text {concrete }} C_{p} \Delta T \\
& q_{\text {water }}=M_{\text {water }} C_{p} \Delta T
\end{aligned}
$$

In Equations 7 to $9, q_{\text {concrete }}$ represents the amount of heat loss by the concrete, $q_{\text {water }}$, the amount of heat gained by the water, $C_{p}$, specific heat of the materials, $\Delta T$, the change in temperature, and $M$, the mass of the materials. 
The experimental procedure entailed placing $3.38 \mathrm{fl} \mathrm{oz}(100 \mathrm{~mL})$ of water into a Styrofoam cup placed in a beaker (shown in Fig. 3.10). A temperature probe was placed in the cup of water while the water temperature stabilized. Whilst the water temperature stabilized, the concrete sample weight was measured. The concrete specimens were cuboids weighing 0.13 to $0.20 \mathrm{lbs}$ (60 to $90 \mathrm{~g}$ ). Concrete samples were oven dried for 24 hours at $212^{\circ} \mathrm{F}\left(100^{\circ} \mathrm{C}\right)$. At the time of testing, the temperature of the sample was taken as the recorded oven temperature. Once the water temperature stabilized, the concrete sample was placed in the water and temperature readings were taken until there was less than 0.10 degree change over a minute. The time duration for the required temperature change to be achieved was approximately 20 minutes. The specific heat $\left(\mathrm{C}_{\mathrm{p}}\right)$ of the concrete was obtained from Equation 7, with the $\mathrm{C}_{\mathrm{p}}$ of water taken as $0.9984 \mathrm{Btu} / \mathrm{lbm}^{\circ} \mathrm{F}\left(4.184 \mathrm{~J} / \mathrm{g}^{\circ} \mathrm{C}\right)$.

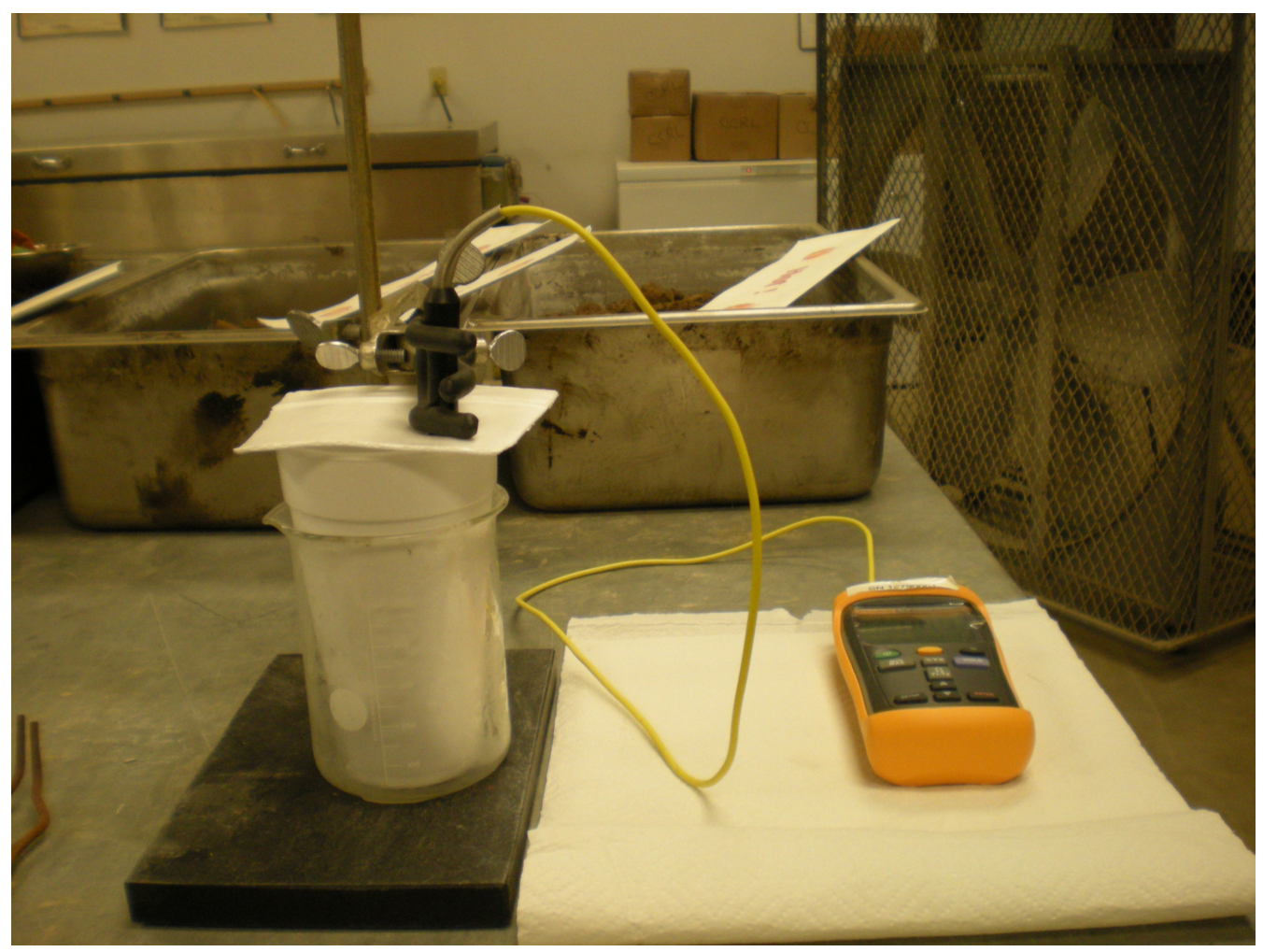

Fig. 3.10. Specific heat test set-up. 
The specific heat of the various concrete mixtures was also computed using the Law of Mixtures (Bentz et al., 2010), which is the weighted average of $C_{p}$ of concrete's constituent materials (Equation 10). Specific heat values for concrete materials are shown in Table 3.8.

$$
c_{p}^{\text {con }}=\left(c_{p}^{w} m_{w}+\sum c_{p}^{c m} m_{c m}+c_{p}^{\text {fagg }} m_{\text {fagg }}+c_{p}^{\text {cagg }} m_{\text {cagg }}+c_{p}^{\text {sfiber }} m_{\text {sfiber }}\right) / \sum m
$$

In Equation 10, $\mathrm{C}_{\mathrm{p}}$ is specific heat and the superscripts/subscripts con, w, m, cm, fagg, cagg and sfiber represent concrete, water, mass, cementitious materials, fine aggregates, coarse aggregates and steel fibers respectively.

Table 3.8 Concrete materials specific heat values (Bentz et al., 2010)

\begin{tabular}{|l|c|c|}
\hline \multirow{2}{*}{ Concrete Material } & \multicolumn{2}{|c|}{ Specific heat $\left(\mathbf{C}_{\mathbf{p}}\right)$} \\
\cline { 2 - 3 } & US units $\left(\mathbf{B t u} / \mathbf{l b m}^{\mathbf{0}} \mathbf{F}\right)$ & SI units $(\mathbf{J} / \mathbf{g K})$ \\
\hline Ordinary portland cement & 0.174 & 0.730 \\
\hline Calcium aluminate cement & 0.174 & 0.730 \\
\hline Fly ash & 0.174 & 0.730 \\
\hline Silica fume & 0.186 & 0.780 \\
\hline Siliceous sand & 0.170 & 0.710 \\
\hline Sandstone & 0.220 & 0.920 \\
\hline Limestone & 0.220 & 0.920 \\
\hline Granite & 0.189 & 0.790 \\
\hline Steel fibers & 0.117 & 0.490 \\
\hline \multirow{2}{*}{ Water } & 0.998 & $4.184 *$ \\
& 0.525 & 2.200 \\
\hline
\end{tabular}

$* \mathrm{C}_{\mathrm{p}}$ of free water

For concrete, most of the mixing water is consumed during hydration. Thus, Waller et al. (1996) proposed the value of $0.5255 \mathrm{Btu} / \mathrm{lbm}^{\circ} \mathrm{F}(2.20 \mathrm{~J} / \mathrm{gK})$ for the specific heat of water combined within concrete mixtures. The larger value of $0.9984 \mathrm{Btu} / \mathrm{lbm}^{\circ} \mathrm{F}(4.18 \mathrm{~J} / \mathrm{gK})$ was used to create an upper limit for which the measured specific heat of the various concrete mixtures is expected to fall. 


\subsubsection{Calibration}

To ensure that the thermal probe used in the thermal conductivity test produced acceptable results, a specimen of high density polypropylene ether (HDPE) with a known value of thermal conductivity of $0.254-0.289 \mathrm{Btu} / \mathrm{ft} . \mathrm{h} .{ }^{0} \mathrm{~F}(0.44-0.50 \mathrm{~W} / \mathrm{mK})$ was tested (Fig. 3.9). The probe was required to produce values within these limits on three separate measurements of thermal conductivity.

Specific heat measurement was determined using a specimen of aluminum, weighing 0.188 $\mathrm{lb}(85.5 \mathrm{~g})$, with a known $\mathrm{C}_{\mathrm{p}}$ of $0.215 \mathrm{Btu} / \mathrm{lbm} \mathrm{F}(0.90 \mathrm{~J} / \mathrm{gK})$. The procedure was presented in Section 3.4.4. The temperature of the specimen ranged from 215 to $223^{\circ} \mathrm{F}\left(102\right.$ to $\left.106^{\circ} \mathrm{C}\right)$ whilst the water temperature ranged from 72 to $74^{\circ} \mathrm{F}\left(22\right.$ to $\left.23^{\circ} \mathrm{C}\right)$. The average of three measurements was taken and a correction factor (actual specific heat/measured specific heat) was determined. The correction factor (1.393) was used as a multiplier for the measured values of concrete specific heat.

\subsubsection{Isothermal Bath}

One cube, measuring 2 in. (51 mm), from each mixture was submerged in molten salt for a period of 500 hours at $1085^{\circ} \mathrm{F}\left(585^{\circ} \mathrm{C}\right)$. Cube weight and dimensions were measured before and after the period of submersion. In addition, compressive strength was measured before and after the testing using the 2 in. $(51 \mathrm{~mm})$ cubes. These tests were conducted to assess the stability of the concrete mixtures when in contact with molten salt at the desired temperature. In addition to the isothermal bath test, specimens ( 2 in. cubes) were thermally cycled between 572 and $1085^{\circ} \mathrm{F}$ (300 and $585^{\circ} \mathrm{C}$ ) whilst submerged in the molten salt.

The testing procedure required the salt to be melted in the test oven at $662^{\circ} \mathrm{F}\left(350^{\circ} \mathrm{C}\right)$. Once the salt was melted, it was removed from the oven and poured slowly and carefully into the pan 
containing the concrete test specimens. The pan with the cubes and molten salt was placed in the oven at $572^{\circ} \mathrm{F}\left(300^{\circ} \mathrm{C}\right)$ to begin the thermal cycling regimen. From this point, the oven temperature was increased at $2.16^{\circ} \mathrm{F} / \mathrm{min} .\left(1.2^{\circ} \mathrm{C} / \mathrm{min}\right.$. $)$ to $1085^{\circ} \mathrm{F}\left(585^{\circ} \mathrm{C}\right)$. This simulated the charging process of the thermocline storage system. The time duration to reach the maximum temperature was four hours. Once the cycle reached the maximum temperature, salt and concrete were held at that temperature for two hours. At this point, the oven temperature was reduced to $572^{\circ} \mathrm{F}\left(300^{\circ} \mathrm{C}\right)$ over a period of four hours. The discharge time considers the actual performance of the thermocline storage system during the discharging phase. The oven temperature was then held at $572^{\circ} \mathrm{F}\left(300^{\circ} \mathrm{C}\right)$ for two additional hours to complete one thermal cycle. After 30 cycles, the salt was drained from the concrete overnight at $572^{\circ} \mathrm{F}\left(300^{\circ} \mathrm{C}\right)$. The specimens were subsequently weighed, measured and tested in compression the following day.

\subsubsection{Splitting Tensile Strength}

The splitting tensile strength test was conducted in accordance with ASTM C496 (Fig. 3.11). This test was run on $4 \times 8$ in. $(100 \times 200 \mathrm{~mm})$ cylindrical specimens, placed as shown in Figure 3.11, before and after heat exposure to assess the tensile strength of the concrete. The splitting tensile strength was determined as follows:

$$
T=\frac{2 P}{\pi l d}
$$

Where:

$\mathrm{T}=$ splitting tensile strength (psi),

$\mathrm{P}=$ maximum applied load (lb),

$1=$ length of the specimen (in.), and

$\mathrm{d}=$ diameter of the specimen (in.). 


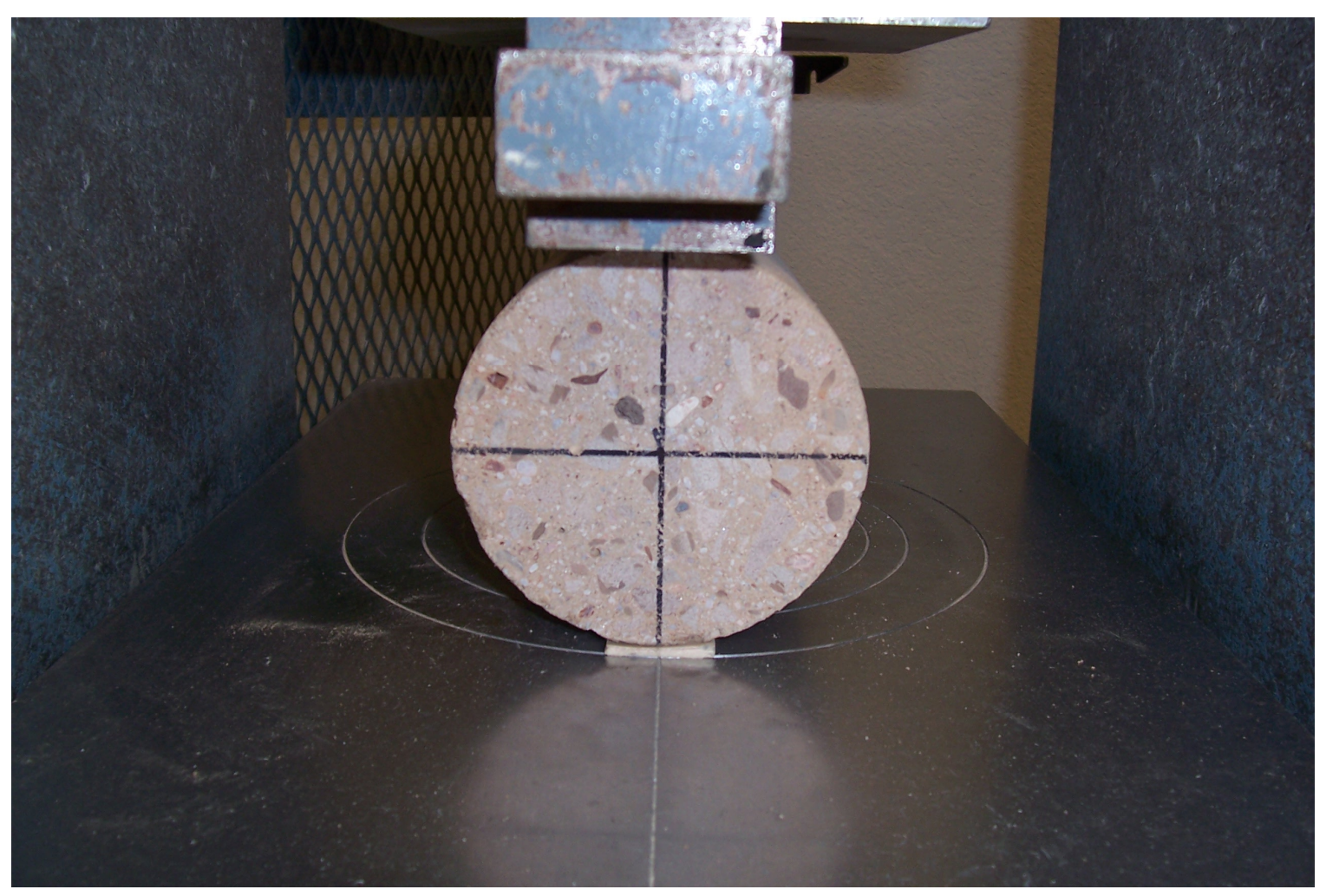

Fig. 3.11. Splitting tensile strength test set-up.

\subsubsection{Static Modulus of Elasticity}

The modulus of elasticity (MOE) was measured in accordance with ASTM C 469 (Fig. 3.12). This test determined concrete's stiffness prior to and after exposure to the high temperatures. The elastic modulus was determined as follows:

$$
E=\frac{\left(S_{2}-S_{1}\right)}{\left(\varepsilon_{2}-0.000050\right)}
$$

Where:

$\mathrm{E}=$ chord modulus of elasticity (ksi),

$\mathrm{S}_{2}=$ stress corresponding to $40 \%$ of the ultimate compressive force (ksi),

$\mathrm{S}_{1}=$ stress corresponding to a longitudinal strain (ksi), $\varepsilon_{1}$, of 50 millionth, and

$\varepsilon_{2}=$ longitudinal strain produced by $\mathrm{S}_{2}$. 


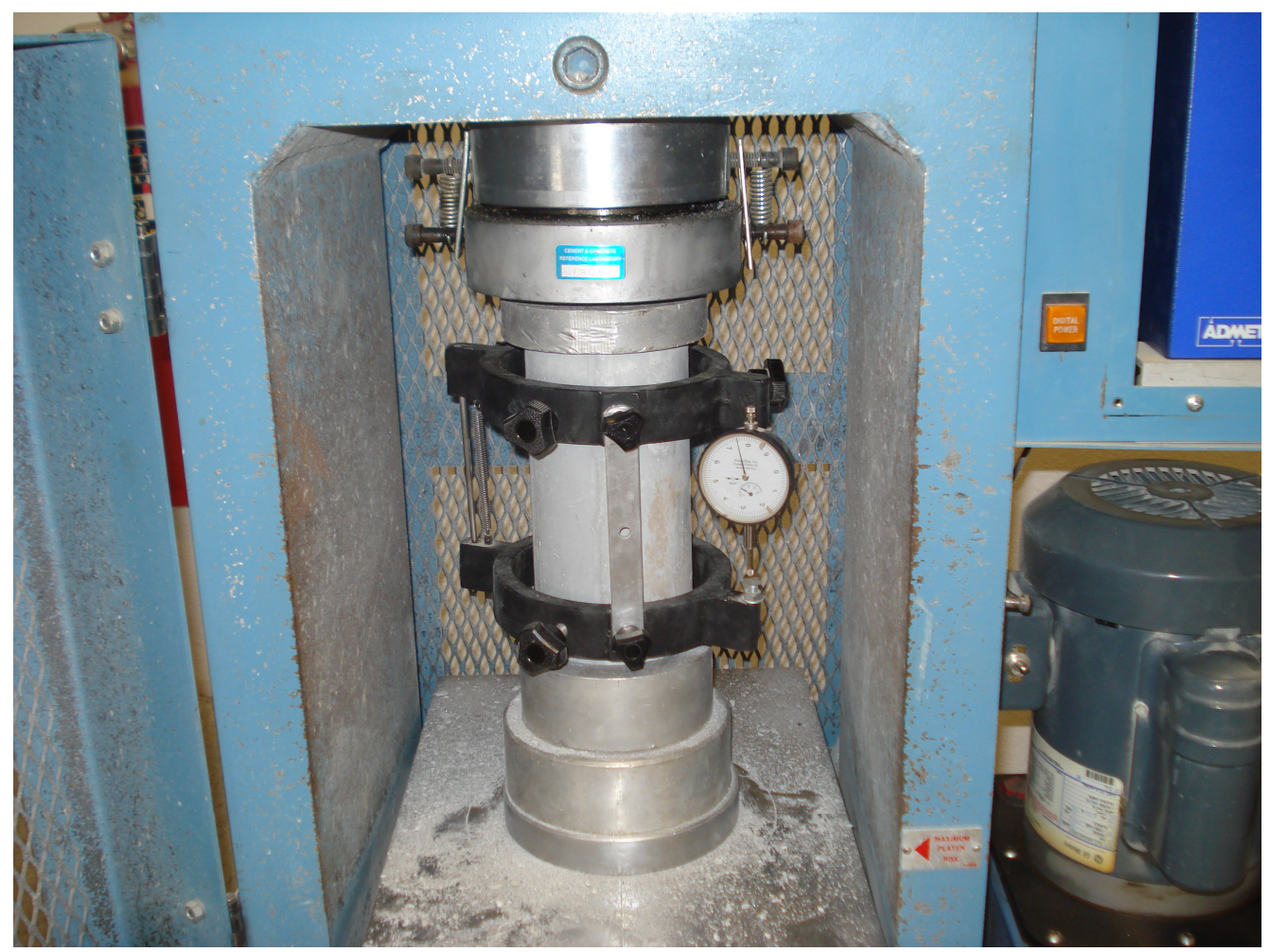

Fig. 3.12. Modulus of elasticity test set-up.

\subsubsection{Concrete Unit Costs}

The costs per cubic yard of the concrete mixtures (except the proprietary mixtures) are based on the prices shown in Table 3.9. The unit cost of concrete, based on the prices shown in Table 3.9, was increased by $0.50 \%$ to account for other admixtures such as water reducers and polypropylene fibers where applicable.

Table 3.9 Concrete material costs

\begin{tabular}{|l|c|}
\hline Materials & Cost (\$/ton) \\
\hline Ordinary portland cement & 100.00 \\
\hline Calcium aluminate cement & 575.00 \\
\hline Fly ash & 30.00 \\
\hline Silica fume & 300.00 \\
\hline Coarse and fine aggregates & 50.00 \\
\hline TC1000 premix & 205.00 \\
\hline Steel fibers & $2.77^{*}$ \\
\hline
\end{tabular}

$*$ price in $\$ / l b$ 


\subsection{Characterization of Selected Concrete Mixtures}

Four of the 26 mixtures presented in Phase III were selected for full characterization based on their refractoriness (resistance to heat) and unit cost. The following properties were used to

characterize the concrete mixtures: unit weight, compressive strength, modulus of elasticity, and splitting tensile strength. The thermal properties were thermal conductivity, specific heat, and mass loss.

The hardened and thermal properties were determined both before and after exposure to 30 thermal cycles of 572 and $1085^{\circ} \mathrm{F}\left(300\right.$ and $\left.585^{\circ} \mathrm{C}\right)$. All tests were performed on concrete that was at least 28 days of age. 


\section{CHAPTER 4 RESULTS AND DISCUSSION}

\subsection{Introduction}

Chapter 4 presents the results of the experiments performed in Chapter 3. In all phases of the research, the effects of elevated temperatures on concrete were examined. In Phase I, concrete's ability to withstand temperatures of $1112^{\circ} \mathrm{F}\left(600^{\circ} \mathrm{C}\right)$ was assessed and PP fiber dosage for the prevention of explosive spalling was determined. In Phase II, concrete mixtures were developed and tested for deployment in the TES system, Option A. The tests included resistance to elevated temperature cycles between ambient temperatures and 752 to $1112^{\circ} \mathrm{F}\left(500\right.$ to $\left.600^{\circ} \mathrm{C}\right)$. The thermo-mechanical properties were evaluated after thermal cycling. These properties include thermal conductivity, specific heat, mass loss, and compressive strength. In Phase III, 26 concrete mixtures were prepared and tested for deployment in the TES system Option B. Concrete's compressive strength, thermal conductivity, and specific heat were evaluated. Finally, the implications of the tests results as they relate to the two options for TES are discussed.

\subsection{Phase I: Effects of Heating Rates and PP Fiber Dosage on the Performance of Concrete at Elevated Temperatures}

\subsubsection{The Effects of Heating Rates and Elevated Temperatures on Concrete}

During Phase I, the effects of elevated temperatures and heating rates on concrete were investigated. Changes in concrete compressive strength were used to assess concrete performance. The mixture proportions were shown in Table 3.1, Chapter 3. Results from these tests are shown in Table 4.1. The results show that at heating rates of 12.6 or $16.2^{\circ} \mathrm{F} / \mathrm{min}$. ( 7 or $9^{\circ} \mathrm{C} / \mathrm{min}$.), the mixtures retained slightly lower compressive strengths when compared to the residual compressive strengths based on heating rates of 5.4 and $9.0^{\circ} \mathrm{F} / \mathrm{min}$. ( 3 and $7^{\circ} \mathrm{C} / \mathrm{min}$.). 
Additionally in Table 4.1, Mixtures 1 to 4 have residual compressive strengths of zero; this signifies that the concrete specimens from these particular mixtures experienced explosive spalling at temperatures lower than the maximum.

Further examination of the results, combined with visual inspection of the concrete specimens upon removal from the furnace, revealed the following:

1. Mixtures 1 to 4 specimens spalled in an explosive manner as shown in Figure 4.1. The explosive spalling was primarily due to the development of internal pressure from the phase change of water within the specimens. This internal pressure resulted in tensile stresses that exceeded concrete's tensile strength. Though these specimens failed, it was observed that at higher heating rates, the specimens were able to withstand slightly higher temperatures before explosion occurred. This ability to withstand higher temperatures may be attributed to faster propagation of micro cracks from the concrete's interfacial transition zone (ITZ) which permitted the dissipation of vapor pressure within the specimens (Bazant 1996, 1997). This assertion is also supported by the residual compressive strengths results, in that; at higher heating rates concrete specimens had lower compressive strengths. For example, specimens heated at 12.6 and $16.2^{\circ} \mathrm{F} / \mathrm{min}$. (7 and $9^{\circ} \mathrm{C} / \mathrm{min}$.) generally had residual compressive strengths 10 to $15 \%$ less than those of specimens heated at 5.4 and $9.0^{\circ} \mathrm{F} / \mathrm{min}$. ( 3 and $5^{\circ} \mathrm{C} / \mathrm{min}$.). The strength reduction indicates an increase in cracks that would have formed in the specimens heated at 12.6 and $16.2^{\circ} \mathrm{F} / \mathrm{min}$. ( $\left(7\right.$ and $9^{\circ} \mathrm{C} / \mathrm{min}$.) when compared to those heated at 5.4 and $9.0^{\circ} \mathrm{F} / \mathrm{min}$. (3 and $5^{\circ} \mathrm{C} / \mathrm{min}$.).

2. High strength concrete without polypropylene (PP) fibers cannot withstand temperatures beyond $932^{\circ} \mathrm{F}\left(500^{\circ} \mathrm{C}\right)$ irrespective of the heating rate. As explained in Chapter 2, the 
low permeability of the concrete specimens does not permit the rapid relief of vapor pressure. This restriction in vapor pressure build-up resulted in explosive spalling of the specimens.

3. Mixtures 5 to 7 specimens in which PP fibers were incorporated achieved temperatures of $1112^{\circ} \mathrm{F}\left(600^{\circ} \mathrm{C}\right)$ without spalling regardless of the heating rates. This demonstrates the effectiveness of using $3.4 \mathrm{lb} / \mathrm{yd}^{3}\left(2 \mathrm{~kg} / \mathrm{m}^{3}\right)$ of multifilament PP fibers as a spalling/explosion prevention measure. Synthetic fibers increase concrete porosity by melting and therefore facilitate the dissipation of vapor pressures.

4. The specimens that attained 932 to $1112^{\circ} \mathrm{F}\left(500\right.$ and $\left.600^{\circ} \mathrm{C}\right)$ at constant heating rates (Fig. 4.2) displayed significant micro cracking. However, for those specimens where the temperature was raised to $752^{\circ} \mathrm{F}\left(400^{\circ} \mathrm{C}\right)$, allowed to rest for 2 hours and subsequently increased at the same rate to $1112^{\circ} \mathrm{F}\left(600^{\circ} \mathrm{C}\right)$, little to no micro cracks were evident. Based on this observation, conditioning of the concrete specimens, that is, allowing the specimens to remain at a lower temperature for a prolonged period, enhanced their refractoriness.

5. During the residual compressive strength tests, specimens with higher levels of micro cracks experienced localized shear failures as shown in Figure 4.3A. The failures of specimens from Mixture 6, in which there was a temperature plateau at $752^{\circ} \mathrm{F}\left(400^{\circ} \mathrm{C}\right)$, exhibited the normal cone failure patterns shown in Figure 4.3B. This suggests that there were no localized weak areas on these specimens compared to those specimens in which the heating rates were constant up to $1112^{\circ} \mathrm{F}\left(600^{\circ} \mathrm{C}\right)$.

6. In terms of compressive strength retained after the heat test, Mixture 6 specimens performed the best. They had residual compressive strengths of approximately $50 \%$. 
Mixtures 5 and 7 specimens retained 20 and 33\% of their compressive strengths, respectively. A comparison of the constituent materials for Mixtures 5 and 6 showed that the main difference was the inclusion of coarse aggregates in Mixture 5 whereas there was none in Mixture 6. Nonetheless, the 28-day compressive strengths before the heat test were the same for both mixtures. The excessive loss in strength seen in Mixture 5 specimens is attributed to the presence of the coarse aggregates. Micro cracks present in the ITZ after curing easily propagated when exposed to elevated temperatures, this combined with the decomposition of the calcium silicate hydrates ( $\mathrm{CSH})$, reduced compressive strength. 
Table 4.1 Residual compressive strength results as a function of heating rates (John, 2010)

\begin{tabular}{|c|c|c|c|c|c|}
\hline Mixture & $\begin{array}{l}\text { Age of Concrete } \\
\text { at Testing } \\
\text { (days) }\end{array}$ & $\begin{array}{l}\text { Heating } \\
\text { Rate } \\
\left({ }^{\circ} \mathbf{F} / \mathbf{m i n} .\right)\end{array}$ & $\begin{array}{c}\text { Maximum } \\
\text { Temperature } \\
\left({ }^{\circ} \mathbf{F}\right)\end{array}$ & $\begin{array}{l}\text { Compressive } \\
\text { Strength before } \\
\text { testing (ksi) }\end{array}$ & $\begin{array}{c}\text { Residual } \\
\text { compressive } \\
\text { Strength } \\
(\mathbf{k s i}) \\
\end{array}$ \\
\hline \multirow{5}{*}{1} & 14 & 12.6 & 910 & 10.8 & \multirow{5}{*}{ (mos) } \\
\hline & 21 & 5.4 & 865 & NA & \\
\hline & 28 & 5.4 & 873 & 13.0 & \\
\hline & 56 & 9.0 & 910 & NA & \\
\hline & 56 & 12.6 & 921 & NA & \\
\hline \multirow{3}{*}{2} & $>8^{1}$ & 5.4 & 756 & \multirow{3}{*}{26.7} & \multirow{3}{*}{0} \\
\hline & $>8^{1}$ & 9.0 & 928 & & \\
\hline & $8^{1}$ & 12.6 & 910 & & \\
\hline \multirow{3}{*}{3} & 28 & 5.4 & 932 & \multirow{3}{*}{15.0} & \multirow{3}{*}{0} \\
\hline & 28 & 9.0 & 932 & & \\
\hline & 28 & 12.6 & 932 & & \\
\hline \multirow{3}{*}{4} & $12^{1}$ & 5.4 & 741 & \multirow{3}{*}{20.0} & \multirow{3}{*}{0} \\
\hline & $12^{1}$ & 9.0 & 797 & & \\
\hline & $12^{1}$ & 12.6 & 871 & & \\
\hline \multirow{3}{*}{5} & 28 & 5.4 & 932* & \multirow{3}{*}{15.0 (air cured) } & $\begin{array}{l}5.8 \\
\end{array}$ \\
\hline & 28 & 9.0 & $932 *$ & & 5.9 \\
\hline & 28 & 12.6 & $932 *$ & & 5.0 \\
\hline \multirow{4}{*}{5} & $>28$ & 5.4 & $1112^{*}$ & \multirow{4}{*}{$\begin{array}{l}19.0 \text { (moist } \\
\text { cured) }\end{array}$} & 4.5 \\
\hline & $>28$ & 9.0 & $1112^{*}$ & & 4.5 \\
\hline & $>28$ & 12.6 & $1112 *$ & & 3.6 \\
\hline & $>28$ & 16.2 & $1112^{*}$ & & 3.7 \\
\hline \multirow{4}{*}{6} & $>28^{2}$ & 5.4 & $1112^{*}$ & \multirow{4}{*}{$\begin{array}{l}19.4 \text { (moist } \\
\text { cured) }\end{array}$} & 10.5 \\
\hline & $>28^{2}$ & 9.0 & $1112^{*}$ & & 9.7 \\
\hline & $>28^{2}$ & 12.6 & $1112^{*}$ & & 9.8 \\
\hline & $>28^{2}$ & 16.2 & $1112^{*}$ & & 8.3 \\
\hline \multirow{4}{*}{6} & $>28^{2}$ & 5.4 & $1112^{*}$ & \multirow{4}{*}{18.0 (air cured) } & 11.0 \\
\hline & $>28^{2}$ & 9.0 & $1112^{*}$ & & 10.2 \\
\hline & $>28^{2}$ & 12.6 & $1112^{*}$ & & 9.4 \\
\hline & $>28^{2}$ & 16.2 & $1112^{*}$ & & 9.4 \\
\hline \multirow{4}{*}{7} & $>28^{2}$ & 5.4 & $1112^{*}$ & \multirow{4}{*}{$\begin{array}{l}11.5 \text { (moist } \\
\text { cured) }\end{array}$} & NA \\
\hline & $>28^{2}$ & 9.0 & $1112^{*}$ & & NA \\
\hline & $>28^{2}$ & 12.6 & $1112 *$ & & NA \\
\hline & $>28^{2}$ & 16.2 & $1112^{*}$ & & 3.8 \\
\hline
\end{tabular}

Two days of steam curing.

* Concrete specimens remained intact after exposure to temperatures greater than $932^{\circ} \mathrm{F}\left(500^{\circ} \mathrm{C}\right)$.

${ }^{2}$ The temperature was raised to $400^{\circ} \mathrm{C}$, remained for two hours, then raised to the maximum level at same heating rate

$1 \mathrm{ksi}=6.9 \mathrm{MPa}$, Fahrenheit $(\mathrm{F})$ to ${ }^{\circ} \mathrm{C}=\left({ }^{\circ} \mathrm{F}-32\right) / 1.8$ 


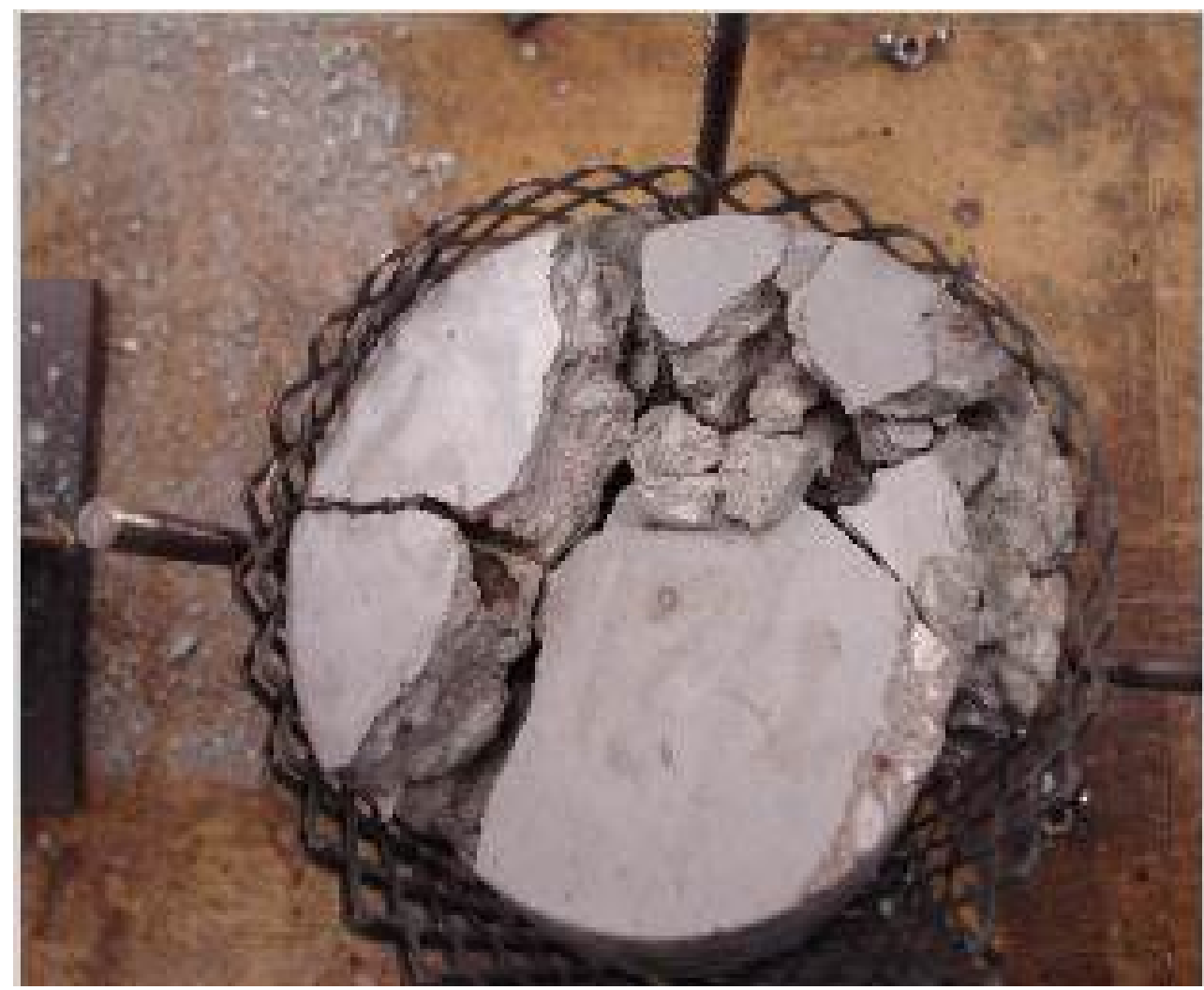

Fig. 4.1. Explosive spalling of concrete specimens (John et al., 2010).

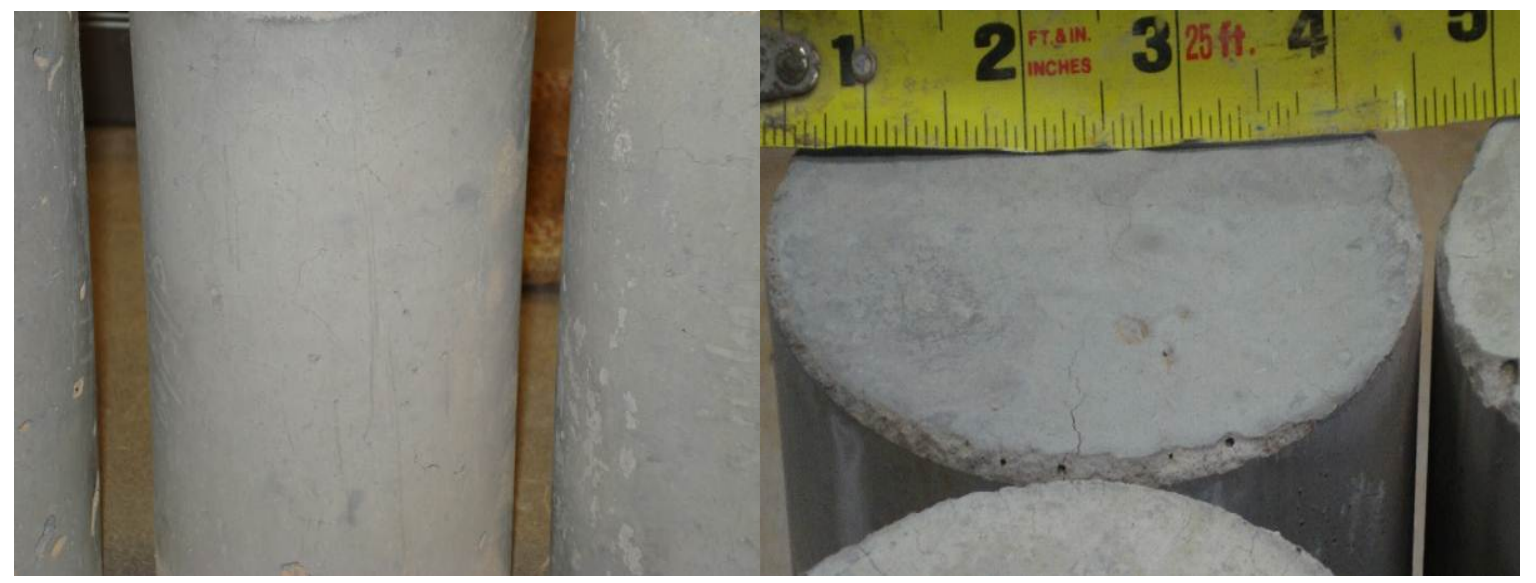

Fig. 4.2. Micro cracks on the surface of concrete specimens (John et al., 2010). 


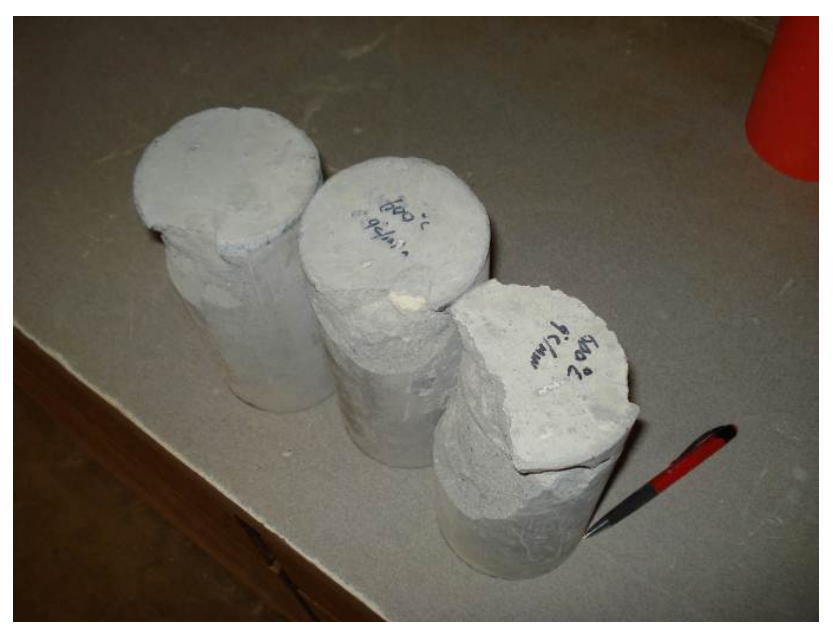

Fig. 4.3A. Localized shear failure of the cracked outer surfaces during compressive testing (John et al., 2010).

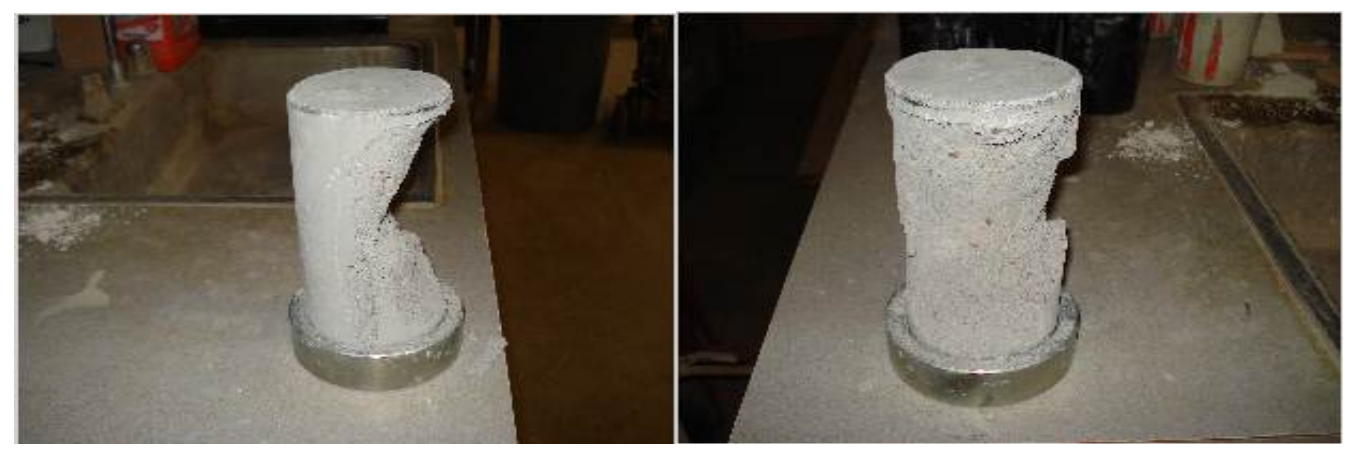

Fig. 4.3B. Cone failure of Mixture 6 in compression after heat testing (John et al., 2010).

\subsubsection{Effects of PP Fibers on the Residual Compressive Strength of Concrete}

Experiments were performed to assess the effects of 3.4, 6.7 and $10 \mathrm{lb} / \mathrm{yd}^{3}\left(2,4\right.$ and $\left.6 \mathrm{~kg} / \mathrm{m}^{3}\right)$ of PP fibers on the residual compressive strength of specimens from three concrete mixtures. The specimens were subjected to temperatures similar to the ASTM E119 heating curve for a typical building fire, shown in Figure 3.5. This heating rate was chosen to subject the concrete to rigorous conditions. The results are summarized below in Table 4.2. 
Table 4.2 Residual compressive strength of concrete with different dosages of PP fibers

\begin{tabular}{|c|c|c|c|c|c|c|c|c|c|c|c|c|}
\hline Mixtures & \multicolumn{4}{|c|}{ Mix 1} & \multicolumn{4}{|c|}{ Mix 2} & \multicolumn{4}{|c|}{ Mix 3} \\
\hline $\begin{array}{l}\text { PP fiber dosage } \\
\left(1 \mathrm{lb} / \mathrm{yd}^{3}\right)\end{array}$ & 0 & 3.4 & 6.7 & 10 & 0 & 3.4 & 6.7 & 10 & 0 & 3.4 & 6.7 & 10 \\
\hline $\mathrm{f}_{\mathrm{c} 56 \text {-day }}(\mathrm{ksi})$ & 12.5 & 11.6 & 13.6 & 13.8 & 14.2 & 13.5 & 15.1 & 11.4 & 15.9 & 15.2 & 15.9 & 15.1 \\
\hline $\mathrm{f}_{\mathrm{c} \text { residual }}(\mathrm{ksi})$ & - & 0.73 & 0.87 & 1.0 & - & 0.87 & 0.87 & 0.87 & & 2.2 & 1.7 & 1.7 \\
\hline
\end{tabular}

Specimens exploded, $1 \mathrm{~kg} / \mathrm{m}^{3}=1.683 \mathrm{lb} / \mathrm{yd}^{3}, 1 \mathrm{ksi}=6.9 \mathrm{MPa}$

The results presented in Table 4.2 verify the fact that high strength concrete (HSC) is prone to explosive spalling if no measure is taken to reduce internal pressure build-up. All three HSC mixtures used in this experiment exploded violently at furnace temperatures of approximately $1112^{\circ} \mathrm{F}\left(600^{\circ} \mathrm{C}\right)$. This temperature represented only 40 minutes of heat exposure.

Table 4.2 shows the residual strengths of Mixtures 1 and 2 to be approximately the same irrespective of the PP fiber dosage. There was little difference between the residual compressive strength for Mixture 3 specimens regardless of fiber dosage. After prolonged exposure to temperatures over $1112^{\circ} \mathrm{F}\left(600^{\circ} \mathrm{C}\right)$, at heating rates shown by the heating curve in Figure 3.5, the residual compressive strengths were between 7 to $12 \%$ of the ambient temperature compressive strengths. The results indicate that increases in PP fiber dosage do not increase residual compressive strength.

\subsection{Phase II: Performance of Concrete Developed for TES Option A}

In Phase II, the performance of concrete mixtures for deployment in TES Option A was assessed. Temperature distribution within specimens was determined. Specimens were thermally cycled following which their mechanical and thermal properties were measured. Specimens were also heated using a TES prototype, the procedure was described in Section 3.3.2.2. Finally, the performance of the mixtures is discussed in relation to their unit costs. 


\subsubsection{Temperature Gradient within Test Specimens}

The temperature gradient in $4 \times 8$ in. (100 x $200 \mathrm{~mm})$ cylindrical specimens was analyzed. A thermocouple was inserted in the center of the specimen, and the cylinders were heated from ambient to $932^{\circ} \mathrm{F}\left(500^{\circ} \mathrm{C}\right)$ at $16.2^{\circ} \mathrm{F} / \mathrm{min} .\left(9^{\circ} \mathrm{C} / \mathrm{min}\right.$. $)$. The heating rate of the oven and the temperature profile of the cylinders are shown in Figure 4.4. This analysis could provide vital information in terms of the storage medium charging time and safe spacing between heat exchangers. Figure 2.1 of Chapter 2 showed the arrangement of the embedded heat exchangers in the concrete modules. It is important to optimize the distance between individual heat exchangers in order to minimize the temperature gradients within the concrete.

Figure 4.4 shows that the core temperature, as expected, lagged behind the furnace temperature. The specimens attained a steady state temperature of $932^{\circ} \mathrm{F}\left(500^{\circ} \mathrm{C}\right)$ after approximately 2 hours of exposure. The figure showed that there was a temperature difference of approximately $392^{\circ} \mathrm{F}\left(200^{\circ} \mathrm{C}\right)$ between the specimen core and the outer surface after 40 minutes of heating. This temperature difference was distributed over 2 in. of concrete in the radial direction. The high temperature difference between the concrete core and the surface increased thermal strains which results in high thermal stresses within the specimens. The specimens' ability to withstand the stresses under this testing regimen is a measure of their refractoriness. This test regimen would be considered severe when compared with a TES Option A set-up. The change in temperature $(\Delta T)$ in a TES system is less than those used in the test, and therefore, one should expect the concrete to be more resistant. 


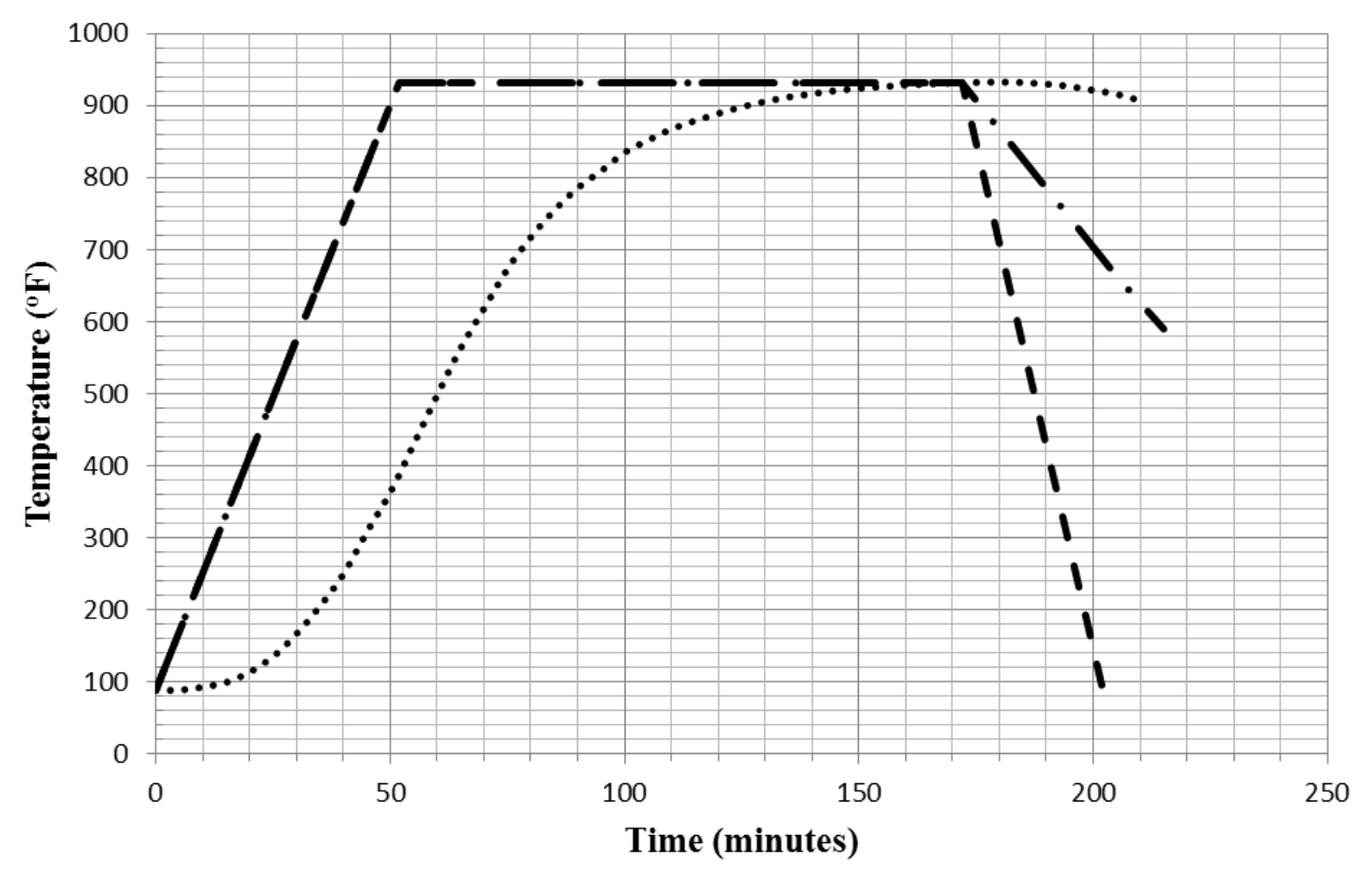

..... Temperature at core of specimens - - Furnace programmed temperature

— Actual furnace temperature

Fig. 4.4. Temperature at the core of the concrete specimens during heat-up.

\subsubsection{Effects of Thermal Cycling on Concrete}

\subsubsection{Effects of Thermal Cycling on Residual Compressive Strength}

Seven concrete mixtures, discussed in Chapter 3, Section 3.3.1, were cycled ten times from ambient to $932^{\circ} \mathrm{F}\left(500^{\circ} \mathrm{C}\right)$. Compressive strength was measured after each cycle; the results are shown in Figure 4.5. The graph shows that there was an immediate decrease in compressive strength after the first cycle, but there was little change after the third cycle. This is an indication that mechanical stability was attained after the first three thermal cycles. Further thermal cycling showed that the concrete specimens maintained their reduced strengths and no indication of further degradation based on visual inspection or strength testing was evident. 
Figure 4.6 shows a number of specimens after ten thermal cycles. The calcium aluminate cement (CAC) mixtures, which were identified as Mixtures $1 \& 2$ in Table 3.3 of Chapter 3 , retained $75 \%$ of their original compressive strength. These mixtures were the most resistant; they not only possess high residual compressive strengths but also there were no visible signs of cracking on the specimens, as shown in Figure 4.6. Compared to OPC concrete, CAC concrete does not produce calcium hydroxide during hydration. In mixtures containing OPC, at high temperatures calcium hydroxide decomposes and forms $\mathrm{CaO}$ (free lime). Free lime causes concrete to become unstable due to the hydration of $\mathrm{CaO}$ at ambient temperatures due to humid air. The hydration of $\mathrm{CaO}$ is an expansive reaction which explains the better performance of the CAC mixtures when compared to OPC mixtures. (Petzold and Rohrs, 1970, Mehta and Monteiro, 2006).

Specimens from Mixtures 4, 5, 6 and 7 retained 50 to $55 \%$ of their original compressive strength, while specimens from Mixture 3 retained 40\%. The properties of the seven mixtures are summarized in Tables 4.3A and 4.3B. Though the CAC mixtures (Mixtures 1 and 2) were the most resistant to the high temperature thermal cycles, their cost was twice that of the other mixtures cast with ordinary portland cement. Consequently, using Mixtures 1 or 2 as a TES medium can only be justified if their thermal properties are significantly better when compared to those of the other five mixtures. 


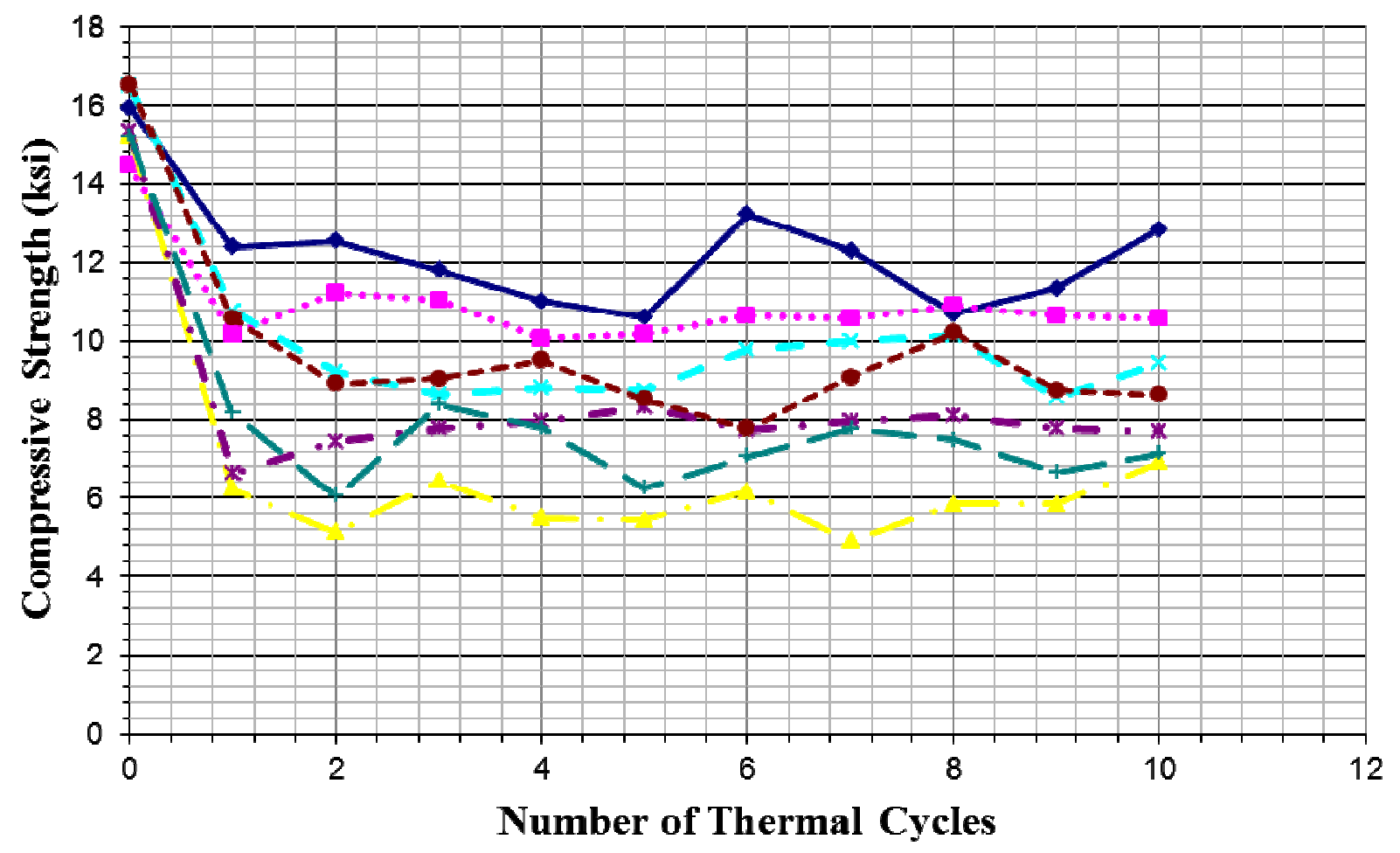

+ Series $1 \ldots+$ Series $2-$ Series $3-x-$ Series $4-* \cdot$ Series $5-\rightarrow-$ Series $6-$ Series 7

Fig. 4.5. Effects of thermal cycling on compressive strength (John, 2011).

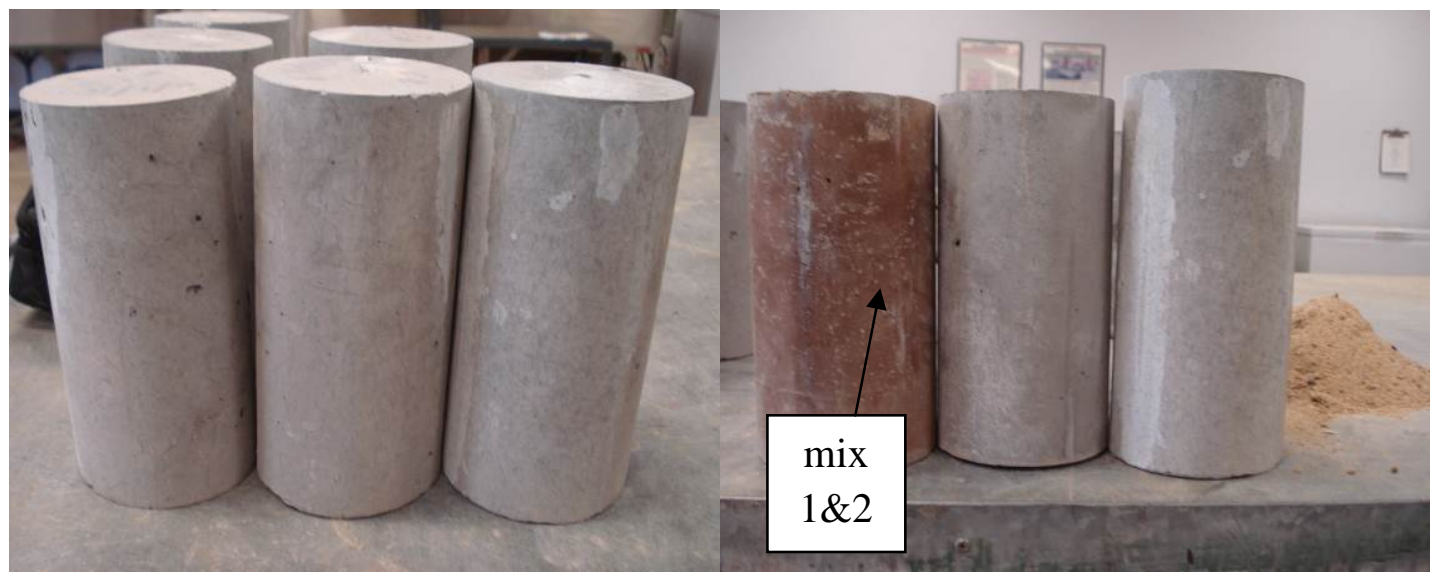

Fig. 4.6. Concrete specimens after 10 thermal cycles (John, 2011). 


\subsubsection{Effects of Thermal Cycling on the Unit Weight}

The unit weight of all seven mixtures before thermal cycling was approximately $150 \mathrm{lb} / \mathrm{ft}^{3}$. After thermal cycling, there was a 9\% unit weight reduction in all cases. The unit weight is an important parameter needed to accurately determine the amount of energy stored for a given volume of concrete under operating conditions. Additionally, to numerically model the thermodynamics of the storage system; accurate thermo-mechanical properties are necessary. The two thermal properties that are of great importance are the thermal conductivity $(K)$ and the specific heat $\left(\mathrm{C}_{\mathrm{p}}\right)$. High values of specific heat increase the system's storage capacity and in addition, less thermal insulation is required. High thermal conductivity ensures the storage system can be charged and discharged with efficiency and in addition, the number of required heat exchangers is less and therefore cost is reduced.

\subsubsection{Thermal Conductivity $(K)$ before and after Thermal Cycling}

The thermal conductivity $(K)$ of the calcium aluminate cement (CAC) mixtures (Mixture 1 and 2) shown in Table 4.3A, is higher when compared to the other five mixtures (Tables 4.3A and 4.3B). Generally, the $K$ values of concrete are dependent on the cement content and the amount and type of aggregates, with the latter having a favorable effect. The addition of fly ash (FA) and silica fume (SF) generally reduces concrete's thermal conductivity. Given that all seven mixtures contained the same amount of total cementitious materials and the absence of mineral admixture (FA and SF) in the CAC mixtures, the relatively high $K$ values observed in these mixtures (Mixtures 1 and 2) can be attributed to the coarse aggregate content. A look at the composition of Mixtures 1 and 2, given in Section 3.3.1 of Chapter 3, showed that their aggregate content was indeed the highest of the seven mixtures. These mixtures contained 14 to $20 \%$ more aggregates compared to the other five mixtures. On average, the $K$ of the two CAC 
mixtures ( 1 and 2) was $33 \%$ higher than that of Mixtures 3, 4, 5, 6 and 7. When comparing the $K$ of Mixtures 1 and 2, Mixture 2 was $12 \%$ higher than that of Mixture 1. The difference was the aggregate type. Mixture 2 contained granite aggregates which has a higher thermal conductivity, $0.98-2.3 \mathrm{Btu} / \mathrm{ft} . \mathrm{h} .{ }^{\circ} \mathrm{F}(1.7-4.0 \mathrm{~W} / \mathrm{mK})$ compared to that of the river sand, $0.14-1.16$

Btu/ft.h. ${ }^{\circ} \mathrm{F}(0.25-2.0 \mathrm{~W} / \mathrm{mK})$ used in Mixture 1. This difference accounted for the increase in the thermal conductivity of Mixture 2 .

The thermal conductivity $(K)$ of the seven mixtures was estimated after thermal cycling using Equation 4, Section 3.3.3, and was also measured for Mixtures 1, 4, and 6. There was a general decrease in the measured $K$ values after heating. The reduction in $K$ was due to the elimination of free and adsorbed water from the specimens and also to changes in both the chemical and physical properties of the mixture's constituent materials after testing. The chemical and physical properties include the dehydration of calcium hydroxide, changes in aggregate composition and the development of fissures. Thermal conductivity derived from Equation 4 was less than $20 \%$ of the measured $K$ values of Mixtures 1, 4 and 6 . For Mixtures 1 and 6, the difference between measured and predicted $K$ values was less than $10 \%$, while in the case of Mixture 4; the difference was approximately 20\%. Further discussion regarding the correlation between predicted and measured $K$ is provided in Section 4.6.

\subsubsection{Specific Heat $(C p)$ before and after Thermal Cycling}

In relation to the specific heat $\left(\mathrm{C}_{\mathrm{p}}\right)$, there was no general trend in the measured values at ambient temperature before thermal cycling. The $\mathrm{C}_{\mathrm{p}}$ ranged from 0.172 to $0.220 \mathrm{Btu} / \mathrm{lbm}^{\circ} \mathrm{F}$ ( 0.720 to $0.920 \mathrm{~J} / \mathrm{gK})$. The measured $\mathrm{C}_{\mathrm{p}}$ values were comparable to those found in the literature for different concrete types, which ranged from 0.19 to $0.26 \mathrm{Btu} / \mathrm{lbm}^{\circ} \mathrm{F}(0.800$ to $1.100 \mathrm{~J} / \mathrm{gK})$. 
For Mixtures 4 and 6, the $\mathrm{C}_{\mathrm{p}}$ measured after thermal cycling decreased in the case of Mixture 4 and increased for Mixture 6 . The $\mathrm{C}_{\mathrm{p}}$ of Mixture 6 decreased by $9 \%$, whereas in the case of Mixture 4 , the $C_{p}$ increased by $5 \%$. These values may be considered statistically insignificant and can be attributed to the testing procedure. However, the specific heat of siliceous aggregate concrete theoretically should decrease after elevated temperature exposure as shown by Kodur and Sultan (2003); therefore the increase observed in Mixture 4 was an anomaly. The effects on the specific heat of concrete containing siliceous and carbonate aggregates were discussed in Section 2.6.2. Further discussion on the values of measured specific heat before and after thermal cycling is presented in Section 4.7.

\subsubsection{Cost Effectiveness of Concrete}

The seven mixtures performed satisfactorily based on compressive strength, thermal conductivity, specific heat, and mass loss, after 10 thermal cycles from ambient temperature to $932^{\circ} \mathrm{F}\left(500^{\circ} \mathrm{C}\right)$. The reduction in the thermal and mechanical properties was such that the concretes can be used as a TES (Option A) medium. The residual thermal conductivity and specific heat, two of the parameters that govern the efficiency of a TES system were comparable to those of the concrete used in the pilot project (Laing et al., 2003). In fact, the residual thermal conductivity of the best performing mixtures was approximately $1.16 \mathrm{Btu} / \mathrm{ft} . \mathrm{h} .{ }^{\circ} \mathrm{F}(2 \mathrm{~W} / \mathrm{mK})$ compared to $0.578 \mathrm{Btu} / \mathrm{ft} . \mathrm{h} .{ }^{\circ} \mathrm{F}(1 \mathrm{~W} / \mathrm{mK})$ for the concrete used in the pilot project. However, the high concrete unit prices may result in a TES system which is not feasible. There were two main contributors to the high unit cost (Tables 4.3A and 4.3B). In the case of Mixtures 1 and 2, the contributing factors are the price of $\mathrm{CAC}$ and steel fibers. The $\mathrm{CAC}$ and steel fiber prices were $\$ 0.29 / \mathrm{lb}(\$ 0.58 / \mathrm{kg})$ and $\$ 2.77 / \mathrm{lb}(\$ 6.10 / \mathrm{kg})$ respectively. These prices were obtained from industry providers of the respective materials. The CAC price was approximately six times that 
of OPC, but it was considerably more resistant to elevated temperatures, thus the reason for its use in this work.

In the case of Mixtures 3 to 7, the factor which had the greatest influence on the unit prices was the steel fibers. In all five cases, steel fibers contributed an additional $\$ 277.00 / \mathrm{yd}^{3}$ to the overall cost. Based on this price analysis, the cost of Mixtures 3 to 7 (Tables 4.3A and 4.3B) would be less than $\$ 150.00 / \mathrm{yd}^{3}$ if the steel fibers were removed. In order to assess the effectiveness of the steel fibers' contribution to $K$, Mixture 4 was mixed with $200 \mathrm{lb} / \mathrm{yd}^{3}$ of steel fibers, which represented twice the amount used in the seven mixtures of Tables 4.3A and 4.3B. The resulting thermal conductivity was $1.34 \mathrm{Btu} / \mathrm{ft} . \mathrm{h} .{ }^{\mathrm{o}} \mathrm{F}(2.31 \mathrm{~W} / \mathrm{mK})$. Mixture 6 was then mixed without steel fibers and tested. The thermal conductivity decreased to $1.05 \mathrm{Btu} / \mathrm{ft} . \mathrm{h} .{ }^{\circ} \mathrm{F}$ $(1.81 \mathrm{~W} / \mathrm{mK})$. This showed that $K$ increased by $16 \%$ when steel fiber dosage was doubled and decreased by $18 \%$ when steel fibers were omitted. If the performance of a TES system is enhanced by an $18 \%$ increase in concrete's thermal conductivity, then the additional cost incurred would be justified. However, Tamme et al. (2003) showed that increases in $K$ greater than $50 \%$ are required to significantly alter the performance of a TES system. Additionally, because of the large amount of concrete needed in these systems, the added TES system cost will outweigh the benefits of small increases in thermal conductivity. Laing et al. (2009) reported that for a 50 megawatt (MW) electric parabolic trough CSP system, corresponding to a total storage capacity of $1100 \mathrm{MWh}_{\text {thermal }}, 65445 \mathrm{yd}^{3}\left(50,000 \mathrm{~m}^{3}\right)$ of concrete is required. These figures were based on maximum operating temperatures of $752^{\circ} \mathrm{F}\left(400^{\circ} \mathrm{C}\right)$ and a $\Delta \mathrm{T}$ of $104^{\circ} \mathrm{F}$ $\left(40^{\circ} \mathrm{C}\right)$. Nevertheless, in order to enhance the post cracking behavior of the concretes, steel fibers should be added to the mixtures but at a dosage rate of less than the initial $100 \mathrm{lb} / \mathrm{yd}^{3}$. One should bear in mind that repeated thermal cycling of any of these concretes in the long-term will 
inevitably lead to the formation of cracks. Thereafter, crack density and size will also increase if the concrete is not reinforced.

For the concretes examined, with an average density of $150 \mathrm{lb} / \mathrm{ft}^{3}$ and $\Delta \mathrm{T}$ of $292^{\circ} \mathrm{F}\left(150^{\circ} \mathrm{C}\right)$, it would require approximately $20000 \mathrm{yd}^{3}\left(15300 \mathrm{~m}^{3}\right)$ of concrete for the same storage capacity. However, the reduction in storage costs derived from the use of less concrete would be offset to some degree by the inclusion of steel fibers.

The complete replacement of OPC for CAC, which was done in Mixtures 1 and 2, may not be justified based on cost and limited differences in $K$ and Cp. Tables 4.3A and 4.3B shows Mixtures 1 and 2 have $K$ values which are on average 33\% higher than the other five mixtures. However, the residual compressive strength and the specific heat of Mixtures 1 and 2 are similar to those of Mixtures 4 and 6. Additionally, the unit costs of Mixtures 1 and 2 are more than twice those of the other five mixtures. Mixture 4 or 6, which are less than half the cost of Mixtures 1 and 2 and which possess similar thermo-mechanical properties would provide satisfactory performance.

Two approaches to reduce the cost of the CAC mixtures include combining CAC with fly ash (FA), which is less expensive than CAC or OPC, and reducing the amount of cementitious materials. Likewise, the cost of OPC mixtures can be decreased by reducing the total amount of cementitious materials and increasing the FA content. These approaches will be discussed in Section 4.3.1. 
Table 4.3A Properties of the concrete mixtures (mixtures 1 to 4)

\begin{tabular}{|c|c|c|c|c|c|c|c|c|}
\hline \multirow{3}{*}{$\begin{array}{l}\text { Concrete } \\
\text { properties }\end{array}$} & \multicolumn{8}{|c|}{ Mixtures } \\
\hline & \multicolumn{2}{|c|}{1} & \multicolumn{2}{|c|}{2} & \multicolumn{2}{|c|}{3} & \multicolumn{2}{|c|}{4} \\
\hline & before & after & before & after & before & after & before & after \\
\hline $\begin{array}{l}\text { Unit weight } \\
\left(l b / f t^{3}\right)\end{array}$ & 152 & 137 & 152 & 137 & 150 & 135 & 150 & 135 \\
\hline $\begin{array}{l}\text { Measured } \\
\text { Specific heat, } \mathrm{C}_{\mathrm{p}} \\
\left(B t u / l b m^{\circ} F\right)\end{array}$ & 0.172 & - & 0.198 & - & 0.203 & - & 0.196 & 0.179 \\
\hline $\begin{array}{l}\text { Calculated } \\
\text { specific heat, } \mathrm{C}_{\mathrm{p}} \\
\left(\text { Btu/lbm }^{\circ} F\right)\end{array}$ & $\begin{array}{l}0.198^{\mathrm{a}} \\
0.234^{\mathrm{b}}\end{array}$ & - & $\begin{array}{l}0.205^{\mathrm{a}} \\
0.240^{\mathrm{b}}\end{array}$ & - & $\begin{array}{l}0.206^{\mathrm{a}} \\
0.244^{\mathrm{b}}\end{array}$ & - & $\begin{array}{l}0.199^{\mathrm{a}} \\
0.237^{\mathrm{b}}\end{array}$ & - \\
\hline $\begin{array}{l}\text { Thermal } \\
\text { conductivity, } K \\
\left(\text { Btu/ft.h. }{ }^{o} F\right)\end{array}$ & 1.45 & $\begin{array}{l}1.13^{2} \\
1.23^{1}\end{array}$ & 1.62 & $1.30^{2}$ & 1.10 & $0.78^{2}$ & 1.16 & $\begin{array}{l}0.84^{2} \\
1.04^{1}\end{array}$ \\
\hline $\begin{array}{l}\text { Appearance of } \\
\text { cracks }\end{array}$ & \multicolumn{2}{|c|}{ none } & \multicolumn{2}{|c|}{ none } & \multicolumn{2}{|c|}{$\begin{array}{l}\text { few micro } \\
\text { cracks }\end{array}$} & \multicolumn{2}{|c|}{$\begin{array}{l}\text { few micro } \\
\text { cracks }\end{array}$} \\
\hline Costs $\left(\$ / y d^{3}\right)$ & \multicolumn{2}{|c|}{895.00} & \multicolumn{2}{|c|}{895.00} & \multicolumn{2}{|c|}{397.00} & \multicolumn{2}{|c|}{397.00} \\
\hline
\end{tabular}

${ }^{1}$ after 10 thermal cycles between ambient temperature and $932^{\circ} \mathrm{F}\left(500^{\circ} \mathrm{C}\right)$, Fahrenheit $(\mathrm{F})$ to ${ }^{\circ} \mathrm{C}=$ $\left({ }^{\circ} \mathrm{F}-32\right) / 1.8,1 \mathrm{Btu} / \mathrm{lbm}^{\circ} \mathrm{F}=4.1868 \mathrm{~J} / \mathrm{gK}, 1 \mathrm{Btu} / \mathrm{ft} . \mathrm{h} .{ }^{\circ} \mathrm{F}=1.73 \mathrm{~W} / \mathrm{mK}, 1 \mathrm{lb} / \mathrm{ft}^{3}=16.02 \mathrm{~kg} / \mathrm{m}^{3}$ ${ }^{2}$ estimate of thermal conductivity based on Equation 3, Section 3.3.3.

${ }^{a}$ Calculated specific heat based on Equation 10 in Section 3.3.4 of Chapter 2 with $\mathrm{C}_{\mathrm{p}}$ of water $=$ $0.5255 \mathrm{Btu} / \mathrm{lbm}^{\circ} \mathrm{F}$

${ }^{\mathrm{b}}$ Calculated specific heat based on Equation 10 in Section 3.3.4 of Chapter 2 with $\mathrm{C}_{\mathrm{p}}$ of water $=$ $0.9984 \mathrm{Btu} / \mathrm{lbm}^{\circ} \mathrm{F}$ 
Table 4.3B Properties of the concrete mixtures (mixtures 5 to 7)

\begin{tabular}{|c|c|c|c|c|c|c|}
\hline \multirow{3}{*}{$\begin{array}{l}\text { Concrete } \\
\text { properties }\end{array}$} & \multicolumn{6}{|c|}{ Mixtures } \\
\hline & \multicolumn{2}{|c|}{5} & \multicolumn{2}{|c|}{6} & \multicolumn{2}{|c|}{7} \\
\hline & before & after & before & after & before & after \\
\hline Unit weight $\left(l b / f t^{3}\right)$ & 150 & 135 & 150 & 135 & 150 & 135 \\
\hline $\begin{array}{l}\text { Measured Specific } \\
\text { heat, } \mathrm{C}_{\mathrm{p}}\left(B t u / l b m^{o} F\right)\end{array}$ & 0.220 & - & 0.177 & $0.186^{*}$ & 0.196 & - \\
\hline $\begin{array}{l}\text { Calculated specific } \\
\text { heat, } C_{\mathrm{p}}\left(B_{t u} / l^{b} m^{o} F\right)\end{array}$ & $\begin{array}{l}0.207^{\mathrm{a}} \\
0.246^{\mathrm{b}}\end{array}$ & - & $\begin{array}{l}0.200^{\mathrm{a}} \\
0.239^{\mathrm{b}}\end{array}$ & - & $\begin{array}{l}0.207^{\mathrm{a}} \\
0.246^{\mathrm{b}}\end{array}$ & - \\
\hline $\begin{array}{l}\text { Thermal } \\
\text { conductivity, } K \\
\left(\text { Btu/ft.h. }{ }^{o} F\right)\end{array}$ & 0.983 & $0.665^{2}$ & 1.27 & $\begin{array}{l}0.954^{2} \\
0.890^{3}\end{array}$ & 1.21 & 0.896 \\
\hline $\begin{array}{l}\text { Appearance of } \\
\text { cracks }\end{array}$ & \multicolumn{2}{|c|}{$\begin{array}{l}\text { high level of micro } \\
\text { cracks }\end{array}$} & \multicolumn{2}{|c|}{$\begin{array}{l}\text { few micro } \\
\text { cracks }\end{array}$} & \multicolumn{2}{|c|}{$\begin{array}{l}\text { high level of micro } \\
\text { cracks }\end{array}$} \\
\hline Costs $\left(\$ / y d^{3}\right)$ & \multicolumn{2}{|c|}{415.00} & \multicolumn{2}{|c|}{415.00} & \multicolumn{2}{|c|}{415.00} \\
\hline
\end{tabular}

${ }^{2}$ estimate of thermal conductivity based on Equation 4, Section 3.3.3.

${ }^{3}$ after 30 thermal cycles between ambient temperature and $932^{\circ} \mathrm{F}\left(500^{\circ} \mathrm{C}\right)$, Fahrenheit $(\mathrm{F})$ to ${ }^{\circ} \mathrm{C}=$ $\left({ }^{\circ} \mathrm{F}-32\right) / 1.8,1 \mathrm{Btu} / \mathrm{lbm}^{\circ} \mathrm{F}=4.1868 \mathrm{~J} / \mathrm{gK}, 1 \mathrm{Btu} / \mathrm{ft} . \mathrm{h} .{ }^{\circ} \mathrm{F}=1.73 \mathrm{~W} / \mathrm{mK}, 1 \mathrm{lb} / \mathrm{ft}^{3}=16.02 \mathrm{~kg} / \mathrm{m}^{3}$

${ }^{a}$ Calculated specific heat based on Equation 10 in Section 3.3.4 of Chapter 2 with $\mathrm{C}_{\mathrm{p}}$ of water $=$ $0.5255 \mathrm{Btu} / \mathrm{lbm}^{\circ} \mathrm{F}$

${ }^{\mathrm{b}}$ Calculated specific heat based on Equation 10 in Section 3.3.4 of Chapter 2 with $\mathrm{C}_{\mathrm{p}}$ of water $=$ $0.9984 \mathrm{Btu} / \mathrm{lbm}^{\circ} \mathrm{F}$

\subsubsection{Assessment of Concrete Performance with Molten Salt as the Heat Transfer Fluid (HTF)}

Prismatic concrete specimens measuring 4 in. by 4 in. by $4 \mathrm{ft}$ were cast from the seven mixtures presented in Chapter 3. The specimens, in which a heat exchanger was embedded, were heated by circulating molten salt through the heat exchanger at approximately $932^{\circ} \mathrm{F}$ $\left(500^{\circ} \mathrm{C}\right)$. Visual inspection of the specimens during the heating process showed that within 5 minutes of heating, longitudinal and transverse cracks developed (Fig. 4.7). Molten salt remains liquid at temperatures above $428^{\circ} \mathrm{F}\left(220^{\circ} \mathrm{C}\right)$; therefore, upon the initiation of flow, the temperature within the heat exchangers was approximately $572^{\circ} \mathrm{F}\left(300^{\circ} \mathrm{C}\right)$. The elevated temperature resulted in an immediate expansion of the heat exchangers which in turn produced excessive tensile stresses in the concrete causing the cracks to develop. The coefficient of thermal expansion (CTE) of these concrete mixtures and that of stainless steel is approximately 
$5.6-6.7 \times 10^{-6} /{ }^{\circ} \mathrm{F}$ and $9.4-10 \times 10^{-6} /{ }^{\circ} \mathrm{F}\left((10.00-12.00) \times 10^{-6} /{ }^{\circ} \mathrm{C}\right.$ and $(17.00-18.00) \times 10^{-}$ ${ }^{6} /{ }^{\circ} \mathrm{C}$ ), respectively. These values show that there is a difference between the CTE of the two materials. However, if the heat exchanger and the concrete were preheated prior to the circulation of the HTF, the extent of cracking may be reduced. It is natural to expect cracks to develop on the surfaces of these concrete specimens, however, the size of the cracks that developed during the test, shown in Figure 4.7, were considered excessive. Excessive crack widths reduce heat transfer between the heat exchangers and the concrete and through the concrete itself. Reduction in heat transfer signifies longer charging times for the TES system.

As mentioned in Section 4.2.2, steel fibers were incorporated to enhance the specimen's post cracking behavior and thus prevent complete disintegration of the specimens from repeated thermal cycles. Methods to reduce the level of cracking of the prismatic concrete specimens were developed and assessed. This approach is discussed in the following section. 


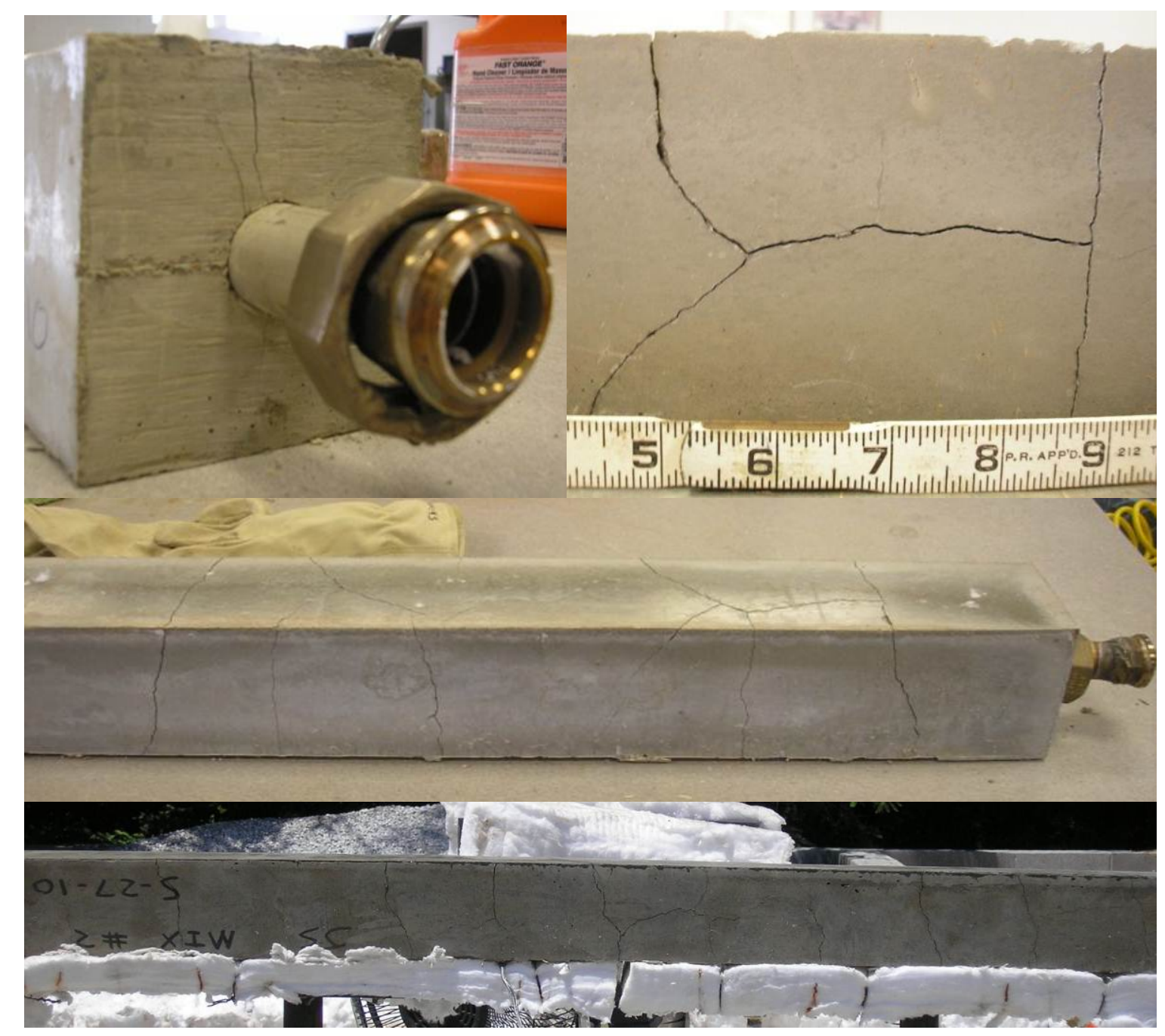

Fig. 4.7. Crack formations on the surface of the prismatic test blocks (Skinner et al., 2011, John et al., 2011).

\subsubsection{Finite Element Analysis}

Skinner et al. (2011) performed finite element (FE) analysis to determine the stresses that developed at the heat exchanger and concrete interface (Fig. 4.8). The FE model simulated two different conditions. In one case (Model I), the model considered a material of low modulus of elasticity (MOE) with a relatively high thermal conductivity placed between the heat exchangerconcrete interface. In the other case (Model II), there was no interface material. The full details 
of the FE Model are provided in Skinner (2011). The results are presented here for clarity and thoroughness of the discussion as it relates to the performance of the various concrete mixtures.

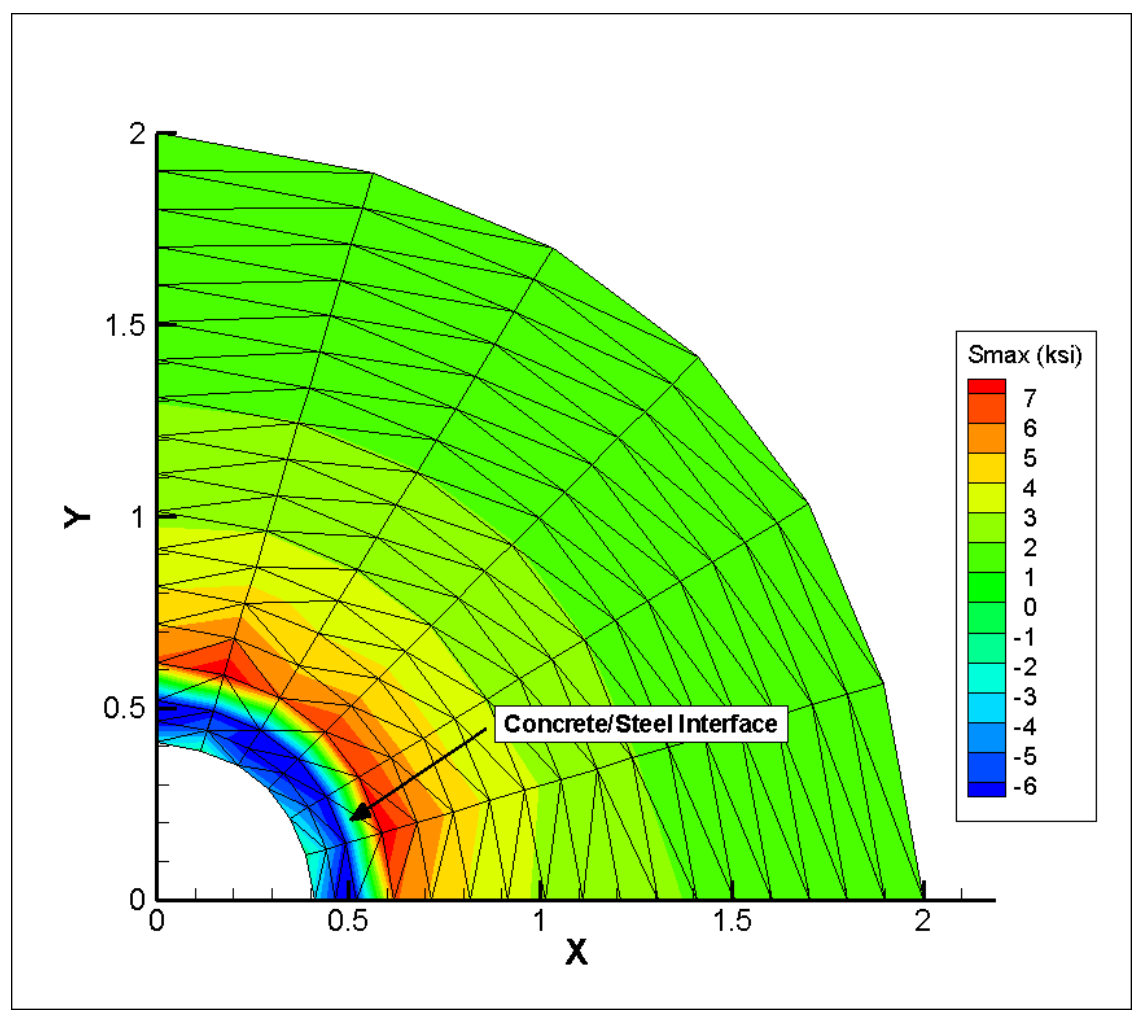

Fig. 4.8. Axisymmetrical $\mathrm{FE}$ analysis of the stainless steel-concrete interface (Axes $\mathrm{X}$ and $Y$ represent stresses in ksi, Skinner et al., 2011).

For Model II, no interface material was used and the model considered both concrete and heat exchanger to have temperatures of 572,752 and $932^{\circ} \mathrm{F}\left(300,400\right.$ and $\left.500^{\circ} \mathrm{C}\right)$. For this model, the principal tensile stresses developed at the heat exchanger-concrete interface were 11 , 14 and $18 \mathrm{ksi}(76,96$ and $124 \mathrm{MPa})$ based on the three temperature levels respectively. For the same model (Model II), the temperature of the heat exchangers was $572^{\circ} \mathrm{F}\left(300^{\circ} \mathrm{C}\right)$ and the concrete temperature was at ambient level. This condition resulted in a principal tensile stress of $24 \mathrm{ksi}(165 \mathrm{MPa})$. The computed principal stresses were more than 20 times the tensile strength 
of these concretes. The tensile strength of concrete is approximately $10 \%$ of the compressive strength (Mehta and Montiero, 2006). This analysis explains the level of cracking shown in Figure 4.7. When considering an interface material (Model I) with a modulus of elasticity of 2 ksi (14 MPa) and for concrete and heat exchanger temperatures of 572, 752 and $932^{\circ} \mathrm{F}(300,400$ and $\left.500^{\circ} \mathrm{C}\right)$, the principal stresses decreased to $0.80,1.00$ and $2.10 \mathrm{ksi}(5.5,7.0$ and $14.5 \mathrm{MPa})$ respectively. If the interface material had a modulus of elasticity that was $0.5 \mathrm{ksi}(3.5 \mathrm{MPa})$, the principal stress reduced to $0.20 \mathrm{ksi}(1.4 \mathrm{MPa})$. The analysis illustrates that with an interface material concrete cracking can be reduced or eliminated. Reduction in cracking or the elimination of cracks will facilitate heat transfer, reduce charging time, and enhance the durability of the storage medium.

Tests were performed using three different interface materials, Teflon tape, Deacon 8875 gasket sealant and aluminum foil. The aluminum foil degraded under the alkaline conditions of the fresh concrete coupled with the elevated temperatures. The Teflon tape deteriorated at temperatures beyond $707^{\circ} \mathrm{F}\left(375^{\circ} \mathrm{C}\right)$. In both cases, a space was left between the heat exchanger and the concrete. This reduced heat transfer from one material to the next. It is important to maintain contact between the heat exchangers and the concrete in order to reduce heat losses and reduce charging time. The Deacon 8875 sealant remained stable at temperatures over $932^{\circ} \mathrm{F}$ $\left(500^{\circ} \mathrm{C}\right)$. In all three cases, the amount of cracking and the crack size decreased after testing as shown in Figure 4.9. The time required to increase the concrete surface temperature from 716 to $806^{\circ} \mathrm{F}\left(\Delta \mathrm{T}=90^{\circ} \mathrm{F}\right)\left(380\right.$ to $\left.430^{\circ} \mathrm{C}\left(\Delta \mathrm{T}=50^{\circ} \mathrm{C}\right)\right)$ for the specimens with Teflon tape, Deacon sealant and aluminum foil was 4250, 5400, and 5600 seconds, respectively. Figure 4.10 shows the temperature profiles of the concrete surface and the HTF as it flowed through the specimen with aluminum foil. At early stages of heating, there was a $\Delta \mathrm{T}$ between the inner and outer 
surface of the specimen of approximately $392^{\circ} \mathrm{F}\left(200^{\circ} \mathrm{C}\right)$. However, the level of cracking observed was minute.

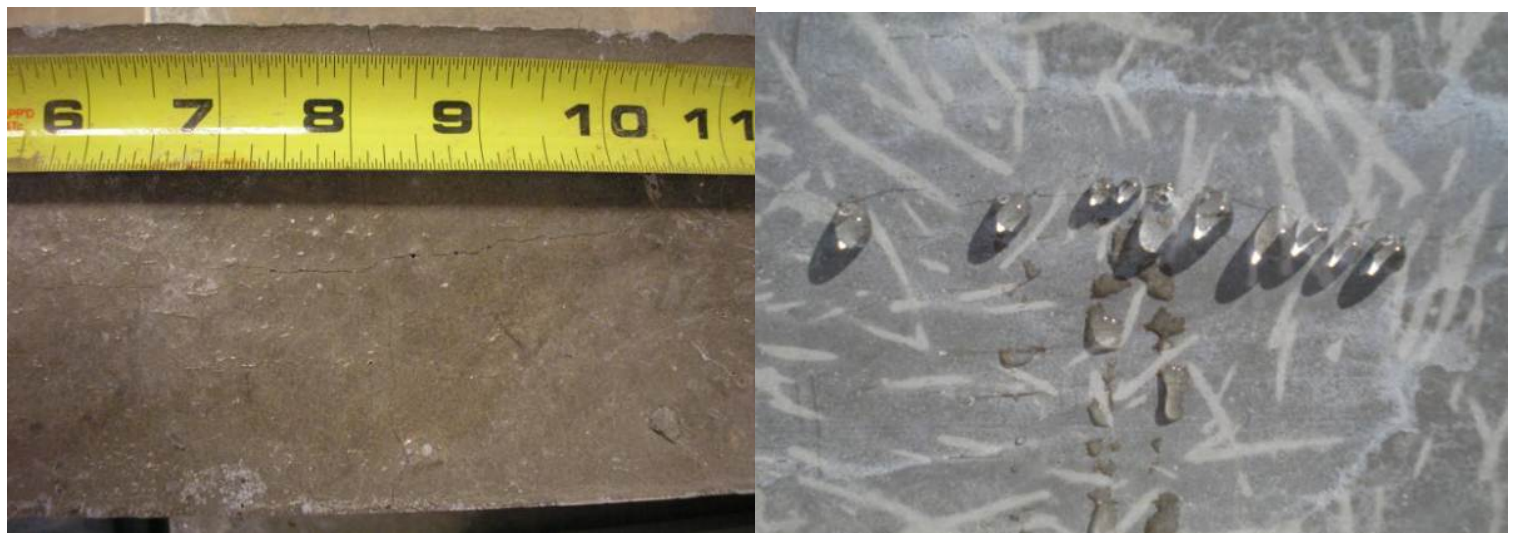

Fig. 4.9. Reduced level of cracking in concrete specimens with interface material (Skinner et al., 2011).

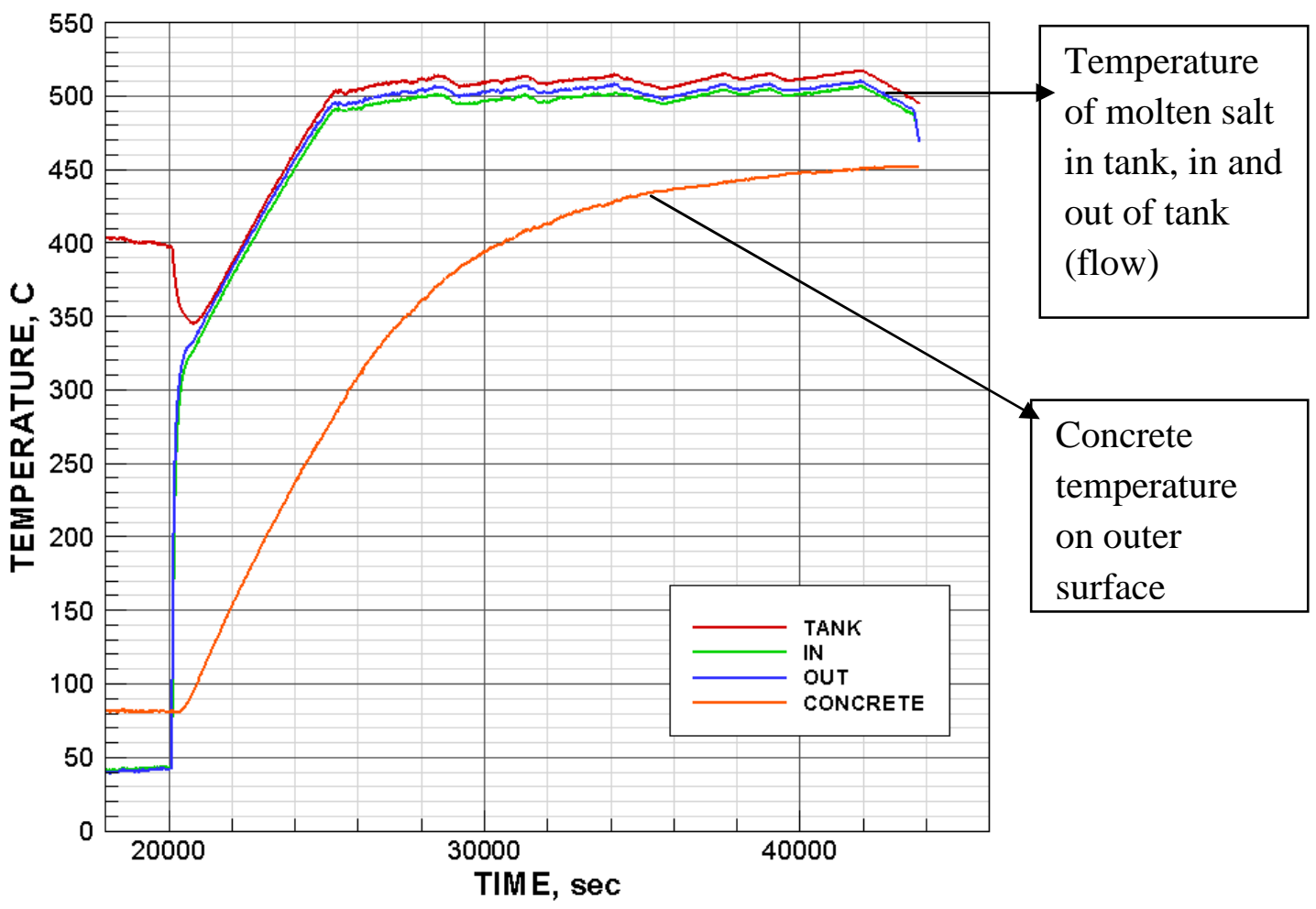

Fig. 4.10. Temperature profiles of HTF and concrete with aluminum foil (outer surface) during heat-up (Skinner et al., 2011). 


\subsubsection{Proprietary Mixture}

The thermo-mechanical properties of a proprietary mixture, TC1000, were evaluated for deployment in TES Option A, as was the case for the seven mixtures discussed in the preceding sections. TC1000 is a premix in which all the cementitious materials and aggregates are combined by the manufacturers. This material contains no coarse aggregates and is referred to as ultra-high performance concrete. TC1000 is sold in a premix bag and end-users add the required amount of water and relevant admixtures for their specific purpose. For the specimens cast with TC1000, the unit weight, compressive strength, splitting tensile strength, modulus of elasticity, thermal conductivity $(K)$, and specific heat $\left(\mathrm{C}_{\mathrm{p}}\right)$ values were measured before and after 30 thermal cycles between 572 and $1112^{\circ} \mathrm{F}\left(300\right.$ and $\left.600^{\circ} \mathrm{C}\right)$. These results are summarized in Table 4.4 .

Table 4.4 Thermo-physical properties of TC1000

\begin{tabular}{|l|c|c|}
\hline \multirow{2}{*}{ Properties } & \multicolumn{2}{|c|}{ TC1000 } \\
\cline { 2 - 3 } & Before heating & After heating \\
\hline Compressive strength $(k s i)$ & 23.0 & 15.8 \\
\hline Splitting tensile strength $(k s i)$ & 3.00 & 1.20 \\
\hline Modulus of elasticity $(k s i)$ & 8620 & 1100 \\
\hline Thermal conductivity $\left(B t u / f t . h^{\circ}{ }^{\circ} F\right)$ & 1.79 & 0.75 \\
\hline Specific heat $\left(B t u / l b m^{\circ} F\right)$ & 0.215 & 0.167 \\
\hline Unit weight $\left(l b / f t^{3}\right)$ & 158.0 & 144.0 \\
\hline $1 \mathrm{ksi}=6.9 \mathrm{MPa}, 1 \mathrm{Btu} / \mathrm{lbm}^{\circ} \mathrm{F}=4.1868 \mathrm{~J} / \mathrm{gK}, 1 \mathrm{Btu} / \mathrm{ft}^{\circ} .{ }^{\circ} .^{\circ} \mathrm{F}=1.73 \mathrm{~W} / \mathrm{mK}, 1 \mathrm{lb} / \mathrm{ft}^{3}=16.02 \mathrm{~kg} / \mathrm{m}^{3}$
\end{tabular}

The unit cost of this proprietary mixture was $\$ 1350.00 / \mathrm{yd}^{3}$ of which $\$ 950.00$ accounts for the steel fibers. The cost was based on the materials and prices shown in Tables 3.7 and 3.9 respectively. A comparison of the residual thermal properties of TC1000 to those given for the seven mixtures in Tables 4.3A and 4.3B indicates similar residual thermal values. In terms of the percentage of retained compressive strength, TC 1000 did not retain a significantly higher percentage than that of the mixtures presented in Tables 4.3A and 4.3B. However, the absolute value was 1.5 to 2 times the residual compressive strengths of the aforementioned mixtures. 
Given that compressive strength is not the most important parameter in the determination of the TES medium, the results shown in Table 4.4 for this particular material do not support its use over the less expensive materials whose properties were presented in Tables 4.3A and 4.3B.

\subsection{Phase III: Performance of Concrete Developed for TES Option B}

\subsubsection{Preliminary Testing Results of Concrete for Deployment in TES Option B}

The focus of Phase III of the research was on concrete's deployment in TES system Option B. In TES system Option B, referred to as a thermocline energy storage system in Chapter 2, the heat transfer fluid (molten salt) is in direct contact with the concrete. Since the concrete would not be subjected to external forces other than its own weight, the two major concerns were compatibility between the concrete and salt, and the ability of the concrete to sustain its selfweight in the presence of molten salt at elevated temperatures. Based on the results of Phases I and II, 26 additional concrete mixtures were batched and tested. To develop the 26 mixtures, a literature review was performed for guidance in combining CAC and FA in concrete mixtures. There was limited information found on the CAC and FA combinations. Therefore, trial batching examined the compatibility of the two materials. The trial batching provided the information that was needed to move forward with mixtures containing both CAC and FA.

Specimens from the 26 mixtures were subjected to 30 thermal cycles (not submerged in molten salt) between 572 and $1112^{\circ} \mathrm{F}\left(300\right.$ and $\left.600^{\circ} \mathrm{C}\right)$. The compressive strength and unit weight of the mixtures were measured before (generally after 28 days) and after thermal cycling. The thermal conductivity was measured at ambient temperature before heating. These preliminary tests were conducted in order to identify the best performing mixtures for which additional tests would be performed and finally, from which specimens would be tested in a 
prototype thermocline storage system. The results of the preliminary tests are summarized in Tables $4.5 \mathrm{~A}$ to $4.5 \mathrm{G}$.

Table 4.5A Properties of thermocline concrete mixtures (Mixtures 1 to 4)

\begin{tabular}{|c|c|c|c|c|c|c|c|c|}
\hline \multirow{3}{*}{$\begin{array}{l}\text { Concrete } \\
\text { Properties }\end{array}$} & \multicolumn{8}{|c|}{ Concrete Mixtures } \\
\hline & \multicolumn{2}{|c|}{1} & \multicolumn{2}{|c|}{2} & \multicolumn{2}{|c|}{3} & \multicolumn{2}{|c|}{4} \\
\hline & before & after & before & after & before & after & before & after \\
\hline $\begin{array}{l}\text { Compressive } \\
\text { strength }(k s i)\end{array}$ & 10.50 & 3.00 & 9.50 & 2.75 & 10.50 & 3.30 & 9.40 & 3.00 \\
\hline $\begin{array}{l}\text { Unit weight } \\
\left(\mathrm{lb} / \mathrm{ft}^{3}\right)\end{array}$ & 135 & 119 & 135 & 119 & 135 & 119 & 135 & 120 \\
\hline $\operatorname{Cost}\left(\$ / y d^{3}\right)$ & \multicolumn{2}{|c|}{260} & \multicolumn{2}{|c|}{184} & \multicolumn{2}{|c|}{305} & \multicolumn{2}{|c|}{284} \\
\hline $\begin{array}{l}\text { Measured } \\
\text { thermal } \\
\text { conductivity, } K \\
\left(\text { Btu/ft. } .^{\circ} F\right)\end{array}$ & \multicolumn{2}{|c|}{0.954} & \multicolumn{2}{|c|}{1.24} & \multicolumn{2}{|c|}{1.21} & \multicolumn{2}{|c|}{1.12} \\
\hline $\begin{array}{l}\text { Predicted } \\
\text { specific heat, } \\
\mathrm{C}_{\mathrm{p}}\left(\text { Btu/lbm}{ }^{\circ} F\right)\end{array}$ & \multicolumn{2}{|c|}{$\begin{array}{l}0.220^{\mathrm{a}} \\
0.285^{\mathrm{b}}\end{array}$} & \multicolumn{2}{|c|}{$\begin{array}{l}0.211^{\mathrm{a}} \\
0.263^{\mathrm{b}}\end{array}$} & \multicolumn{2}{|c|}{$\begin{array}{l}0.210^{\mathrm{a}} \\
0.262^{\mathrm{b}}\end{array}$} & \multicolumn{2}{|c|}{$\begin{array}{l}0.211^{\mathrm{a}} \\
0.263^{\mathrm{b}}\end{array}$} \\
\hline
\end{tabular}

${ }^{\mathrm{a}}$ Calculated specific heat based on Equation 10 in Section 3.3.4 of Chapter 2 with $\mathrm{C}_{\mathrm{p}}$ of water $=$ $0.5255 \mathrm{Btu} / \mathrm{lbm}^{\circ} \mathrm{F}$

${ }^{\mathrm{b}}$ Calculated specific heat based on Equation 10 in Section 3.3.4 of Chapter 2 with $\mathrm{C}_{\mathrm{p}}$ of water $=$ $0.9984 \mathrm{Btu} / \mathrm{lbm}^{\circ} \mathrm{F}$

$1 \mathrm{ksi}=6.9 \mathrm{MPa}, 1 \mathrm{Btu} / \mathrm{lbm}^{\circ} \mathrm{F}=4.1868 \mathrm{~J} / \mathrm{gK}, 1 \mathrm{Btu} / \mathrm{ft} . \mathrm{h} .{ }^{\circ} \mathrm{F}=1.73 \mathrm{~W} / \mathrm{mK}, 1 \mathrm{lb} / \mathrm{ft}^{3}=16.02 \mathrm{~kg} / \mathrm{m}^{3}$ 
Table 4.5B Properties of thermocline concrete mixtures (Mixtures 5 to 8)

\begin{tabular}{|c|c|c|c|c|c|c|c|c|}
\hline \multirow{3}{*}{$\begin{array}{l}\text { Concrete } \\
\text { Properties }\end{array}$} & \multicolumn{8}{|c|}{ Concrete Mixtures } \\
\hline & \multicolumn{2}{|c|}{5} & \multicolumn{2}{|c|}{6} & \multicolumn{2}{|c|}{7} & \multicolumn{2}{|c|}{8} \\
\hline & before & after & before & after & before & after & before & after \\
\hline $\begin{array}{l}\text { Compressive } \\
\text { strength }(k s i)\end{array}$ & 7.25 & $\begin{array}{l}1.30 \\
1.20^{1}\end{array}$ & 4.60 & 0.75 & 5.30 & $\begin{array}{l}1.70 \\
2.80^{1}\end{array}$ & 3.60 & 0.65 \\
\hline $\begin{array}{l}\text { Unit weight } \\
\left(l b / f t^{3}\right)\end{array}$ & 142 & 126 & 142 & 129 & 142 & 131 & 142 & 131 \\
\hline $\operatorname{Cost}\left(\$ / y d^{3}\right)$ & \multicolumn{2}{|c|}{218} & \multicolumn{2}{|c|}{200} & \multicolumn{2}{|c|}{166} & \multicolumn{2}{|c|}{155} \\
\hline $\begin{array}{l}\text { Measured } \\
\text { thermal } \\
\text { conductivity, } K \\
\left(\text { Btu/ft.h. }{ }^{o} F\right)\end{array}$ & \multicolumn{2}{|c|}{1.10} & \multicolumn{2}{|c|}{1.27} & \multicolumn{2}{|c|}{1.39} & \multicolumn{2}{|c|}{1.32} \\
\hline $\begin{array}{l}\text { Predicted } \\
\text { specific heat, } \\
\mathrm{C}_{\mathrm{p}}\left(B t u / l b m^{\circ} F\right)\end{array}$ & \multicolumn{2}{|c|}{$\begin{array}{l}0.218^{\mathrm{a}} \\
0.258^{\mathrm{b}}\end{array}$} & \multicolumn{2}{|c|}{$\begin{array}{l}0.226^{\mathrm{a}} \\
0.277^{\mathrm{b}}\end{array}$} & \multicolumn{2}{|c|}{$\begin{array}{l}0.217^{\mathrm{a}} \\
0.255^{\mathrm{b}}\end{array}$} & \multicolumn{2}{|c|}{$\begin{array}{l}0.222^{\mathrm{a}} \\
0.268^{\mathrm{b}}\end{array}$} \\
\hline
\end{tabular}

${ }^{\mathrm{a}}$ Calculated specific heat based on Equation 10 in Section 3.3.4 of Chapter 2 with $\mathrm{C}_{\mathrm{p}}$ of water $=$ $0.5255 \mathrm{Btu} / \mathrm{lbm}^{\circ} \mathrm{F}$

${ }^{\mathrm{b}}$ Calculated specific heat based on Equation 10 in Section 3.3.4 of Chapter 2 with $\mathrm{C}_{\mathrm{p}}$ of water $=$ $0.9984 \mathrm{Btu} / \mathrm{lbm}^{\circ} \mathrm{F}$

$1 \mathrm{ksi}=6.9 \mathrm{MPa}, 1 \mathrm{Btu} / \mathrm{lbm}^{\circ} \mathrm{F}=4.1868 \mathrm{~J} / \mathrm{gK}, 1 \mathrm{Btu} / \mathrm{ft} \cdot \mathrm{h} .{ }^{\circ} \mathrm{F}=1.73 \mathrm{~W} / \mathrm{mK}, 1 \mathrm{lb} / \mathrm{ft}^{3}=16.02 \mathrm{~kg} / \mathrm{m}^{3}$

${ }^{1}$ Specimens were conditioned before thermal cycling

Table 4.5C Properties of thermocline concrete mixtures (Mixtures 9 to 12)

\begin{tabular}{|c|c|c|c|c|c|c|c|c|}
\hline \multirow{3}{*}{$\begin{array}{l}\text { Concrete } \\
\text { Properties }\end{array}$} & \multicolumn{8}{|c|}{ Concrete Mixtures } \\
\hline & \multicolumn{2}{|c|}{9} & \multicolumn{2}{|c|}{10} & \multicolumn{2}{|c|}{11} & \multicolumn{2}{|c|}{12} \\
\hline & before & after & before & after & before & after & before & after \\
\hline $\begin{array}{l}\text { Compressive } \\
\text { strength }(k s i)\end{array}$ & 8.10 & $\begin{array}{r}1.90 \\
2.50^{1}\end{array}$ & 5.20 & $\begin{array}{l}0.85 \\
1.30^{1}\end{array}$ & 7.00 & $\begin{array}{r}2.00 \\
2.00^{1}\end{array}$ & 3.00 & 0.85 \\
\hline $\begin{array}{l}\text { Unit weight } \\
\left(l b / f t^{3}\right)\end{array}$ & 142 & 128 & 142 & 128 & 142 & 129 & 142 & 128 \\
\hline $\operatorname{Cost}\left(\$ / y d^{3}\right)$ & \multicolumn{2}{|c|}{245} & \multicolumn{2}{|c|}{223} & \multicolumn{2}{|c|}{191} & \multicolumn{2}{|c|}{$\frac{1}{176}$} \\
\hline $\begin{array}{l}\text { Measured } \\
\text { thermal } \\
\text { conductivity, } K \\
\left(\text { Btu/ft. } .^{o} F\right)\end{array}$ & \multicolumn{2}{|c|}{1.33} & \multicolumn{2}{|c|}{1.23} & \multicolumn{2}{|c|}{1.09} & \multicolumn{2}{|c|}{ NA } \\
\hline $\begin{array}{l}\text { Predicted } \\
\text { specific heat, } \\
\mathrm{C}_{\mathrm{p}}\left(B t u / l b m^{o} F\right)\end{array}$ & \multicolumn{2}{|c|}{$\begin{array}{l}0.219^{\mathrm{a}} \\
0.259^{\mathrm{b}}\end{array}$} & \multicolumn{2}{|c|}{$\begin{array}{l}0.226^{\mathrm{a}} \\
0.277^{\mathrm{b}}\end{array}$} & \multicolumn{2}{|c|}{$\begin{array}{l}0.218^{\mathrm{a}} \\
0.259^{\mathrm{b}}\end{array}$} & \multicolumn{2}{|c|}{$\begin{array}{l}0.226^{\mathrm{a}} \\
0.278^{\mathrm{b}}\end{array}$} \\
\hline
\end{tabular}

${ }^{a}$ Calculated specific heat based on Equation 10 in Section 3.3.4 of Chapter 2 with $\mathrm{C}_{\mathrm{p}}$ of water $=$ $0.5255 \mathrm{Btu} / \mathrm{lbm}^{\circ} \mathrm{F}$

${ }^{\mathrm{b}}$ Calculated specific heat based on Equation 10 in Section 3.3.4 of Chapter 2 with $\mathrm{C}_{\mathrm{p}}$ of water $=$ $0.9984 \mathrm{Btu} / \mathrm{lbm}^{\circ} \mathrm{F}$

$1 \mathrm{ksi}=6.9 \mathrm{MPa}, 1 \mathrm{Btu} / \mathrm{lbm}^{0} \mathrm{~F}=4.1868 \mathrm{~J} / \mathrm{gK}, 1 \mathrm{Btu} / \mathrm{ft} \cdot \mathrm{h}^{\circ} \mathrm{F}=1.73 \mathrm{~W} / \mathrm{mK}, 1 \mathrm{lb} / \mathrm{ft}^{3}=16.02 \mathrm{~kg} / \mathrm{m}^{3}$

${ }^{1}$ Specimens were conditioned before thermal cycling 
Table 4.5D Properties of thermocline concrete mixtures (Mixtures 13 to 16)

\begin{tabular}{|c|c|c|c|c|c|c|c|c|}
\hline \multirow{3}{*}{$\begin{array}{l}\text { Concrete } \\
\text { Properties }\end{array}$} & \multicolumn{8}{|c|}{ Concrete Mixtures } \\
\hline & \multicolumn{2}{|c|}{13} & \multicolumn{2}{|c|}{14} & \multicolumn{2}{|c|}{15} & \multicolumn{2}{|c|}{16} \\
\hline & before & after & before & after & before & after & before & after \\
\hline $\begin{array}{l}\text { Compressive } \\
\text { strength }(k s i)\end{array}$ & 5.4 & 0.83 & 2.30 & 0.45 & 10.6 & $\begin{array}{l}3.30 \\
2.70^{1}\end{array}$ & 9.80 & $\begin{array}{r}2.80 \\
2.90^{1}\end{array}$ \\
\hline $\begin{array}{l}\text { Unit weight } \\
\left(l b / f t^{3}\right)\end{array}$ & 142 & 129 & 142 & 129 & 140 & 125 & 140 & 125 \\
\hline $\operatorname{Cost}\left(\$ / y d^{3}\right)$ & \multicolumn{2}{|c|}{204} & \multicolumn{2}{|c|}{187} & \multicolumn{2}{|c|}{95} & \multicolumn{2}{|c|}{114} \\
\hline $\begin{array}{l}\text { Measured } \\
\text { thermal } \\
\text { conductivity, } K \\
\left(\text { Btu/ft.h. } .^{o} F\right)\end{array}$ & \multicolumn{2}{|c|}{1.27} & \multicolumn{2}{|c|}{ NA } & \multicolumn{2}{|c|}{ NA } & \multicolumn{2}{|c|}{ NA } \\
\hline $\begin{array}{l}\text { Predicted } \\
\text { specific heat, } \\
\mathrm{C}_{\mathrm{p}}\left(B t u / l b m^{o} F\right)\end{array}$ & \multicolumn{2}{|c|}{$\begin{array}{l}0.218^{\mathrm{a}} \\
0.259^{\mathrm{b}}\end{array}$} & \multicolumn{2}{|c|}{$\begin{array}{l}0.227^{\mathrm{a}} \\
0.278^{\mathrm{b}}\end{array}$} & \multicolumn{2}{|c|}{$\begin{array}{l}0.208^{\mathrm{a}} \\
0.256^{\mathrm{b}}\end{array}$} & \multicolumn{2}{|c|}{$\begin{array}{l}0.211^{\mathrm{a}} \\
0.263^{\mathrm{b}}\end{array}$} \\
\hline
\end{tabular}

${ }^{\mathrm{a}}$ Calculated specific heat based on Equation 10 in Section 3.3.4 of Chapter 2 with $\mathrm{C}_{\mathrm{p}}$ of water $=$ $0.5255 \mathrm{Btu} / \mathrm{lbm}^{\circ} \mathrm{F}$

${ }^{\mathrm{b}}$ Calculated specific heat based on Equation 10 in Section 3.3.4 of Chapter 2 with $\mathrm{C}_{\mathrm{p}}$ of water $=$ $0.9984 \mathrm{Btu} / \mathrm{lbm}^{\circ} \mathrm{F}$

$1 \mathrm{ksi}=6.9 \mathrm{MPa}, 1 \mathrm{Btu} / \mathrm{lbm}^{\circ} \mathrm{F}=4.1868 \mathrm{~J} / \mathrm{gK}, 1 \mathrm{Btu} / \mathrm{ft} . \mathrm{h}{ }^{\circ} \mathrm{F}=1.73 \mathrm{~W} / \mathrm{mK}, 1 \mathrm{lb} / \mathrm{ft}^{3}=16.02 \mathrm{~kg} / \mathrm{m}^{3}$

${ }^{1}$ Specimens were conditioned before thermal cycling

Table 4.5E Properties of thermocline concrete mixtures (Mixtures 17 to 20)

\begin{tabular}{|c|c|c|c|c|c|c|c|c|}
\hline \multirow{3}{*}{$\begin{array}{l}\text { Concrete } \\
\text { Properties }\end{array}$} & \multicolumn{8}{|c|}{ Concrete Mixtures } \\
\hline & \multicolumn{2}{|c|}{17} & \multicolumn{2}{|c|}{18} & \multicolumn{2}{|c|}{19} & \multicolumn{2}{|c|}{20} \\
\hline & before & after & before & after & before & after & before & after \\
\hline $\begin{array}{l}\text { Compressive } \\
\text { strength }(k s i)\end{array}$ & 4.3 & $0.90^{1}$ & 5.00 & $1.10^{1}$ & 7.90 & NA & 5.2 & NA \\
\hline $\begin{array}{l}\text { Unit weight } \\
\left(l b / f t^{3}\right)\end{array}$ & 142 & 130 & 142 & 130 & 146 & 133 & 144 & 131 \\
\hline $\operatorname{Cost}\left(\$ / y d^{3}\right)$ & \multicolumn{2}{|c|}{135} & \multicolumn{2}{|c|}{135} & \multicolumn{2}{|c|}{99} & \multicolumn{2}{|c|}{99} \\
\hline $\begin{array}{l}\text { Measured } \\
\text { thermal } \\
\text { conductivity, } K \\
\left(\text { Btu/ft.h. } .^{o} F\right)\end{array}$ & \multicolumn{2}{|c|}{ NA } & \multicolumn{2}{|c|}{ NA } & \multicolumn{2}{|c|}{ NA } & \multicolumn{2}{|c|}{ NA } \\
\hline $\begin{array}{l}\text { Predicted } \\
\text { specific heat, } \\
\mathrm{C}_{\mathrm{p}}\left(B t u / l b m^{o} F\right)\end{array}$ & \multicolumn{2}{|c|}{$\begin{array}{l}0.222^{\mathrm{a}} \\
0.257^{\mathrm{b}}\end{array}$} & \multicolumn{2}{|c|}{$\begin{array}{l}0.222^{\mathrm{a}} \\
0.257^{\mathrm{b}}\end{array}$} & \multicolumn{2}{|c|}{$\begin{array}{l}0.223^{\mathrm{a}} \\
0.263^{\mathrm{b}}\end{array}$} & \multicolumn{2}{|c|}{$\begin{array}{l}0.211^{\mathrm{a}} \\
0.252^{\mathrm{b}}\end{array}$} \\
\hline
\end{tabular}

${ }^{a}$ Calculated specific heat based on Equation 10 in Section 3.3.4 of Chapter 2 with $\mathrm{C}_{\mathrm{p}}$ of water $=$ $0.5255 \mathrm{Btu} / \mathrm{lbm}^{\circ} \mathrm{F}$

${ }^{\mathrm{b}}$ Calculated specific heat based on Equation 10 in Section 3.3.4 of Chapter 2 with $\mathrm{C}_{\mathrm{p}}$ of water $=$ $0.9984 \mathrm{Btu} / \mathrm{lbm}^{\circ} \mathrm{F}$

$1 \mathrm{ksi}=6.9 \mathrm{MPa}, 1 \mathrm{Btu} / \mathrm{lbm}^{0} \mathrm{~F}=4.1868 \mathrm{~J} / \mathrm{gK}, 1 \mathrm{Btu} / \mathrm{ft} \cdot \mathrm{h}^{\circ} \mathrm{F}=1.73 \mathrm{~W} / \mathrm{mK}, 1 \mathrm{lb} / \mathrm{ft}^{3}=16.02 \mathrm{~kg} / \mathrm{m}^{3}$

${ }^{1}$ Specimens were conditioned before thermal cycling 
Table 4.5F Properties of thermocline concrete mixtures (Mixtures 21 to 24)

\begin{tabular}{|c|c|c|c|c|c|c|c|c|}
\hline \multirow{3}{*}{$\begin{array}{l}\text { Concrete } \\
\text { properties }\end{array}$} & \multicolumn{8}{|c|}{ Concrete Mixtures } \\
\hline & \multicolumn{2}{|c|}{21} & \multicolumn{2}{|c|}{22} & \multicolumn{2}{|c|}{23} & \multicolumn{2}{|c|}{24} \\
\hline & before & after & before & after & before & after & before & after \\
\hline $\begin{array}{l}\text { Compressive } \\
\text { strength }(k s i)\end{array}$ & 6.20 & $1.80^{1}$ & 4.90 & 0.70 & 3.50 & $0.87^{1}$ & 4.00 & NA \\
\hline $\begin{array}{l}\text { Unit weight } \\
\left(l b / f t^{3}\right)\end{array}$ & 145 & 132 & 145 & 132 & 145 & 132 & 145 & 132 \\
\hline $\operatorname{Cost}\left(\$ / y d^{3}\right)$ & \multicolumn{2}{|c|}{100} & \multicolumn{2}{|c|}{108} & \multicolumn{2}{|c|}{95} & \multicolumn{2}{|c|}{$\frac{1}{95}$} \\
\hline $\begin{array}{l}\text { Measured } \\
\text { thermal } \\
\text { conductivity, } K \\
\left(\text { Btu/ft.h. }{ }^{o} F\right)\end{array}$ & \multicolumn{2}{|c|}{ NA } & \multicolumn{2}{|c|}{ NA } & \multicolumn{2}{|c|}{ NA } & \multicolumn{2}{|c|}{ NA } \\
\hline $\begin{array}{l}\text { Predicted } \\
\text { specific heat, } \\
\mathrm{C}_{\mathrm{p}}\left(B t u / l b m^{o} F\right)\end{array}$ & \multicolumn{2}{|c|}{$\begin{array}{l}0.223^{\mathrm{a}} \\
0.259^{\mathrm{b}}\end{array}$} & \multicolumn{2}{|c|}{$\begin{array}{l}0.219^{\mathrm{a}} \\
0.258^{\mathrm{b}}\end{array}$} & \multicolumn{2}{|c|}{$\begin{array}{l}0.223^{\mathrm{a}} \\
0.263^{\mathrm{b}}\end{array}$} & \multicolumn{2}{|c|}{$\begin{array}{l}0.209^{\mathrm{a}} \\
0.249^{\mathrm{b}}\end{array}$} \\
\hline
\end{tabular}

${ }^{\mathrm{a}}$ Calculated specific heat based on Equation 10 in Section 3.3.4 of Chapter 2 with $\mathrm{C}_{\mathrm{p}}$ of water $=$ $0.5255 \mathrm{Btu} / \mathrm{lbm}^{\circ} \mathrm{F}$

${ }^{\mathrm{b}}$ Calculated specific heat based on Equation 10 in Section 3.3.4 of Chapter 2 with $\mathrm{C}_{\mathrm{p}}$ of water $=$ $0.9984 \mathrm{Btu} / \mathrm{lbm}^{\circ} \mathrm{F}$

$1 \mathrm{ksi}=6.9 \mathrm{MPa}, 1 \mathrm{Btu} / \mathrm{lbm}^{\circ} \mathrm{F}=4.1868 \mathrm{~J} / \mathrm{gK}, 1 \mathrm{Btu} / \mathrm{ft} \cdot \mathrm{h} .{ }^{\circ} \mathrm{F}=1.73 \mathrm{~W} / \mathrm{mK}, 1 \mathrm{lb} / \mathrm{ft}^{3}=16.02 \mathrm{~kg} / \mathrm{m}^{3}$

${ }^{1}$ Specimens were conditioned before thermal cycling

Table 4.5G Properties of thermocline concrete mixtures (Mixtures 25 and 26)

\begin{tabular}{|c|c|c|c|c|}
\hline \multirow{3}{*}{$\begin{array}{l}\text { Concrete } \\
\text { Properties }\end{array}$} & \multicolumn{4}{|c|}{ Concrete Mixtures } \\
\hline & \multicolumn{2}{|c|}{25} & \multicolumn{2}{|c|}{26} \\
\hline & before & after & before & after \\
\hline $\begin{array}{l}\text { Compressive } \\
\text { strength }(k s i)\end{array}$ & 6.00 & $1.00^{1}$ & 23.00 & $\begin{array}{l}14.00 \\
15.80^{1}\end{array}$ \\
\hline $\begin{array}{l}\text { Unit weight } \\
\left(l b / f t^{3}\right)\end{array}$ & 145 & 132 & 158 & 150 \\
\hline $\operatorname{Cost}\left(\$ / y d^{3}\right)$ & \multicolumn{2}{|c|}{95} & \multicolumn{2}{|c|}{390} \\
\hline $\begin{array}{l}\text { Measured thermal } \\
\text { conductivity, } K \\
\left(\text { Btufft.h. } .^{o}\right)\end{array}$ & \multicolumn{2}{|c|}{ NA } & \multicolumn{2}{|c|}{1.73} \\
\hline $\begin{array}{l}\text { Predicted specific } \\
\text { heat, } \mathrm{C}_{\mathrm{p}} \\
\left(\text { Btu/lbm }{ }^{o} F\right)\end{array}$ & \multicolumn{2}{|c|}{$\begin{array}{l}0.223^{\mathrm{a}} \\
0.263^{\mathrm{b}}\end{array}$} & \multicolumn{2}{|c|}{$\begin{array}{l}- \\
-\end{array}$} \\
\hline
\end{tabular}

${ }^{\mathrm{a}}$ Calculated specific heat based on Equation 10 in Section 3.3.4 of Chapter 2 with $\mathrm{C}_{\mathrm{p}}$ of water $=$ $0.5255 \mathrm{Btu} / \mathrm{lbm}^{\circ} \mathrm{F}$

${ }^{\mathrm{b}}$ Calculated specific heat based on Equation 10 in Section 3.3.4 of Chapter 2 with $\mathrm{C}_{\mathrm{p}}$ of water $=$ $0.9984 \mathrm{Btu} / \mathrm{lbm}^{\circ} \mathrm{F}$

$1 \mathrm{ksi}=6.9 \mathrm{MPa}, 1 \mathrm{Btu} / \mathrm{lbm}^{\circ} \mathrm{F}=4.1868 \mathrm{~J} / \mathrm{gK}, 1 \mathrm{Btu} / \mathrm{ft} . \mathrm{h} .{ }^{\circ} \mathrm{F}=1.73 \mathrm{~W} / \mathrm{mK}, 1 \mathrm{lb} / \mathrm{ft}^{3}=16.02 \mathrm{~kg} / \mathrm{m}^{3}$

${ }^{1}$ Specimens were conditioned before thermal cycling 
The compressive strengths before thermal cycling (not submerged in molten salt) of Mixtures 1 to 25 , as shown in Tables $4.5 \mathrm{~A}$ to $4.5 \mathrm{G}$, were between 4 and $10 \mathrm{ksi}(28$ and $70 \mathrm{MPa}$ ). Mixture 26, which is a proprietary mixture, had a compressive strength of $23 \mathrm{ksi}(159 \mathrm{MPa})$. After 30 thermal cycles between 572 and $1112^{\circ} \mathrm{F}\left(300\right.$ and $\left.600^{\circ} \mathrm{C}\right)$, the residual compressive strengths of Mixtures 1 through 25 ranged from $450 \mathrm{psi}$ (3.1 MPa) to approximately $3 \mathrm{ksi}$ ( 21 MPa) and $14 \mathrm{ksi}(97 \mathrm{MPa}$ ) for Mixture 26. The mixtures without coarse aggregates (Mixtures 1 4), retained on average $30 \%$ of their initial compressive strength. These mixtures contained the same quantity of total cementitious materials but with different proportions of CAC, FA and SF. The CAC to FA ratio for Mixtures 1, 2 and 3 was 1.0, 0.43 and 1.5 respectively, these mixtures contained no SF. Mixture 4 had a CAC to FA ratio of 1.25 combined with $10 \%$ SF. However, there was not a significant difference between the residual compressive strength of these four mixtures. The variation in residual compressive strengths was less than $600 \mathrm{psi}$ (4.1 MPa). These results indicate that the different combinations of CAC, FA, and SF have little effect on residual compressive strength for concrete containing only fine aggregates (mortars). Visual inspection of Mixtures 1 - 4 revealed a low level of micro cracking on the surface of all specimens.

The other mortar mixtures were Mixtures 15, 16 and 26. In the case of Mixture 26, there was a reduction in compressive strength of approximately $40 \%$ and no cracks were observed on the surface of specimens. Mixtures 15 and 16 retained approximately $30 \%$ of their initial compressive strength. Low levels of micro cracking were observed on specimens from these mixtures.

Concrete specimens from selected mixtures were also conditioned before the thermal cycling test. In Tables $4.5 \mathrm{~A}$ to $4.5 \mathrm{G}$, these mixtures were identified with the superscript 1 . 
Conditioning entailed heating the specimens at very low heating rates, $0.3^{\circ} \mathrm{F} / \mathrm{min}$. up to $230^{\circ} \mathrm{F}$ and subsequently at $1.2^{\circ} \mathrm{F} / \mathrm{min}$. up to $1112^{\circ} \mathrm{F}\left(0.17^{\circ} \mathrm{C} / \mathrm{min}\right.$. up to $110^{\circ} \mathrm{C}$ and at $0.67^{\circ} \mathrm{C} / \mathrm{min}$. up to $\left.600^{\circ} \mathrm{C}\right)$. Thereafter, the specimens were thermally cycled at $16 \cdot 2^{\circ} \mathrm{F} / \mathrm{min} .\left(9^{\circ} \mathrm{C} / \mathrm{min}.\right)$. In three of the cases where the concrete specimens were conditioned before thermal cycling, Mixtures 7, 9 and 10 , there was an improvement of 64,32 , and $53 \%$, respectively in residual compressive strength. In the other cases (Mixtures 5,11,15,16,26) there was little or no improvement in residual strengths. Petzold and Rohrs (1970) and LaBar (1974) explained that concrete that is conditioned before commissioning are more resistant to thermal cycling. Improved resistance to thermal cycling was observed in Mixtures 7, 9 and 10 and to a lesser extent in Mixtures 5, 11, 15,16 and 26 . Thermal cycling fatigues the concrete and therefore, in many cases, improvement in compressive strength that would have resulted from conditioning was subsequently lost.

The results for Mixtures 5 to 14 are shown in Tables 4.5B to 4.5D. The results show that in order to obtain compressive strengths (28-day) consistently greater than $4 \mathrm{ksi}(28 \mathrm{MPa})$ in CACFA or CAC-FA-SF mixtures, a cementitious material content greater than $800 \mathrm{lb} / \mathrm{yd}^{3}\left(474 \mathrm{~kg} / \mathrm{m}^{3}\right)$ with FA replacements of at least 50\% was required. The $4 \mathrm{ksi}$ benchmark represents the compressive strength of normal strength concrete.

Supplementary cementitious materials (SCM) such as FA and SF are added to concrete mixtures to react with the calcium hydroxide that is produced during the hydration process to form additional calcium silicate hydrates. However, when these SCMs are combined with CAC, this reaction does not occur because calcium hydroxide is not one of the hydration products. This assertion is supported by comparing the 28-day compressive strengths of Mixtures 5 - 14 to Mixtures 18, 21 and 23. In the latter cases where OPC and FA were combined with total cementitious materials of $650 \mathrm{lb} / \mathrm{yd}^{3}\left(385 \mathrm{~kg} / \mathrm{m}^{3}\right)$ or less, the 28 -day compressive strengths were 
similar to or higher than those of the former cases where CAC and FA were combined with total cementitious material content of up to $900 \mathrm{lb} / \mathrm{yd}^{3}\left(534 \mathrm{~kg} / \mathrm{m}^{3}\right)$.

The results in Tables $4.5 \mathrm{~B}$ to $4.5 \mathrm{D}$ also showed that mixtures containing CAC and FA (with coarse aggregates) with total cementitious material content of $800 \mathrm{lb} / \mathrm{yd}^{3}\left(474 \mathrm{~kg} / \mathrm{m}^{3}\right)$ had residual compressive strengths of $1 \mathrm{ksi}(7 \mathrm{MPa})$ or less. Similar mixtures that contained 900 $\mathrm{lb} / \mathrm{yd}^{3}\left(534 \mathrm{~kg} / \mathrm{m}^{3}\right)$ of cementitious material retained twice the compressive strength of those mixtures with $800 \mathrm{lb} / \mathrm{yd}^{3}\left(474 \mathrm{~kg} / \mathrm{m}^{3}\right)$. Of the CAC mixtures containing coarse aggregates (5 to 14), Mixtures 7, 9 and 11 had residual compressive strengths of approximately $2 \mathrm{ksi}(14 \mathrm{MPa})$. The other CAC mixtures with coarse aggregates had residual compressive strengths of $1 \mathrm{ksi}$ (7 $\mathrm{MPa})$ or less. The greater residual compressive strengths observed in Mixtures 7, 9 and 11 can be attributed to stronger bonds based on the higher initial compressive strengths.

For Mixtures 13 and 14 which contained CAC, FA and SF, the residual compressive strengths were less than $1 \mathrm{ksi}(7 \mathrm{MPa})$. Given mixtures with $900 \mathrm{lb} / \mathrm{yd}^{3}\left(534 \mathrm{~kg} / \mathrm{m}^{3}\right)$ retained up to $2 \mathrm{ksi}$ (14 MPa) compressive strength after thermal cycling; evidence suggests that SF negatively impacted residual compressive strengths. Silica fume does not possess self-cementing properties, hence, in the absence of calcium hydroxide SF did not contribute to compressive strength. However, from a physical standpoint, SF contributes to the packing density of the concrete matrix (Justnes, 2007).

The results in Tables $4.5 \mathrm{E}$ to $4.5 \mathrm{G}$ indicate that mixtures containing OPC, FA and SF (Mixtures 19, 20 and 21) generally performed better than those containing only OPC and FA (Mixtures 17, 18, 23 and 25) when thermally cycled in the absence of molten salt. This showed that the use of SF in OPC-FA mixtures improved their refractoriness. 
In Mixture 22, OPC was the only cementitious material used. This mixture retained 14\%, $700 \mathrm{psi}$ (4.8 MPa), of its initial strength and had a high level of cracking, both in terms of crack density and the crack sizes as shown in Figures 4.11A and 4.11B. This shows that SCMs improve the refractoriness of OPC concretes. The mixtures examined in this phase were intended for deployment in TES Option B. For this option, concrete would serve as the TES medium replacing the aggregate filler used in the original investigations. Based on the crack sizes shown in Figures 4.11A and 4.11B, Mixture 22 may disintegrate over time leading to thermal ratcheting, the problem which the research sought to address.

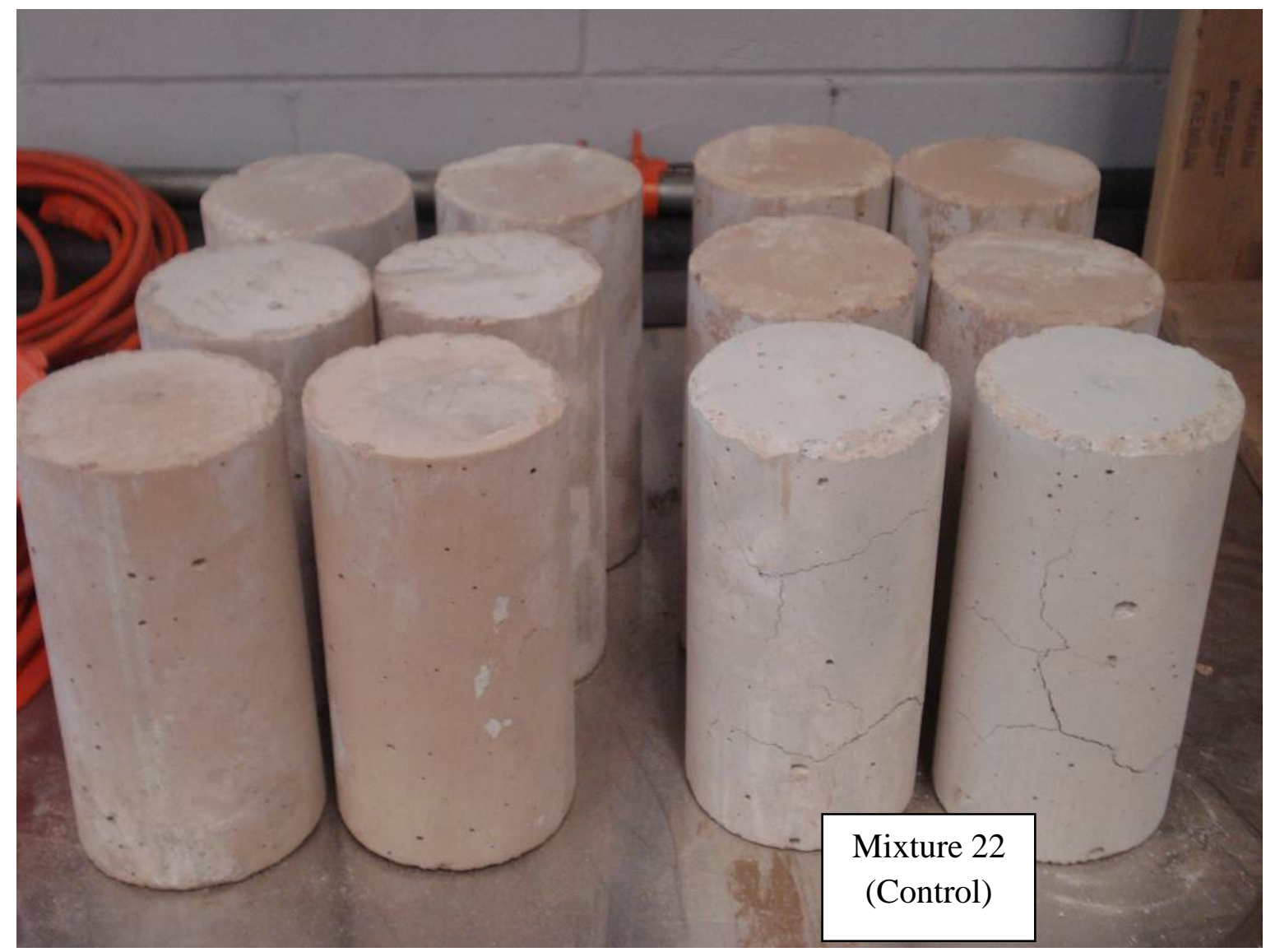

Fig. 4.11A. Level of cracks of control specimens compared to CAC-FA mixtures. 


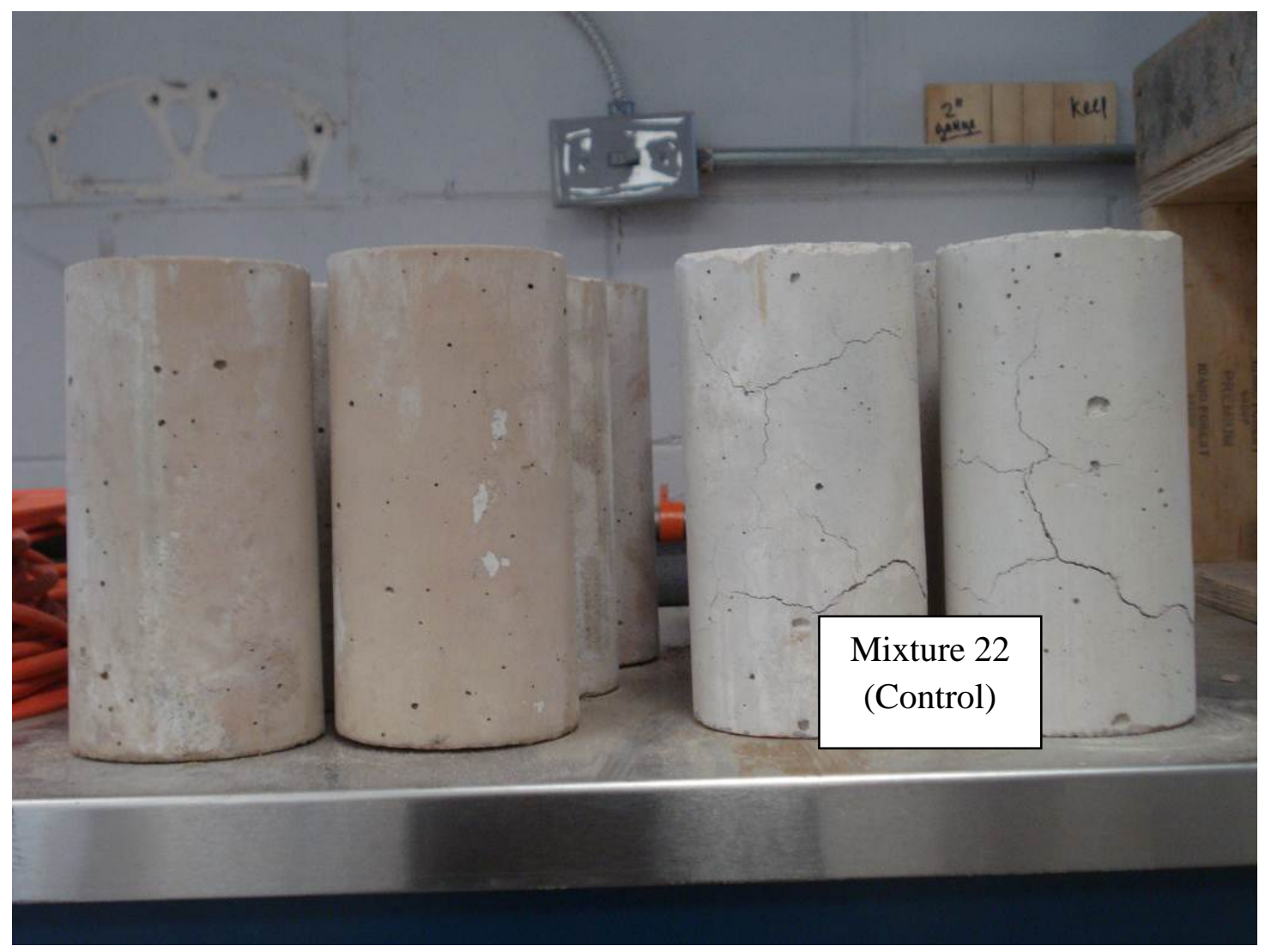

Fig. 4.11B. Level of cracks of control specimens compared to CAC-FA mixtures.

In all cases except for Mixture 26, there was 8 to $12 \%$ mass loss after thermal cycling. Mixture 26 had a mass loss of 5\%. The water to cementitious material (w/cm) ratio for Mixture 26 was less than 0.20 , thus almost all of the water in the mixture was consumed during hydration leaving very little free water to evaporate during high temperature exposures. The other 25 mixtures had w/cm ranging from 0.30 to 0.36 . A w/cm of approximately 0.25 is needed to chemically combine with the anhydrous cement particles (Neville, 1981). Water in excess of 0.25 is adsorbed to and trapped within $\mathrm{CSH}$ pores and also trapped within capillary pores. The greater volume of free and adsorbed water present within these specimens, evaporated when exposed to elevated temperatures. This accounted for the greater mass loss in these concrete mixtures when compared to Mixture 26. Another possibility for the high mass loss observed in 
the CAC-FA mixtures could be conversion. Mehta and Monteiro (2006) explained that in CAC concrete, the unstable hydration products, $\mathrm{CAH}_{10}$ and $\mathrm{C}_{2} \mathrm{AH}_{8}$, convert to a more stable product, $\mathrm{C}_{3} \mathrm{AH}_{6}$. This reaction is accompanied by a $50 \%$ reduction in the solid volume and increases porosity. This phenomenon occurs under normal storage conditions. Whether or not conversion would occur when specimens are submerged in molten salt is difficult to determine, however, CAC concrete behavior when submerged in molten salt was assessed and discussed Section

\subsection{2.}

In terms of the effect of elevated temperatures on the specimens' thermal properties, there was no trend in measured thermal conductivity $(K)$ in relation to the amount and type of cementitious material. However, one observation that was made was that the mixtures containing coarse aggregates generally have higher $K$ when compared to those with fine aggregates only. Researchers have shown that $K$ increases with density, thus validating this observation (Bentz et al., 2010). The unit weight for mixtures containing coarse aggregates was approximately $145 \mathrm{lb} / \mathrm{ft}^{3}\left(2320 \mathrm{~kg} / \mathrm{m}^{3}\right)$, while that for the fine aggregate mixtures was $135 \mathrm{lb} / \mathrm{ft}^{3}$ $\left(2160 \mathrm{~kg} / \mathrm{m}^{3}\right)$.

At this stage of the investigations the specific heat $\left(\mathrm{C}_{\mathrm{p}}\right)$ for the different mixtures was calculated based on the Law of Mixtures (Equation 10). The calculations indicated that $\mathrm{C}_{\mathrm{p}}$ was not significantly affected by the total cementitious material content or by their individual quantities. Specific heat was mainly affected by the amount of water and the amount and type of coarse aggregates within the concrete, with the former having the greater effect. Generally, higher amounts of water increase $C_{p}$. The $C_{p}$ of water is more than five times that of the other concrete ingredients. 


\subsubsection{Assessment of Concrete Specimens in Direct Contact with Molten Salt}

Two inch cubic specimens were placed in an isothermal bath at $1085^{\circ} \mathrm{F}\left(585^{\circ} \mathrm{C}\right)$ for 500 hours. Specimens were also thermally cycled between $572^{\circ} \mathrm{F}$ and $1085^{\circ} \mathrm{F}\left(300\right.$ and $\left.585^{\circ} \mathrm{C}\right)$ for 30 cycles while submerged in molten salt (Fig. 4.12, 4.13. 4.14). Weights, dimensions, and compressive strengths were measured before and after testing. Weight and dimension results of the isothermal and thermal cycle tests are presented in Tables 4.6A and 4.6B respectively. The compressive strength results for the isothermal and thermal cycle tests are presented in Tables 4.7A and 4.7B respectively.

Table 4.6A showed that all specimens gained 10 to $15 \%$ in weight after the isothermal bath. However, the specimens had minimal or no length change. Thus, the added weight was attributed to molten salt trapped within the concrete void spaces. On the other hand, specimens cast from the same mixtures gained up to $22 \%$ after thermal cycling (Table 4.6B). The addition in weight was accompanied by length changes that were widely scattered, ranging from 1 to $8 \%$ (Table 4.6B). To gain further insight into the behavior of concrete when heated in the presence of molten salt, the residual compressive strengths of the mixtures, shown in Tables 4.7A and 4.7B, were analyzed. The analysis indicated that specimens submerged in the salt at $1085^{\circ} \mathrm{F}$ $\left(585^{\circ} \mathrm{C}\right)$ gained significant compressive strength upon removal (Table $\left.4.7 \mathrm{~A}\right)$, whereas specimens cast from the same mixtures loss significant compressive strengths or in some instances, the compressive strength was maintained when cycled (Table 4.7B).

Thermally cycled specimens underwent volumetric changes. The chemical bonds that accounts for the concrete's strength were altered during this process which softened the specimens as evidenced by compressive strength losses. The softening process may be gradual and with continued thermal cycles, most of the specimens may experience further compressive 
strength loss or complete decomposition. In fact, Mixture 23's specimen disintegrated (Fig. 4.12) after the thermal cycling test. This mixture contained OPC - FA $(50-50)$, fine aggregate (river sand) and coarse aggregates (sandstone). It may well mean that the deterioration process of the sandstone accelerated in the presence of OPC when compared to CAC. There was evidence that the sandstone mixtures containing CAC and FA also underwent significant volumetric changes and, in the case of Mixtures 5 and 9, compressive strength loss when thermally cycled. When Mixtures 7 and 9 specimens were submerged in the molten salt bath (without cycling), a weight gain of $10 \%$ was observed and length changes were 0.20 and $0.35 \%$ for Mixtures 7 and 9 respectively. When thermally cycled, the weight gain was $21 \%$ and length change was approximately $4 \%$.

It is interesting to note that of the CAC mixtures containing sandstone (Mixture 5 - 14); Mixtures 5 and 9 experienced compressive strength losses. Mixtures 5 and 9 had the highest CAC to FA ratio (50 - 50 and 60 - 40 respectively) and the highest quantity of CAC by weight for mixtures with cementitious material content of $900 \mathrm{lb} / \mathrm{yd}^{3}\left(534 \mathrm{~kg} / \mathrm{m}^{3}\right)$. For similar mixtures containing similar amounts of total cementitious materials and similar amounts of aggregates, increases in compressive strengths were recorded. This suggests that higher amounts of CAC may accelerate the reduction in compressive strengths for mixtures containing sandstone.

Of the mixtures without coarse aggregates (Mixtures 1-4, 15, 16 and 26), mixtures containing CAC and FA (Mixtures 1 to 4) experienced significant volume change and compressive strength loss after thermal cycling. However, the mixtures containing OPC and FA (15 and 16) had increases in compressive strength after thermal cycling. Again, the compressive strength results show that mixtures containing CAC are less resistant to thermal cycles when submerged in molten salt at elevated temperatures. 


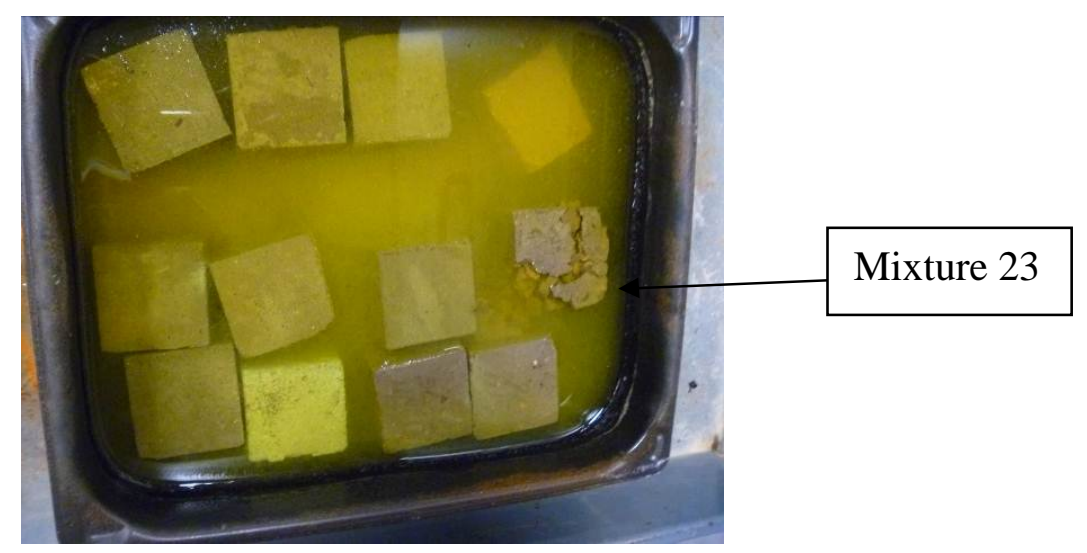

Fig. 4.12. Concrete samples in molten salt after thermal cycling.

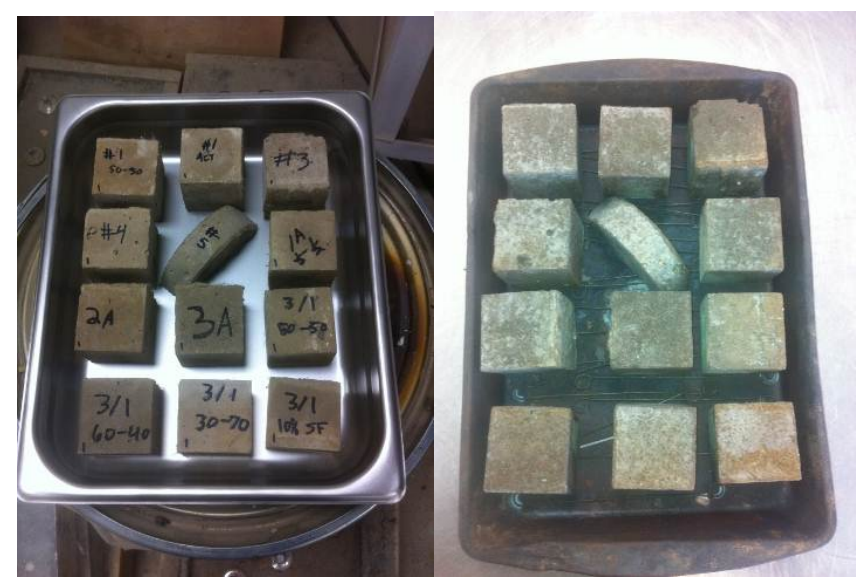

Fig. 4.13. Concrete cubes before (left) and after (right) 500 hours in molten salt at $1085^{\circ} \mathrm{F}\left(5_{85}^{\circ} \mathrm{C}\right)$.

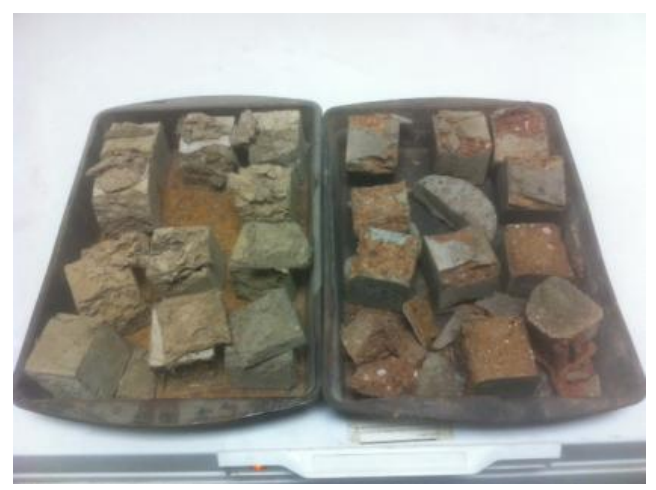

Fig. 4.14. Concrete cubes after compressive test before (left) and after (right) submersion in the molten salt for 500 hours at $1085^{\circ} \mathrm{F}\left(585^{\circ} \mathrm{C}\right)$ 
Table 4.6A Weights and dimensions before and after 500 hours in molten salt at $1085^{\circ} \mathrm{F}$ $\left(585^{\circ} \mathrm{C}\right)$

\begin{tabular}{|c|c|c|c|c|c|c|}
\hline Mixtures & $\begin{array}{c}\text { Weight } \\
\text { before (lb) }\end{array}$ & $\begin{array}{c}\text { Weight } \\
\text { after (lb) }\end{array}$ & $\begin{array}{c}\text { \% Weight } \\
\text { gained }\end{array}$ & $\begin{array}{c}\text { Width } \\
\text { before (in.) }\end{array}$ & $\begin{array}{c}\text { Width } \\
\text { after (in.) }\end{array}$ & $\begin{array}{c}\text { \% Length } \\
\text { change }\end{array}$ \\
\hline 1 & 0.6660 & 0.7410 & 11 & 2.008 & 2.007 & 0.00 \\
\hline 2 & 0.6955 & 0.7815 & 12 & 2.003 & 2.006 & 0.15 \\
\hline 3 & 0.7010 & 0.7825 & 12 & 2.008 & 2.017 & 0.45 \\
\hline 4 & 0.6360 & 0.7340 & 15 & 2.008 & 2.016 & 0.40 \\
\hline 5 & 0.6850 & 0.7625 & 11 & 2.036 & 2.036 & 0.00 \\
\hline 6 & 0.6540 & 0.7450 & 14 & 2.012 & 2.022 & 0.50 \\
\hline 7 & 0.7000 & 0.7730 & 10 & 2.015 & 2.019 & 0.20 \\
\hline 8 & 0.6955 & 0.7855 & 13 & 2.015 & 2.027 & 0.60 \\
\hline 9 & 0.7080 & 0.7810 & 10 & 2.011 & 2.018 & 0.35 \\
\hline 10 & 0.6840 & 0.7800 & 14 & 2.043 & 2.036 & 0.34 \\
\hline 11 & 0.6795 & 0.7600 & 12 & 2.029 & 2.036 & 0.34 \\
\hline 12 & - & - & - & - & - & - \\
\hline 13 & $0.3725^{*}$ & $0.4255^{*}$ & 14 & $3.848^{*}$ & $3.886^{*}$ & $1.00^{*}$ \\
\hline 14 & - & - & - & - & - & - \\
\hline
\end{tabular}

* Test specimen were not cubes, Fahrenheit $(\mathrm{F})$ to ${ }^{\circ} \mathrm{C}=\left({ }^{\circ} \mathrm{F}-32\right) / 1.8,1 \mathrm{lb}=0.454 \mathrm{~kg}, 1 \mathrm{inch}=$ $25.4 \mathrm{~mm}$ 
Table 4.6B Weights and dimensions before and after thermal cycling in molten salt

\begin{tabular}{|c|c|c|c|c|c|c|}
\hline Mixture & $\begin{array}{c}\text { Weight } \\
\text { before (lb) }\end{array}$ & $\begin{array}{c}\text { Weight } \\
\text { after (lb) }\end{array}$ & $\begin{array}{c}\text { \% Weight } \\
\text { gained }\end{array}$ & $\begin{array}{c}\text { Width } \\
\text { before } \\
\text { (in.) }\end{array}$ & $\begin{array}{c}\text { Width } \\
\text { after (in.) }\end{array}$ & $\begin{array}{c}\text { \% } \\
\text { Length } \\
\text { change }\end{array}$ \\
\hline 1 & - & - & - & - & - & - \\
\hline 2 & 0.680 & 0.817 & 20 & 2.013 & 2.088 & 3.70 \\
\hline 3 & 0.675 & 0.813 & 20 & 2.010 & 2.169 & 7.90 \\
\hline 4 & 0.650 & 0.790 & 22 & 2.050 & 2.085 & 1.70 \\
\hline 5 & 0.692 & 0.813 & 18 & 2.021 & 2.072 & 2.50 \\
\hline 6 & 0.669 & 0.810 & 21 & 2.011 & 2.087 & 3.80 \\
\hline 7 & 0.688 & 0.834 & 21 & 2.052 & 2.141 & 4.30 \\
\hline 8 & 0.675 & 0.817 & 21 & 2.052 & 2.074 & 1.07 \\
\hline 9 & 0.712 & 0.859 & 21 & 2.020 & 2.101 & 4.00 \\
\hline 10 & 0.694 & 0.849 & 22 & 2.022 & 2.092 & 3.50 \\
\hline 11 & 0.700 & 0.836 & 19 & 2.007 & 2.096 & 4.43 \\
\hline 12 & 0.679 & 0.822 & 21 & 2.010 & 2.073 & 3.10 \\
\hline 13 & - & - & - & - & - & - \\
\hline 14 & 0.694 & 0.837 & 21 & 2.055 & 2.071 & 0.80 \\
\hline 15 & 0.690 & 0.783 & 14 & 2.009 & 2.029 & 1.00 \\
& 0.675 & 0.770 & 14 & 2.006 & 2.038 & 1.60 \\
\hline 16 & 0.651 & 0.753 & 16 & 2.050 & 2.021 & 1.40 \\
\hline 17 & 0.651 & 0.757 & 16 & 2.059 & 2.030 & 1.40105 \\
\hline 18 & - & - & - & - & - & - \\
\hline 19 & - & - & - & - & - & - \\
\hline 20 & 0.705 & 0.856 & 21 & 2.012 & 2.091 & 3.90 \\
\hline 21 & - & 0.815 & 15 & 2.016 & 2.096 & 4.00 \\
\hline 22 & 0.688 & 0.807 & 17 & 2.019 & 2.119 & 5.00 \\
\hline 23 & 0.681 & - & - & 2.016 & - & - \\
\hline 24 & 0.657 & 0.765 & 16 & 2.041 & 2.057 & 0.80 \\
\hline 25 & 0.695 & 0.856 & 23 & 2.014 & 2.101 & 4.30 \\
\hline 26 & 0.698 & 0.806 & 15 & 2.007 & 2.063 & 2.80 \\
\hline$S p 6$ & - & - & - & - & - \\
\hline
\end{tabular}

Specimens were subjected to 30 thermal cycles between 572 and $1085^{\circ} \mathrm{F}\left(300\right.$ and $\left.585^{\circ} \mathrm{C}\right)$, Fahrenheit $(\mathrm{F})$ to ${ }^{\circ} \mathrm{C}=\left({ }^{\circ} \mathrm{F}-32\right) / 1.8,1 \mathrm{lb}=0.454 \mathrm{~kg}, 1$ inch $=25.4 \mathrm{~mm}$ 
Table 4.7A Compressive strength before and after 500 hours in molten salt at $1085^{\circ} \mathrm{F}$ $\left(5^{\circ} 5^{\circ} \mathrm{C}\right)$

\begin{tabular}{|c|c|c|c|}
\hline Mixture & $\begin{array}{c}\text { Compressive strength } \\
\text { before (ksi) }\end{array}$ & $\begin{array}{c}\text { Compressive strength } \\
\text { after (ksi) }\end{array}$ & \% strength gained or loss \\
\hline 1 & 10.4 & 19.8 & 90 \\
\hline 2 & $10.5^{\text {a }}$ & - & 16.00 \\
\hline 3 & 11.1 & 12.9 & 150.00 \\
\hline 4 & 9.3 & 23.3 & 111.00 \\
\hline 5 & 8.3 & 17.5 & 52.00 \\
\hline 6 & 8.3 & 12.6 & 85.00 \\
\hline 7 & 6.6 & 12.2 & 166.00 \\
\hline 8 & 6.4 & 17.0 & 97.00 \\
\hline 9 & 5.9 & 11.6 & 38.00 \\
\hline 10 & 8.7 & 12.0 & 149.00 \\
\hline 11 & 5.9 & 14.7 & 66.00 \\
\hline 12 & 8.7 & 14.4 & - \\
\hline 13 & - & - & - \\
\hline 14 & - & - & - \\
\hline
\end{tabular}

Fahrenheit (F) to ${ }^{\circ} \mathrm{C}=\left({ }^{\circ} \mathrm{F}-32\right) / 1.8,1 \mathrm{ksi}=6.9 \mathrm{MPa}$

a cylinder compressive strength

Note: In cases where there are two values of initial compressive strength, the percent strength gained or loss was based on the cube strength. 
Table 4.7B Compressive strength before and after thermal cycling in molten salt

\begin{tabular}{|c|c|c|c|}
\hline Mixture & $\begin{array}{c}\text { Compressive strength } \\
\text { before (ksi) }\end{array}$ & $\begin{array}{c}\text { Compressive strength } \\
\text { after (ksi) }\end{array}$ & \% strength gained or loss \\
\hline 1 & - & - & - \\
\hline 2 & $\begin{array}{l}11.1 \\
9.5^{\mathrm{a}} \\
\end{array}$ & 3.9 & -65.00 \\
\hline 3 & $\begin{array}{c}9.3 \\
10.5^{\mathrm{a}}\end{array}$ & 4.5 & -52.00 \\
\hline 4 & $\begin{array}{r}8.3 \\
9.4^{\mathrm{a}} \\
\end{array}$ & 5.2 & -37.00 \\
\hline 5 & $\begin{array}{l}8.3 \\
7.3^{\mathrm{a}} \\
\end{array}$ & 5.6 & -33.00 \\
\hline 6 & $\begin{array}{l}6.6 \\
4.6^{\mathrm{a}} \\
\end{array}$ & 7.5 & 14.00 \\
\hline 7 & \begin{tabular}{|l|l}
6.4 \\
$5.3^{\mathrm{a}}$ \\
\end{tabular} & 9.3 & 45.00 \\
\hline 8 & $\begin{array}{r}5.9 \\
3.6^{\mathrm{a}} \\
\end{array}$ & 6.1 & 3.40 \\
\hline 9 & $\begin{array}{l}8.7 \\
8.1^{\mathrm{a}} \\
\end{array}$ & 5.4 & -38.00 \\
\hline 10 & $\begin{array}{l}5.9 \\
5.2^{\mathrm{a}} \\
\end{array}$ & 6.0 & 2.00 \\
\hline 11 & $\begin{array}{l}8.7 \\
7.0^{\mathrm{a}}\end{array}$ & 9.4 & 8.00 \\
\hline 12 & $3.0^{\mathrm{a}}$ & 6.1 & 103.00 \\
\hline 13 & $\begin{array}{l}\mathrm{NA} \\
5.4 \mathrm{a}\end{array}$ & $\mathrm{NA}$ & - \\
\hline 14 & $2.3^{\mathrm{a}}$ & 7.7 & 235.00 \\
\hline 15 & $10.6^{\mathrm{a}}$ & $\begin{array}{l}10.8 \\
11.7\end{array}$ & $\begin{array}{c}2.00 \\
10.00\end{array}$ \\
\hline 16 & $9.8^{\mathrm{a}}$ & $\begin{array}{l}13.8 \\
11.7 \\
\end{array}$ & $\begin{array}{l}41.00 \\
19.00 \\
\end{array}$ \\
\hline 17 & $4.3^{\mathrm{a}}$ & NA & - \\
\hline 18 & $5.0^{\mathrm{a}}$ & NA & - \\
\hline 19 & $7.9^{\mathrm{a}}$ & 6.7 & -15.00 \\
\hline 20 & $5.2^{\mathrm{a}}$ & 7.9 & 52.00 \\
\hline 21 & $6.2^{\mathrm{a}}$ & NA & - \\
\hline 22 & $4.9^{\mathrm{a}}$ & 4.0 & -18.00 \\
\hline 23 & $3.5^{\mathrm{a}}$ & failed & - \\
\hline 24 & $4.0^{\mathrm{a}}$ & 9.6 & 140.00 \\
\hline 25 & $6.0^{\mathrm{a}}$ & 8.5 & 42.00 \\
\hline 26 & $23.0^{\mathrm{a}}$ & 18.3 & -20.00 \\
\hline
\end{tabular}

${ }^{\mathrm{a}}$ cylinder compressive strength, Fahrenheit $(\mathrm{F})$ to ${ }^{\circ} \mathrm{C}=\left({ }^{\circ} \mathrm{F}-32\right) / 1.8,1 \mathrm{ksi}=6.9 \mathrm{MPa}$. Note: In cases where there are two values of initial compressive strength, the percent strength gained or loss was based on the cube strength. 


\subsection{Selection and Characterization of Concrete Mixtures for Final Testing}

Four concrete mixtures were identified for further characterization and performance testing as the TES medium in the thermocline storage system, Option B. The four mixtures were selected from the 26 mixtures presented in Tables $4.3 \mathrm{~A}$ to $4.3 \mathrm{G}$. The selection was based on costs and performance, without considering the results of the thermal cycling test with specimens submerged in molten salt. The selected Mixtures were 2,11, 15 and 26. These mixtures are shown in Table 4.8.

Mixture 26, the proprietary mixture had unit cost that was more than twice the cost of the other three mixtures. However, this mixture exhibited superior thermal and mechanical properties both prior to and after exposure to temperatures of $1112^{\circ} \mathrm{F}\left(600^{\circ} \mathrm{C}\right)$. It was therefore prudent to assess its performance when integrated in the prototype thermocline storage system.

Table 4.8 Selected mixtures for TES Option B

\begin{tabular}{|c|c|c|c|c|}
\hline \multirow{2}{*}{$\begin{array}{l}\text { Materials } \\
\left(\mathbf{l b} / \mathbf{y d} \mathbf{d}^{3}\right)\end{array}$} & \multicolumn{4}{|c|}{ Mixtures } \\
\hline & 2 & 11 & 15 & 26 \\
\hline Cement & 398 & 360 & 675 & - \\
\hline Fly ash & 927 & 540 & 675 & - \\
\hline Silica fume & - & - & - & - \\
\hline Fine aggregates & 1855 & 1285 & 1978 & - \\
\hline $\begin{array}{l}\text { Coarse } \\
\text { aggregates }\end{array}$ & - & 1285 & - & - \\
\hline Water & 398 & 325 & 378 & 236 \\
\hline PP fiber & 3.4 & 3.4 & 3.4 & 3.4 \\
\hline Steel fiber & - & - & - & 263 \\
\hline HRWR & - & - & - & 51 \\
\hline Premix & - & - & - & 3738 \\
\hline
\end{tabular}

$1 \mathrm{lb} / \mathrm{yd}^{3}=0.593 \mathrm{~kg} / \mathrm{m}^{3}$

The four selected concrete mixtures were characterized based on their compressive strength, splitting tensile strength, modulus of elasticity, thermal conductivity $(K)$, and specific heat $\left(\mathrm{C}_{\mathrm{p}}\right)$ values. These parameters were measured before and after exposure to 30 thermal cycles (in the 
absence of molten salt) between 572 and $1112^{\circ} \mathrm{F}\left(300\right.$ to $\left.600^{\circ} \mathrm{C}\right)$. The detailed results are given in Appendix B. A summary of the properties is presented in Table 4.9.

Based on the results presented in Table 4.9, Mixture 26 is the most resistant to thermal cycles as evidenced by the residual properties. Its residual compressive strength, $10 \mathrm{ksi}$ (70 MPa), was three times that of Mixtures 2 and 15 and five times that of Mixture 11. The residual splitting tensile strength was more than four times that of the other mixtures and its modulus of elasticity was more than twice that of the other three mixtures. In terms of the thermal properties, its specific heat was comparable to that of Mixtures 2, 11 and 15 but the residual thermal conductivity was 1.5 to 2 times that of the other mixtures. In fact, the residual properties of Mixture 26 (except for the MOE) are as good or even better when compared to normal strength concrete not exposed to elevated temperatures. However, the cost of the mixture was about twice that of Mixtures 2 and 11 and four times that of Mixture 15.

Mixture 11 was approximately twice the cost of Mixture 15 but it possessed better thermal properties and its residual compressive strength was the lowest of the four mixtures. However, as mentioned previously, these concretes are only required to support their self-weight and therefore, the residual compressive strength of Mixture 11 was deemed acceptable for this application. When cycled in the presence of the molten salt, Mixtures 15, 16, 20, 24, 25 and Mixture 26 show promise as candidate materials for deployment in the TES system Option B. Mixture 26, though it showed a compressive strength loss of $20 \%$, was identified as a candidate material because of its high compressive strength and higher thermal properties when compared to other mixtures.

The selection of candidate materials based on residual compressive strength focused more on the compressive strength results obtained from thermal cycling in the absence of molten salt. 
The residual compressive strength of specimens cycled in molten salt is not indicative of the actual compressive strength of the specimens. The compressive strength is altered by the presence of hardened molten salt within the concrete pores. After thermal cycling in molten salt, the specimens were allowed to return to ambient temperature before testing. At ambient temperatures molten salt solidifies and therefore, trapped molten salt within the concrete pores could account for increases in strength. The compressive strength of molten salt at ambient temperatures is approximately $24 \mathrm{ksi}$ (164 MPa) (Iverson et al., 2010). Under actual operating conditions, the salt is in a liquid state and will not contribute to the concrete's compressive strength.

Table 4.9 Thermo-mechanical properties of selected mixtures

\begin{tabular}{|c|c|c|c|c|c|c|c|c|}
\hline \multirow[b]{2}{*}{ Properties } & \multicolumn{2}{|c|}{ Mixture 2} & \multicolumn{2}{|c|}{ Mixture 11} & \multicolumn{2}{|c|}{ Mixture 15} & \multicolumn{2}{|c|}{ Mixture 26} \\
\hline & $\begin{array}{c}\text { Before } \\
\text { heating }\end{array}$ & $\begin{array}{c}\text { After } \\
\text { heating }\end{array}$ & $\begin{array}{c}\text { Before } \\
\text { heating }\end{array}$ & $\begin{array}{c}\text { After } \\
\text { heating }\end{array}$ & $\begin{array}{c}\text { Before } \\
\text { heating }\end{array}$ & $\begin{array}{c}\text { After } \\
\text { heating }\end{array}$ & $\begin{array}{c}\text { Before } \\
\text { heating }\end{array}$ & $\begin{array}{c}\text { After } \\
\text { heating }\end{array}$ \\
\hline $\begin{array}{l}\text { Compressive } \\
\text { strength } \\
(k s i)\end{array}$ & 9.70 & 3.00 & 6.90 & 1.80 & 10.80 & 3.80 & 21.00 & 10.00 \\
\hline $\begin{array}{l}\text { Splitting } \\
\text { tensile } \\
\text { strength } \\
(k s i)\end{array}$ & 0.860 & 0.130 & 0.470 & 0.140 & 0.820 & 0.130 & 1.30 & 0.60 \\
\hline $\begin{array}{l}\text { Modulus of } \\
\text { elasticity } \\
(k s i)\end{array}$ & 4550 & 200 & 3505 & 250 & 5060 & 390 & 7680 & 920 \\
\hline $\begin{array}{l}\text { Thermal } \\
\text { conductivity } \\
(K) \\
\left(B t u / f t . h^{o}{ }^{o} F\right)\end{array}$ & 1.10 & 0.38 & 1.156 & 0.578 & 1.243 & 0.439 & 1.387 & 0.867 \\
\hline $\begin{array}{l}\text { Specific heat } \\
\left(\mathrm{C}_{\mathrm{p}}\right) \\
\left(B t u / l b m^{o} F\right)\end{array}$ & 0.232 & 0.222 & 0.229 & 0.196 & 0.210 & 0.174 & 0.236 & 0.196 \\
\hline $\begin{array}{l}\text { Unit weight } \\
\left(l b / f t^{3}\right)\end{array}$ & 140 & 120 & 145 & 130 & 140 & 123 & 150 & 140 \\
\hline
\end{tabular}

$1 \mathrm{ksi}=6.9 \mathrm{MPa}, 1 \mathrm{Btu} / \mathrm{lbm}^{\circ} \mathrm{F}=4.1868 \mathrm{~J} / \mathrm{gK}, 1 \mathrm{Btu} / \mathrm{ft} . \mathrm{h} .{ }^{\circ} \mathrm{F}=1.73 \mathrm{~W} / \mathrm{mK}, 1 \mathrm{lb} / \mathrm{ft}^{3}=16.02 \mathrm{~kg} / \mathrm{m}^{3}$ 


\subsection{Thermal Conductivity $(K)$}

The thermal conductivity of selected mixtures developed during the three phases was measured before and after thermal cycling. In addition, the thermal conductivity after thermal cycling was estimated based on Equation 4 given in Chapter 3. The results of the measured and calculated $K$ are shown in Table 4.10. Table 4.10 shows that the measured and calculated $K$ for Mixtures 1, 4 and 6 from Phase II and Mixture 26 from Phase III are in reasonable agreement, the difference being less than $20 \%$. However, for the remaining mixtures, the equation over estimated $K$ by as much as $90 \%$ after thermal cycling. It was difficult to point to a specific reason to explain the observed trend; however, the mixtures that were thermally cycled at the higher temperatures, between 572 and $1112^{\circ} \mathrm{F}$ compared to 73 to $932^{\circ} \mathrm{F}\left(300\right.$ and $600^{\circ} \mathrm{C}$ compared to 23 to $500^{\circ} \mathrm{C}$ ), generally showed a greater difference between the predicted and the measured $K$ values. Given the discrepancy between the calculated and measured residual $K$ shown in Table 4.12, the use of the proposed equation to predict residual $K$ is not recommended.

Concrete specimens that were cycled between ambient and $932^{\circ} \mathrm{F}\left(500^{\circ} \mathrm{C}\right)$ had losses in $K$ of less than $30 \%$. Those cycled at the higher temperatures had losses ranging from 40 to $65 \%$. No definitive conclusions about the reduction in the $K$ values of concrete can be made based on these tests. It is possible that at higher temperatures, specimens developed more micro cracks hence the higher reduction in $K$. Another possible explanation for the high reduction in $K$ observed in mixtures thermally cycled at higher temperatures is transformation of the hydration products. At these higher temperatures, chemically combined water evaporates. Water has a higher $K$ than air and this may account for the reduction in $K$. 
Table 4.10 Predicted and measured $K$ values

\begin{tabular}{|l|c|c|c|c|c|}
\hline \multirow{2}{*}{ Mixtures } & \multicolumn{5}{|c|}{ Thermal Conductivity $\left(\right.$ Btu/ft.h. $\left.{ }^{\boldsymbol{o}} \boldsymbol{F}\right)$} \\
\cline { 2 - 6 } & Before & After & Calculated & Predicted/measured & \% loss \\
\hline$\# 1^{1}$ & 1.445 & 1.231 & $1.127^{\mathrm{a}}$ & 0.92 & 14.8 \\
\hline$\# 4^{1}$ & 1.156 & 1.040 & $0.838^{\mathrm{a}}$ & 0.81 & 10.0 \\
\hline$\# 6^{1}$ & 1.272 & 0.890 & $0.954^{\mathrm{a}}$ & 1.07 & 30.0 \\
\hline TC1000 & 1.792 & 0.750 & $1.410^{\mathrm{b}}$ & 1.88 & 58.0 \\
\hline$\# 2^{2}$ & 1.100 & 0.376 & $0.717^{\mathrm{b}}$ & 1.91 & 66.0 \\
\hline$\# 11^{2}$ & 1.156 & 0.578 & $0.775^{\mathrm{b}}$ & 1.34 & 50.0 \\
\hline$\# 15^{2}$ & 1.243 & 0.439 & $0.861^{\mathrm{b}}$ & 1.96 & 65.0 \\
\hline$\# 26^{2}$ & 1.387 & 0.867 & $1.01^{\mathrm{b}}$ & 1.16 & 38.0 \\
\hline
\end{tabular}

"TC1000 without steel fibers, ${ }^{1}$ Phase II mixtures, ${ }^{2}$ Phase III mixtures

${ }^{a}$ concrete specimens thermally cycled between ambient and $932^{\circ} \mathrm{F}\left(500^{\circ} \mathrm{C}\right)$

${ }^{\mathrm{b}}$ concrete specimens thermally cycled between 572 and $1112^{\circ} \mathrm{F}\left(300\right.$ and $\left.600^{\circ} \mathrm{C}\right)$

$1 \mathrm{Btu} / \mathrm{ft} . \mathrm{h} .{ }^{\circ} \mathrm{F}=1.73 \mathrm{~W} / \mathrm{mK}$, Fahrenheit $(\mathrm{F})$ to ${ }^{\circ} \mathrm{C}=\left({ }^{\circ} \mathrm{F}-32\right) / 1.8$

\subsection{Specific Heat $\left(C_{p}\right)$}

The specific heat $\left(\mathrm{C}_{\mathrm{p}}\right)$ of 12 of the 26 mixtures was measured before thermal cycling. The procedure for measuring $C_{p}$ was outlined in Chapter 3. The average measured $C_{p}$ plotted in Figure 4.15 represents the average of three tests. The error bars represent a 90\% confidence interval for the mean based on measured $\mathrm{C}_{\mathrm{p}}$. The two dotted lines are the upper and lower bound of $\mathrm{C}_{\mathrm{p}}$ based on the assumption that all the water in the mixtures was free water (upper bound values), in which case $\mathrm{C}_{\mathrm{p}}$ was $0.9984 \mathrm{Btu} / \mathrm{bm}^{\circ} \mathrm{F}(4.18 \mathrm{~J} / \mathrm{gK})$, and the lower bound $\mathrm{C}_{\mathrm{p}}$ value was $0.5255 \mathrm{Btu} / \mathrm{lbm}^{\circ} \mathrm{F}(2.20 \mathrm{~J} / \mathrm{gK})$. In the case of the lower bound $\mathrm{C}_{\mathrm{p}}$ values, the water in the mixtures was considered chemically bonded or adsorbed, in which case its heat capacity is reduced (Waller et al., 1996). It can be observed from Figure 4.15 that the measured values are in good correlation with the calculated lower bound values.

In a number of cases the measured $\mathrm{C}_{\mathrm{p}}$ values fell just below the lower bound limits. This could be explained from the manner in which $\mathrm{C}_{\mathrm{p}}$ was measured. That is, the concrete specimens were allowed to dry at $212^{\circ} \mathrm{F}\left(100^{\circ} \mathrm{C}\right)$ for 24 hours before testing. This process removed any free water that would have otherwise increased the measured $\mathrm{C}_{\mathrm{p}}$. One can also observe that the 
average measured $C_{p}$ do not vary significantly from one mixture to the other even if the mixtures are quite different in terms of their material constituents. This was expected because $\mathrm{C}_{\mathrm{p}}$ of the constituent materials was similar. Water is the only constituent material which can significantly alter the $C_{p}$, because the $C_{p}$ of water is much higher than the $C_{p}$ of the other constituent materials. All mixtures that are shown in Figure 4.15 had water contents of approximately $300 \mathrm{lb} / \mathrm{yd}^{3}$ (178 $\mathrm{kg} / \mathrm{m}^{3}$ ), except for Mixtures 8, 9 and 10. These mixtures had water contents of 378, 398 and 325 $\mathrm{lb} / \mathrm{yd}^{3}\left(224,236\right.$ and $\left.193 \mathrm{~kg} / \mathrm{m}^{3}\right)$ respectively and therefore have higher average measured $\mathrm{C}_{\mathrm{p}}$. The mixture with $325 \mathrm{lb} / \mathrm{yd}^{3}\left(193 \mathrm{~kg} / \mathrm{m}^{3}\right)$ of water also contained sandstone which has a higher $\mathrm{C}_{\mathrm{p}}$ than the fine aggregates that were used in the other mixtures. This accounts for the relatively high measured $\mathrm{C}_{\mathrm{p}}$ for Mixture 10. The upper and lower bound lines did not extend to include Mixtures 11 and 12. Since they are the proprietary mixtures, their exact material constituents are not known. However, if the upper and lower bound $\mathrm{C}_{\mathrm{p}}$ lines were extrapolated based on the knowledge that the $\mathrm{w} / \mathrm{cm}$ of these mixtures is less than 0.20 , the measured values will fall within these bounds and closer to the lower bound line. This analysis shows that the Law of Mixtures can be used to estimate the $\mathrm{C}_{\mathrm{p}}$ values of concrete mixtures. 


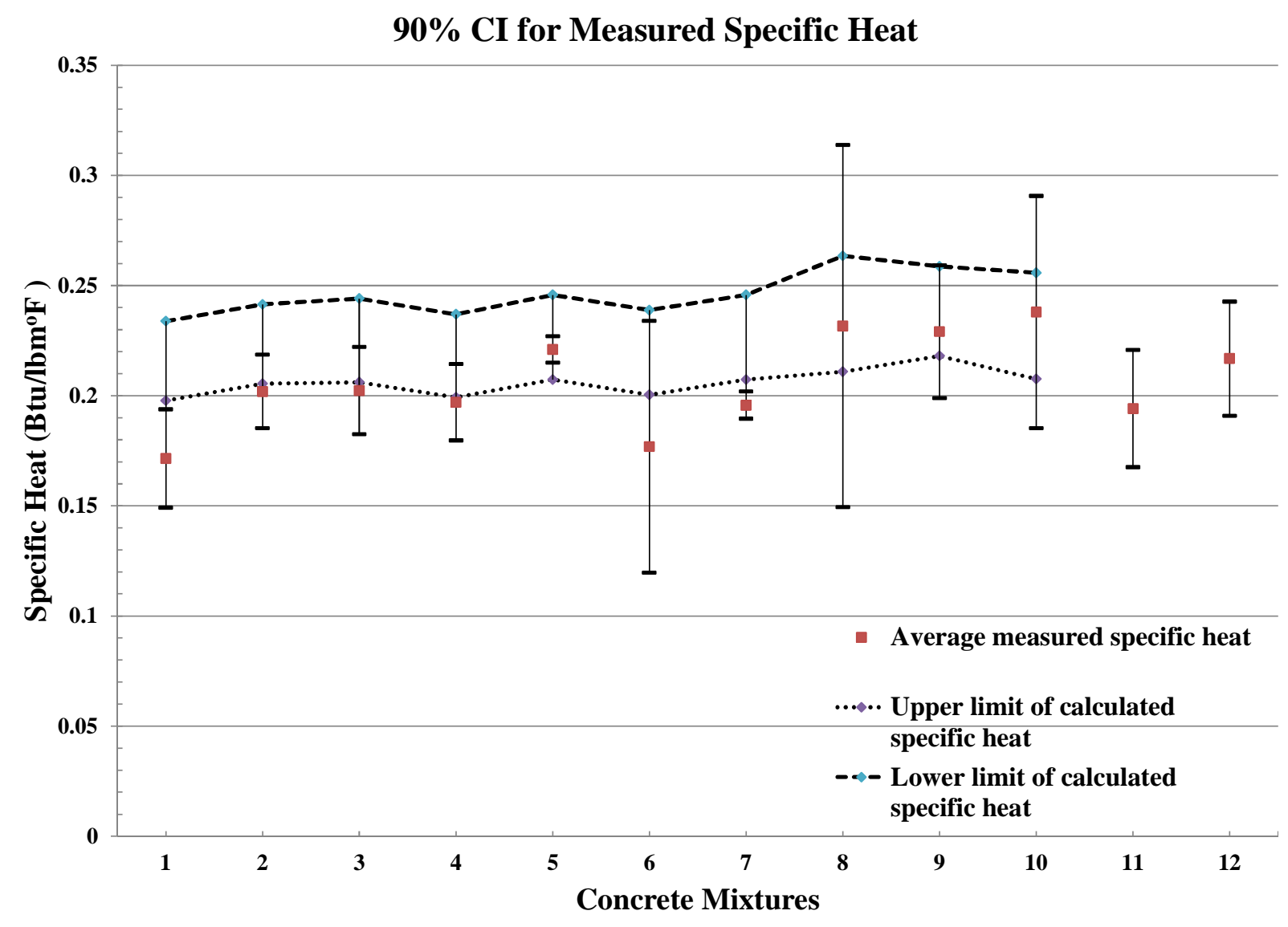

Fig. 4.15. Measured and calculated values of specific heat.

- Dashed and dotted lines represent the upper and lower limits of the calculated specific heat based on Equation 10, respectively.

- Squares are the average measured specific heat.

- Mixtures 1 to 7 are those in Tables 4.3A and 4.3B, Mixture 8 is Mixture 2 in Table 4.5A, Mixture 9 is 15 in Table 4.5D, Mixture 10 is Mixture 11 in Table 4.5C, Mixture 11 is Mixture 26 in Table 4.5G and Mixture 12 is the Mixture in Table 4.4.

- the upper and lower bound lines do not extend to include Mixtures 11 and 12 because their constituent materials are not known.

The measured specific heat $\left(\mathrm{C}_{\mathrm{p}}\right)$ for seven concrete mixtures before and after thermal cycling is presented in Table 4.11. The table shows that the two CAC-FA mixtures (Mixtures 2 and 11) had similar initial $\mathrm{C}_{\mathrm{p}}$ values; however, the percentage reduction after thermal cycling was 4 and 15\% respectively. It should be noted that Mixture 2 contained no coarse aggregates whereas Mixture 11 contained equal amounts of fine and coarse (sandstone) aggregates. The 
difference between the two mixtures was in the amount and type of coarse aggregates. The reduction in $\mathrm{C}_{\mathrm{p}}$ value experienced by Mixture 11 (with coarse aggregates) can be attributed to the presence of the coarse aggregates. It appears that CAC-FA mixtures containing coarse aggregates would have a greater reduction in $\mathrm{C}_{\mathrm{p}}$ when compared to similar mixtures without coarse aggregates.

The proprietary mixture, TC1000 with and without steel fibers identified as TC1000 and Mixture 26 in Table 4.11, had $\mathrm{C}_{\mathrm{p}}$ reductions of 22 and 17\% respectively. The mixture containing steel fibers had a slightly higher percentage $\mathrm{C}_{\mathrm{p}}$ loss. Mixtures 2 and 15 are similar mixtures except they contain different cementitious materials in different proportions. In Mixture 2, CAC and FA were combined in proportions of $30: 70$ by weight of the total cementitious materials whereas in Mixture 15, OPC and FA were used in proportions of 50:50. These two mixtures (2 and 15) had reductions in their $C_{p}$ after thermal cycling of 4 and 17\%, respectively. This shows that OPC-FA mixtures would experience higher $\mathrm{C}_{\mathrm{p}}$ losses after thermal cycling. Mixture 4, which is also an OPC-FA mixture, had a $\mathrm{C}_{\mathrm{p}}$ loss of $8.5 \%$. The difference between Mixture 4 and Mixture 15, which had a $17 \% \mathrm{C}_{\mathrm{p}}$ loss, was in the total amount of cementitious materials. Mixture 4 contained 1.5 times the total cementitious material content of Mixture 15. The increase in the amount of cementitious materials decreased the fine aggregate content. Therefore, the percent $\mathrm{C}_{\mathrm{p}}$ loss was affected more by the aggregate content than by cementitious material content or type. The increase in the $\mathrm{C}_{\mathrm{p}}$ value for Mixture 6 must be an anomaly because the $\mathrm{C}_{\mathrm{p}}$ values of siliceous aggregate concrete should theoretically decrease after elevated temperature exposure. Kodur and Sultan (2003) showed a reduction in $\mathrm{C}_{\mathrm{p}}$ values for siliceous aggregate concrete over a temperature range from ambient to $1832^{\circ} \mathrm{F}\left(1000^{\circ} \mathrm{C}\right)$. 
Table 4.11 Specific heat $\left(C_{p}\right)$ values before and after thermal cycling

\begin{tabular}{|l|c|c|c|}
\hline \multirow{2}{*}{ Mixtures } & \multicolumn{3}{|c|}{$\mathbf{C}_{\mathbf{p}}$ values $\left(\right.$ Btu/lbm $\left.^{\boldsymbol{o}} \boldsymbol{F}\right)$} \\
\cline { 2 - 4 } & before cycling & after cycling & \% loss \\
\hline$\# 4^{\mathrm{a}}$ & 0.196 & 0.179 & 8.5 \\
\hline$\# 6^{\mathrm{a}}$ & 0.177 & 0.186 & 5.0 gain \\
\hline $\mathrm{TC} 1000^{\mathrm{a}}$ & 0.215 & 0.167 & 22.0 \\
\hline$\# 2^{\mathrm{b}}$ & 0.232 & 0.222 & 4.0 \\
\hline$\# 11^{\mathrm{b}}$ & 0.229 & 0.196 & 15.0 \\
\hline$\# 15^{\mathrm{b}}$ & 0.210 & 0.174 & 17.0 \\
\hline$\# 26^{\mathrm{b}}$ & 0.236 & 0.196 & 17.0 \\
\hline
\end{tabular}

$1 \mathrm{Btu} / \mathrm{lbm}^{\circ} \mathrm{F}=4.1868 \mathrm{~J} / \mathrm{gK},{ }^{\mathrm{a}}$ Phase II mixtures, ${ }^{\mathrm{b}}$ Phase III mixtures

\subsection{Significance of the Test Results as they Relate to Thermal Energy Storage Systems}

In keeping with the objectives of the research, outlined in Chapter 2, the results of the various tests that were presented in the preceding phases are now put into perspective as it relates to their implications on the two options for thermal energy storage (TES).

The Department of Energy (DOE) has a mandate to develop and sponsor programs that will change the way electrical power is provided in the US. Their focus is to ultimately meet the population's demand for energy at a low cost and with reduced environmental impact. In keeping with this mandate, a number of studies have been conducted and is on-going to identify and test alternative sources of energy.

One of the more attractive options for electricity production that was identified by researchers is concentrating solar power (CSP) parabolic trough technology. This technology has already been proven both at the laboratory scale and in the field. One of the major limitations of this technology lies in the nature of the power source, sunlight. Sunlight is intermittent in nature and peak demand for electric power does not coincide with the period of maximum insolation (solar radiation). This limitation highlights the need for alternative energy systems such as CSP technologies to incorporate an energy storage subsystem that is low cost 
and efficient. The two types of energy storage systems that this research addressed are TES systems, Options A and B, which were presented and explained in Chapter 2. The sections which follow look at how the results that were presented in the three phases of the investigations relate to each storage option.

\subsubsection{Thermal Energy Storage (TES) Option A}

In thermal energy storage Option A, heat exchangers are embedded in concrete modules. The heat exchangers act as conduits for the flow of a heat transfer fluid (HTF) which is the source for charging and discharging the concrete modules. This concept was described in details in Chapter 2. The major areas of concern for the storage medium in this TES technology are:

- The thermal conductivity

- The specific heat and specific heat capacity

- Long-term resistance to thermal cycling

- Thermal expansion

- Material cost

A high level of heat transfer is desired within these systems in order to facilitate thermodynamic efficiency. The literature review of storage media for TES Option A that was presented in Chapter 2 showed that concrete was the most promising storage medium that was studied. The performance of concrete was only previously investigated at maximum temperatures up to $752^{\circ} \mathrm{F}$ $\left(400^{\circ} \mathrm{C}\right)$. At that temperature level the thermal conductivity of the storage material was reported as $0.578 \mathrm{Btu} / \mathrm{ft} . \mathrm{h} .{ }^{\circ} \mathrm{F}(1 \mathrm{~W} / \mathrm{mK})$. In this research, the concretes that were studied were exposed to temperatures of up to $1112^{\circ} \mathrm{F}\left(600^{\circ} \mathrm{C}\right)$ and their residual thermal conductivity were as high as 1.16 Btu/ft.h. ${ }^{o} \mathrm{~F}(2 \mathrm{~W} / \mathrm{mK})$ in some cases. That is, the thermal conductivity was twice that of the concrete that was used by earlier researchers. 
Tamme et al. (2003) performed parametric analyses to assess the effect of varying factors on the performance of the storage system. The thermal conductivity of the storage medium was one of the parameters studied. They found that for a charging time of 3600 seconds, thermal conductivities greater than $0.867 \mathrm{Btu} / \mathrm{ft} . \mathrm{h} .{ }^{\circ} \mathrm{F}(1.5 \mathrm{~W} / \mathrm{mK})$ were needed to obtain a maximum operating temperature of $390^{\circ} \mathrm{C}$. In their study, the distance between the centerline of adjacent heat exchangers was 3.15 in. $(80 \mathrm{~mm})$. Tamme et al. (2003) highlighted the need for the temperature at the center of the concrete between adjacent heat exchangers to reach maximum operating temperatures. Failure to achieve maximum temperatures result in temperature gradients within the storage medium after charging. During the period of rest before discharge, temperature equilibrium is reached and the quality of the stored energy is reduced. Thus, high thermal conductivity serves to reduce the charging time of the TES system and ensure that the storage medium achieves maximum operating temperatures.

The specific heat capacity $\left(\rho \times C_{p}\right)$ is directly proportional to concrete density. A high density signifies higher energy storage for a given volume of material. However, higher densities also mean that the concretes are more susceptible to explosive spalling. The concretes that were studied for deployment in this TES system, which were presented in Phase II are all dense; however the use of a small amount of PP fibers provided the porosity required to alleviate internal pressure during the first heating cycle of the concrete modules.

In terms of the long term resistance to thermal cycling, the concretes that were studied were subjected to 10 thermal cycles between ambient temperatures and $932^{\circ} \mathrm{F}\left(500^{\circ} \mathrm{C}\right)$ and in one case between 572 and $1112^{\circ} \mathrm{F}\left(300\right.$ and $\left.600^{\circ} \mathrm{C}\right)$ for 30 cycles. The concretes had reductions in compressive strength after 3 thermal cycles and also developed hairline cracks. However, subsequent cycling resulted in no further degradation of the specimens. It is expected that 
fatigue, due to repeated thermal cycles, will cause hairline cracks to develop into fissures after some time but because of the presence of steel fibers, the post cracking behavior of these concretes are enhanced. The concrete modules are therefore more durable and may remain in service for a longer period.

The question of thermal expansion is still a problem for this TES option, particularly given the increase in operating temperatures that are facilitated by the use of molten salt as the heat transfer fluid. Since salt is used, the heat exchangers must be stainless steel which has a coefficient of thermal expansion that is approximately twice that of the concretes used. However, the testing showed that the use of an interface material reduced the stress development in the concrete when the system is heated, thus reducing cracking. The heat exchanger-concrete interface should maintain full contact, this facilitates heat transfer. Therefore the interface material ensures that contact is maintained, while enhancing the durability of the storage medium.

In terms of the material cost, steel fibers increased the unit cost of the mixtures and in those cases in which calcium aluminate cement (CAC) was used; the unit costs were even higher. These prices were given in Tables 4.3A and 4.3B of Section 4.2. If the amount of steel fibers used in some of these mixtures were reduced or removed, the material cost would be less than $\$ 150.00 / \mathrm{yd}^{3}\left(\$ 196.00 / \mathrm{m}^{3}\right)$. When this figure is compared to the unit cost of $\$ 130.00 / \mathrm{yd}^{3}$ $\left(\$ 170.00 / \mathrm{m}^{3}\right)$, which represents 2002 dollar amount, for the concrete that was used by earlier researchers, these mixtures are comparable. One must bear in mind that the overall objectives of thermal energy storage are to increase annual solar electric contribution, to improve the efficiency of CSP and to reduce the cost of solar electric production. These objectives can only be achieved if the storage medium is low cost, efficient and durable. 


\subsubsection{Thermal Energy Storage Option B}

In the case of energy storage Option B, molten salt flows directly over the concrete during the charging and discharging phases. The working concept of this storage system was presented in Chapter 2. The main concerns for using concrete as a storage medium in this TES system are:

- The long term stability of the concrete in the presence of molten salt

- Retention of satisfactory thermal properties, mainly thermal conductivity and specific heat, after repeated thermal cycles

The concretes that were studied for deployment in this TES option were presented in Section 4.3. Specimens subjected to repeated thermal cycles between 572 and $1085^{\circ} \mathrm{F}\left(300\right.$ and $\left.585^{\circ} \mathrm{C}\right)$ in the presence of molten salt experienced volumetric changes and reduction in compressive strength. The mixtures which showed promise as it relates to their mechanical stability were Mixtures 15 , 16, 20, 24, 25 and 26. However, it was shown that mixtures containing coarse aggregates and OPC developed high levels of micro cracking and compressive strength loss when tested in the absence of salt. Therefore, Mixtures 20, 24 and 25 may be eliminated as possible candidate materials.

The residual thermal properties of these mixtures are contingent on their residual compressive strengths. The compressive strength test was used as an indicator of the residual thermal properties of the mixtures. In that, if the ambient temperature compressive strengths are retained or even increase after exposure to the different testing regimens, then one can expect the concrete mixtures to also maintain their ambient temperature thermal properties.

As was the case for TES Option A, high thermal conductivity reduces charging time and eliminates thermal gradients within the storage medium at the end of the charging period. High specific heat reduces thermal losses and less material for thermal insulation is required. 


\section{CHAPTER 5 CONCLUSIONS AND RECOMMENDATIONS}

\subsection{Introduction}

Solar electric generating system (SEGS) must have an integrated thermal energy storage system in order to improve reliability. Solar electric generating systems (SEGS) may never completely replace traditional forms of electric power generation (oil, natural gas and coal) but it can complement traditional power generating systems thereby improving dispatchability and

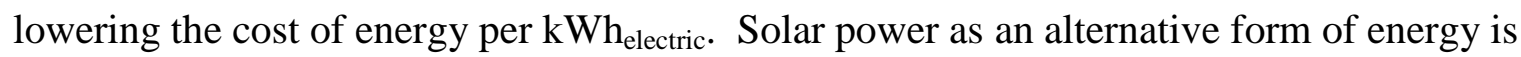
beneficial in the following ways;

1. Sunlight is an inexhaustible energy source

2. Solar power generation has a reduced impact on the environment

3. Countries adapting solar power as an alternative form of energy are less dependent on fossil fuels.

In this research program, two options for thermal energy storage (TES) were identified and discussed. In TES Option A, thermal energy is stored in concrete modules that are charged and discharged by a heat transfer fluid flowing through metallic heat exchangers embedded in the concrete modules. The heat transfer fluid (HTF) is heated in the solar field and flows through a loop of metallic heat exchangers that connects the three subsystems, the solar field, the storage system and the power generating system. Thermal energy storage Option B, referred to as a thermocline energy storage system, is a one-tank system in which stacked concrete bricks are proposed as the storage medium. The system is charged and discharged by the direct flow of the HTF over the storage medium. In both cases, the HTF is a high temperature molten salt which is capable of withstanding temperatures up $1112^{\circ} \mathrm{F}\left(600^{\circ} \mathrm{C}\right)$ without changing phase. Concrete as a storage medium is required to possess the following properties; 
1. A relatively high thermal conductivity, greater than $0.578 \mathrm{Btu} / \mathrm{ft} . \mathrm{h} .{ }^{\circ} \mathrm{F}(1 \mathrm{~W} / \mathrm{mK})$

2. A high heat capacity $\left(\mathrm{C}_{\mathrm{p}}>0.21 \mathrm{Btu} / \mathrm{lbm}^{0} \mathrm{~F}(0.880 \mathrm{~J} / \mathrm{gK})\right)$

3. Low cost

4. Resistant to temperatures up to $1112^{\circ} \mathrm{F}\left(600^{\circ} \mathrm{C}\right)$

5. Have satisfactory long-term resistance to high temperature thermal cycling The following conclusions were drawn from the experimental work conducted in this research for the different phases;

\subsection{Phase I: Effects of Heating Rates and PP Fiber Dosage on the Performance of Concrete at Elevated Temperatures}

In Phase I, concrete's ability to withstand temperatures of $1112^{\circ} \mathrm{C}\left(600^{\circ} \mathrm{C}\right)$ was assessed and PP fiber dosage for the prevention of explosive spalling was determined. Changes in concrete compressive strength were used to assess concrete performance. The following conclusions were made;

- High strength concrete not containing polypropylene fibers will explode or spall violently when exposed to elevated temperatures, between $662^{\circ} \mathrm{F}$ and $1112^{\circ} \mathrm{F}\left(350^{\circ} \mathrm{C}\right.$ and $\left.600^{\circ} \mathrm{C}\right)$, irrespective of the rate of heating.

- The inclusion of $3.4 \mathrm{lb} / \mathrm{yd}^{3}\left(2 \mathrm{~kg} / \mathrm{m}^{3}\right)$ of multifilament polypropylene fibers are adequate to prevent explosive spalling in concrete. Temperatures up $1800^{\circ} \mathrm{F}\left(982^{\circ} \mathrm{C}\right)$, characterized by ASTM E119 heating rates (Fig. 3.5) were investigated.

- Concrete with coarse aggregates $(\geq 3 / 8$ " limestone) and ordinary portland cement (with or without supplementary cementitious materials) as the binder will retain approximately 
$20 \%$ of their initial compressive strength after exposure to temperature of $1112^{\circ} \mathrm{F}$ $\left(600^{\circ} \mathrm{C}\right)$

- Concrete without coarse aggregates (mortars) will retain approximately 50\% of their initial compressive strength after elevated temperature (up to $1112^{\circ} \mathrm{F}$ ) exposure.

\subsection{Phase II: Concrete Developed for TES Option A}

In Phase II, concrete mixtures were developed and tested for deployment in TES system Option A. Resistance to elevated temperature cycles between ambient temperatures and 752 to $1112^{\circ} \mathrm{F}\left(500\right.$ to $\left.600^{\circ} \mathrm{C}\right)$ was evaluated. Thermal conductivity, specific heat, mass loss, and compressive strength were evaluated after 10 thermal cycles. The following conclusions were made;

- Calcium aluminate cement (CAC) mortar mixtures are highly resistant to elevated temperature cycles. These concretes will retain up to $75 \%$ of their initial compressive strength.

- Mortar mixtures with high volumes of cementitious materials $\left(2000 \mathrm{lb} / \mathrm{yd}^{3}\right)$ in which silica fume and fly ash replace $35 \%$ of the ordinary portland cement, are resistant to elevated temperature cycles. These concrete types will retain up to 55\% of their initial compressive strength.

- The mass loss in high strength concrete after elevated temperature cycles range from 5 to $12 \%$.

- The thermal conductivity $(K)$ of high strength mortars with unit weights of approximately $150 \mathrm{lb} / \mathrm{ft}^{3}$ is approximately $1.2 \mathrm{Btu} / \mathrm{ft} .{ }^{.}{ }^{\circ} \mathrm{F}(2 \mathrm{~W} / \mathrm{mK})$. This value is similar to that of conventional concrete; however, the performance of conventional concrete at the 
temperatures studied in this research is not comparable. Increased $K$ values are dependent on the aggregate type. There is a direct relationship between the $K$ values of the aggregates and the overall $K$ value of the mortar and/or concrete. Granite based fines will increase the $K$ values of mortar mixtures by approximately $12 \%$ when compared to silica sand.

- The inclusion of fly ash and silica fume in concrete mixtures decreases their $K$ values. Additionally, by increasing in the supplementary cementitious material content of concrete and/or mortar mixtures, the aggregate content per cubic yard will decrease, resulting in the reduction of $K$.

- The inclusion of steel fibers to improve the $K$ values of concrete is not cost effective. The resulting increase in $K$ values is less than $20 \%$ and the corresponding unit price of the concrete mixtures increases three times with $100 \mathrm{lb} / \mathrm{yd}^{3}$ of steel fibers.

- The specific heat $\left(\mathrm{C}_{\mathrm{p}}\right)$ of mortar mixtures is not dependent on the cement type or the cementitious materials $(\mathrm{CM})$ proportions. The $\mathrm{C}_{\mathrm{p}}$ values are mostly affected by the $w / \mathrm{cm}$. Higher $w / \mathrm{cm}$ results in higher room temperature $C_{p}$ values and vice-versa.

- Ordinary portland cement with supplementary cementitious materials (SCM) replacements are resistant to high temperature exposure and thermal cycles. The use of the more expensive CAC (5 to 6 times more than OPC) in concrete mixtures for TES application is not justified. Ordinary portland cement mixtures with SCMs provide acceptable thermo-mechanical properties at a lower cost.

- In the case of TES Option A, the stainless steel metallic heat exchangers must be coated with a thin layer of heat resistant material (with a heat rating $>1112^{\circ} \mathrm{F}\left(600^{\circ} \mathrm{C}\right)$ ) of low modulus of elasticity ( $<0.50 \mathrm{ksi})$ and high $K$. This approach will prevent excessive 
cracking of the concrete and maintain good surface contact between the heat exchanger and the concrete. Deacon 8875 gasket sealant proved effective in this regard.

- Though the proprietary mixture, TC1000, possesses superior thermo-mechanical properties when compared to the other mortar mixtures that were studied, its unit cost is high. The improvement in the thermo-mechanical properties when compared to the cost of this mixture shows that it is not cost-effective. A TES system which uses TC1000 as the storage medium may perform well but the cost of the storage material may render the system unfeasible.

\subsection{Phase III: Concrete Developed for TES Option B}

In Phase III, 26 concrete mixtures were batched and tested for deployment in TES Option B. The major concerns regarding the use of concrete as a thermal energy storage medium for Option B were its compatibility with salt and its ability to sustain its self-weight in the presence of molten salt at temperatures up to $1112^{\circ} \mathrm{F}\left(600^{\circ} \mathrm{C}\right)$. Concrete's compressive strength, thermal conductivity, and specific heat were evaluated. The following conclusions were made;

- Calcium aluminate cement can be combined with supplementary cementitious materials such as type $\mathrm{C}$ fly ash in concrete mixtures.

- Calcium aluminate cement and fly ash mixtures require in excess of $800 \mathrm{lb} / \mathrm{yd}^{3}$ of total cementitious material in order to develop compressive strengths in excess of $4 \mathrm{ksi}$ (28 $\mathrm{MPa})$.

- The fly ash replacement in CAC-FA mixtures could be as high as 50\%.

- The addition of silica fume to CAC-FA mixtures does not increase the compressive strength of the concrete nor its resistance to elevated temperatures. 
- Calcium aluminate cement-fly ash or CAC-FA- (10\%) SF mortar mixtures do not show significant variations in the residual compressive strength after elevated temperature cycling.

- Mortar mixtures with a ratio of cementitious materials to fine aggregates of 1:1.4 retained $33 \%$ of their compressive strength after thermal cycling.

- The conditioning of concrete specimens before thermal cycling affects the residual compressive strengths of concrete. Conditioning entails heating the specimens at very low heating rates, $0.3^{\circ} \mathrm{F} / \mathrm{min}$. up to $230^{\circ} \mathrm{F}$ and subsequently at $1.2^{\circ} \mathrm{F} / \mathrm{min}$. up to $1112^{\circ} \mathrm{F}$ $\left(0.17^{\circ} \mathrm{C} / \mathrm{min}\right.$. up to $110^{\circ} \mathrm{C}$ and at $0.67^{\circ} \mathrm{C} / \mathrm{min}$. up to $\left.600^{\circ} \mathrm{C}\right)$. Residual compressive strengths generally increased after thermal cycling.

- Generally, concrete and mortars when thermally cycled in the presence of molten salt experienced significant reduction in compressive strength (softening). However, OPCFA mortars and the proprietary mixture, TC1000, showed high resistance to this testing regimen.

- Concrete mixtures containing sandstone as the coarse aggregate and OPC, soften quicker when thermally cycled in the presence of molten salt than mixtures containing CAC and sandstone.

\subsubsection{Thermal Conductivity}

High thermal conductivity of the storage medium serves to reduce the charging time of TES systems and ensures that maximum operating temperatures are achieved. In addition, for TES Option A, a high thermal conductivity of the storage medium reduces the number of required heat exchangers. Below are the finding of the research program relating to this parameter. 
- High-volume cementitious material mortar mixtures $\left(2000 \mathrm{lb} / \mathrm{yd}^{3}\right)$ showed less than $40 \%$ reduction in $K$ after thermal cycling in the absence of molten salt (for temperatures up to $\left.1112^{\circ} \mathrm{F}\right)$

- Concrete mixtures of CAC and FA (total CM content $<1000 \mathrm{lb} / \mathrm{yd}^{3}$ ) and mortar mixtures of CAC-FA or OPC-FA (total CM content $<1300 \mathrm{lb} / \mathrm{yd}^{3}$ ) experienced reductions in $K$ of more than $50 \%$ after thermal cycling.

- The proprietary mixture, TC1000, showed reductions in $K$ of $50 \%$ on average after thermal cycling.

- The use of Kodur and Sultan's proposed equation for residual $K$ value computation is unreliable.

\subsubsection{Specific Heat}

The total energy stored by the system is directly proportional to the specific heat of the storage medium. For a TES system, high specific heat implies greater energy storage per unit volume of storage material and in addition, reduces thermal insulation requirements. The following are the findings of the research program relating to this parameter.

- The specific heat of any concrete mixture before exposure to high temperatures can be reliably estimated using the Law of Mixtures with a $C_{p}$ value for the combined water of $0.5255 \mathrm{Btu} / \mathrm{lbm}^{\circ} \mathrm{F}(2.20 \mathrm{~J} / \mathrm{gK})$.

- The $\mathrm{C}_{\mathrm{p}}$ value of concrete range from 0.17 to $0.23 \mathrm{Btu} / \mathrm{lbm}^{\circ} \mathrm{F}(0.72$ to $0.96 \mathrm{~J} / \mathrm{gK})$.

- Aggregate content has a higher effect on $\mathrm{C}_{\mathrm{p}}$ reduction after thermal cycling than cementitious material content. Generally, a high aggregate content will result in higher 
$\mathrm{C}_{\mathrm{p}}$ reductions and in particular, coarse aggregate content seems to have a higher impact on $\mathrm{C}_{\mathrm{p}}$ reduction.

- The reduction in concrete's $\mathrm{C}_{\mathrm{p}}$ values is generally less than $20 \%$ after elevated temperature cycles.

\subsection{Recommendations}

The following are recommendations for concrete mixture proportion and constituent material for TES systems Option A and B.

- The use of a mortar mixture of OPC-FA-SF for TES Option A. The total CM content should be approximately $1500 \mathrm{lb} / \mathrm{yd}^{3}\left(890 \mathrm{~kg} / \mathrm{m}^{3}\right)$ with up to $15 \% \mathrm{SF}$ and $30 \%$ Type C FA replacement. The mixture should also contain $30-50 \mathrm{lb} / \mathrm{yd}^{3}$ of steel fibers to enhance the post cracking behavior of the concrete. The mixture should also have a w/cm between 0.20 and 0.25 . An appropriate amount of high range water reducer must be used to improve the workability of the fresh mixture. The ratio of $\mathrm{CM}$ to aggregates should range from 1:1 to $1: 1.4$ and the maximum aggregate size should be less than $1 / 4$ " $(6.35$ $\mathrm{mm})$. The use of a well graded aggregate is recommended. Based on this research program, granite is a suitable option. However, the use of heavy-weight aggregates possessing high thermal conductivity would be ideal. The mixture must also contain 3.4 $\mathrm{lb} / \mathrm{yd}^{3}\left(2 \mathrm{~kg} / \mathrm{m}^{3}\right)$ of multifilament polypropylene (PP) fibers.

- The use of a mortar mixture containing OPC-FA in proportions of 50-50 as the storage medium for TES Option B. The total CM content should be between 1300 and 1500 $\mathrm{lb} / \mathrm{yd}^{3}$ combined with silica sand and a w/cm of 0.28 to 0.30 . The mixture must also contain $3.4 \mathrm{lb} / \mathrm{yd}^{3}\left(2 \mathrm{~kg} / \mathrm{m}^{3}\right)$ of multifilament polypropylene (PP) fibers. 
- Use bricks of relatively small dimensions, 4 x 4 × 8 to 12 in., (100 x 100 x 200 to 305 $\mathrm{mm}$ ) for TES Option B to minimize the temperature gradients within the individual bricks, thereby reducing the tendency of the bricks to crack.

\subsection{Contribution to Body of Knowledge}

- Economical concrete mixtures were developed that resisted temperatures up to $1112^{\circ} \mathrm{F}$ $\left(600^{\circ} \mathrm{C}\right)$ which is $50 \%$ greater than that currently in use. At this temperature, with a $\Delta \mathrm{T}$ of $500^{\circ} \mathrm{F}\left(260^{\circ} \mathrm{C}\right)$ the unit cost of energy stored in concrete is estimated as $\$ 0.88$ to $\$ 1.00 / \mathrm{kWh}_{\text {thermal }}$. These concrete mixtures will aid significantly in reducing the cost of TES systems and the unit price of electricity, and increase the use of electricity generated by solar power.

- Research results showed that $3.4 \mathrm{lb} / \mathrm{yd}^{3}\left(2 \mathrm{~kg} / \mathrm{m}^{3}\right)$ of multifilament polypropylene fibers is optimal for concretes with compressive strengths up to $23 \mathrm{ksi}$ (158 MPa) when exposed to temperatures up to $1800^{\circ} \mathrm{F}\left(982^{\circ} \mathrm{C}\right)$.

- Mortar mixtures containing ordinary portland cement in combination with fly ash and/or silica fume were developed that were resistant to temperature exposures up to $1112^{\circ} \mathrm{C}$ $\left(600^{\circ} \mathrm{C}\right)$. Research results showed that these mortars were mechanical stable after 2 to 3 thermal cycles which means that no further concrete deterioration will occur after 3 thermal cycles. 


\subsection{Future Work}

- Investigate the use of heavy weight/high thermal conductivity fines such as iron oxide, chromite, silicon carbide, trap rock and/or diabase in the OPC-FA-SF mixture for TES Option A. This will increase the unit weight and as a result reduce the system's storage volume.

- Examine the thermal resistance of the OPC-FA mixture proposed for TES Option B over a longer period ( 2 years) in the presence of molten salt.

- Examine the performance of OPC-FA- quartzite rock and silica sand mixtures in direct contact with molten salt at elevated temperature. Thermal cycling should be conducted instead of an isothermal bath.

- Assess the performance of a CAC-FA mixture (Mixtures 2, 5, 7, 9 or 11) after heating the specimens beyond $1832^{\circ} \mathrm{F}\left(1000^{\circ} \mathrm{C}\right)$. At this temperature, it is possible that a ceramic bond, which is stronger than the original hydraulic bond, could be developed. 


\section{References}

Abrams, M.S. (1971). Compressive strength of concrete at temperatures to $1600^{\circ} \mathrm{F}$. ACI SP 25 , Temperature and Concrete. Detroit, Michigan.

Allen C. (2006). Fire Protection Engineering for New and Existing Tunnels '06: Concrete Solutions to Fire. International Tunneling Association, London.

American Concrete Institute. (1979). Refractory concrete. Detroit, MI: Fowler, T. J. (Ed.).

Ataer, E. O. (2008). Storage of thermal energy. Energy Storage Systems, 1. Retrieved from http://www.eolss.net/Sample-Chapters/C08/E3-14-02-00.pdf

Bazant, Z.P. (1997). International Workshop on Fire Performance of High Strength Concrete, NIST SP 919 '97: Analysis of Pore Pressure, Thermal Stress and Fracture in Rapidly Heated Concrete (155-164). Gaithersburg, MD.

Behloul, M., Chanvillard, G., Casanova, P., \& Orange, G. (2002). Proceedings of the 1st fib Congress, Development of New Materials '02: Fire Resistance of Ductal Ultra-high Performance Concrete. Osaka, Japan.

Bentz, D.P., Peltz, M.A., Duran-Herrera, A., Valdez P., \& Juarez C.A. (2010). Thermal properties of high-volume fly ash mortars and concretes. Journal of Building Physics. 34 (3), 263-275. DOI: 10.1177/1744259110376613.

Bilodeau, A., Kodur, V.R., \& Hoff, G.C. (2004). Optimization of the type and amount of polypropylene fibers for preventing the spalling of lightweight concrete subjected to hydrocarbon fire. Cement Concrete Composite Journal. 26 (2), 163-175.

Bilodeau, A., Malhotra, V.M., \& Hoff, G.C. (1998). International Symposium on High Performance and Reactive Powder Concrete '98: Hydrocarbon Fire Resistance of High Strength Normal Weight and Light Weight Concrete Incorporating Polypropylene Fibers (271-296). Sherbrooke, QC.

Both, C., Van de Haar, P., Tan, G., \& Wolsink, G. (1999). Proceedings, International Conference on Tunnel Fires \& Escape from Tunnels '99: Evaluation of Passive Fire Protection Measures for Concrete Tunnel Linings (95-104). Lyon, France.

Canisius, T.D.G., Waleed, N., \& Matthews, S.L. (2003). Proceedings (CIB Publication No. 290, Eds. Shafi, F., Bukowski, R. \& Klemencic, R.), CIB-CTBUH International Conference on Tall Buildings '03: Evaluation of Effects of the Fire Test on Cardington Concrete Building (353-360). Kuala Lumpur, Malaysia.

Castillo, C., \& Durrani, A. J. (1990). Effect of transient high temperature on high-strength concrete. ACI Materials Journal, 87 (1) 47-53. 
Chan, S.Y.N., Peng, G., \& Chan, J.K.W. (1996). Comparison between high strength concrete and normal strength concrete subjected to high temperature. Journal of Materials and Structures. 29 (12), 616-619.

Cheng, F., Kodur, V.K.R., \& Wang, T. (2004). Stress-strain curves for high strength concrete at elevated temperatures. Journal of Materials in Civil Engineering. 16 (1), 84-90.

Cruz, C. R. (1966). Elastic properties of concrete at high temperatures. Journal of Portland Cement Association Research and Development. 8, 3745.

Diederichs, U., Jumppanen, U. M., \& Penttala, V. (1989). Behavior of high strength concrete at high temperatures. Report No. 92. Helsinki University of Technology, Department of Structural Engineering. Helsinki, Finland.

Faas, S. E. (1983). 10 MWe solar thermal central receiver pilot plant: Thermal storage subsystem evaluation, subsystem activation and controls testing phase. SAND 83-8015, Sandia National Laboratories, Albuquerque. Albuquerque, NM.

Felicetti, R., Gambarova, P. G., Rosati, G. P., Corsi, F., \& Giannuzzi, G. (1996). Proceedings, 4th International Symposium on Utilization of High-Strength/High-Performance Concrete '96: Residual Mechanical Properties of HSC Subjected to High-temperature Cycles (579588). Paris, France.

Fletcher, I.A., Welch, S., Torrero, J.L., Carvel, R.O., \& Usmani, A. (2007). The behavior of concrete structures in fire. Journal of Thermal Science. 11 (2), 37-52.

Fummura, F., Abe, T., \& Shinohara, Y. (1995). Proceedings of the Fourth Weimar Workshop on High Performance Concrete. Material Properties and Design '95: Mechanical Properties of High Strength Concrete at High Temperatures (237-254). Weimar, Germany.

Graybeal, B. A. (2006). Material property characterization of ultra-high performance concrete. Report No. FHWA-HRT-06-103. Federal Highway Administration, McLean, VA.

Hammer, T.A. (1995). High-strength concrete Phase III: Compressive strength and elastic modulus at elevated temperatures. SP6 Fire Resistance, Report 6.1, SINTEF Structures and Concrete.

Han, C., Han, M., \& Heo, Y. (2008). Spalling properties of high strength concrete mixed with various mineral admixtures subjected to fire. International Journal of Concrete Structures and Materials. 2 (1), 41-48.

Hannant, D.J. (1998). Durability of polypropylene fibers in portland cement-based composites: eighteen years of data. Cement and Concrete Research. 28 (12), 1809-1817.

Harmathy, T.Z. (1965). Effects of moisture on the fire endurance of building elements. ASTM Special Technical Publication. 385, 74-95. 
Hermann, U., \& Kearney, D.W. (2002). Survey of thermal energy storage for concentrating solar power plants. Journal of Solar Energy. 124, 145-152.

Hertz, K. (1984). Heat induced explosion of dense concretes. Rep. No. 166. Institute of Building Design. Technical University of Denmark, Denmark.

Iverson, B. D., Broome, S. T., \& Siegel, N. P. (2010). Temperature dependent mechanical property testing of nitrate thermal storage salts. SANDIA National Laboratories. Retrieved from http://s3.amazonaws.com/zanran_storage/www.sandia.gov/ContentPages/109987172.pdf

John, E., Hale, W., \& Selvam, P. (2010). Proceedings of ASME 4th International Conference on Energy Sustainability. Effect of Heating Rates on High Strength Concrete for use as Thermal Energy Storage. Paper No. ES2010-90096. Phoenix, AZ.

John, E., Hale, W., \& Selvam, R. (2011). Proceedings of ASME 2011 5th International Conference on Energy Sustainability. Development of a High Performance Concrete to Store Thermal Energy for Concentrating Solar Power Plants. Paper No. ES2011-54177. Washington, DC.

John, E., Hale, W., Selvam, R., \& Brown, B. (2011). ASME 2011 International Mechanical Engineering Congress on Exposition Energy and Water Scarcity. Development and Performance Evaluation of High Temperature Concrete for Thermal Energy Storage for Solar Power Generation. Denver, CO.

Justnes, H. (2011). Silica fume in high-quality concrete - A review of mechanism and performance. International Concrete Research (special publication). 242, 63-78.

Kearney, D.W. (2004). Engineering evaluation of a molten salt heat transfer fluid in a parabolic trough solar field. NREL NAA-1-30441-04.

Khoury G.A. (2000). Effect of fire on concrete and concrete structures. Progress in Structural Engineering and Materials. 2 (4), 429-447.

Khoury, G.A, \& Algar, S. (1999). Paper Presented at ACI International Conference on State-ofthe-Art in High Performance Concrete '99: Mechanical Behavior of HPC and UHPC Concretes at High Temperatures in Compression and Tension. Illinois.

Kodur, V.K.R. (1998). Performance of high strength concrete-filled steel columns exposed to fire. Canadian Journal of Civil Engineering. 25 (6), 975-981.

Kodur, V.K.R. (2000). ASCE Structures Congress Proceedings '00: Spalling in High Strength Concrete Exposed to Fire - Concerns, Causes, Critical Parameters and Cures (1 - 8). Philadelphia, USA. 
Kodur, V.K.R. (2003). Specialty Conference of Designing Structures for Fire and JFPE '03: Fire Resistance Design Guidelines for High Strength Concrete Columns (1-11). NRCC-46116 ASCE/SFPE. Baltimore, MD.

Kodur, V.K.R., \& Dwaikat, M.B. (2008). Effect of fire induced spalling on the response of reinforced concrete beams. International Journal of Concrete Structures and Materials. 2 (2), 71-81.

Kodur, V.K.R., \& Lie, T.T. (1997). Fiber Reinforced Concrete: Present and the Future, Canadian Society of Civil Engineers '97: Fire Resistance of Fiber-reinforced Concrete (189-213). Canada.

Kodur, V.K.R., \& Phan, L. (2007). Critical factors governing the fire performance of high strength concrete systems. Fire Safety Journal. 42, 482-488.

Kodur, V.K.R., \& Phan, L. (2007). Critical factors governing the fire performance of high strength concrete systems. Fire Safety Journal. 42, 482-488.

DOI:10.1016/j.firesaf.2006.10.006.

Kodur, V.K.R., \& Sultan, M.A. (1998). International Symposium on High Performance and Reactive Powder Concrete '08: Structural Behavior of High Strength Concrete Columns Exposed to Fire (217-232). Sherbrooke, QC.

Kodur, V.K.R., \& Sultan, M.A. (2003). Effects of temperature on thermal properties of highstrength concrete. Journal of Materials. 15 (2), 101-107.

Kodur, V.K.R., (1999). ACI Spring Convention (SP) '99: Fire Performance of High Strength Concrete Columns. Chicago, IL.

Kodur, V.K.R., Cheng, F., Wang, T., \& Sultan, M.A. (2003). Effect of strength and fiber reinforcement on fire resistance of high-strength concrete columns. Journal of Structural Engineering. 129 (2), 253-259.

Kodur, V.R. (2005). Guidelines for fire resistance design of high strength concrete columns. Journal of Fire Protection Engineering. 15 (2), 93-106.

Kodur, V.R., \& McGrath, R.C. (2003). Fire endurance of high strength concrete columns. Journal of Fire Technology. 39 (1), 73-87.

Kolb, G, L., \& Hassani, V. (2006). Proceedings of ISEC ASME International Solar Energy Conference '06: Performance Analysis of Thermocline Energy Storage Proposed for the 1 MW Saguaro Solar Trough Plant. Denver, CO.

Kutzing, L. (1999). Fire resistance of high performance concrete with fiber cocktails. LACER 4. 
Laing, D., Lehmann, D., Bahl, C., \& Zublin, E. (2008). 3rd International Renewable Energy Storage Conference '08: Concrete Storage for Solar Thermal Power Plants and Industrial Process Heat. Berlin, Germany.

Laing, D., Steinmann, W., Tamme, R., \& Richter, C. (2006). Solid media thermal storage for parabolic trough power plants. Solar Energy, 80, 1283-1289.

Lie, T. T. (Ed.). (1993). Structural fire protection: Manual of practice. New York: ASCE.

Lomborg, M. (2001). The skeptical environmentalist: Measuring the real state of the world. (2nd ed.). Cambridge, United Kingdom: Cambridge University Press.

Malhotra, V. M (1990). Durability of Concrete incorporating high volume of low calcium fly ash. Cement and Concrete Composite. 12 (4), 271-277.

Mehta, K. P., \& Monteiro, P. J. M. (2006). Concrete microstructure, properties and materials. (3rd ed.). New York: McGraw Hill.

Morita, T., Saito, H., \& Kumagai, H. (Eds.). (1992). Summaries of Technical Papers of Annual Meeting, Architectural Institute of Japan, Niigata '92: Residual Mechanical Properties of High Strength concrete Members Exposed to High Temperature - Part 1. Test on Material Properties. Niigata, Japan.

Neville, A. M (1981). Properties of concrete. (3rd ed.). Essex, England: Pearson Education Limited.

Neville, A. M (1996). Properties of concrete. (4th ed.). Essex, England: Pearson Education Limited.

Noumowe, A.N., Clastres, P., Debicki, G., \& Costaz, J. L. (1996). Proceedings, 4th International Symposium on Utilization of High Strength/High-Performance Concrete '96: Thermal Stresses and Water Vapor Pressure of High Performance Concrete at High Temperature. Paris, France.

Olszewski, M. (1993). Thermal Energy Storage. Rep. No. ORNL/TM-12384, USDOE, Washington, DC. Retrieved From http://www.osti.gov/energycitations/purl.cover.jsp?purl=/10178460-TyBgvc

OVE ARUP, (2005). HSE fire resistance of concrete enclosures. Final report. London, UK: Yin, R., \& Lamont, S.

Pacheco, J. E., Showalter, S. K., \& Kolb, W. J. (2001). Proceedings of Solar Forum, Solar Energy: The Power to Choose '01: Development of a Molten-salt Thermocline Thermal Storage System for Parabolic Trough Plants. Washington, DC.

Petzold, A., \& Rohrs, M. (1970). Concrete for high temperatures. (2nd ed.). London: McLaren. 
Phan, L. (2007). Concrete under Severe Conditions: Environment \& Loading, CONSEC '07: Spalling and Mechanical Properties of High Strength Concrete at High Temperature (15951608). France.

Phan, L. T., Carino, N. J., Duthinh, D., \& Garboczi, E. (Eds.). (1997). Proceedings from NIST SP 919 '97: NIST International Workshop on Fire Performance of High Strength Concrete. NIST, Gaithersburg, MD.

Phan, L.T. (2007). Concrete under severe conditions: Environment \& loading, CONSEC '07: Spalling and Mechanical Properties of High Strength Concrete at High Temperature. France.

Phan, L.T., \& Carino, N.J. (1998). Review of mechanical properties of HSC at elevated temperatures. Journal of Materials in Civil Engineering. 10 (1), 58-64.

Phan, L.T., Lawson, L.J.R., \& Davis, F.L. (2001). Effects of elevated temperature exposure on heating characteristics, spailing, and residual properties of high performance concrete. Journal of Materials and Structures. 34, 83-91.

Schnieder, U. (1976). Behavior of concrete under thermal steady state and non-steady state conditions. Fire and Materials. 1 (1), 103-115.

Segre, N., Tonella, E., \& Joekes, I. (1998). Evaluation of the stability of polypropylene fibers in environments aggressive to cement-based materials. Cement and Concrete Research. 28 (12), 1809-1817.

Skalny, J., \& Roberts, L. R. (1987). High strength concrete. Annual Review Material Science. 17, $35-56$.

Skinner, J. (2011). Testing of ultra-high performance concrete as a thermal energy storage medium at high temperatures. (Unpublished master's thesis). University of Arkansas, Fayetteville, AR.

Skinner, J., Brown, B., \& Selvam R.P. (2011). Proceedings of ASME 2011 5th International Conference on Energy Sustainability. Testing of high performance concrete as a thermal energy storage medium at high temperatures. Paper No. ESFuelCell 2011-54463. Washington, DC.

Suhaendi, S.L., Horiguchi, T., \& Shimura, K. (2008). Proceedings of International Conference, Concrete for Fire Engineering '08: Effect of Polypropylene Fiber Geometry on Explosive Spalling Mitigation in High Strength Concrete Under Elevated Temperature Conditions (149-156).

Sullivan, P.J.E., \& Shanshar, R. (1992). Performance of concrete at elevated temperatures (as measured by the reduction in compressive strength). Fire Technology 28 (3) 240-250. 
Swedish National Road Administration, (2000). Fire Safety Design: Concrete spalling review. Report. Stockholm, Sweden: Khoury, G.A., \& Anderberg, Y.

Tatnall, P.C. (2002). Shortcrete in fires: Effects of fibers on explosive spalling. Shortcrete, 1012.

Tenchev, R., \& Purnell, P. (2005). An application of a damage constitutive model to concrete at high temperature and prediction of spalling. International Journal of Solids \& Structures. 42 (26), 6550-6565.

Waller, V., De Larrard F., \& Roussel P. (1996). $4^{\text {th }}$ International Symposium on Utilization of High-Strength/High-Performance Concrete, RILEM '06: Modeling the Temperature Rise in Massive HPCStructures (415-421). Paris, France.

Yan, X., Li, H., \& Wong, Y.L. (2007). Effect of aggregate on high-strength concrete in fire. Magazine of Concrete Research. 59 (5), 323-328.

Yang, Z., \& Garimella, S. (2010). Thermal Analysis of Solar Thermal Energy Storage in a Molten-salt Thermocline. CTRC Research Publications. Paper 144. http://docs.lib.purdue.edu/coolingpubs/144 


\section{Appendix A}

Table A3.1 Properties of ordinary portland cement, Type I

\begin{tabular}{ll}
\hline Compound composition range (\%) & \\
\hline $\mathbf{C}_{3} \mathbf{S}$ & $50-55$ \\
$\mathbf{C}_{2} \mathbf{S}$ & $15-20$ \\
$\mathbf{C}_{3} \mathbf{A}$ & $5-12$ \\
$\mathbf{C}_{4} \mathbf{A F}$ & $6-10$ \\
Fineness: minimum $\left(\mathbf{m}^{2} / \mathbf{k g}\right)$ & 280 \\
Specific gravity & 3.15 \\
Initial set: min. (minutes) & 45 \\
Final set: max. (minutes) & 375 \\
\hline
\end{tabular}

Table A3.2 Categories of calcium aluminate cement

\begin{tabular}{|c|c|c|c|}
\hline Composition & Low purity & Intermediate purity & High purity \\
\hline $\mathrm{Al}_{2} \mathrm{O}_{3}(\%)$ & $36-47$ & $48-62$ & $70-80$ \\
\hline $\mathrm{Fe}_{2} \mathrm{O}_{3}(\%)$ & $7-6$ & $1-3$ & $0.1-0.2$ \\
\hline $\mathrm{CaO}(\%)$ & $35-42$ & $26-39$ & $18-26$ \\
\hline $\mathrm{SiO}_{2}(\%)$ & $3.5-9.0$ & $3.5-9.0$ & $0-0.5$ \\
\hline Surface area $\left(\mathrm{cm}^{2} / \mathrm{g}\right)$ & $2600-4400$ & $3200-6200$ & $3600-10300$ \\
\hline Initial set time (hr:min) & $4: 00-7: 00$ & $1: 30-8: 00$ & $0: 30-4: 00$ \\
\hline Specific gravity & $2.95-3.25$ & $2.95-3.25$ & $2.95-3.25$ \\
\hline
\end{tabular}

Table A3.3 Chemical composition and properties of Lumnite MG4

\begin{tabular}{cccc}
\hline Physical properties & & Chemicals (\%) & \\
\hline Blaine fineness & 3980 & $\mathrm{SiO}_{2}$ & 3.5 \\
Set time (initial) & $3: 54$ & $\mathrm{Al}_{2} \mathrm{O}_{3}$ & 39.4 \\
\hline Final set & $4: 22$ & $\mathrm{Fe}_{2} \mathrm{O}_{3}$ & 14.93 \\
$\begin{array}{c}24 \text { hour Compressive } \\
\text { strength (MPa) } \\
\text { Temp. resistance }\end{array}$ & 67.9 & $\mathrm{CaO}$ & 39.5 \\
\hline
\end{tabular}

Table A3.4 Chemical composition and properties of Class C fly ash Chemical composition range $(\%)$

\begin{tabular}{ll}
\hline $\mathrm{SiO}_{2}$ & $40-60$ \\
$\mathrm{Al}_{2} \mathrm{O}_{3}$ & $20-30$ \\
$\mathrm{Fe}_{2} \mathrm{O}_{3}$ & $4-10$ \\
$\mathbf{C a O}$ & $5-30$ \\
Fineness $\left(\mathbf{m}^{2} / \mathbf{k g}\right)$ & 420 \\
Specific gravity & 2.65 \\
\hline
\end{tabular}


Table A3.5 Chemical composition and properties of silica fume

\begin{tabular}{ll}
\hline Compound composition range (\%) & \\
\hline $\mathrm{SiO}_{2}$ & $85-97$ \\
$\mathrm{CaO}$ & $<1$ \\
\hline Fineness $\left(\mathrm{m}^{2} / \mathrm{kg}\right)$ & $15000-30000$ \\
Specific gravity & 2.22 \\
\hline
\end{tabular}




\section{Appendix B}

Tables B4.1 Actual measurements of the thermo-mechanical properties of Mixture 26 before exposure to thermal cycling

Residual Compressive Strength

\begin{tabular}{|c|c|c|c|c|}
\hline Specimens & $\begin{array}{c}\text { Force applied } \\
\text { (lbs) }\end{array}$ & Comp. strength (psi) & $\begin{array}{c}\text { Avg. force } \\
\text { applied (lbs) }\end{array}$ & $\begin{array}{c}\text { 40\% of avg. } \\
\text { force (lbs) }\end{array}$ \\
\hline 1 & 283111 & 22529 & 273080 & 109232 \\
\hline 2 & 263195 & 20955 & & \\
\hline
\end{tabular}

$1 \mathrm{lb}=0.454 \mathrm{~kg}, 1 \mathrm{psi}=6.895 \mathrm{kPa}$

Modulus of Elasticity

\begin{tabular}{|c|c|c|c|c|c|c|c|}
\hline Spec. & $\begin{array}{c}\text { Init. strain } \\
\left(10^{-4}\right)\end{array}$ & $\begin{array}{c}\text { Force at } \\
\text { init. strain } \\
\text { (lbs) }\end{array}$ & $\begin{array}{c}\text { Strain at } \\
40 \% \text { of avg. } \\
\text { force }\end{array}$ & $\begin{array}{c}\text { Avg } \\
\text { diameter } \\
\text { (in.) }\end{array}$ & $\begin{array}{l}\text { Avg. } \\
\text { length } \\
\text { (in.) }\end{array}$ & $\begin{array}{c}\text { MOE } \\
\text { (ksi) }\end{array}$ & $\begin{array}{c}\text { Avg. } \\
\text { MOE } \\
\text { (ksi) }\end{array}$ \\
\hline \multirow{3}{*}{1} & 5.3 & 7000 & 115 & \multirow{3}{*}{4.000} & \multirow{3}{*}{7.986} & \multirow{3}{*}{7934} & \multirow{9}{*}{7753} \\
\hline & 5.3 & 5190 & 116 & & & & \\
\hline & 5.3 & 5190 & 115 & & & & \\
\hline \multirow{3}{*}{2} & 5.3 & 4990 & 122 & \multirow{3}{*}{4.000} & \multirow{3}{*}{7.969} & \multirow{3}{*}{7572} & \\
\hline & 5.3 & 4590 & 122 & & & & \\
\hline & 5.3 & 4890 & 121 & & & & \\
\hline \multirow{3}{*}{3} & - & - & - & \multirow{3}{*}{4.000} & \multirow{3}{*}{7.740} & \multirow{3}{*}{-} & \\
\hline & - & - & - & & & & \\
\hline & - & - & - & & & & \\
\hline
\end{tabular}

$1 \mathrm{lb}=0.454 \mathrm{~kg}, 1 \mathrm{ksi}=6.9 \mathrm{MPa}$

Splitting Tensile Strength

\begin{tabular}{|c|c|c|c|}
\hline specimen & Force applied (lbs) & Tensile strength (psi) & Avg. tensile strength (psi) \\
\hline 1 & 63680 & 1269 & \multirow{2}{*}{1288} \\
\hline 2 & 64500 & 1288 & \\
\hline 3 & 63580 & 1307 & \\
\hline
\end{tabular}

$1 \mathrm{lb}=0.454 \mathrm{~kg}, 1 \mathrm{psi}=6.895 \mathrm{kPa}$

Specific Heat $\left(\mathrm{C}_{\mathrm{p}}\right)$

\begin{tabular}{|c|c|c|c|c|c|c|}
\hline specimen & $\begin{array}{c}\text { Mass } \\
(\mathbf{g})\end{array}$ & $\begin{array}{c}\text { Init. water } \\
\text { temp. }\left({ }^{\mathbf{0}} \mathbf{C}\right)\end{array}$ & $\begin{array}{c}\text { Concrete } \\
\text { temp. }\left({ }^{\mathbf{0}} \mathbf{C}\right)\end{array}$ & $\begin{array}{c}\text { Equilibrium } \\
\text { temp. }\left({ }^{\mathbf{0}} \mathbf{C}\right)\end{array}$ & $\begin{array}{c}\text { Specific } \\
\text { heat }(\mathbf{J} / \mathbf{g K})\end{array}$ & $\begin{array}{c}\text { Avg. specific } \\
\text { heat }(\mathbf{J} / \mathbf{g K})\end{array}$ \\
\hline 1 & 70.2 & 20.44 & 124.90 & 28.90 & 0.738 & \multirow{2}{*}{0.813} \\
\hline 2 & 78.7 & 20.11 & 113.90 & 29.70 & 0.836 & \\
\hline 3 & 75.9 & 19.94 & 102.8 & 28.80 & 0.864 & \\
\hline
\end{tabular}

$1 \mathrm{~J} / \mathrm{gK}=0.2388 \mathrm{Btu} / \mathrm{lbm}^{\circ} \mathrm{F},{ }^{\circ} \mathrm{C}$ to Fahrenheit $(\mathrm{F})=\left({ }^{\circ} \mathrm{C} \times 1.8\right)+32$ 
Thermal conductivity $(K)$

\begin{tabular}{|c|c|c|c|c|c|c|}
\hline specimen & $\begin{array}{c}\mathbf{t}_{\mathbf{1}} \\
(\mathbf{s e c} \text { ) }\end{array}$ & $\begin{array}{c}\mathbf{t}_{\mathbf{2}} \\
(\mathbf{s e c} .)\end{array}$ & $\begin{array}{c}\mathbf{T}_{\mathbf{1}} \\
\left({ }^{\mathbf{1}} \mathbf{C}\right)\end{array}$ & $\begin{array}{c}\mathbf{T}_{\mathbf{2}} \\
\left({ }^{\mathbf{}} \mathbf{C}\right)\end{array}$ & $\begin{array}{c}\text { Thermal } \\
\text { conductivity } \\
\text { (W/mK) }\end{array}$ & $\begin{array}{c}\text { Avg. thermal } \\
\text { conductivity (W/mK) }\end{array}$ \\
\hline 1 & 180 & 1210 & 23.4 & 24.8 & 2.60 & \multirow{2}{*}{3.30} \\
\hline 2 & 570 & 1510 & 31.8 & 32.5 & 4.00 & \\
\hline
\end{tabular}

$1 \mathrm{~W} / \mathrm{mK}=0.578 \mathrm{Btu} / \mathrm{ft} . \mathrm{h} .{ }^{\circ} \mathrm{F},{ }^{\circ} \mathrm{C}$ to Fahrenheit $(\mathrm{F})=\left({ }^{\circ} \mathrm{C} \times 1.8\right)+32$

Tables B4.2 Actual measurements of the thermo-mechanical properties of Mixture 26 after exposure to elevated temperature thermal cycling

Residual Compressive Strength

\begin{tabular}{|c|c|c|c|c|}
\hline Specimens & $\begin{array}{c}\text { Force applied } \\
\text { (lbs) }\end{array}$ & $\begin{array}{c}\text { Comp. strength } \\
\text { (psi) }\end{array}$ & $\begin{array}{c}\text { Avg. force } \\
\text { applied (lbs) }\end{array}$ & $\begin{array}{c}\text { 40\% of avg. } \\
\text { load (lbs) }\end{array}$ \\
\hline 1 & 122485 & 9752 & 126290 & 50516 \\
\hline 2 & 130096 & 10358 & & \\
\hline
\end{tabular}

Modulus of Elasticity

\begin{tabular}{|c|c|c|c|c|c|c|c|}
\hline Spec. & $\begin{array}{l}\text { Init. Strain } \\
\qquad\left(1^{-4}\right)\end{array}$ & $\begin{array}{c}\text { Force at } \\
\text { init. } \\
\text { Strain } \\
\text { (lbs) }\end{array}$ & $\begin{array}{c}\text { Strain at } \\
40 \% \text { of avg. } \\
\text { Force }\end{array}$ & $\begin{array}{l}\text { Avg. } \\
\text { diameter } \\
\text { (in.) }\end{array}$ & $\begin{array}{c}\text { Avg. } \\
\text { length } \\
\text { (in.) }\end{array}$ & $\frac{\text { MOE }}{\text { (ksi) }}$ & $\begin{array}{c}\text { Avg. } \\
\text { MOE } \\
\text { (ksi) }\end{array}$ \\
\hline \multirow{3}{*}{1} & 5.3 & 320 & 605 & \multirow{3}{*}{4.023} & \multirow{3}{*}{7.846} & \multirow{3}{*}{1027} & \multirow{9}{*}{919} \\
\hline & 5.3 & 410 & 405 & & & & \\
\hline & 5.3 & 390 & 415 & & & & \\
\hline \multirow{3}{*}{2} & 5.3 & 390 & 695 & \multirow{3}{*}{4.023} & \multirow{3}{*}{7.960} & \multirow{3}{*}{874} & \\
\hline & 5.3 & 410 & 485 & & & & \\
\hline & 5.3 & 400 & 475 & & & & \\
\hline \multirow{3}{*}{3} & 5.3 & 380 & 710 & \multirow{3}{*}{4.028} & \multirow{3}{*}{8.027} & \multirow{3}{*}{856} & \\
\hline & 5.3 & 410 & 492 & & & & \\
\hline & 5.3 & 420 & 485 & & & & \\
\hline
\end{tabular}

Splitting Tensile Strength

\begin{tabular}{|c|c|c|c|}
\hline specimen & Force applied (lbs) & $\begin{array}{c}\text { Tensile strength } \\
\text { (psi) }\end{array}$ & $\begin{array}{c}\text { Avg. tensile } \\
\text { strength (psi) }\end{array}$ \\
\hline 1 & 30750 & 600 & \multirow{2}{*}{613} \\
\hline 2 & 32170 & 640 & \\
\hline 3 & 30020 & 600 & \\
\hline
\end{tabular}


Specific Heat

\begin{tabular}{|c|c|c|c|c|c|c|}
\hline specimen & $\begin{array}{c}\text { Mass } \\
(\mathbf{g})\end{array}$ & $\begin{array}{c}\text { Init. water } \\
\text { temp. }\left({ }^{\mathbf{0}} \mathbf{C}\right)\end{array}$ & $\begin{array}{c}\text { Concrete } \\
\text { temp. }\left({ }^{\mathbf{0}} \mathbf{C}\right)\end{array}$ & $\begin{array}{c}\text { Equilibrium } \\
\text { temp. }\left({ }^{\mathbf{0}} \mathbf{C}\right)\end{array}$ & $\begin{array}{c}\text { Specific heat } \\
(\mathbf{J} / \mathbf{g K})\end{array}$ & $\begin{array}{c}\text { Avg. specific } \\
\text { heat }(\mathbf{J} / \mathbf{g K})\end{array}$ \\
\hline 1 & 63.6 & 20.10 & 100 & 25.50 & 0.557 & \multirow{2}{*}{0.467} \\
\hline 2 & 76.2 & 19.20 & 100 & 26.30 & 0.683 & \\
\hline 3 & 65.2 & 18.60 & 100 & 24.70 & 0.713 & \\
\hline
\end{tabular}

Thermal Conductivity $(K)$

\begin{tabular}{|c|c|c|c|c|c|c|}
\hline specimen & $\begin{array}{c}\mathbf{t}_{\mathbf{1}} \\
(\mathbf{s e c} .)\end{array}$ & $\begin{array}{c}\mathbf{t}_{\mathbf{2}} \\
(\mathbf{s e c} .)\end{array}$ & $\begin{array}{c}\mathbf{T}_{\mathbf{1}} \\
\left(\mathbf{(}^{\mathbf{0}} \mathbf{C}\right)\end{array}$ & $\begin{array}{c}\mathbf{T}_{\mathbf{2}} \\
\left({ }^{\mathbf{}} \mathbf{C}\right)\end{array}$ & $\begin{array}{c}\text { Thermal conductivity } \\
(\mathbf{W} / \mathbf{m K})\end{array}$ & $\begin{array}{c}\text { Avg. thermal } \\
\text { conductivity (W/mK) }\end{array}$ \\
\hline 1 & 130 & 1400 & 32.20 & 39.00 & 1.28 & \multirow{2}{*}{1.30} \\
\hline 2 & 290 & 1450 & 31.60 & 34.20 & 1.34 & \\
\hline
\end{tabular}

Tables B4.3 Actual measurements of the thermo-mechanical properties of Mixture TC 1000 before exposure to elevated temperature thermal cycling

Compressive Strength

\begin{tabular}{|c|c|c|c|c|c|}
\hline Specimens & $\begin{array}{c}\text { Force } \\
\text { applied (lbs.) }\end{array}$ & $\begin{array}{c}\text { Comp. } \\
\text { strength (psi) }\end{array}$ & $\begin{array}{c}\text { Avg. comp. } \\
\text { strength (psi) }\end{array}$ & $\begin{array}{c}\text { Avg. force } \\
\text { applied (lbs) }\end{array}$ & $\begin{array}{c}\text { 40\% of avg. } \\
\text { force (lbs) }\end{array}$ \\
\hline 1 & 292610 & 23297 & & & \\
\cline { 1 - 3 } 2 & 287649 & 22902 & 23244 & 291945 & 116837 \\
\hline 3 & 295574 & 23533 & & & \\
\hline
\end{tabular}

Modulus of Elasticity

\begin{tabular}{|c|c|c|c|c|c|c|c|}
\hline Spec. & $\begin{array}{c}\text { Init. strain } \\
\left(10^{-4}\right)\end{array}$ & $\begin{array}{c}\text { Force at } \\
\text { init. strain } \\
(\mathrm{lbs})\end{array}$ & $\begin{array}{c}\text { Strain at } \\
40 \% \text { of avg. } \\
\text { force }\end{array}$ & $\begin{array}{l}\text { Avg. } \\
\text { diameter } \\
\text { (in.) }\end{array}$ & $\begin{array}{l}\text { Avg. } \\
\text { length } \\
\text { (in.) }\end{array}$ & $\begin{array}{c}\text { MOE } \\
\text { (ksi) }\end{array}$ & $\begin{array}{l}\text { Avg. } \\
\text { MOE } \\
\text { (ksi) }\end{array}$ \\
\hline \multirow{3}{*}{1} & 5.3 & 6860 & 109 & \multirow{3}{*}{4.010} & \multirow{3}{*}{7.880} & \multirow{3}{*}{8858} & \multirow{9}{*}{8620} \\
\hline & 5.3 & 6860 & 110 & & & & \\
\hline & 5.3 & 6860 & 109 & & & & \\
\hline \multirow{3}{*}{2} & 5.3 & 5150 & 115 & \multirow{3}{*}{4.010} & \multirow{3}{*}{7.480} & \multirow{3}{*}{8755} & \\
\hline & 5.3 & 6290 & 112 & & & & \\
\hline & 5.3 & 6860 & 110 & & & & \\
\hline \multirow{3}{*}{3} & 5.3 & 5290 & 119 & \multirow{3}{*}{4.010} & \multirow{3}{*}{7.440} & \multirow{3}{*}{8246} & \\
\hline & 5.3 & 5460 & 120 & & & & \\
\hline & 5.3 & 5770 & 117 & & & & \\
\hline
\end{tabular}


Splitting Tensile Strength

\begin{tabular}{|c|c|c|c|}
\hline specimen & Force applied (lbs) & Tensile strength (psi) & \multirow{2}{*}{ Avg. tensile strength (psi) } \\
\hline 1 & 163660 & 3252 & \multirow{2}{*}{3131} \\
\hline 2 & 131940 & 2793 & \\
\hline 3 & 157270 & 3347 & \\
\hline
\end{tabular}

Specific Heat $\left(\mathbf{C}_{\mathrm{p}}\right)$

\begin{tabular}{|c|c|c|c|c|c|c|}
\hline specimen & $\begin{array}{c}\text { Mass } \\
(\mathbf{g})\end{array}$ & $\begin{array}{c}\text { Init. water } \\
\text { temp. }\left({ }^{\mathbf{0}} \mathbf{C}\right)\end{array}$ & $\begin{array}{c}\text { Concrete } \\
\text { temp. }\left({ }^{\mathbf{0}} \mathbf{C}\right)\end{array}$ & $\begin{array}{c}\text { Equilibrium } \\
\text { temp. }\left({ }^{\mathbf{0}} \mathbf{C}\right)\end{array}$ & $\begin{array}{c}\text { Specific heat } \\
(\mathbf{J} / \mathbf{g K})\end{array}$ & $\begin{array}{c}\text { Avg. specific } \\
\text { heat } \mathbf{( J / g K})\end{array}$ \\
\hline 1 & 79.1 & 22.20 & 100 & 30.60 & 1.010 & \multirow{2}{*}{0.908} \\
\cline { 1 - 5 } 2 & 76.3 & 23.40 & 100 & 30.30 & 0.788 & \\
\cline { 1 - 5 } 3 & 70.5 & 22.70 & 100 & 29.50 & 0.903 & \\
\hline 4 & 64.3 & 22.30 & 100 & 31.80 & 0.929 & \\
\hline
\end{tabular}

Thermal conductivity $(K)$

\begin{tabular}{|c|c|c|c|c|c|c|}
\hline specimen & $\begin{array}{c}\mathbf{t}_{\mathbf{1}} \\
(\mathbf{s e c})\end{array}$ & $\begin{array}{c}\mathbf{t}_{\mathbf{2}} \\
(\mathbf{s e c})\end{array}$ & $\begin{array}{c}\mathbf{T}_{\mathbf{1}} \\
\left({ }^{\mathbf{0}} \mathbf{C}\right)\end{array}$ & $\begin{array}{c}\mathbf{T}_{\mathbf{2}} \\
\left({ }^{\mathbf{0}} \mathbf{C}\right)\end{array}$ & $\begin{array}{c}\text { Thermal conductivity } \\
(\mathbf{W} / \mathbf{m K})\end{array}$ & $\begin{array}{c}\text { Avg. thermal } \\
\text { conductivity (W/mK) }\end{array}$ \\
\hline 1 & 230 & 1020 & 26.95 & 28.30 & 2.97 & \multirow{2}{*}{3.10} \\
\hline 2 & 300 & 1200 & 29.76 & 31.40 & 2.80 & \\
\hline 3 & 320 & 1230 & 28.50 & 29.65 & 3.52 & \\
\hline
\end{tabular}

Tables B4.4 Actual measurements of the thermo-mechanical properties of Mixture TC 1000 after exposure to elevated temperature thermal cycling

Compressive Strength

\begin{tabular}{|l|l|l|c|c|c|}
\hline Specimens & $\begin{array}{c}\text { Force } \\
\text { applied (lbs) }\end{array}$ & $\begin{array}{c}\text { Comp. } \\
\text { strength (psi) }\end{array}$ & $\begin{array}{c}\text { Avg. comp. } \\
\text { strength (psi) }\end{array}$ & $\begin{array}{c}\text { Avg. force } \\
\text { applied (lbs) }\end{array}$ & $\begin{array}{c}\text { 40\% of avg. } \\
\text { force (lbs) }\end{array}$ \\
\cline { 1 - 2 } 1 & 228931 & 18227 & \multirow{2}{*}{15835} & \multirow{2}{*}{198892} & \multirow{2}{*}{79557} \\
\cline { 1 - 2 } 3 & 163280 & 13000 & & & \\
\hline
\end{tabular}


Modulus of Elasticity

\begin{tabular}{|c|c|c|c|c|c|c|c|}
\hline Spec. & $\begin{array}{l}\text { Init. strain } \\
\quad\left(10^{-4}\right)\end{array}$ & $\begin{array}{c}\text { Force at } \\
\text { init. strain } \\
\text { (lbs) }\end{array}$ & $\begin{array}{c}\text { Strain at } \\
40 \% \text { of avg. } \\
\text { force }\end{array}$ & $\begin{array}{l}\text { Avg. } \\
\text { diameter } \\
\text { (in.) }\end{array}$ & $\begin{array}{l}\text { Avg. } \\
\text { length } \\
\text { (in.) }\end{array}$ & $\begin{array}{c}\text { MOE } \\
\text { (ksi) }\end{array}$ & $\begin{array}{c}\text { Avg. } \\
\text { MOE } \\
\text { (ksi) }\end{array}$ \\
\hline \multirow{3}{*}{1} & 5.3 & 360 & 780 & \multirow{3}{*}{4.038} & \multirow{3}{*}{7.383} & \multirow{3}{*}{1142} & \multirow{9}{*}{1100} \\
\hline & 5.3 & 460 & 595 & & & & \\
\hline & 5.3 & 370 & 586 & & & & \\
\hline \multirow{3}{*}{2} & 5.3 & 490 & 935 & \multirow{3}{*}{4.033} & \multirow{3}{*}{7.699} & \multirow{3}{*}{1005} & \\
\hline & 5.3 & 470 & 674 & & & & \\
\hline & 5.3 & 470 & 665 & & & & \\
\hline \multirow{3}{*}{3} & 5.3 & 450 & 450 & \multirow{3}{*}{4.029} & \multirow{3}{*}{7.749} & \multirow{3}{*}{1162} & \\
\hline & 5.3 & 430 & 430 & & & & \\
\hline & 5.3 & 430 & 430 & & & & \\
\hline
\end{tabular}

Splitting Tensile Strength

\begin{tabular}{|c|c|c|c|}
\hline Specimen & Force applied (lbs) & Tensile strength (psi) & Avg. tensile strength (psi) \\
\hline 1 & 47730 & 966 & \multirow{2}{*}{1208} \\
\hline 2 & 61170 & 1255 & \\
\hline 3 & 65680 & 1403 & \\
\hline
\end{tabular}

Specific Heat $\left(C_{p}\right)$

\begin{tabular}{|c|c|c|c|c|c|c|}
\hline Specimen & $\begin{array}{c}\text { Mass } \\
(\mathbf{g})\end{array}$ & $\begin{array}{c}\text { Init. water } \\
\text { temp. }\left({ }^{\mathbf{0}} \mathbf{C}\right)\end{array}$ & $\begin{array}{c}\text { Concrete } \\
\text { temp. }\left({ }^{\mathbf{0}} \mathbf{C}\right)\end{array}$ & $\begin{array}{c}\text { Equilibrium } \\
\text { temp. }\left({ }^{\mathbf{0}} \mathbf{C}\right)\end{array}$ & $\begin{array}{c}\text { Specific } \\
\text { heat }(\mathbf{J} / \mathbf{g K})\end{array}$ & $\begin{array}{c}\text { Avg. specific } \\
\text { heat }(\mathbf{J} / \mathbf{g K})\end{array}$ \\
\hline 1 & 79.7 & 19.70 & 102.80 & 27.10 & 0.706 & \\
\hline 2 & 87.3 & 19.60 & 102.80 & 27.40 & 0.692 & 0.695 \\
\hline 3 & 82.3 & 19.30 & 106.10 & 26.90 & 0.687 & \\
\hline
\end{tabular}

Thermal Conductivity $(K)$

\begin{tabular}{|c|c|c|c|c|c|c|}
\hline Specimen & $\begin{array}{c}\mathbf{t}_{\mathbf{1}} \\
(\mathbf{s e c})\end{array}$ & $\begin{array}{c}\mathbf{t}_{\mathbf{2}} \\
(\mathbf{s e c} .)\end{array}$ & $\begin{array}{c}\mathbf{T}_{\mathbf{1}} \\
\left({ }^{\mathbf{0}} \mathbf{C}\right)\end{array}$ & $\begin{array}{c}\mathbf{T}_{\mathbf{2}} \\
\left({ }^{\mathbf{0}} \mathbf{C}\right)\end{array}$ & $\begin{array}{c}\text { Thermal } \\
\text { conductivity } \\
(\mathbf{W} / \mathbf{m K})\end{array}$ & $\begin{array}{c}\text { Avg. thermal } \\
\text { conductivity } \\
\text { (W/mK) }\end{array}$ \\
\hline 1 & 440 & 1400 & 36.50 & 38.90 & 1.28 & \multirow{2}{*}{1.30} \\
\hline 2 & 290 & 1450 & 31.60 & 34.20 & 1.34 & \\
\hline
\end{tabular}

Tables B4.5 Actual measurements of the thermo-mechanical properties of Mixture 11 before exposure to elevated temperature thermal cycling

Compressive Strength

\begin{tabular}{|c|c|c|c|c|c|}
\hline Specimens & $\begin{array}{c}\text { Force } \\
\text { applied (lbs) }\end{array}$ & $\begin{array}{c}\text { Comp. } \\
\text { strength (psi) }\end{array}$ & $\begin{array}{c}\text { Avg. comp. } \\
\text { strength (psi) }\end{array}$ & $\begin{array}{c}\text { Avg. force } \\
\text { applied (lbs) }\end{array}$ & $\begin{array}{c}\text { 40\% of avg. } \\
\text { force (lbs) }\end{array}$ \\
\hline 1 & 87129 & 6937 & \multirow{2}{*}{6} & & \multirow{2}{*}{345635} \\
\hline 2 & 87800 & 6987 & 6873 & & \\
\hline 3 & 84140 & 6696 & & & \\
\hline
\end{tabular}


Modulus of Elasticity

\begin{tabular}{|c|c|c|c|c|c|c|c|}
\hline Spec. & $\begin{array}{c}\text { Init. strain } \\
\left(\mathbf{1 0}^{-4}\right)\end{array}$ & $\begin{array}{c}\text { Force at } \\
\text { init. strain } \\
\text { (lbs) }\end{array}$ & $\begin{array}{c}\text { Strain at } \\
\mathbf{4 0 \%} \text { of avg. } \\
\text { force }\end{array}$ & $\begin{array}{c}\text { Avg. } \\
\text { diameter } \\
\text { (in.) }\end{array}$ & $\begin{array}{l}\text { Avg. } \\
\text { length } \\
\text { (in.) }\end{array}$ & $\begin{array}{c}\text { MOE } \\
(\mathbf{k s i})\end{array}$ & $\begin{array}{l}\text { Avg. } \\
\text { MOE } \\
\text { (ksi) }\end{array}$ \\
\hline \multirow{3}{*}{1} & 5.3 & 2780 & 87 & \multirow{3}{*}{4.013} & \multirow{3}{*}{7.903} & \multirow{3}{*}{ - } & \multirow{9}{*}{3505} \\
\hline & 5.3 & 2840 & 82 & & & & \\
\hline & 5.3 & 2880 & 82 & & & & \\
\hline \multirow{3}{*}{2} & 5.3 & 1890 & 100 & \multirow{3}{*}{4.005} & \multirow{3}{*}{7.862} & \multirow{3}{*}{ - } & \\
\hline & 5.3 & 1980 & 92 & & & & \\
\hline & 5.3 & 2450 & 87 & & & & \\
\hline \multirow{3}{*}{3} & 5.3 & 2560 & 89 & \multirow{3}{*}{4.010} & \multirow{3}{*}{7.807} & \multirow{3}{*}{3505} & \\
\hline & 5.3 & 2550 & 82 & & & & \\
\hline & 5.3 & 2450 & 82 & & & & \\
\hline
\end{tabular}

Splitting Tensile Strength

\begin{tabular}{|c|c|c|c|}
\hline specimen & Force applied (lbs) & Tensile strength (psi) & \multirow{2}{*}{ Avg. tensile Strength (psi) } \\
\hline 1 & 22960 & 460 & \multirow{2}{*}{477} \\
\hline 2 & 22580 & 456 & \\
\hline 3 & 25340 & 515 & \\
\hline
\end{tabular}

Specific Heat $\left(\mathbf{C}_{\mathrm{p}}\right)$

\begin{tabular}{|c|c|c|c|c|c|c|}
\hline specimen & $\begin{array}{c}\text { Mass } \\
(\mathbf{g})\end{array}$ & $\begin{array}{c}\text { Init. water } \\
\text { temp. }\left({ }^{\mathbf{0}} \mathbf{C}\right)\end{array}$ & $\begin{array}{c}\text { Concrete } \\
\text { temp. }\left({ }^{\mathbf{0}} \mathbf{C}\right)\end{array}$ & $\begin{array}{c}\text { Equilibrium } \\
\text { temp. }\left({ }^{\mathbf{0}} \mathbf{C}\right)\end{array}$ & $\begin{array}{c}\text { Specific } \\
\text { heat }(\mathbf{J} / \mathbf{g K})\end{array}$ & $\begin{array}{c}\text { Avg. specific } \\
\text { heat }(\mathbf{J} / \mathbf{g K})\end{array}$ \\
\hline 1 & 67.0 & 20.30 & 180.00 & 35.80 & 0.939 & \multirow{2}{*}{0.958} \\
\hline 2 & 66.5 & 20.40 & 174.00 & 35.80 & 0.979 & \\
\hline
\end{tabular}

Thermal conductivity $(K)$

\begin{tabular}{|c|c|c|c|c|c|c|}
\hline Specimen & $\begin{array}{c}\mathbf{t}_{\mathbf{1}} \\
\text { (sec.) }\end{array}$ & $\begin{array}{c}\mathbf{t}_{\mathbf{2}} \\
(\mathbf{s e c} .)\end{array}$ & $\begin{array}{c}\mathbf{T}_{\mathbf{1}} \\
\left({ }^{\mathbf{}} \mathbf{C}\right)\end{array}$ & $\begin{array}{c}\mathbf{T}_{\mathbf{2}} \\
\left({ }^{\mathbf{}} \mathbf{C}\right)\end{array}$ & $\begin{array}{c}\text { Thermal conductivity } \\
(\mathbf{W} / \mathbf{m K})\end{array}$ & $\begin{array}{c}\text { Thermal conductivity } \\
(\mathbf{W} / \mathbf{m K})\end{array}$ \\
\hline 1 & 130 & 1200 & 27.95 & 29.60 & 1.93 & \multirow{2}{*}{2.04} \\
\hline 2 & 120 & 1120 & 27.40 & 29.00 & 2.14 & \\
\hline
\end{tabular}

Tables B4.6 Actual measurements of the thermo-mechanical properties of Mixture 11 after exposure to elevated temperature thermal cycling

Compressive Strength

\begin{tabular}{|c|c|c|c|c|c|}
\hline Specimens & $\begin{array}{c}\text { Force } \\
\text { applied (lbs) }\end{array}$ & $\begin{array}{c}\text { Comp. strength } \\
\text { (psi) }\end{array}$ & $\begin{array}{c}\text { Avg. comp. } \\
\text { strength (psi) }\end{array}$ & $\begin{array}{c}\text { Avg. force } \\
\text { applied (lbs) }\end{array}$ & $\begin{array}{c}\text { 40\% of } \\
\text { avg. force } \\
\text { (lbs) }\end{array}$ \\
\hline 1 & 21350 & 1699 & & & \\
\hline 2 & 21500 & 1711 & 1792 & 22517 & 9007 \\
\hline 3 & 24700 & 1965 & & & \\
\hline
\end{tabular}


Modulus of Elasticity

\begin{tabular}{|c|c|c|c|c|c|c|c|}
\hline Spec. & $\begin{array}{c}\text { Init. strain } \\
\left(1^{-4}\right)\end{array}$ & $\begin{array}{c}\text { Force at } \\
\text { init. } \\
\text { strain } \\
\text { (lbs) }\end{array}$ & $\begin{array}{l}\text { Strain at } \\
\mathbf{4 0 \%} \text { of avg. } \\
\text { force }\end{array}$ & $\begin{array}{l}\text { Avg. } \\
\text { diameter } \\
\text { (in.) }\end{array}$ & $\begin{array}{c}\text { Avg. } \\
\text { length } \\
\text { (in.) }\end{array}$ & $\begin{array}{c}\text { MOE } \\
\text { (ksi) }\end{array}$ & $\begin{array}{c}\text { Avg. } \\
\text { MOE } \\
\text { (ksi) }\end{array}$ \\
\hline \multirow{3}{*}{1} & 5.3 & 120 & 530 & \multirow{3}{*}{4.033} & \multirow{3}{*}{7.922} & \multirow{3}{*}{249} & \multirow{9}{*}{250} \\
\hline & 5.3 & 140 & 300 & & & & \\
\hline & 5.3 & 120 & 300 & & & & \\
\hline \multirow{3}{*}{2} & 5.3 & 140 & 500 & \multirow{3}{*}{4.011} & \multirow{3}{*}{7.955} & \multirow{3}{*}{250} & \\
\hline & 5.3 & 110 & 305 & & & & \\
\hline & 5.3 & 110 & 305 & & & & \\
\hline \multirow{3}{*}{3} & 5.3 & 130 & 512 & \multirow{3}{*}{4.019} & \multirow{3}{*}{7.943} & \multirow{3}{*}{250} & \\
\hline & 5.3 & 120 & 310 & & & & \\
\hline & 5.3 & 110 & 305 & & & & \\
\hline
\end{tabular}

Splitting Tensile Strength

\begin{tabular}{|c|c|c|c|}
\hline specimen & Force applied (lbs) & Tensile strength (psi) & Avg. tensile strength (psi) \\
\hline 1 & 6860 & 137 & 138 \\
\hline 2 & 7000 & 140 & \\
\hline
\end{tabular}

Specific Heat $\left(\mathbf{C}_{\mathrm{p}}\right)$

\begin{tabular}{|c|c|c|c|c|c|c|}
\hline Specimen & $\begin{array}{c}\text { Mass } \\
(\mathbf{g})\end{array}$ & $\begin{array}{c}\text { Init. water } \\
\text { temp. }\left({ }^{\mathbf{O}} \mathbf{C}\right)\end{array}$ & $\begin{array}{c}\text { Concrete } \\
\text { temp. }\left({ }^{(} \mathbf{C}\right)\end{array}$ & $\begin{array}{c}\text { Equilibrium } \\
\text { temp. }\left({ }^{\mathbf{}} \mathbf{C}\right)\end{array}$ & $\begin{array}{c}\text { Specific heat } \\
(\mathbf{J} / \mathbf{g K})\end{array}$ & $\begin{array}{c}\text { Avg. specific } \\
\text { heat }(\mathbf{J} / \mathbf{g K})\end{array}$ \\
\hline 1 & 59.8 & 18.20 & 100.00 & 24.30 & 0.787 & \multirow{2}{*}{0.826} \\
\hline 2 & 67.3 & 17.40 & 100.00 & 24.90 & 0.865 & \\
\hline
\end{tabular}

Thermal Conductivity $(K)$

\begin{tabular}{|c|c|c|c|c|c|c|}
\hline Specimen & $\begin{array}{c}\mathbf{t}_{\mathbf{1}} \\
(\text { sec.) }\end{array}$ & $\begin{array}{c}\mathbf{t}_{\mathbf{2}} \\
(\text { sec.) }\end{array}$ & $\begin{array}{c}\mathbf{T}_{\mathbf{1}} \\
\left({ }^{\mathbf{0}} \mathbf{C}\right)\end{array}$ & $\begin{array}{c}\mathbf{T}_{\mathbf{2}} \\
\left.\mathbf{(}^{\mathbf{0}} \mathbf{C}\right)\end{array}$ & $\begin{array}{c}\text { Thermal conductivity } \\
(\mathbf{W} / \mathbf{m K})\end{array}$ & $\begin{array}{c}\text { Avg. thermal } \\
\text { conductivity (W/mK) }\end{array}$ \\
\hline 1 & 200 & 1230 & 27.30 & 29.90 & 0.990 & 0.96 \\
\hline 2 & 200 & 1220 & 28.80 & 31.50 & 0.933 & 0.93 \\
\hline
\end{tabular}

Tables B4.7 Actual measurements of the thermo-mechanical properties of Mixture 2 before exposure to elevated temperature thermal cycling

Compressive Strength

\begin{tabular}{|c|c|c|c|c|c|}
\hline Specimens & $\begin{array}{c}\text { Force } \\
\text { applied (lbs) }\end{array}$ & $\begin{array}{c}\text { Comp. } \\
\text { strength (psi) }\end{array}$ & $\begin{array}{c}\text { Avg. comp. } \\
\text { strength (psi) }\end{array}$ & $\begin{array}{c}\text { Avg. force } \\
\text { applied (lbs) }\end{array}$ & $\begin{array}{c}\text { 40\% of avg. } \\
\text { force (lbs) }\end{array}$ \\
\hline 1 & 133440 & 10619 & & & \\
\hline 2 & 108030 & 8597 & 9747 & 122465 & 48986 \\
\hline 3 & 125980 & 10026 & & & \\
\hline
\end{tabular}


Modulus of Elasticity

\begin{tabular}{|c|c|c|c|c|c|c|c|}
\hline Spec. & $\begin{array}{c}\text { Init. strain } \\
\left(1^{-4}\right)\end{array}$ & $\begin{array}{c}\text { Load at } \\
\text { init. } \\
\text { strain } \\
\text { (lbs) }\end{array}$ & $\begin{array}{l}\text { Strain at } \\
\mathbf{4 0 \%} \text { of avg. } \\
\text { force }\end{array}$ & $\begin{array}{l}\text { Avg. } \\
\text { diameter } \\
\text { (in.) }\end{array}$ & $\begin{array}{c}\text { Avg. } \\
\text { length } \\
\text { (in.) }\end{array}$ & $\begin{array}{c}\text { MOE } \\
\text { (ksi) }\end{array}$ & $\begin{array}{c}\text { Avg. } \\
\text { MOE } \\
\text { (ksi) }\end{array}$ \\
\hline \multirow{3}{*}{1} & 5.3 & 2800 & 91 & \multirow{3}{*}{4.000} & \multirow{3}{*}{7.886} & \multirow{3}{*}{4810} & \multirow{9}{*}{4556} \\
\hline & 5.3 & 2350 & 87 & & & & \\
\hline & 5.3 & 2450 & 87 & & & & \\
\hline \multirow{3}{*}{2} & 5.3 & 2400 & 96 & \multirow{3}{*}{4.002} & \multirow{3}{*}{7.951} & \multirow{3}{*}{4411} & \\
\hline & 5.3 & 2240 & 94 & & & & \\
\hline & 5.3 & 2370 & 95 & & & & \\
\hline \multirow{3}{*}{3} & 5.3 & 2750 & 100 & \multirow{3}{*}{4.020} & \multirow{3}{*}{7.891} & \multirow{3}{*}{4450} & \\
\hline & 5.3 & 2830 & 92 & & & & \\
\hline & 5.3 & 2760 & 92 & & & & \\
\hline
\end{tabular}

Splitting Tensile Strength

\begin{tabular}{|c|c|c|c|}
\hline specimen & Force applied (lbs) & Tensile strength (psi) & Avg. tensile Strength (psi) \\
\hline 1 & 44690 & 902 & \multirow{2}{*}{862} \\
\hline 2 & 37000 & 740 & \\
\hline 3 & 47110 & 945 & \\
\hline
\end{tabular}

Specific Heat $\left(\mathbf{C}_{\mathrm{p}}\right)$

\begin{tabular}{|c|c|c|c|c|c|c|}
\hline Specimen & $\begin{array}{c}\text { Mass } \\
\text { (g) }\end{array}$ & $\begin{array}{c}\text { Init. water } \\
\text { temp. }\left({ }^{\mathbf{}} \mathbf{C}\right)\end{array}$ & $\begin{array}{c}\text { Concrete } \\
\text { temp. }\left({ }^{\mathbf{C}} \mathbf{C}\right)\end{array}$ & $\begin{array}{c}\text { Equilibrium } \\
\text { temp. }\left({ }^{\circ} \mathbf{C}\right)\end{array}$ & $\begin{array}{c}\text { Specific heat } \\
(\mathbf{J} / \mathbf{g K})\end{array}$ & $\begin{array}{c}\text { Avg. specific } \\
\text { heat }(\mathbf{J} / \mathbf{g K})\end{array}$ \\
\hline 1 & 74.1 & 17.10 & 100.00 & 26.60 & 1.024 & \multirow{2}{*}{0.970} \\
\hline 2 & 70.3 & 16.70 & 110.00 & 25.90 & 0.915 & \\
\hline
\end{tabular}

Thermal Conductivity $(K)$

\begin{tabular}{|c|c|c|c|c|c|c|}
\hline specimen & $\begin{array}{c}\mathbf{t}_{\mathbf{1}} \\
(\mathbf{s e c})\end{array}$ & $\begin{array}{c}\mathbf{t}_{\mathbf{2}} \\
(\mathbf{s e c} .)\end{array}$ & $\begin{array}{c}\mathbf{T}_{\mathbf{1}} \\
\left({ }^{\mathbf{0}} \mathbf{C}\right)\end{array}$ & $\begin{array}{c}\mathbf{T}_{\mathbf{2}} \\
\left({ }^{\circ} \mathbf{C}\right)\end{array}$ & $\begin{array}{c}\text { Thermal conductivity } \\
(\mathbf{W} / \mathbf{m K})\end{array}$ & $\begin{array}{c}\text { Avg. thermal } \\
\text { conductivity (W/mK) }\end{array}$ \\
\hline 1 & 170 & 1170 & 28.20 & 29.95 & 1.77 & \multirow{2}{*}{1.88} \\
\hline 2 & 150 & 1270 & 27.50 & 29.46 & 1.98 & \\
\hline
\end{tabular}

Tables B4.8 Actual measurements of the thermo-mechanical properties of Mixture 2 after exposure to elevated temperature thermal cycling

Compressive Strength

\begin{tabular}{|c|c|c|c|c|c|}
\hline Specimens & $\begin{array}{c}\text { Force } \\
\text { applied (lbs) }\end{array}$ & $\begin{array}{c}\text { Comp. } \\
\text { strength (psi) }\end{array}$ & $\begin{array}{c}\text { Avg. comp. } \\
\text { strength (psi) }\end{array}$ & $\begin{array}{c}\text { Avg. force } \\
\text { applied (lbs) }\end{array}$ & $\begin{array}{c}\text { 40\% of avg. } \\
\text { force (lbs) }\end{array}$ \\
\hline 1 & 36590 & 2911 & 2983 & 37490 & 14996 \\
\hline 2 & 38390 & 3055 & 2983 & \\
\hline
\end{tabular}


Modulus of Elasticity

\begin{tabular}{|c|c|c|c|c|c|c|c|}
\hline Spec. & $\begin{array}{c}\text { Init. } \\
\text { strain } \\
\left(10^{-4}\right)\end{array}$ & $\begin{array}{c}\text { Force at init. } \\
\text { strain (lbs) }\end{array}$ & $\begin{array}{c}\text { Strain at } \\
40 \% \text { of avg. } \\
\text { force }\end{array}$ & $\begin{array}{c}\text { Avg. } \\
\text { diameter } \\
\text { (in.) }\end{array}$ & $\begin{array}{c}\text { Avg. } \\
\text { length } \\
\text { (in.) }\end{array}$ & $\underset{\text { (ksi) }}{\text { MOE }}$ & $\begin{array}{l}\text { Avg. } \\
\text { MOE } \\
\text { (ksi) }\end{array}$ \\
\hline \multirow{3}{*}{1} & - & - & - & \multirow{3}{*}{4.025} & \multirow{3}{*}{7.960} & \multirow{3}{*}{195} & \multirow{6}{*}{201} \\
\hline & 5.3 & 60 & 645 & & & & \\
\hline & 5.3 & 60 & 645 & & & & \\
\hline \multirow{3}{*}{2} & - & - & - & \multirow{3}{*}{4.021} & \multirow{3}{*}{7.900} & \multirow{3}{*}{207} & \\
\hline & 5.3 & 80 & 612 & & & & \\
\hline & 5.3 & 60 & 600 & & & & \\
\hline
\end{tabular}

Splitting Tensile strength

\begin{tabular}{|c|c|c|c|}
\hline Specimen & Force applied (lbs) & Tensile strength (psi) & \multirow{2}{*}{ Avg. tensile strength (psi) } \\
\hline 1 & 6940 & 138 & \multirow{2}{*}{128} \\
\hline 2 & 6280 & 126 & \\
\hline 3 & 5970 & 119 & \\
\hline
\end{tabular}

Specific Heat $\left(\mathbf{C}_{\mathrm{p}}\right)$

\begin{tabular}{|c|c|c|c|c|c|c|}
\hline Specimen & $\begin{array}{c}\text { Mass } \\
(\mathbf{g})\end{array}$ & $\begin{array}{c}\text { Init. water } \\
\text { temp. }\left({ }^{\mathbf{e}} \mathbf{C}\right)\end{array}$ & $\begin{array}{c}\text { Concrete } \\
\text { temp. }\left({ }^{(} \mathbf{C}\right)\end{array}$ & $\begin{array}{c}\text { Equilibrium } \\
\text { temp. }\left({ }^{(} \mathbf{C}\right)\end{array}$ & $\begin{array}{c}\text { Specific } \\
\text { heat (J/gK) }\end{array}$ & $\begin{array}{c}\text { Avg. specific } \\
\text { heat }(\mathbf{J} / \mathbf{g K})\end{array}$ \\
\hline 1 & 60.4 & 20.40 & 170.00 & 32.90 & 0.880 & \multirow{2}{*}{0.935} \\
\hline 2 & 49.1 & 20.40 & 162.20 & 31.30 & 0.989 & \\
\hline
\end{tabular}

Thermal Conductivity $(K)$

\begin{tabular}{|c|c|c|c|c|c|c|}
\hline specimen & $\begin{array}{c}\mathbf{t}_{\mathbf{1}} \\
(\mathbf{s e c} \text { ) }\end{array}$ & $\begin{array}{c}\mathbf{t}_{\mathbf{2}} \\
(\mathbf{s e c} .)\end{array}$ & $\begin{array}{c}\mathbf{T}_{\mathbf{1}} \\
\left({ }^{\mathbf{0}} \mathbf{C}\right)\end{array}$ & $\begin{array}{c}\mathbf{T}_{\mathbf{2}} \\
\left({ }^{\circ} \mathbf{C}\right)\end{array}$ & $\begin{array}{c}\text { Thermal } \\
\text { conductivity } \\
(\mathbf{W} / \mathbf{m K})\end{array}$ & $\begin{array}{c}\text { Avg. thermal } \\
\text { conductivity (W/mK) }\end{array}$ \\
\hline 1 & 300 & 1400 & 30.30 & 33.70 & 0.65 & \multirow{2}{*}{0.65} \\
\hline 2 & 300 & 1360 & 30.70 & 34.10 & 0.64 & \\
\hline
\end{tabular}

Tables B4.9 Actual measurements of the thermo-mechanical properties of Mixture 15 before exposure to elevated temperature thermal cycling

Compressive Strength

\begin{tabular}{|c|c|c|c|c|c|}
\hline Specimens & $\begin{array}{c}\text { Force } \\
\text { applied (lbs) }\end{array}$ & $\begin{array}{c}\text { Comp. } \\
\text { strength (psi) }\end{array}$ & $\begin{array}{c}\text { Avg. comp. } \\
\text { strength (psi) }\end{array}$ & $\begin{array}{c}\text { Avg. force } \\
\text { applied (lbs) }\end{array}$ & $\begin{array}{c}\text { 40\% of avg. } \\
\text { force (lbs) }\end{array}$ \\
\hline 1 & 144450 & 11495 & \multirow{2}{*}{10828} & \multirow{2}{*}{136077} & 54430 \\
\hline 2 & 134060 & 10668 & & & \\
\hline 3 & 129720 & 10323 & & & \\
\hline
\end{tabular}


Modulus of Elasticity

\begin{tabular}{|c|c|c|c|c|c|c|c|}
\hline Spec. & $\begin{array}{c}\text { Init. } \\
\text { strain } \\
\left(10^{-4}\right)\end{array}$ & $\begin{array}{c}\text { Force at init. } \\
\text { strain (lbs) }\end{array}$ & $\begin{array}{c}\text { Strain at } \\
40 \% \text { of avg. } \\
\text { force }\end{array}$ & $\begin{array}{c}\text { Avg. } \\
\text { diameter } \\
\text { (in.) }\end{array}$ & $\begin{array}{l}\text { Avg. } \\
\text { length } \\
\text { (in.) } \\
\end{array}$ & $\begin{array}{c}\text { MOE } \\
\text { (ksi) }\end{array}$ & $\begin{array}{l}\text { Avg. } \\
\text { MOE } \\
\text { (ksi) }\end{array}$ \\
\hline \multirow{3}{*}{1} & 5.3 & 3370 & 91 & \multirow{3}{*}{4.003} & \multirow{3}{*}{7.837} & \multirow{3}{*}{5034} & \multirow{9}{*}{5068} \\
\hline & 5.3 & 3280 & 91 & & & & \\
\hline & 5.3 & 3140 & - & & & & \\
\hline \multirow{3}{*}{2} & 5.3 & 2840 & 93 & \multirow{3}{*}{4.008} & \multirow{3}{*}{7.847} & \multirow{3}{*}{5056} & \\
\hline & 5.3 & 2890 & 91 & & & & \\
\hline & 5.3 & 2820 & 91 & & & & \\
\hline \multirow{3}{*}{3} & 5.3 & 3870 & 87 & \multirow{3}{*}{4.020} & \multirow{3}{*}{7.814} & \multirow{3}{*}{5116} & \\
\hline & 5.3 & 3480 & 88 & & & & \\
\hline & 5.3 & 3420 & 89 & & & & \\
\hline
\end{tabular}

Splitting Tensile Strength

\begin{tabular}{|c|c|c|c|}
\hline specimen & Force applied (lbs) & Tensile strength (psi) & Avg. tensile strength (psi) \\
\hline 1 & 38040 & 772 & \multirow{2}{*}{822} \\
\hline 2 & 44700 & 906 & \\
\hline 3 & 38900 & 788 & \\
\hline
\end{tabular}

Specific Heat $\left(C_{p}\right)$

\begin{tabular}{|c|c|c|c|c|c|c|}
\hline Specimen & $\begin{array}{c}\text { Mass } \\
(\mathbf{g})\end{array}$ & $\begin{array}{c}\text { Init. water } \\
\text { temp. }\left({ }^{\mathbf{0}} \mathbf{C}\right)\end{array}$ & $\begin{array}{c}\text { Concrete } \\
\text { temp. }\left({ }^{\mathbf{0}} \mathbf{C}\right)\end{array}$ & $\begin{array}{c}\text { Equilibrium } \\
\text { temp. }\left({ }^{\mathbf{0}} \mathbf{C}\right)\end{array}$ & $\begin{array}{c}\text { Specific heat } \\
(\mathbf{J} / \mathbf{g K})\end{array}$ & $\begin{array}{c}\text { Avg. specific } \\
\text { heat } \mathbf{( J / g K})\end{array}$ \\
\hline 1 & 59.2 & 16.30 & 100.00 & 23.70 & 0.961 & \multirow{2}{*}{0.996} \\
\hline 2 & 71.1 & 16.00 & 100.00 & 25.40 & 1.031 & \\
\hline
\end{tabular}

Thermal Conductivity $(K)$

\begin{tabular}{|c|c|c|c|c|c|c|}
\hline specimen & $\begin{array}{c}\mathbf{t}_{\mathbf{1}} \\
(\text { sec.) }\end{array}$ & $\begin{array}{c}\mathbf{t}_{\mathbf{2}} \\
(\mathbf{s e c} .)\end{array}$ & $\begin{array}{c}\mathbf{T}_{\mathbf{1}} \\
\left({ }^{\mathbf{0}} \mathbf{C}\right)\end{array}$ & $\begin{array}{c}\mathbf{T}_{\mathbf{2}} \\
\left({ }^{\mathbf{0}} \mathbf{C}\right)\end{array}$ & $\begin{array}{c}\text { Thermal } \\
\text { conductivity } \\
\text { (W/mK) }\end{array}$ & $\begin{array}{c}\text { Avg. thermal } \\
\text { conductivity } \\
\text { (W/mK) }\end{array}$ \\
\hline 1 & 200 & 1300 & 30.60 & 32.26 & 1.53 & \multirow{2}{*}{1.70} \\
\hline 2 & 160 & 1210 & 24.80 & 26.40 & 1.89 & \\
\hline
\end{tabular}


Tables B4.10 Actual measurements of the thermo-mechanical properties of Mixture 15 after exposure to elevated temperature thermal cycling

Compressive Strength

\begin{tabular}{|c|c|c|c|c|c|}
\hline Specimens & $\begin{array}{c}\text { Force } \\
\text { applied (lbs) }\end{array}$ & $\begin{array}{c}\text { Comp. } \\
\text { strength (psi) }\end{array}$ & $\begin{array}{c}\text { Avg. comp. } \\
\text { strength (psi) }\end{array}$ & $\begin{array}{c}\text { Avg. force } \\
\text { applied (lbs) }\end{array}$ & $\begin{array}{c}\text { 40\% of avg. } \\
\text { force (lbs) }\end{array}$ \\
\hline 1 & 46360 & 3689 & & & \multirow{2}{*}{3763} \\
\hline 2 & 50020 & 3980 & 47290 & 18916 \\
\hline 3 & 45490 & 3620 & & & \\
\hline
\end{tabular}

Modulus of Elasticity

\begin{tabular}{|c|c|c|c|c|c|c|c|}
\hline Spec. & $\begin{array}{c}\text { Init. } \\
\text { strain } \\
\left(10^{-4}\right)\end{array}$ & $\begin{array}{l}\text { Force at } \\
\text { init. strain } \\
\text { (lbs) }\end{array}$ & $\begin{array}{l}\text { Strain at } 40 \% \\
\text { of avg. force }\end{array}$ & $\begin{array}{c}\text { Avg. } \\
\text { diameter } \\
\text { (in.) }\end{array}$ & $\begin{array}{l}\text { Avg. } \\
\text { length } \\
\text { (in.) }\end{array}$ & $\begin{array}{c}\text { MOE } \\
\text { (ksi) }\end{array}$ & $\begin{array}{l}\text { Avg. } \\
\text { MOE } \\
\text { (ksi) }\end{array}$ \\
\hline \multirow{3}{*}{1} & 5.3 & - & - & \multirow{3}{*}{3.998} & \multirow{3}{*}{7.840} & \multirow{3}{*}{452} & \multirow{9}{*}{390} \\
\hline & 5.3 & 110 & 360 & & & & \\
\hline & 5.3 & 140 & 353 & & & & \\
\hline \multirow{3}{*}{2} & 5.3 & - & - & \multirow{3}{*}{4.014} & \multirow{3}{*}{7.896} & \multirow{3}{*}{360} & \\
\hline & 5.3 & 100 & 455 & & & & \\
\hline & 5.3 & 100 & 432 & & & & \\
\hline \multirow{3}{*}{3} & 5.3 & - & - & \multirow{3}{*}{4.028} & \multirow{3}{*}{7.810} & \multirow{3}{*}{358} & \\
\hline & 5.3 & 130 & 443 & & & & \\
\hline & 5.3 & 120 & 440 & & & & \\
\hline
\end{tabular}

Splitting Tensile Strength

\begin{tabular}{|c|c|c|c|}
\hline specimen & Force applied (lbs) & Tensile strength (lbs) & Avg. tensile strength (lbs) \\
\hline 1 & 6740 & 137 & 134 \\
\hline 2 & 6460 & 131 & \\
\hline
\end{tabular}

Specific Heat $\left(\mathbf{C}_{\mathrm{p}}\right)$

\begin{tabular}{|c|c|c|c|c|c|c|}
\hline specimen & $\begin{array}{c}\text { Mass } \\
\text { (g) }\end{array}$ & $\begin{array}{c}\text { Init. water } \\
\text { temp. }\left({ }^{\circ} \mathbf{C}\right)\end{array}$ & $\begin{array}{c}\text { Concrete } \\
\text { temp. }\left({ }^{\circ} \mathbf{C}\right)\end{array}$ & $\begin{array}{c}\text { Equilibrium } \\
\text { temp. }\left({ }^{\mathbf{i}} \mathbf{C}\right)\end{array}$ & $\begin{array}{c}\text { Specific } \\
\text { heat }(\mathbf{J} / \mathbf{g K})\end{array}$ & $\begin{array}{c}\text { Avg. specific } \\
\text { heat }(\mathbf{J} / \mathbf{g K})\end{array}$ \\
\hline 1 & 61.2 & 19.90 & 177.80 & 30.70 & 0.697 & \multirow{2}{*}{0.822} \\
\hline 2 & 60.9 & 20.20 & 182.20 & 34.70 & 0.946 & \\
\hline
\end{tabular}

Thermal Conductivity (K)

\begin{tabular}{|c|c|c|c|c|c|c|}
\hline specimen & $\begin{array}{c}\mathbf{t}_{\mathbf{1}} \\
(\mathbf{s e c} \text { ) }\end{array}$ & $\begin{array}{c}\mathbf{t}_{\mathbf{2}} \\
(\mathbf{s e c} .)\end{array}$ & $\begin{array}{c}\mathbf{T}_{\mathbf{1}} \\
\left({ }^{\circ} \mathbf{C}\right)\end{array}$ & $\begin{array}{c}\mathbf{T}_{\mathbf{2}} \\
\left({ }^{\mathbf{}} \mathbf{C}\right)\end{array}$ & $\begin{array}{c}\text { Thermal conductivity } \\
(\mathbf{W} / \mathbf{m K})\end{array}$ & $\begin{array}{c}\text { Avg. thermal } \\
\text { conductivity } \\
(\mathbf{W} / \mathbf{m K})\end{array}$ \\
\hline 1 & 300 & 1270 & 37.65 & 40.30 & 0.80 & 0.77 \\
\hline 2 & 300 & 1300 & 33.00 & 35.80 & 0.73 & 0.77 \\
\hline
\end{tabular}




\section{Appendix C}

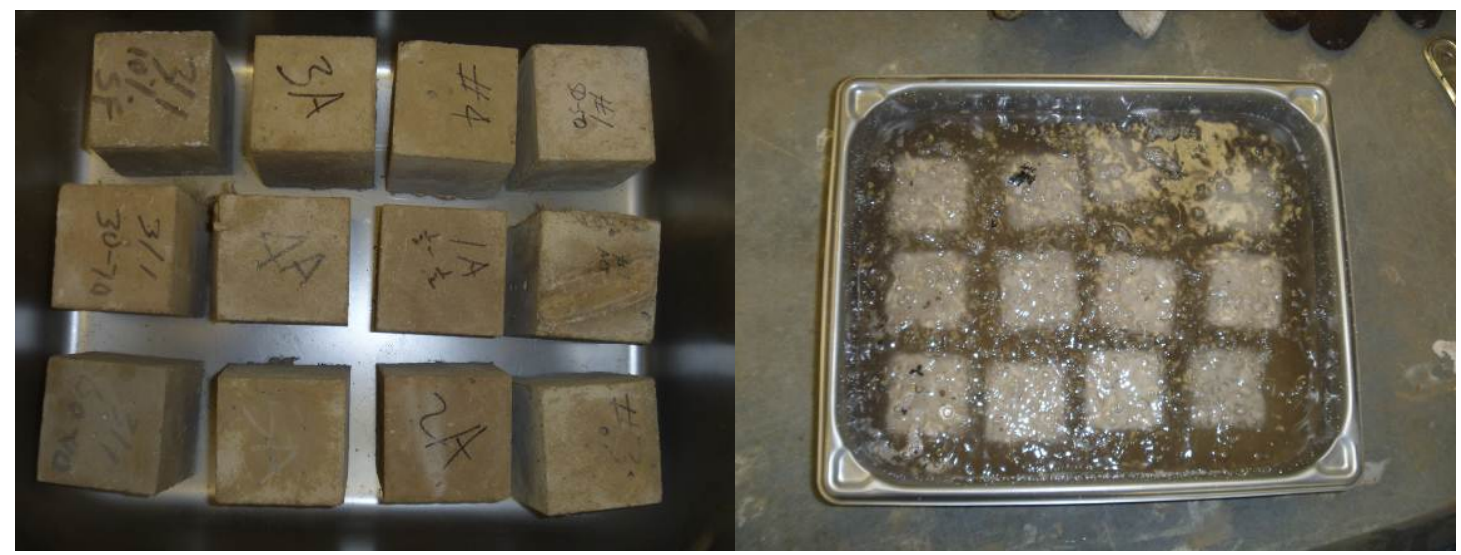

Fig. C4.1. Specimens from mixtures 1 to 12 before and after thermal cycling in the presence of molten salt.

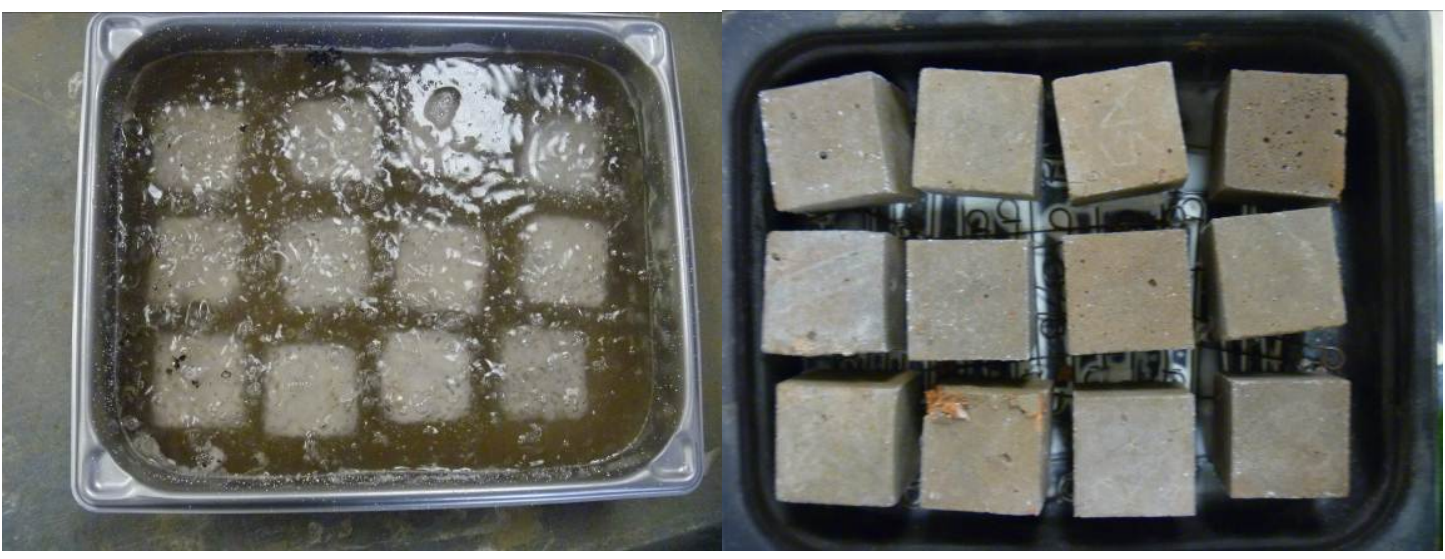

Fig. C4.2. Specimens from mixtures 15 to 26 after thermal cycling in the presence of molten salt.

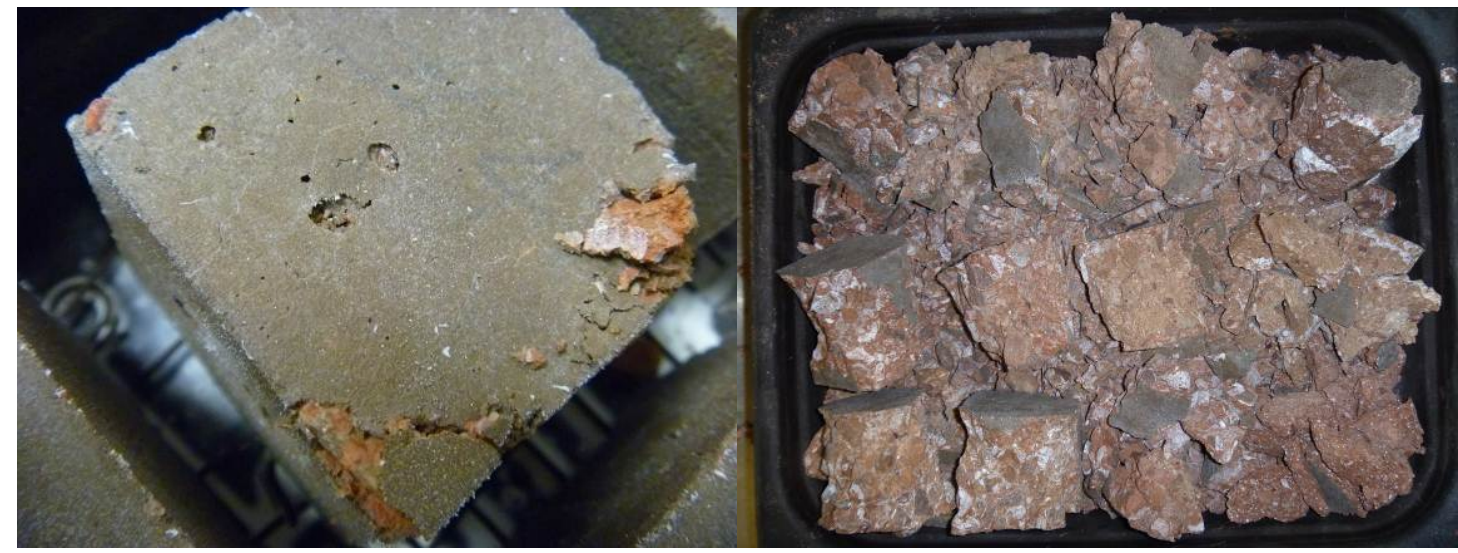

Fig. C4.3. Disintegration of specimen (left) and specimens after residual compression test (right). 
Vitae

EDUCATION

Ph.D., Civil Engineering, University of Arkansas, August 2012

Dissertation: Development and Performance Evaluation of High Performance Concrete as Thermal Energy Storage Medium in Concentrating Solar Power Plants

Supervising Professor: Dr. W. Micah Hale

M.S., Civil Engineering, University of Arkansas, May 2009

Report: $\quad$ Statistical Comparison of Results between Manual and Automatic

Processing Based on UK SCANNER Cracking Protocol

Supervising Professor: Dr. Kelvin C. Wang

B.S., Civil Engineering, La Universidad de Camaguey, Camaguey, Cuba, July 2004

Thesis: $\quad$ Catalog of Imperfections in Flexible Pavements

Supervising Professor: Engineer, Yanelis Plaza Gonzales

\section{ProfeSSIONAL EXPERIENCE}

Instructor (Spring 2012), Department of Civil Engineering, University of Arkansas

- Instructor of record for Reinforced Concrete Design (CVEG 4303). Duties included developing and delivering lectures for the three hour course and the preparation and grading of both homework problems and exams.

Research Assistant (2009 - present), Department of Civil Engineering, University of Arkansas

- Developing high performance concrete mixtures for use as a thermal storage medium for concentrating solar power plants. Concrete mixtures were developed, batched, and tested. The variables examined in the study included water to cementitious materials ratio $(\mathrm{w} / \mathrm{cm})$, cement type and content, supplementary cementitious material type and content, fiber content, and aggregate type and content. Developed testing protocol, manufactured testing equipment, and performed tests that included thermal cycling, thermal conductivity, specific heat, and other typical hardened concrete tests such as compressive strength and modulus of elasticity.

- Examined the thermal properties of Ultra-High Performance Concrete (UHPC). Duties included batching, curing, and testing UHPC specimens.

- Investigated the performance of precast/prestressed beams cast with UHPC. Analyzed the flexural and shear capacity of the beams and adequacy of conventional methods to predict flexure and shear capacities. Examined the bond of prestressing strands cast in UHPC (transfer and development length) as well as the prestress losses of UHPC beams.

- Assisted in research projects that developed and tested lightweight and normal weight, self-consolidating concrete (SCC). Work in these projects included the fabrication and casting of a box culvert and precast/prestressed girders.

Test Proctor (2009 - present), Center for Training Transportation Professionals

- Served as proctor for fresh and hardened concrete properties, soil, and aggregate tests. 
Teaching Assistant (2010 - present), Department of Civil Engineering, University of Arkansas

- Taught the laboratory sections of Structural Materials (CVEG 2113). Duties included laboratory instruction and providing help sessions for the ACI Gr. I Field Technician Certification.

Research Assistant (2008 - 2009), Department of Civil Engineering, University of Arkansas

- Analyzed automated pavement cracking data. Automated cracking data from various segments of roads were statistically compared to semi-automated and manual cracking data from the same road segments to illustrate that the level of error inherent in automated pavement cracking data is acceptable.

Civil Engineer (2005 - 2007), Glean's Construction and Engineering, Grenada

- Performed structural design of residential and commercial buildings. Design included both steel and reinforced concrete structures. Additional duties included supervising construction crews and preparing/reviewing technical reports.

- Performed structural design of short single-span bridge abutment walls

Trainee Engineer (2005), Civil Design and Surveying Systems, St. Vincent

- Assisted in the data acquisition process for a comprehensive drainage study for the island of St. Vincent and the Grenadines.

Engineering Technician (2003), Ministry of Transportation and Works, St. Vincent

- Assisted in the design of a major road rehabilitation project.

\section{Publications}

\section{Journal Publications}

John, E., Ruiz, E., Floyd, R., and Hale, W. "Transfer and Development Length and Prestress Losses in Ultra-High Performance Concrete Beams." Transportation Research Record, Journal of the Transportation Research Board, Vol. 2251/2011, pp 76-81. DOI $10.3141 / 2251-08$.

Peyton, S., Sanders, C., John, E., and Hale, W. "Bridge Deck Cracking: A Field Study on Concrete Placement, Curing, and Performance." Construction and Building Materials (accepted for publication).

\section{Refereed Conference Presentations and Publications}

John, E., Hale, W., Selvam, R., and Brown, B. "Development and Performance Evaluation of High Temperature Concrete for Thermal Energy Storage for Solar Power Generation.” ASME 2011 International Mechanical Engineering Congress on Exposition Energy and Water Scarcity, 2011.

John, E., Hale, W., and Selvam, R. "Development of a High Performance Concrete to Store Thermal Energy for Concentrating Solar Power Plants." Proceedings of ASME 2011 5th International Concrete on Energy Sustainability, 2011, Paper No. ES201154177. 
John, E., Ruiz, E., Floyd, R., and Hale, W. "Transfer and Development Length and Prestress Losses in Ultra-High Performance Concrete." Proceedings of the

Transportation Research Board 90th Annual Meeting, Washington, DC., 2011.

John, E., Hale, W., and Selvam, P. "Effect of Heating Rates on High Strength Concrete for use as Thermal Energy Storage." Proceedings of ASME 4th International Conference on Energy Sustainability, 2010, Paper No. ES2010-90096.

\section{Reports}

Prepared quarterly reports (a total of 12) to the Department of Energy on the progress of the development and evaluation of concrete for thermal energy storage (2009 - present)

\section{HONORS AND AWARDS}

2010 Fourth Place, Zone 6, PCI Big Beam Contest

2009 Graduate Research Assistantship (through 2012)

2008 Fulbright Fellowship through the Organization of American States (OAS)

1998 St. Vincent and the Grenadines' Unity Labor Party Scholarship

\section{Professional ACTIVITIES}

\section{Professional Affiliations}

Member, American Concrete Institute (ACI)

Member, University of Arkansas Student Chapter (ACI)

Member, Precast/Prestressed Concrete Institute (PCI)

Member, National Society of Professional Engineers (NSPE)

Member, Grenada Institute of Professional Engineers (GIPE)

\section{Professional Registration/Certification}

Registered Engineer Intern, Arkansas

ACI Grade I Certification

\section{Professional Development}

2006 Two day seminar on multi-hazard building design which focuses on designing to resist hurricanes and earthquakes in the Caribbean.

2005 One week seminar on continuously operating reference stations (CORS) at the Faculty of Civil Engineering, St. Augustine Campus of the University of the West Indies (Trinidad and Tobago).

\section{LANGUAGES}

Fluent in Spanish

\section{COURSEWORK}

Construction Management

Steel Design I 
Prestressed Concrete Design

Reinforced Concrete Design II

Concrete Mixture and Proportioning

Concrete Mixture and Proportioning II

Plates and Shells

Transportation Soil Engineering

Finite Element Methods

Advanced Foundation Design

Transportation Management Systems
Steel Design II

Advanced Mechanics of Materials

Advanced Numerical Methods

Reinforced Concrete Slab Design

Ordinary Differential Equations

Structural Dynamics

Experimental Design Statistics

Highway Bridge Design

Sensors in Transportation

\section{SKILLS}

Proficient in the use of the computational and data softwares MATLAB and EXCEL Proficient in the use of the structural analysis and design softwares STAAD.PRO and SAP2000

Proficient in the use of AutoCAD

Proficient in the use of the structural design codes, ACI 318, AISC, ASCE 07, and AASHTO LRFD

\section{COMmunity Service}

Past President of the Caribbean Students Association at the University of Arkansas (2010-2011)

Past Secretary of the Caribbean Students Association (CSA) at the University of Arkansas (2009-2010)

Past President of the Biabou Soccer Organizing Committee (2005) 
